\title{
PROBLEMAS DE SAÚDE MENTAL \\ DA CRIANÇA EM IDADE ESCOLAR: \\ OPORTUNIDADES E POSSIBILIDADES DE \\ ABORDAGEM NA ATENÇÃO BÁSICA
}

\section{EDITH LAURIDSEN RIBEIRO}

Tese de Doutorado apresentada ao

Departamento de Saúde Materno-Infantil

da Faculdade de Saúde Pública

da Universidade de São Paulo

para a obtenção do Grau de Doutor

Área de concentração: Saúde Materno-Infantil

Orientador: Professor Titular

OSWALDO YOSHIMI TANAKA

São Paulo

2003

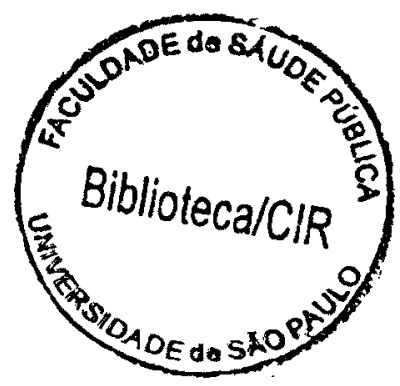


Autorizo, exclusivamente para fins acadêmicos e científicos, a reprodução total ou parcial desta tese, por processos fotocopiadores.

Assinatura:

Data: 
Em memória da Dra: Dulce Vieira Marcondes Machado, que soube, como ninguém, ensinar as questões de saúde mental aos pediatras.

Para as crianças, por um mundo mais justo e feliz.

Para Roberto, Pedro e Francisco. 
Ao Professor Oswaldo Yoshimi Tanaka pela orientação competente e amiga, pela convivência de nove anos plena de lições aprendidas, pela compreensão quando eu não queria mudar de idéia e pela capacidade de me fazer mudar de idéia quando era necessário, muito obrigada.

Aos colegas do setor de Psiquiatria e Psicologia da Infância e Adolescência do Hospital do Servidor Público Municipal, que viram este projeto nascer, pelo apoio nos primeiros passos desta jornada.

Aos companheiros do Ambulatório de Especialidades Jardim Peri Peri, em especial Lígia Santos Barosa e Ángela M. Stape Herrera, pela compreensão e colaboração no dia a dia do Ambulatório.

Aos colegas do Distrito de Saúde Escola do Butantã, em especial Alexandre Nemes Filho, Marta Akemi Horii e Gracia M. G. Boscov Olivi pela possibilidade de maior dedicação ao final deste trabalho.

Aos professores e funcionários do Departamento de Saúde Materno-Infantil pela acolhida nestes nove anos.

À direção do Centro de Saúde Escola do Butantã pela autorização para realização deste trabalho e a seus funcionários, que colaboraram, sempre com presteza, com a coleta dos dados.

Às entrevistadoras do Centro de Saúde Cleusa Aparecida da Costa, Ivete Parra de Andrade, Maria de Lourdes B. S. Costa, Marly de Oliveira Couto e Terezinha Paixão de Souza pelo carinho e afinco com que fizeram seu trabalho.

Um agradecimento especial à Maria Helena Valente, Hugo Issler, Filumena M. S. Gomes, Sandra J. F. E. Grisi, Renato M. Yamamoto, Sérgio Sarrubo, Viviane M. Terra, Paulette C. Douek, Jussara M. Santos, Lúcia F. Bricks e Luiza A. S. Mascaretti pela colaboração sem a qual este trabalho não teria se concretizado.

À Cristina M. M. de Melo pela calorosa ajuda nas questöes da metodologia qualitativa e por muitas outras conversas.

À Cristiane S. Duarte pela colaboração no início desta caminhada e pelo treinamento das entrevistadoras. 
À professora Isabel A. S. Bordin e ao professor Ivan França Júnior pelas preciosas sugestões do exame de qualificação, que permitiram a elaboração do desenho final deste trabalho.

Ao meu filho Pedro, companheiro desde o início deste projeto, pela construção dos bancos de dados, pela digitação dos dados, pela leitura atenta do texto, pelos palpites, pelas correções e, acima de tudo, pelo grande prazer de tê-lo ao meu lado neste percurso.

Aos pais das crianças que responderam uma grande quantidade de questões, provavelmente acreditando que estavam colaborando para a melhoria do atendimento de seus filhos e de outras crianças, que eu consiga, pelo menos em parte, corresponder aos seus anseios.

À FAPESP pelo apoio financeiro imprescindível para realização do projeto. (Processo FAPESP n. ${ }^{\circ}$ 99/07475-5). 


\title{
VERDADE
}

\begin{abstract}
A porta da verdade estava aberta, mas só deixava passar meia pessoa de cada vez.
\end{abstract}

Assim não era possível atingir toda a verdade, porque a meia pessoa que entrava só trazia o perfil de meia verdade.

E sua segunda metade voltava igualmente com meio perfil. $E$ os meios perfis não coincidiam.

Arrebentaram a porta. Derrubaram a porta.

Chegaram ao lugar luminoso onde a verdade esplendia seus fogos. Era dividida em metades diferentes uma da outra.

Chegou-se a discutir qual a metade mais bela. Nenhuma das duas era totalmente bela.

E carecia optar. Cada um optou conforme seu capricho, sua ilusão, sua miopia. 
RESUMO

Lauridsen-Ribeiro E. Problemas de saúde mental da criança em idade escolar: oportunidades e possibilidades de abordagem na atenção básica. São Paulo; 2003. [Tese de Doutorado - Faculdade de Saúde Pública da Universidade de São Paulo].

Objetivo. Este trabalho avaliou como o atendimento das crianças na atenção básica enfoca os problemas de saúde mental (PSM). Procurou-se também identificar a freqüencia dos PSM identificados pelos pediatras $e$ comparou-se-a à freqüência dos PSM identificados por questionário padronizado (CBCL). Métodos. Foram estudadas crianças de 5 anos a 11 anos e 11 meses atendidas em um Centro de Saúde (CS) no Município de São Paulo. Foi feito um levantamento de 411 prontuários e foram selecionadas as crianças com diagnóstico de PSM feito pelo pediatra. Foram feitas 206 visitas domiciliares para aplicação do CBCL e da entrevista com os pais. Também foram realizadas onze entrevistas com os pediatras. Resultados. Os pediatras fizeram hipóteses diagnósticas de PSM em 72 crianças $(17,5 \%)$. O CBCL encontrou 130 crianças com escore clínico. Destas 130 crianças os pediatras só identificaram 33. As outras 97 não foram identificadas durante a consulta. A presença de preocupação dos pais com os PSM está estatisticamente associada ao escore clínico do CBCL. Nas crianças com escore clínico do $\mathrm{CBCL}$, a presença de preocupação dos pais não melhora o reconhecimento dos PSM pelos pediatras. Os médicos identificaram dificuldades para lidar com os PSM e apontaram como seus determinantes falhas na formação profissional, falta de tecnologia adequada, pouco tempo para as consultas, ausência de equipe multiprofissional no CS e falta de retaguarda especializada em Saúde Mental. Conclusão. Os médicos do CS estudado têm dificuldade em fazer hipóteses diagnósticas de PSM em crianças, principalmente nas áreas ansiedade/depressão, problemas de atenção e transtornos de conduta.

Descritores: Saúde Mental Infantil. Atenção Básica. Psiquiatria Infantil. 
SUMMARY

Lauridsen-Ribeiro E. Mental health problems of school-age children: opportunities and possibilities of approach to basic care. São Paulo (BR); 2003. [Doctorate Thesis - Faculdade de Saúde Pública da Universidade de São Paulo].

Objective. This work evaluated how child attendance in primary care assess mental health problems (MHP). It also sought to identify the frequency of MHP identified by the pediatricians, which was compared to the frequency of MHP identified by a standardized questionnaire (CBCL). Methods. Children between 5 years old and 11 years and 11 months old, attended at a Health Center (HC) in the City of São Paulo, were studied. A raising of 411 prontuaries was made, and the children with diagnostic hypothesis of MHP made by the pediatrician were selected. Household visits were made in 206 such cases for the application of the $\mathrm{CBCL}$ questionnaire and interview with the parents. Eleven interviews with the pediatricians were held as well. Results. The pediatricians made diagnostic hypoteses of MHP about 72 children (17,5\%). The CBCL questionnaire found 130 children with clinical score. Among these, the pediatricians identified only 33 . The 97 remaining ones were not detected during consultation. The presence of parents' worriness with MHP is statistically related to CBCL's clinical score. For children with clinical score on $\mathrm{CBCL}$, the presence of parents' worriness does not improve the recognizability of MHP by the pediatricians. The physicians identified difficulties in dealing with MHP and remarked as their determinants flaws in professional formation, lack of proper technology, too short a time of consultation, absence of a multiprofessional team at the $\mathrm{HC}$, and lack of specialized backup in Mental Health. Conclusion. The physicians of the HC under study have difficulty in making diagnostic hypotheses of MHP in children, mainly in the areas of anxiety/depression, attention problems and behavioral distress.

Keywords. Child Mental Health. Basic Care. Child Psychiatry. 
APRESENTAÇÃO

É estranho chegar ao fim deste projeto. Foram muitos anos de caminhada, entre a pediatria e a psiquiatria. Este trabalho reflete, de um certo modo, o percurso de uma vida, a minha vida.

Lembro-me do vestibular, 1969. Fazia cursinho para faculdade de psicologia. No meio do ano, a mudança. Faria vestibular para medicina, para fazer psiquiatria. Iniciei a faculdade de medicina em 1970. Minha mãe, feliz da vida por ter uma filha médica, levou-me para conhecer a madre Cristina, do Sedes. Experiência inesquecivel. O caminho parecia traçado. Até inscrição no Instituto de Psicanálise eu tinha.

No entanto, a vida não é tão simples assim. No meio do curso mudei de idéia. A psiquiatria da faculdade não me conquistou. $A$ pediatria sim. $A$ partir do quarto ano todas as minhas energias foram investidas na pediatria. Sexto ano opcional, residência, três anos com especialização em neonatologia. Depois fui assistente do berçário do HC. Depois o Hospital Universitário, também o berçário. Em 1982 pedi demissão do Hospital Universitário. A vida pessoal me chamava, os filhos eram mais importantes. Fui trabalhar no Hospital Menino Jesus, no berçário. Muitos amigos, nove anos. Deixei a Universidade, o saber; caí na vida, no fazer.

Permaneci sonhando com a pós-graduação. Em 1983 comecei o doutorado na área de neonatologia. Três anos depois, outra grande mudança. Em 1986 deixei a pós e comecei minha volta para a psiquiatria, agora impregnada pela pediatria. Três anos de formação em psiquiatria infantil, ainda trabalhando como pediatra. Em 1990 comecei a trabalhar como psiquiatra numa unidade básica de saúde.

Em 1991, outra guinada. Fui convidada para ser assessora de saúde da criança do distrito de saúde do Butantã. Aceitei, meio temerosa. Deixei de vez a neonatologia. Foi uma descoberta. A saúde pública, sua complexidade, a interdisciplinaridade. Comecei pela prática cotidiana. Foi 
envolvente, denso. No entanto, em 1993, mudança de governo. Deixei a assessoria, fui para o ambulatório. Comecei a montar o serviço de saúde mental infantil. Batizei de CISMI (Centro Integrado de Saúde Mental Infantil).

Conquistada pela Saúde Pública, fui fazer curso de Especialização em 1993 na FSP da USP. No departamento de Saúde Materno-Infantil, iniciei o mestrado, em 1994, com o Professor Tanaka. Trabalhei com o banco de dados do Professor Chester: morbidade referida de saúde mental em crianças e adolescentes. Estava feita a mistura: pediatria, psiquiatria infantil e saúde pública. Terminei o mestrado em 1998. Parte do sonho da pós-graduação realizado.

Durante este período, na Prefeitura do Município de São Paulo, em 1996, foi instalado o PAS. Muitas marcas dolorosas nas vidas de muitas pessoas. Serviços e trabalhos desmontados, inclusive o meu. Fiquei errante até 1998, quando fui acolhida pelo pessoal da PPIA do Hospital do Servidor Público Municipal. Fiquei lá três anos. Muito trabalho, equipe fantástica.

Permanecia o desejo do doutorado. Durante um ano desenvolvi, junto com o professor Tanaka, uma idéia que me acompanhava há muito tempo: como funcionava a interface entre a pediatria e a psiquiatria, no contexto da saúde pública, dos serviços. Apesar do namoro com a academia, sempre fui dos serviços, do fazer cotidiano. Meu estudo tinha que ter esta cara. Em 1999, quando o projeto de pesquisa criou corpo, me inscrevi no doutorado, um sonho. Mandamos o projeto para FAPESP, foi aprovado, uma enorme alegria.

Após o exame de qualificação fui para o campo. Os seis meses que permaneci, quase diariamente, no Centro de Saúde Escola do Butantã, foram pontilhados de recordações (dos meus anos de pediatra), de emoções nas falas dos colegas médicos, no fazer dedicado das entrevistadoras, na lide com as mães e familiares das crianças, e de muito trabalho braçal. Gostei de cada instante, mesmo dos mais estressantes. 
Em 2001 nova mudança de governo na prefeitura de São Paulo. Acabou o PAS, retornei ao distrito de saúde do Butantã. Deixei a PPIA. Foi difícil, gostava muito de trabalhar lá. Mas precisava voltar. Deixei este estudo um pouco de lado; a prática me chamava.

Ainda em 2001 uma experiência marcante. Levada pelo professor Yunes, participei de um grupo de trabalho, em SES, que elaborou uma proposta de organização da assistência às crianças na área de saúde mental. Foi um trabalho iluminado. Conhecidos novos e antigos, trabalhamos juntos a Ana, o Raul, a Sônia, a Josiane, o Sérgio, a Eliana, a Cristina, a Marisa e a Toninha. Construimos um sonho: o de poder, efetivamente, melhorar a qualidade de vida das nossas crianças.

Agora estou terminando este projeto. Precisei tirar férias para acabálo, mas acho que consegui. Talvez não da forma que tinha idealizado, mas do jeito que a vida permitiu.

Por fim, como uma pessoa mais dos serviços do que da academia, gostaria que este trabalho tivesse alguma utilidade prática, não ficasse apenas na prateleira de bibliotecas. Mais um sonho? Talvez... Mas o que seria de nós sem os sonhos? 


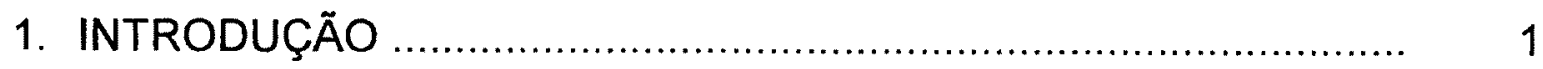

1.1 Considerações iniciais .............................................................. 1

1.2 Estudos de prevalência dos transtornos mentais ...................... 3

1.3 Sistema de saúde e saúde mental infantil ............................... 9

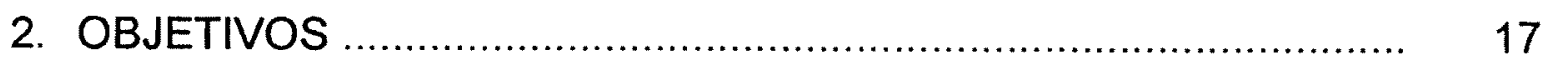

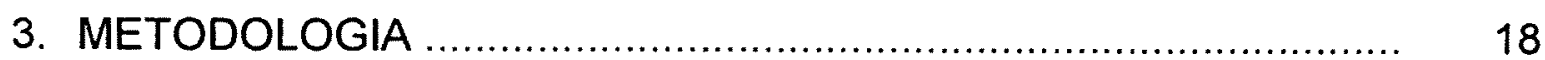

3.1 Opção teórico-metodológica: trajetória ...................................... 18

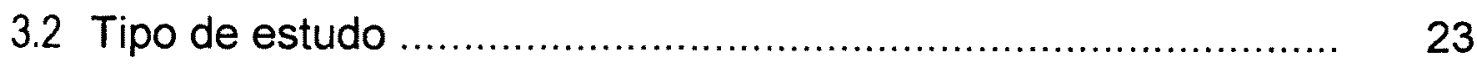

3.3 Objeto de estudo ...................................................................... 24

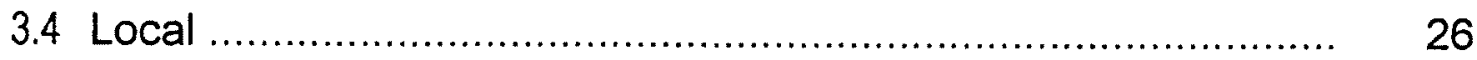

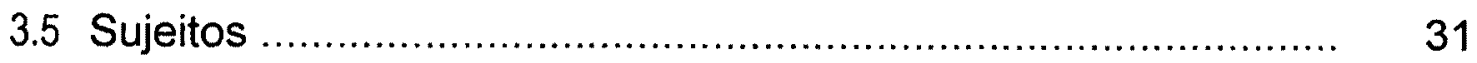

3.6 Relação dos instrumentos utilizados ...................................... 32

3.7 Procedimentos metodológicos .............................................. 37

3.7.1 Levantamento dos dados ......................................... $\quad 37$

3.7.2 Desenho da análise ................................................. 40

3.8 Aspectos éticos ........................................................... 46

4. RESULTADOS E DISCUSSÃO …............................................. 48

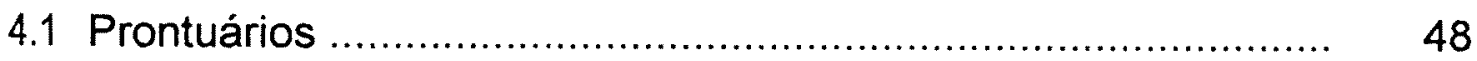

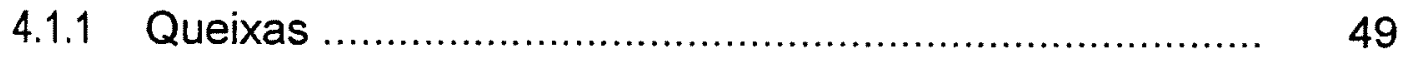

4.1.2 Diagnósticos ............................................................... 53

4.1.3 Queixa X diagnóstico médico .................................... $\quad 59$

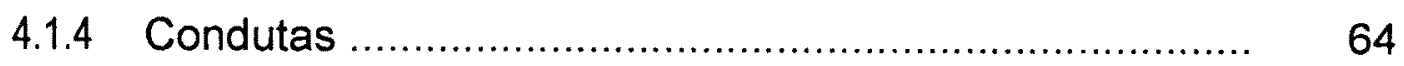

4.2 Questionário de Capacidades e Dificuldades (SDQ)

4.3 SDQ X diagnóstico de PSM feito pelo pediatra

4.4 Visita domiciliar

4.4.1 Identificação

4.4.2 SDQ

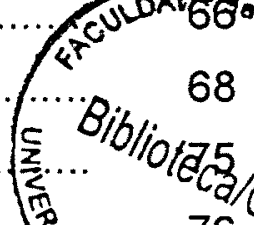

68
75
76

$76 \mathrm{c/p}$

4.4.3 CBCL

4.4.4 Questionário para pais sobre as preocupações relativas às dificuldades das crianças 
4.5 CBCL X diagnóstico de PSM feito pelo pediatra ...................... 82

4.6 Entrevistas com os médicos pediatras .................................... 88

4.6.1 Concepção de problemas de saúde mental .................. $\quad 92$

4.6.2 Reconhecimento dos problemas de saúde mental ........ $\quad 99$

4.6.3 Ação do pediatra frente aos problemas de saúde mental

4.6.4 Propostas de mudanças: uma luz no fim do túnel ......... 124

4.6.5 O papel do pediatra ................................................... 127

5. CONCLUSÕES E COMENTÁRIOS FINAIS …............................. 128

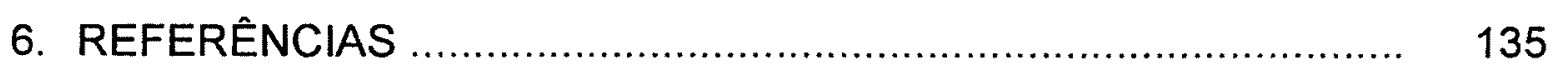

\section{ANEXOS}

1 FORMULÁRIO PARA REVISÃO DO PRONTUÁRIO

2 FORMULÁRIOS DAS CONSULTAS DO CSE BUTANTÃ

3 QUESTIONÁRIO DE CAPACIDADES E DIFICULDADES - SDQ

4 INVENTÁRIO DE COMPORTAMENTOS DA INFÂNCIA E ADOLESCÊNCIA - CBCL

5 FICHA DE IDENTIFICAÇÃO DA VISITA DOMICILIAR

6 QUESTIONÁRIO PARA OS PAIS SOBRE AS PREOCUPAÇÕES RELATIVAS ÀS DIFICULDADES DAS CRIANÇAS

7 ROTEIRO DAS ENTREVISTAS COM OS PEDIATRAS

8 EXEMPLO DE PERFIL GERADO PELO CBCL

9 TERMO DE RESPONSABILIDADE DO PESQUISADOR - PAIS

10 TERMO DE RESPONSABILIDADE DO PESQUISADOR - PEDIATRAS

11 LISTA COMPLETA DAS QUEIXAS

12 CID-10 CAPITULO V: TRANSTORNOS MENTAIS E COMPORTAMENTAIS (FOO-F99)

13 LISTA COMPLETA DOS DIAGNÓSTICOS

14 CASOS COM QUEIXAS E/OU HIPÓTESES DIAGNÓSTICAS DE PSM

15 CASOS COM HIPÓTESES DIAGNÓSTICAS DE PSM E CONDUTA DO PEDIATRA

16 CASOS COM SDQ ANORMAL E IMPACTO ANORMAL

17 ESCORES DO CBCL

18 MAPAS DAS ENTREVISTAS COM OS PEDIATRAS 
I Mapa da área de abrangência do Centro de Saúde Escola

II "Autantã PSM feitas pelos pediatras

III "Árvore" da relação entre SDQ e hipóteses diagnósticas de PSM feitas pelos pediatras

IV "Árvore" da relação entre $\mathrm{CBCL}$, presença de preocupação dos pais e hipóteses diagnósticas de PSM feitas pelos pediatras

$\checkmark$ "Árvore" das verbalizações e explicações do eixo temático CONCEPÇÃO DE PROBLEMA DE SAÚDE MENTAL

VI "Árvore das verbalizações e explicações do eixo temático RECONHECIMENTO DOS PROBLEMAS DE SAÚDE MENTAL NA INFÂNCIA

VII "Árvore" das verbalizações e explicações do eixo temático AÇÃO DOS PEDIATRAS FRENTE AOS PROBLEMAS DE SAÚDE MENTAL NA INFÂNCIA 


\section{ÍNDICE DE GRÁFICOS}

1 Distribuição do número de crianças segundo sexo e idade

2 Distribuição da percentagem das crianças com CBCL clínico segundo sub-escalas do CBCL, hipóteses diagnósticas de PSM feitas pelo pediatra e presença de preocupação dos pais 
1 Ideário da Pediatria relacionado à Saúde Mental identificado pelos pediatras

2 Concepção de PSM relacionada à descrição de comportamentos identificados pelos pediatras

3 Concepção de PSM relacionada aos limites da patologia identificados pelos pediatras - CSE Butantã

4 Concepção de causalidade dos PSM identificada pelos pediatras

5 Magnitude dos PSM no cotidiano da Pediatria identificada pelos pediatras

6 Categorização das queixas durante o atendimento pediátrico identificada pelos pediatras

8 Dificuldades para detectar PSM identificadas pelos pediatras 106

9 Diferenças entre as linguagens específicas da pediatria e da psiquiatria identificadas pelos pediatras

10 Falhas na formação profissional identificadas pelos pediatras

11 Características de personalidade do médico identificadas pelos pediatras

12 Tipos de tecnologia para abordar os PSM considerados ausentes pelos pediatras

13 Tipos de intervenção do pediatra frente aos PSM identificados pelos pediatras

14 Características da organização do processo de trabalho do médico identificadas como deficientes pelos pediatras

15 Características da organização do processo de trabalho no Centro da Saúde identificadas como deficientes pelos pediatras

16 Características da organização do sistema de saúde identificadas como deficientes pelos pediatras

17 Tipos de preconceitos identificados pelos pediatras nos distintos atores envolvidos

18 Sentimentos expressados pelos pediatras frente aos PSM

19 Propostas para melhoria da assistência aos PSM identificadas pelos pediatras: Interação com profissionais de saúde mental

20 Propostas para melhoria da assistência aos PSM identificadas pelos pediatras: Utilização de instrumentos adequados

21 Propostas para melhoria da assistência aos PSM identificadas pelos pediatras: Mudanças na formação médica

22 O papel identificado para o pediatra no atendimento dos PSM na atenção básica 


\section{ÍNDICE DE QUADROS}

1 Acesso à atenção psiquiátrica: 5 niveis e 4 filtros

2 Relação das fontes de dados

3 Distribuição do número e percentagem dos tipos de anotações sobre desenvolvimento

4 Índice de "validade" das hipóteses diagnósticas dos médicos segundo critério de referência (queixas)

5 Índices de "validade" das hipóteses diagnósticas dos médicos

6 Hipóteses diagnósticas feitas pelos pediatras em crianças com SDQ anormal e impacto anormal

7 Hipóteses diagnósticas feitas pelos pediatras em quatro crianças com SDQ normal e impacto anormal

8 Hipóteses diagnósticas feitas pelos pediatras em crianças com SDQ normal e impacto normal

9 Características familiares das crianças entrevistadas

10 Índices de "validade" das hipóteses diagnósticas de PSM segundo critério de referência (CBCL)

11 Descrição e explicação dos tipos de PSM citados pelos pediatras nas entrevistas 
1 Distribuição do número e percentagem das crianças segundo tipo de consulta

2 Distribuição do número e percentagem das crianças segundo idade e sexo

3 Distribuição do número e percentagem das queixas segundo os 159 grupos

4 Distribuição do número e percentagem das queixas segundo agrupamentos sintomáticos

5 Distribuição do número e percentagem das crianças segundo diagnóstico nutricional

6 Distribuição do número e percentagem das crianças segundo diagnóstico de crescimento

7 Distribuição do número e percentagem das crianças segundo diagnóstico alimentar

8 Distribuição do número e percentagem das crianças segundo diagnóstico de vacinação

9 Distribuição do número e percentagem das crianças segundo diagnóstico do desenvolvimento neuropsicomotor

10 Distribuição do número e percentagem das crianças segundo diagnóstico do ambiente físico

11 Distribuição do número e percentagem das crianças segundo diagnóstico do ambiente emocional

12 Distribuição do número e percentagem das hipóteses diagnósticas feitas pelos pediatras

13 Distribuição do número e percentagem das hipóteses diagnósticas do capítulo $V$ da CID-10

14 Distribuição do número e percentagem das crianças segundo especificações de ambiente emocional inadequado

15 Distribuição do número e percentagem das crianças segundo queixas e hipóteses diagnósticas de PSM

16 Distribuição do número e percentagem dos crianças segundo queixas e hipóteses diagnósticas de problemas respiratórios

17 Distribuição do número e percentagem das crianças com diagnóstico de PSMI segundo tipo de conduta do pediatra

18 Distribuição do número e percentagem das crianças segundo pontuação do SDQ e do impacto

19 Distribuição do número e percentagem das crianças segundo pontuação do SDQ e do impacto (casos com SDQ/impacto limítrofes incorporados aos normais)

20 Distribuição do número e percentagem das crianças segundo resultado total do SDQ (sem impacto) e hipótese diagnóstica de PSM feita pelo pediatra 
21 Distribuição do número e percentagem das crianças segundo resultado total do SDQ (com impacto) e hipótese diagnóstica de PSM feita pelo pediatra

22 Distribuição do número e percentagem das crianças com visita domiciliar segundo idade e sexo

23 Distribuição do número e percentagem das crianças segundo perfil comportamental e escalas do CBCL

24 Distribuição do número e percentagem das crianças com preocupação dos pais com PSM segundo motivo de não comentar com o pediatra

25 Distribuição do número e percentagem das crianças segundo escores das escalas do CBCL e hipótese diagnóstica de PSM feita pelo pediatra

26 Distribuição do número e percentagem das crianças segundo escores das escalas do CBCL e preocupação dos pais com os PSM

27 Distribuição das crianças com escore do CBCL clínico segundo hipótese diagnóstica de PSM feita pelo pediatra e preocupação dos pais 


\section{BRINCAR NA RUA}

Tarde?

$O$ dia dura menos que um dia.

$O$ corpo ainda não parou de brincar

e já estão chamando da janela:

É tarde.

Ouço sempre este som: é tarde, tarde.

A noite chega de manhã?

Só existe a noite e seu sereno?

O mundo não é mais, depois das cinco?

É tarde.

A sombra me proíbe.

Amanhã a mesma coisa.

Sempre tarde antes de ser tarde.

Carlos Drummond de Andrade

\section{INTRODUÇÃO}




\subsection{CONSIDERAÇÕES INICIAIS}

A atenção integral à saúde da criança e do adolescente, como preconizada pelos programas oficiais, envolve ações visando à promoção, prevenção e tratamento, com enfoques orgânico, psíquico e social. Em 1984, o MINISTÉRIO DA SAÚDE, na introdução do documento "ASSISTÊNCIA INTEGRAL À SAÚDE DA CRIANÇA: AÇÕES BÁSICAS", preconizou:

“O programa (...) deverá possibilitar a criação de um elo de ligação entre aquele grupo populacional e os serviços, através do acompanhamento sistemático de seu crescimento e desenvolvimento. Uma vez responsável por um efetivo cuidado com o processo de crescimento e desenvolvimento de cada uma e de todas as crianças da população adstrita, os serviços deverão estar preparados para resolver, a partir da unidade mais elementar, a maioria dos problemas de saúde das crianças. Do mesmo modo, devem estar capacitados a atuar contra os fatores indesejáveis do meio ambiente que impedem ou restringem cada criança de realizar seu potencial genético" (p.6).

Nos últimos anos, com a mudança do perfil da morbidade da faixa etária pediátrica devida à redução da importância de doenças como a diarréia e aquelas passíveis de prevenção pela vacinação, foi ressaltada a importância das doenças respiratórias, dos acidentes e das queixas relativas a transtornos psicossociais.

É na atenção básica, via de regra, que chegam todos os tipos de queixas. No nosso país, principalmente nas grandes cidades, o pediatra é o profissional que geralmente faz este atendimento. Existe disponibilidade 
deste profissional na maior parte dos serviços de saúde, sejam estes públicos ou privados, e ele é tido como responsável pelo atendimento das crianças e, às vezes, também dos adolescentes. Outros profissionais, como médicos de família, clínicos gerais e outros componentes da equipe de saúde, como a enfermagem e os agentes comunitários, podem constituir-se nos responsáveis pelo atendimento desta população na atenção básica. Desta forma acentua-se a importância do conhecimento e da atenção que todos estes profissionais dão às queixas e sintomas na área de saúde mental. Outro fator que ressalta esta necessidade é a falta de equipes de saúde mental na atenção básica.

De forma geral, pode-se dizer que o médico ou o profissional que realiza o atendimento na atenção básica tem dois papéis distintos. Por um lado, a escuta cuidadosa das queixas pode possibilitar uma intervenção efetiva e imediata por parte da equipe local. Por outro, o adequado encaminhamento das crianças com problemas na área de saúde mental para serviços especializados pode permitir uma intervenção terapêutica mais precisa e oportuna.

A introdução de um componente de saúde mental na atenção básica vem sendo cada vez mais enfatizada. A ORGANIZAÇÃO MUNDIAL DA SAÚDE (OMS) (1990) vem apontando para a importância e magnitude deste tipo de queixa em todos os atendimentos clínicos, e para a necessidade de incorporação de abordagem apropriada para que seu reconhecimento e tratamento sejam adequados cientificamente e culturalmente. Outros autores, entre eles SARACENO e col. (1994), discutiram como aumentar a capacidade das equipes da atenção primária de lidar com estas questões. $A$ ORGANIZAÇÃO PAN-AMERICANA DA SAÚDE (OPAS) e a OMS, no Relatório sobre a Saúde no Mundo - 2001, enfatizam o manejo e tratamento dos transtornos mentais no contexto da atenção primária como a primeira de suas dez recomendações para uma nova concepção na atenção em saúde mental. 


\subsection{ESTUDOS DE PREVALÊNCIA DOS TRANSTORNOS MENTAIS}

Os estudos epidemiológicos dos transtornos mentais com base populacional produzem informações para aprimorar o conhecimento do curso e co-ocorrência dos transtornos mentais de uma dada população, apontando freqüências e tendências destes transtornos nos vários grupos sociais e avaliando o prejuizo no funcionamento social que eles causam. São também importante fonte de dados para formulação e implementação de políticas públicas e para a implantação de serviços de saúde.

A maioria dos levantamentos já feitos em epidemiologia psiquiátrica buscou determinar a prevalência de doença mental na população. Este indicador é expresso em termos de taxas populacionais, que são proporções entre o número de casos (numerador) e o número total da população, isto é, incluindo casos e não casos (denominador). O termo "prevalência" abrange vários tipos de índices, mas sempre refere-se aos casos que apresentam o transtorno em um momento especificado, independente da data do início dos sintomas. As taxas de prevalência podem também ser avaliadas por periodo determinado ( 6 meses anteriores à entrevista, por exemplo) ou prevalência na vida, entre outras (REGIER e BURKE 1999).

Os trabalhos mais recentes, realizados na população adulta, mostraram que a prevalência dos transtornos mentais é alta, chegando até $50 \%$ em alguns deles. Nos Estados Unidos, ROBINS e REGIER (1991) estudaram a prevalência dos transtornos mentais na população de mais de 18 anos em cinco comunidades, tendo encontrado $20,0 \%$ dos individuos com transtorno mental no momento da pesquisa e 32,0\% com história de pelo menos um episódio durante a vida. Observaram também que apenas $19,0 \%$ dos indivíduos com "doença ativa" recebiam tratamento especializado.

No Brasil, ALMEIDA FILHO e col. (1992) realizaram uma pesquisa em três áreas metropolitanas (Brasília, Porto Alegre e São Paulo) na 
população de maiores de 15 anos e encontraram taxas de prevalência global dos transtornos mentais, incluindo qualquer nível de sintomatologia, entre $30,0 \%$ e $50,0 \%$. Estudaram também a estimativa de demanda potencial de serviços destinados ao tratamento de distúrbios psiquiátricos (casos potencialmente necessitados de assistência estabelecida através de autoreferência do entrevistado). Estas estimativas oscilaram entre $20,0 \%$ e $35,0 \%$.

Estudo realizado na cidade de São Paulo por ANDRADE e col. (1998), em população de 18 anos ou mais, encontrou que 33,1\% desta população tinha apresentado algum transtorno mental (exceto dependência de tabaco) ao longo da vida, $18,5 \%$ no ano anterior e $15,2 \%$ no mês anterior à entrevista. Este trabalho também buscou descrever o uso dos serviços de saúde pela população estudada. Entre os achados, encontrou-se que $8,3 \%$ procuraram atendimento psicológico no mês anterior à entrevista e que a presença de transtornos psiquiátricos aumenta o uso de serviços de saúde em geral, e esta utilização é maior se o transtorno ocorreu no ano anterior à entrevista.

Os trabalhos de investigação epidemiológica dos transtornos mentais na infância e adolescência têm características e dificuldades próprias. Em 1990, VERHULST (citado por PEDREIRA e col. 1993) esquematizou algumas das principais características do levantamento de informações sobre morbidade em saúde mental na infância:

$\checkmark$ Critérios de morbidade:

Que conduta considerar anormal?

Para que idade?

Patologias ou variações qualitativas/quantitativas?

$\checkmark$ Aspectos do desenvolvimento:

Idades

Procedimento de avaliação: Escalas

Entrevistas 
$\checkmark$ Escolher informantes

Pais

Pediatras

Professores

Crianças

- Grau elevado de acordo

- Favorecer multi-informantes

- Saber o peso da informação

$\checkmark$ Escolher instrumentos de avaliação

$\mathrm{Na}$ população infantil também são encontradas altas taxas de prevalência de transtornos mentais. Em revisão recentemente publicada por ROBERTS e col. (1998), que incluiu trabalhos realizados a partir de 1980 , foram encontradas taxas de prevalência global de transtornos mentais que variaram de $1,0 \%$ a $51,0 \%$ (média de $15,8 \%$ ). Estes estudos foram realizados em mais de 20 países, e a faixa etária pesquisada variou de um a 18 anos. As idades dos sujeitos variaram amplamente entre os estudos. As taxas de prevalência tendem a aumentar proporcionalmente com a idade, sendo que a prevalência média entre os pré-escolares (idade de um a cinco ou seis anos) foi de $10,2 \%$, entre os pré-adolescentes (seis a 12 ou 13 anos) de $13,2 \%$, e entre os adolescentes (12 ou 13 anos ou mais) de $16,5 \%$. Pesquisas que incluiram amostras com grandes variações de faixas etárias tendiam a apresentar taxas de prevalência global maiores (média de $21,9 \%$ ).

As taxas de prevalência podem variar sob a influência de diversos fatores metodológicos. Um dos mais importantes e problemáticos é o critério utilizado para definição de caso. O aparecimento de classificações internacionais, como a Classificação Internacional da Doenças, atualmente na Décima Edição (CID-10) (OMS 2000), e o Manual Diagnóstico e Estatístico de Transtornos Mentais, em sua quarta edição (DSM-IV) (AMERICAN PSYCHIATRIC ASSOCIATION 1995), tem contribuído para minorar esta dificuldade. Existe a necessidade de avaliar 
normalidade/patologia na infância, adequando-a a cada grupo etário e classificando a conduta detectada como patológica ou como uma variação quali-quantitativa da norma. Nesta questão do diagnóstico e classificação, outra dificuldade detectada é a delimitação de diferentes categorias diagnósticas. CANTWELL e RUTTER (1994) discutiram a questão dos limites entre os quadros mórbidos na infância, apontando para as altas taxas de co-morbidade encontradas nas pesquisas.

COSTELLO (1989b) compilou uma revisão de cinco estudos realizados durante a década de 80 , que utilizaram critérios do DSM-III (terceira edição do Manual Diagnóstico e Estatístico de Transtornos Mentais), e encontrou taxas de prevalência global de transtornos mentais de $17,6 \%$ a $22,0 \%$, na faixa etária de quatro a 20 anos.

Outra forma de definir caso é utilizar a construção de síndromes empiricas a partir de sintomas referidos. $O$ instrumento mais conhecido desta abordagem é o "Child Behavior Checklist" (CBCL) (ACHENBACH e EDELBROCK 1981; ACHENBACH 1991). As sindromes obtidas a partir desta metodologia não correspondem a diagnósticos psiquiátricos, pois são apenas um agregado de sintomas e não entidades nosológicas definidas. BIRD (1996), compilando trabalhos realizados com esta metodologia, encontrou taxa de prevalência global de prováveis transtornos mentais entre $20,0 \%$ e $35,4 \%$.

Outro aspecto importante é a escolha dos instrumentos de avaliação possíveis de serem utilizados: escalas diagnósticas (desenvolvidas a partir da tradição psicométrica) ou entrevistas clínicas (baseadas no exame clínico psiquiátrico) (CANTWELL e RUTTER 1994; COSTELLO 1989b; PEDREIRA e col. 1993; RUTTER 1989). Há necessidade de levar em conta que a validade e a confiabilidade das escalas diagnósticas podem estar comprometidas por numerosos problemas de ordem conceitual ou prática, em sua construção, uso ou interpretação. 
A escolha do informante também é fundamental. Eles devem ser pessoas de referência na vida da criança (pais, professores, pediatras). Sempre que possivel, a própria criança deve também ser entrevistada. São vários os trabalhos que apontam discordância entre os informantes (BRANDENBURG e col. 1989; COSTELLO 1989b; PEDREIRA e col. 1993; RUTTER 1989). Isto põe em evidência o grau de acordo necessário para qualificação das condutas. Por vezes é necessário obter-se dados de vários informantes com a finalidade de uma descrição mais objetiva, que pode ajudar a valorizar o peso específico de cada informação.

Um aspecto que tem sido cada vez mais valorizado é o uso de critérios de impacto dos sintomas detectados na vida da criança (PICKLES e col. 2001). Não basta apenas listar sintomas, pois muitas crianças têm alguns sintomas na área da saúde mental e cerca de $30,0 \%$ a $50,0 \%$ das crianças com sintomas preenchem critérios diagnósticos (FLEITLICH e GOODMAN 2000). Entretanto em apenas $5,0 \%$ a $15,0 \%$ das crianças observa-se impacto significativo dos sintomas, trazendo sofrimento psíquico, tanto para as crianças como para suas famílias.

Um exemplo interessante de como a avaliação do impacto dos sintomas pode ter efeitos importantes sobre as taxas de prevalência é o estudo realizado por SHAFFER e col. (1996), conhecido por Methods for the Epidemiology of Child and Adolescent Mental Disorders (MECA). Patrocinado pelo National Institute of Mental Health (NIMH), esta pesquisa foi realizada em um único estágio, utilizando uma entrevista diagnóstica padronizada para crianças/adolescentes e para pais especialmente elaborada para esta ocasião. Foi também utilizada uma escala de funcionamento social. Os critérios utilizados para definição de caso foram dos DSM-III-R, DSM-IV e CID-10. Foram estudadas 1.285 crianças e adolescentes de nove a 17 anos em quatro diferentes regiōes dos Estados Unidos: Columbia, Georgia, Yale e Porto Rico. As taxas de prevalência encontradas variaram de acordo com os critérios de disfunção social empregados: quando não é empregado nenhum critério de disfunção social, 
a prevalência chega a $50,6 \%$. A prevalência global de casos moderados e graves foi de $11,5 \%$.

No Brasil existem poucos estudos na área de epidemiologia dos transtornos mentais na infância. O mais importante, quanto ao rigor metodológico, é o de ALMEIDA FILHO (1982, 1985). Nessa pesquisa foi estudada uma amostra de 829 crianças de cinco a 14 anos residentes em Amaralina, Salvador - Bahia. O autor usou uma escala de gravidade de três níveis '(duvidoso/leve, moderado e severo). A prevalência global de transtornos mentais para o grupo em estudo foi de $23,1 \%$ e era composta de $1,6 \%$ de transtornos do desenvolvimento, 15,3\% de distúrbios neuróticos e psicossomáticos, $2,5 \%$ de transtornos orgânico-cerebrais, $2,6 \%$ de retardo mental e 1,2\% para outros diagnósticos de menor ocorrência.

No pesquisa "Morbidade referida e utilização de serviços de saúde no ERSA 12 - 1989-90" foram estudadas as queixas referidas de "problemas dos nervos" de crianças e adolescentes de um a 19 anos (LAURIDSEN 1998). A morbidade referida é aquela em que a própria população alvo define a presença do problema pesquisado, não havendo nenhum outro tipo de comprovação. A taxa de prevalência encontrada foi de $4,7 \%$.

Estes são apenas alguns dos trabalhos que demonstram as altas taxas encontradas e reforçam a magnitude do problema.

Transtornos mentais levam a um grande sofrimento, tanto para as próprias crianças afetadas, como para suas famílias e comunidades. Estes transtornos variam em relação a idade de início, tipos de sintomas, nível de disfunção que provocam e prognóstico a longo prazo. Mesmo usando uma taxa de prevalência mais conservadora, como a do Institute of Medicine (OFFORD e FLEMING 1996), que é de 12,0\%, pode-se estimar que, no Município de São Paulo, ao redor de 100.000 crianças e adolescentes entre cinco e 14 anos apresentam algum tipo de transtorno psiquiátrico (FUNDAÇÃO IBGE 2000). 


\subsection{SISTEMA DE SAÚDE E SAÚDE MENTAL INFANTIL}

No Brasil são poucas as iniciativas que buscam ampliar o conhecimento e a formulação de práticas de atenção à saúde mental na faixa etária pediátrica. As principais linhas de trabalho que têm sido colocadas dizem respeito à saúde mental do adulto, tendo como base de intervenção, entre outras, o movimento da luta anti-manicomial. $A$ atenção às crianças tem-se mantido à margem deste processo.

SARTORIUS e GRAHAM (1984), avaliando pesquisas em saúde mental na infância realizadas pela Organização Mundial de Saúde (OMS) em oito países no final da década de 70 , ressaltaram as seguintes recomendações:

1. "A pesquisa, particularmente em aspectos de saúde mental infantil relacionados à saúde pública, é uma área negligenciada, que merece uma fração importante da atenção dos especialistas em saúde mental infantil. Seu enfoque deveria ser centrado na aquisição de dados que serão úteis em planejamento e formação de politicas. Entre tópicos específicos, é recomendada prioridade em: pesquisas que conduzam a um melhoramento dos procedimentos de assistência à saúde mental; pesquisas em serviços e sua avaliação; epidemiologia do retardo mental grave; e pesquisas que desenvolvam indicadores de saúde mental infantil e em efetivação de intervenções promotoras de saúde. Estudos sobre o impacto da escolaridade em diferente estratos sociais são de particular interesse.

2. Pessoas que lidam com saúde mental infantil deveriam assumir a responsabilidade não só sobre o tratamento da criança individual, mas também sobre a divulgação da idéia de que as necessidades de saúde mental infantil devem ser levadas em conta na formulação de políticas nacionais de saúde e desenvolvimento social. 
3. A preparação dos pais para os cuidados com os filhos e o treinamento de profissionais de saúde em geral para as questões referentes à saúde mental infantil são da mais alta importância e merecem grande prioridade. Isto requer uma mudança no papel tradicional dos especialistas em saúde mental infantil: grande parte de seu tempo deveria ser, daí em diante, destinado ao treinamento de outros que são passiveis de lidarem de forma significativa com transtornos mentais e com tarefas que poderiam promover a saúde mental das crianças" ( $p$. 211).

De modo geral, os serviços especializados em saúde mental para crianças e adolescentes são escassos e de difícil acesso, geralmente com longas filas de espera. Na maioria das vezes, crianças com dificuldades emocionais são atendidas por profissionais de saúde não especializados ou mesmo por profissionais da área da educação ou de outras áreas sociais (assistentes sociais, conselhos tutelares, etc.). Nem sempre estes profissionais estão capacitados para este tipo de atenção e acabam por minimizar o problema ou encaminhá-lo de forma inadequada, postergando intervenções necessárias que, por vezes, tornar-se-ão mais difíceis e custosas no futuro.

Questōes como a violência crescente entre os adolescentes, delinqüência, uso de drogas são apenas alguns dos elos visiveis desta cadeia de eventos. Surge então uma sociedade perplexa, que não sabe o que fazer com estas crianças e adolescentes. Na maioria das vezes essas histórias iniciaram-se anos antes, manifestando-se por problemas muito menores e que, se reconhecidos, poderiam ter sido alvo de uma intervenção que revertesse esta evolução perversa.

Vários trabalhos apontam para $\circ$ pequeno reconhecimento ou valorização, pelos pediatras e outros profissionais da atenção básica, dos transtornos mentais na infância e adolescência. COSTELLO (1986), revisando 12 pesquisas sobre avaliação e tratamento dos transtornos mentais por pediatras, encontrou grande amplitude das taxas de diagnóstico, 
que variaram de $0,6 \%$ a $16,0 \%$. A maioria destas pesquisas encontrou taxas entre $4,0 \%$ e $7,0 \%$, aproximadamente metade daquelas encontradas pelos estudos de base populacional. Esta revisão também apresenta outras análises interessantes:

1) Os pais não costumam queixar-se dos problemas emocionais ou de comportamento de seus filhos aos pediatras.

2) Os pediatras têm dificuldade de identificar os problemas ou valorizar sua importância.

3) Os pediatras têm receio de colocar "rótulos deletérios" em seus pequenos pacientes.

4) Os pediatras são relutantes em expressar o diagnóstico para os pais por recear não ter tempo ou habilidade suficientes para lidar com o problema.

GIEL e col. (1981), em um estudo patrocinado pela OMS na África, encontraram taxas de prevalência de transtornos mentais entre $12,0 \%$ e $29,9 \%$, em crianças que buscavam atendimento na atenção primária. Foi detectada baixa capacidade dos técnicos de identificar o problema, pois apenas foram reconhecidos entre $10,0 \%$ e $29,0 \%$ dos casos com diagnóstico de transtorno mental feito por instrumento padronizado.

GARRALDA e BAILEY (1986), analisando crianças de sete a 12 anos avaliadas por médicos da atenção primária, encontraram $23,0 \%$ de casos com distúrbios psiquiátricos. Estes distürbios foram mais freqüentes em meninas que em meninos e os transtornos emocionais foram os distúrbios mais comuns. Os médicos que realizaram as consultas foram capazes de identificar apenas $11,8 \%$ de todas as crianças diagnosticadas como casos.

COSTELLO e col. (1988a) descreveram o pequeno reconhecimento feito por estes profissionais, principalmente dos transtornos mentais mais leves. Estudando 789 crianças de sete a 11 anos atendidas por pediatras na 
atenção primária, encontraram taxa de prevalência de transtornos mentais de $22,0 \%$. Neste mesmo estudo a prevalência deste tipo de problema encontrada pelos pediatras foi de 5,6\% (COSTELLO e col. 1988b). De modo geral, os pediatras têm alta especificidade, isto é, têm boa capacidade para distinguir os verdadeiros negativos, mas apresentam alto limiar para reconhecer os verdadeiros positivos (baixa sensibilidade) (ALMEIDA FILHO e ROUQUAYROL 1992). Neste estudo americano os pediatras identificaram só $17,0 \%$ das crianças com problemas de saúde mental, levando a uma "new hidden morbidity" de $83,0 \%$, conforme os autores denominaram os falsos negativos.

LAVIGNE e col. (1993), estudando 3.876 crianças em idade préescolar (entre dois e cinco anos), observaram diagnósticos de distúrbios mentais feitos por pediatras em $8,7 \%$ das crianças, e por técnicos de saúde mental em 13,0\%. A sensibilidade dos pediatras foi de 20,5\%, e a especificidade $92,7 \%$. Este autores reforçam que pelo menos $51,7 \%$ das crianças com problemas emocionais ou de comportamento não receberam orientação, medicação ou encaminhamento para serviços especializados.

BRIGGS-GOWAN e col. (2000) estudaram 1.060 crianças entre cinco e nove anos em consultórios pediátricos e encontraram taxa de prevalência de transtornos mentais de 16,8\%. Neste trabalho não foi avaliado o diagnóstico feito pelo pediatra. Além disso, observaram que metade dos pais de crianças com transtornos mentais não se queixaram ao médico destes problemas, que acabaram passando desapercebidos na consulta.

DULCAN e col. (1990) estudaram a importância de haver a queixa relacionada aos problemas mentais: quando os pais expressam suas preocupações aumenta a probabilidade do pediatra identificar o problema.

CHANG e col. (1988) também apontaram que a dificuldade do médico em fazer hipóteses diagnósticas na área de saúde mental advém, entre outros motivos, do fato de que os pais e as crianças não se queixam 
de seus problemas nesta área, e geralmente buscam atendimento para doenças físicas coexistentes ou manifestações somáticas dos problemas psiquiátricos.

HORWITZ e col. (1992) desenvolveram um interessante estudo buscando compreender melhor os determinantes das dificuldades dos pediatras em reconhecer os transtornos mentais nas crianças. Esta pesquisa envolveu 1.886 crianças de quatro a oito anos. Os pediatras preencheram um questionário sobre sintomas da área de saúde mental especialmente preparado para atenção primária. Este instrumento compreendeu, além dos problemas emocionais, de comportamento e de relacionamentos, questōes relacionadas ao crescimento, desenvolvimento e questões familiares e sociais. A partir deste instrumento, os pediatras identificaram 515 crianças $(27,3 \%)$ com pelo menos um problema psicossocial ou de desenvolvimento. Os achados dos pediatras não foram comparados com outro tipo de avaliação de transtornos mentais das crianças. Este estudo aponta para a importância do instrumento utilizado nas pesquisas e o diferente enfoque que a pediatria faz dos problemas da área de saúde mental.

Estes autores também encontraram que algumas características da consulta influenciam o reconhecimento destes problemas. Os médicos identificam mais problemas de saúde mental durante consultas de controle de saúde, isto é, quando não há problemas de saúde agudos, e quando conhecem bem as crianças.

Outro aspecto importante a ser considerado é a conduta dos profissionais da atenção primária frente a um diagnóstico de transtorno mental. LAVIGNE e col. (1993) observaram que, dos casos identificados pelos pediatras, $69,4 \%$ recebiam algum tipo de orientação, $8,1 \%$ receberam prescrição de medicamentos e 41,9\% foram encaminhados para serviços de saúde mental. HORWITZ e col. (1992) reportaram que as condutas dos pediatra nos casos diagnosticados eram: 40,0\% avaliação, tratamento ou orientação pelos próprios pediatras, $31,0 \%$ permaneciam sem tratamento, 
$16,0 \%$ eram encaminhados para serviços especializados e $13,0 \%$ sem informação.

Além de um pequeno reconhecimento dos distúrbios mentais pelos profissionais da atenção básica, também foi observado um reduzido número de encaminhamentos aos serviços especializados. Este achado pode ter várias causas, desde a pouca disponibilidade destes serviços até dificuldades pessoais dos profissionais em relação a este tipo de morbidade (não querer colocar rótulos deletérios em seus pacientes ou a pouca valorização das queixas, com conduta do tipo: "é da idade, vai passar").

Os fatores que favorecem o encaminhamento das crianças identificadas como portadoras de transtornos psiquiátricos para serviços especializados mereceram análises. GARRALDA e BAILEY (1988) observaram que o encaminhamento para atendimento especializado estava relacionado com o sexo masculino, gravidade do transtorno, problemas mentais nas mães, alto nível de estresse psicossocial na familia e falta de suporte em famílias grandes. BAILEY e GARRALDA (1989), estudando as razões explicitadas pelos médicos, encontraram que os principais motivos que favorecem os encaminhamentos são ansiedade da família, solicitação dos pais e gravidade do problema da criança.

GOLDBERG e HUXLEY (1980) descreveram um esquema que permite compreender o caminho trilhado na busca de atendimento na área de saúde mental. Estes autores criaram um modelo para descrever 0 processo de seleção que ocorre entre pessoas com transtornos mentais e que determina quais buscarão atendimento; quais, tendo buscado ajuda, terão seus distúrbios diagnosticados; $e$, tendo seus distúrbios diagnosticados, quais serão tratados pela atenção primária e quais serão encaminhados aos serviços psiquiátricos. São descritos cinco niveis, cada um representando uma população de sujeitos diferentes. Para ir de um nível para outro é necessário ultrapassar um filtro (Quadro 1). 
Quadro 1 - Acesso à atenção psiquiátrica: 5 níveis e 4 filtros

\begin{tabular}{|c|c|c|c|c|c|c|c|c|c|}
\hline & \multirow{2}{*}{$\begin{array}{c}\text { Comunidade } \\
\text { NIVEL } 1 \\
\end{array}$} & & \multicolumn{3}{|c|}{ Consulta de clinica geral } & & \multicolumn{3}{|c|}{ Serviços psiquiátricos especializados } \\
\hline & & & NIVEL 2 & & NIVEL 3 & & NIVEL 4 & & NIVEL 5 \\
\hline & $\begin{array}{c}\text { Estudos de } \\
\text { morbidade em } \\
\text { amostras } \\
\text { representativas } \\
\text { da comunidade }\end{array}$ & & $\begin{array}{l}\text { Morbidade } \\
\text { psiquiátrica total } \\
\text { na atenção } \\
\text { básica }\end{array}$ & & $\begin{array}{l}\text { Morbidade } \\
\text { psiquiátrica } \\
\text { conspicua }\end{array}$ & & $\begin{array}{c}\text { Total de } \\
\text { pacientes } \\
\text { psiquiátricos }\end{array}$ & & $\begin{array}{l}\text { Pacientes } \\
\text { psiquiátricos } \\
\text { internados }\end{array}$ \\
\hline FILTROS & & PRIMEIRO & & SEGUNDO & & TERCEIRO & & QUARTO & \\
\hline $\begin{array}{l}\text { Caracteristicas } \\
\text { dos filtros }\end{array}$ & & $\begin{array}{l}\text { Conduta do } \\
\text { paciente }\end{array}$ & & $\begin{array}{l}\text { Detecção do } \\
\text { transtorno }\end{array}$ & & $\begin{array}{l}\text { Encaminhamento } \\
\text { ao psiquiatra }\end{array}$ & & $\begin{array}{l}\text { Admissão ao } \\
\text { hospital } \\
\text { psiquiátrico }\end{array}$ & \\
\hline $\begin{array}{l}\text { INDIVÍDUO } \\
\text { CHAVE }\end{array}$ & & PACIENTE & & $\begin{array}{l}\text { MÉDICO } \\
\text { CLÍNICO }\end{array}$ & & $\begin{array}{l}\text { MÉDICO } \\
\text { CLÍNICO }\end{array}$ & & $\begin{array}{c}\text { MÉDICO } \\
\text { PSIQUIATRA }\end{array}$ & \\
\hline $\begin{array}{l}\text { Fatores que } \\
\text { operam no }\end{array}$ & & $\begin{array}{l}\text { Tipo e } \\
\text { gravidade dos }\end{array}$ & & $\begin{array}{l}\text { Técnicas de } \\
\text { entrevistas }\end{array}$ & & $\begin{array}{l}\text { Confiança e } \\
\text { habilidade para }\end{array}$ & & $\begin{array}{l}\text { Disponibilidade } \\
\text { de leitos }\end{array}$ & \\
\hline individuo chave & & sintomas & & Fatores de & & manejar 0 & & Disponibilidade & \\
\hline & & Estresse & & personalidade & & paciente & & de serviços & \\
\hline & & psicossocial & & Treinamento e & & Disponibilidade e & & psiquiátricos & \\
\hline & & $\begin{array}{l}\text { Padrões } \\
\text { aprendidos de } \\
\text { conduta perante }\end{array}$ & & atitude & & $\begin{array}{l}\text { qualidade dos } \\
\text { serviços } \\
\text { psiquiátricos }\end{array}$ & & $\begin{array}{l}\text { adequados na } \\
\text { comunidade }\end{array}$ & \\
\hline & & a doença & & & & $\begin{array}{l}\text { Atitude para com } \\
\text { os psiquiatras }\end{array}$ & & & \\
\hline Outros fatores & & $\begin{array}{l}\text { Atitude dos } \\
\text { familiares }\end{array}$ & & $\begin{array}{l}\text { Padrão de } \\
\text { sintomas }\end{array}$ & & $\begin{array}{l}\text { Padrão } \\
\text { sintomatológico }\end{array}$ & & $\begin{array}{l}\text { Padrão } \\
\text { sintomatológico }\end{array}$ & \\
\hline & & Disponibilidade & & apresentados & & do paciente & & do paciente & \\
\hline & & $\begin{array}{l}\text { de serviços } \\
\text { médicos }\end{array}$ & & $\begin{array}{l}\text { Caracteristicas } \\
\text { sócio- }\end{array}$ & & $\begin{array}{l}\text { Atitudes de } \\
\text { paciente e }\end{array}$ & & $\begin{array}{l}\text { Riscos para si e } \\
\text { para os demais }\end{array}$ & \\
\hline & & $\begin{array}{l}\text { Acesso } \\
\text { econômico ao } \\
\text { tratamento }\end{array}$ & & $\begin{array}{l}\text { demográficas do } \\
\text { paciente }\end{array}$ & & familiares & & $\begin{array}{l}\text { Atitudes do } \\
\text { paciente e } \\
\text { familiares }\end{array}$ & \\
\hline
\end{tabular}


$\mathrm{Na}$ população infantil, questões como o reconhecimento do problema pela familia, a consideração de buscar ajuda e a conduta do profissional de saúde estão baseadas tanto na presença da sintomatologia como também nas atitudes e crenças da familia (PAVULURI e col. 1995).

De acordo com o modelo de GOLDBERG e HUXLEY (1980), poderse-ia dizer que o médico da atenção básica corresponde ao segundo e terceiro filtros, sendo responsável pelo reconhecimento do problema e encaminhamento aos serviços especializados. 
MODA DA MENINA TROMBUDA

É a moda

da menina muda

da menina trombuda que muda de modos

e dá medo.

(A menina mimadal)

É a moda

da menina muda

que muda

de modos

e já não é trombuda.

(A menina amadal)

Cecília Meireles 


\subsection{OBJETIVO GERAL}

- Avaliar como o atendimento rotineiro das crianças pelos médicos da atenção básica aborda os problemas de saúde mental.

\subsection{OBJETIVOS ESPECÍFICOS}

- Identificar a proporção de crianças diagnosticadas como tendo algum tipo de problema de saúde mental pelo médico da atenção básica.

- Comparar e analisar, utilizando as abordagens quantitativa e qualitativa, a relação entre a freqüência dos tipos de problemas de saúde mental detectados pelo médico da atenção básica e aquela obtida através de um instrumento padronizado de avaliação.

- Analisar os determinantes da conduta do médico frente à suspeita diagnóstica de problemas de saúde mental. 
$O$ menino dorme. Para que o menino Durma sossegado, Sentada a seu lado A mãezinha canta:

- "Dodói, vai-te embora! "Deixa o meu filhinho. "Dorme... dorme... meu..."

Morta de fadiga. Ela adormeceu. Então, no ombro dela, Um vulto de santa, na mesma cantiga, na mesma voz dela, se debruça e canta:

- "Dorme, meu amor. "Dorme meu benzinho..."

e o menino dorme.

Manuel Bandeira 


\subsection{OPÇÃO TEÓRICO-METODOLÓGICA: TRAJETÓRIA}

Um dos aspectos mais complexos deste trabalho foi a opção teóricometodológica. Após a delimitação do tema e do problema a ser estudado, defrontei-me com a busca de referenciais teóricos que dessem conta da amplitude de análise que pretendia realizar.

Num primeiro momento ficou claro que a simples constatação numérica das possiveis diferenças entre as hipóteses diagnósticas de problemas de saúde mental feitas pelo médico na atenção básica e os prováveis diagnósticos de transtornos mentais feitos através de instrumentos padronizados não seria suficiente para contemplar os objetivos da investigação. $O$ aprofundamento das análises estatísticas, com ênfase nas relações entre as variáveis estudadas, também não parecia ser 0 caminho que me levasse ao resultado que pretendia obter.

Apesar de achar importante a descrição numérica das evidências do campo, algo mais era necessário. Entender o significado desta diferença, principalmente do ponto de vista dos médicos pediatras, parecia-me indispensável.

Algumas caracteristicas especificas deste estudo são de fundamental importância para a compreensão das escolhas metodológicas realizadas:

- Como pesquisadora encontrava-me profundamente envolvida com as questōes estudadas. Tendo uma trajetória pessoal tanto como pediatra quanto como psiquiatra, sentia-me identificada com os pediatras incluídos no estudo. Minhas hipóteses de trabalho emergiram da minha prática cotidiana nos serviços de 
saúde e eu tinha uma compreensão própria do problema estudado.

- Todas as evidências coletadas no campo foram obtidas a partir da interação com as diversas pessoas envolvidas na pesquisa. Além das entrevistas com os médicos, situação claramente colocada como interação explicitada, todos os outros dados emergiram de interações ${ }^{1}$. A aplicação dos questionários padronizados e as consultas médicas, cujo conteúdo foi captado através da análise do prontuário, também são situações claramente interacionais. A psiquiatria tem tentado, exaustivamente mas sem muito êxito, buscar instrumentos mais "objetivos" para realização de diagnósticos na área de saúde mental. Apesar da busca de marcadores biológicos para as doenças mentais, da construção de entrevistas padronizadas e testes psicológicos complexos e da elaboração de novas classificações tidas como mais objetivas (DSM IV e CID-10), quase toda a prática psiquiátrica, diagnóstica e também boa parte da terapêutica (exceção talvez da psicofarmacoterapia) baseia-se na interação entre duas pessoas.

- Pareceu-me também importante a contextualização dos achados, tanto no seu espaço geográfico específico como na história do serviço estudado. A escolha de um serviço de saúde com características tão próprias tem como um dos seus propósitos o aprofundamento da análise e uma compreensão mais abrangente do fenômeno estudado, mesmo que isto implique em redução da validade externa dos achados.

\footnotetext{
1 Segundo DENZIN (1989) interação compreende o agir de um sobre o outro, ser capaz de ação mútua. Para os seres humanos a interação é simbólica, envolvendo 0 uso da linguagem.
} 
Para realizar a análise dos achados deste estudo utilizei conceitos, ainda que algumas vezes de maneira aproximada, de duas propostas teórico-metodológicas.

A primeira delas é o Construcionismo Social, conforme descrito por SPINK (2000). Esta autora define, nas palavras de GERGEN (1985), o que vem a ser a investigação construcionista:

"A investigação sócio-construcionista preocupa-se sobretudo com a explicação dos processos por meio dos quais as pessoas descrevem, explicam ou dão conta do mundo (incluindo a si mesmo) em que vivem" (p. 26).

O núcleo desta proposta metodológica, também nas palavras de GERGEN (1985), citado por SPINK e MENEGON (2000) é a compreensão de que:

"os termos em que o mundo é compreendido são artefatos sociais, produtos de trocas historicamente situadas entre as pessoas" ( $p .76)$.

Nesta opção teórico-metodológica a pesquisa científica é concebida como uma prática reflexiva e crítica e também como uma prática social. A produção de sentido processa-se no contexto da ação social e é dialógica.

Segundo SPINK e MEDRADO (2000), a visão construcionista:

"alia-se à tradição hermenêutica de processo criativo mediado pelas expectativas e pressupostos que a pessoa traz para a situação, à tradição interacionista de valorização da presença - real ou imaginária - do outro e à onipresença da linguagem na perspectiva das práticas discursivas" (p. 59).

A segunda proposta teórico-metodológica é o Interacionismo Interpretativo como idealizado por DENZIN (1989) para ser uma modalidade de pesquisa avaliativa. Segundo esse autor, esta abordagem é uma tentativa de unir a abordagem interacionista simbólica com os trabalhos 
fenomenológicos e interpretativos de Heidegger e a tradição associada com a hermenêutica. Uma das teses básicas desta proposta é a importância da interpretação e da compreensão dos fatores-chave da vida social. A vida cotidiana gira em torno da interpretação e dos julgamentos que as pessoas fazem sobre os comportamentos e experiências de si mesmos e dos outros.

DENZIN (1989) descreve seis passos fundamentais para o processo interpretativo:

1. Delimitação da questão da pesquisa - que compreende não apenas formular o problema, mas também contextualizá-lo.

2. Desconstrução - refere-se a uma revisão da literatura crítica, desconstrutiva, que busca identificar viéses e pré-concepções.

3. Captação do fenômeno - corresponde à coleta de dados; envolve localizar e situar o que está sendo estudado.

4. Isolamento - separar o fenômeno do contexto no qual ocorre e tomá-lo à parte, para uma inspeção acurada, examinando seus elementos constituintes.

5. Construção - envolve reunir os elementos chaves de um fenômeno em uma seqüência, buscando recriar cada experiência vivida e reunir as diversas experiências que se relacionam com o fenômeno em investigação.

6. Contextualização - implica na recolocação do fenômeno isolado de volta ao mundo da experiência vivida. Nesta fase o pesquisador localiza o fenômeno no tempo e no espaço, trazendo-o à vida nas palavras de individuos em interação.

DENZIN (1989) reforça a importância de se obter uma descrição densa das evidências obtidas no campo. Descrições densas são relatos detalhados e profundos, que tentam resgatar os significados e experiências 
que ocorrem na situação da pesquisa. É a partir de descriçōes densas que sāo feitas interpretações densas.

Mesmo contando com aportes preciosos destas duas propostas teórico-metodológicas, as evidências do campo sempre nos colocam questões complexas e que extrapolam os formatos pré-definidos das teorias. Se por um lado não é possível dispensar referenciais teóricos, por outro, durante o percurso da pesquisa, a criatividade e a necessidade, nem sempre nesta ordem, acabam agregando técnicas e métodos que, naquele momento específico, pareceram ser as mais adequadas. As limitações impostas pelo meu conhecimento, pelas restrições do campo de pesquisa e outras questões que fugiram ao meu domínio acabaram também, de algum modo, conformando o desenho e a análise do estudo.

Acredito que o conhecimento é sempre inacabado e que os resultados deste estudo podem e deveriam suscitar mais questionamentos que certezas.

MINAYO (1994) cita um comentário de POIRIER que me parece muito pertinente:

“... num curso ministrado na França por LAZARSFELD (um dos renomados pesquisadores sociais de nosso século) sobre técnicas de análise de conteúdo aplicadas a histórias de vida, um dos alunos the perguntou sobre a condução de certos problemas práticos. Sorrindo, o mestre the respondeu: "A gente diz e escreve muitas coisas, mas na verdade a gente faz como pode" (POIRER et alli: 1987, 72)" (p. 228). 


\subsection{TIPO DE ESTUDO}

Este trabalho é uma pesquisa avaliativa que utilizou como estratégia - desenho de um estudo de caso de caráter descritivo e explanatório (TRIVIÑOS 1987; PATTON 1990; YIN 1994). Procurou-se fazer inicialmente uma descrição densa do problema estudado e do contexto e, a seguir, buscar respostas para as questões instigadoras da pesquisa. A opção pelo estudo de caso foi pautada no fato de que o objeto de estudo sofre influências do contexto e de variáveis de difícil controle, e com o propósito da pesquisadora de reter o aspecto holístico e naturalístico da situação estudada. 


\subsection{OBJETO DE ESTUDO}

Esta pesquisa ocupou-se do estudo dos problemas relacionados com a saúde mental de crianças. Foi utilizado o termo Problemas de Saúde Mental (PSM) para designar as hipóteses diagnósticas encontradas neste estudo que se enquadraram no capítulo $V$ (Transtornos mentais e comportamentais) da CID-10.

Os termos "transtorno" e "distúrbio" são utilizados ao invés de "doença" pois as condições estudadas serão definidas em termos de disfunção ou desvantagem. Além disso, os termos "distúrbios" e "transtornos" psiquiátricos não trazem a conotação de que o tratamento necessariamente beneficiará a criança nem qualquer implicação de que os psiquiatras são os terapeutas mais apropriados para tais casos. Alguns autores (CANTWELL e RUTTER 1994) definem estas alterações de comportamento ou emoções, com algumas exceções, não como "doenças" ou "enfermidades" qualitativamente diferentes do normal, mas sim desvios quantitativos do normal.

O conceito de transtornos psiquiátricos tradicionalmente utilizada em pesquisas é o de RUTTER e col. (1970) que define transtornos psiquiátricos como:

"(...) anormalidades de comportamentos, emoções ou relacionamentos suficientemente importantes e prolongadas para causar à criança prejuízo em seu funcionamento social elou levar a distúrbios na família ou na comunidade" (p. 148).

A essência desta definição, apesar de utilizada há mais de 30 anos e das inúmeras mudanças das classificações ocorridas neste período, permanece válida até hoje. CANTWELL (1999) afirma que:

"A ciência básica da psiquiatria infantil atualmente é o estudo sistemático de psicopatologia em crianças e adolescentes. 
Psicopatologia infantil e do adolescente clinicamente significativa pode ser definida como um transtorno em uma ou mais das seguintes áreas: comportamento manifesto, estados emocionais, relacionamentos interpessoais e função cognitiva. As anormalidades devem ser de duração e gravidade suficientes a ponto de causarem prejuizo funcional. Prejuízo funcional pode ser definido como um prejuízo que interfere no desenvolvimento de uma ou mais áreas, entre elas o rendimento escolar, comportamento na escola, relacionamentos interpessoais em casa, com os pares, na escola e na comunidade, o uso do tempo livre e o desenvolvimento de um senso de self e identidade" (p. 2345). 


\subsection{LOCAL}

Este estudo foi realizado em uma Unidade Básica de Saúde, pois a idéia central do projeto é avaliar como o atendimento rotineiro das crianças, pelos médicos da atenção básica, enfoca as questões de saúde mental.

A escolha recaiu sobre o Centro de Saúde Escola Samuel Barnsley Pessoa (CSE Butantã). Este Centro de Saúde, ligado à Universidade de São Paulo, propiciou condições adequadas aos objetivos da pesquisa, como área de abrangência definida e melhor documentação dos procedimentos realizados durante as consultas. Além disto, conta com equipe técnica com experiência em pesquisas.

O CSE Butantã situa-se na região oeste do Município de São Paulo, próximo ao Instituto Butantã e ao campus da Cidade Universitária Armando Salles de Oliveira, e constitui uma das 14 Unidades Básicas de Saúde que compõem o Distrito de Saúde Escola do Butantã (DSE Butantã). O DSE do Butantã corresponde a cinco distritos administrativos (DA): Butantã, Rio Pequeno, Morumbi, Vila Sônia e Raposo Tavares, ocupando área de 56,1 $\mathrm{km}^{2}$. A população da área de abrangência do DSE Butantã era, em 2000, de 377.576 habitantes (FUNDAÇÃO IBGE 2000) e densidade demográfica de 6.730 habitantes por $\mathrm{km}^{2}$.

O CSE Butantã atende a uma população moradora em área adstrita (Figura I) de 48.170 habitantes (FUNDAÇÃO IBGE 1996). O CSE Butantã foi inaugurado em 1977 e tem registrado uma constante busca de inovação e criação de alternativas tecnológicas no campo da Saúde Coletiva (CHIESA 1999).

A população que utiliza o CSE Butantã foi estudada por SALA e KON (2000), que encontraram as seguintes características (a amostra estudada corresponde à população cadastrada entre janeiro de 1997 a setembro de 1999): 
- A distribuição etária e por sexo dos usuários apresenta uma larga base de crianças menores de 12 anos, correspondendo a $36,6 \%$ do total, com proporção aproximadamente igual entre os sexos. $\mathrm{Na}$ população acima desta idade é evidente o predomínio do sexo feminino (4,3 mulheres para cada homem na população de 20 a 49 anos).

- Em relação à moradia, verificou-se que aproximadamente metade dos usuários moram em condições de habitação insatisfatórias. Observou-se uma associação positiva entre idade e qualidade de moradia; na faixa etária de menores de 12 anos somente $46,0 \%$ moram em condições satisfatórias (casa ou apartamento).

- Verificou-se associação negativa entre idade e escolaridade a partir dos 20 anos, o que deve refletir a progressiva melhoria de acesso à escola, verificada nas últimas décadas. Deste modo, é na população acima dos 50 anos que se encontra, ainda, proporção significativa de pessoas sem escolaridade, ou mesmo analfabetas.

O setor de Pediatria do CSE Butantã é coordenado pelo Departamento de Pediatria da Faculdade de Medicina da Universidade de São Paulo (FMUSP) e é utilizado como campo de ensino para alunos de medicina e residentes de pediatria (MASCARETTI 1997). Não existe atendimento especializado em saúde mental (psicólogo, psiquiatra infantil ou equipe multiprofissional) para crianças. O CSE Butantã tem um Setor de Saúde Mental, inserido na área programática de Atenção ao Adulto e vinculado ao Departamento de Medicina Preventiva da FMUSP (GIORDANO Jr e PEREIRA 1996). Este serviço não atende crianças menores de 12 anos. O CSE Butantã conta também com um Serviço de Fonoaudiologia, vinculado ao Departamento de Fonoaudiologia, Fisioterapia e Terapia Ocupacional da 
FMUSP, que propicia campo de estágio para os alunos do Curso de Fonoaudiologia.

O Departamento de Pediatria da FMUSP promove assistência, ensino e pesquisa na área de saúde mental através do Serviço de Higiene Mental do Instituto da Criança. DIAZ (1991), ao referir-se a este serviço, comenta:

"Como área de apoio este serviço é visto ocupando uma posição peculiar... (citando artigo da Revista de Pediatria; 1979) 'sua presença é prioritária nas áreas de formação fundamental. O objetivo é, através do processo de assessoria, contribuir para a formação de um pensamento pediátrico psicossomático, sem o que não se cumprirá o primeiro item dos objetivos do Instituto da Criança, que diz ser necessário à Pediatria abranger os problemas orgânicos e psíquicos da criança.'".

O Serviço de Higiene Mental foi criado em 1955 pelo Prof. Pedro de Alcântara nos moldes das "Child Guidance Clinics" norte-americanas (ASSUMPÇÃO Jr 1995). A filosofia de trabalho inicial do Serviço de Higiene Mental fundamentava-se em diretriz da Organização Mundial de Saúde que definiu, em 1952, Higiene Mental como atividades técnicas que promovem e mantém a Saúde Mental, e Saúde Mental como a capacidade do indivíduo de integrar-se ao grupo (DIAZ 1991). A partir de 1974, com a fundação do Instituto da Criança, a postura do serviço passou a ser mais psicodinâmica, com equipes multidisciplinares nas diversas especialidades: berçário, isolamento e UTI, de acordo com os modelos da Psiquiatria de Ligação (ASSUMPÇÃO Jr 1995).

O Departamento de Pediatria da FMUSP tem viabilizado pesquisas vinculadas às atividades assistenciais no CSE Butantã (LEONE e col. 1995). Nesta linha de trabalho, foi possivel localizar uma pesquisa de morbidade em escolares, realizada no CSE Butantã em 1996 (MASCARETTI e col. 1998). Foram estudados 440 prontuários de crianças de seis a 11 anos. Foi 
encontrado que $15,5 \%$ das crianças tinham hipóteses diagnósticas do capítulo $V$ da CID-10. Os transtornos encontrados foram: distúrbios de linguagem $(6,8 \%)$, enurese noturna $(4,5 \%)$, distúrbio de comportamento $(2,0 \%)$, transtorno de fixação na infância $(0,5 \%)$, alteração do desenvolvimento neuropsicomotor $(0,5 \%)$, gagueira $(0,2 \%)$, sonambulismo $(0,2 \%)$, hiperatividade $(0,2 \%)$, abuso sexual $(0,2 \%)$ e distúrbio de conduta $(0,2 \%)$. 


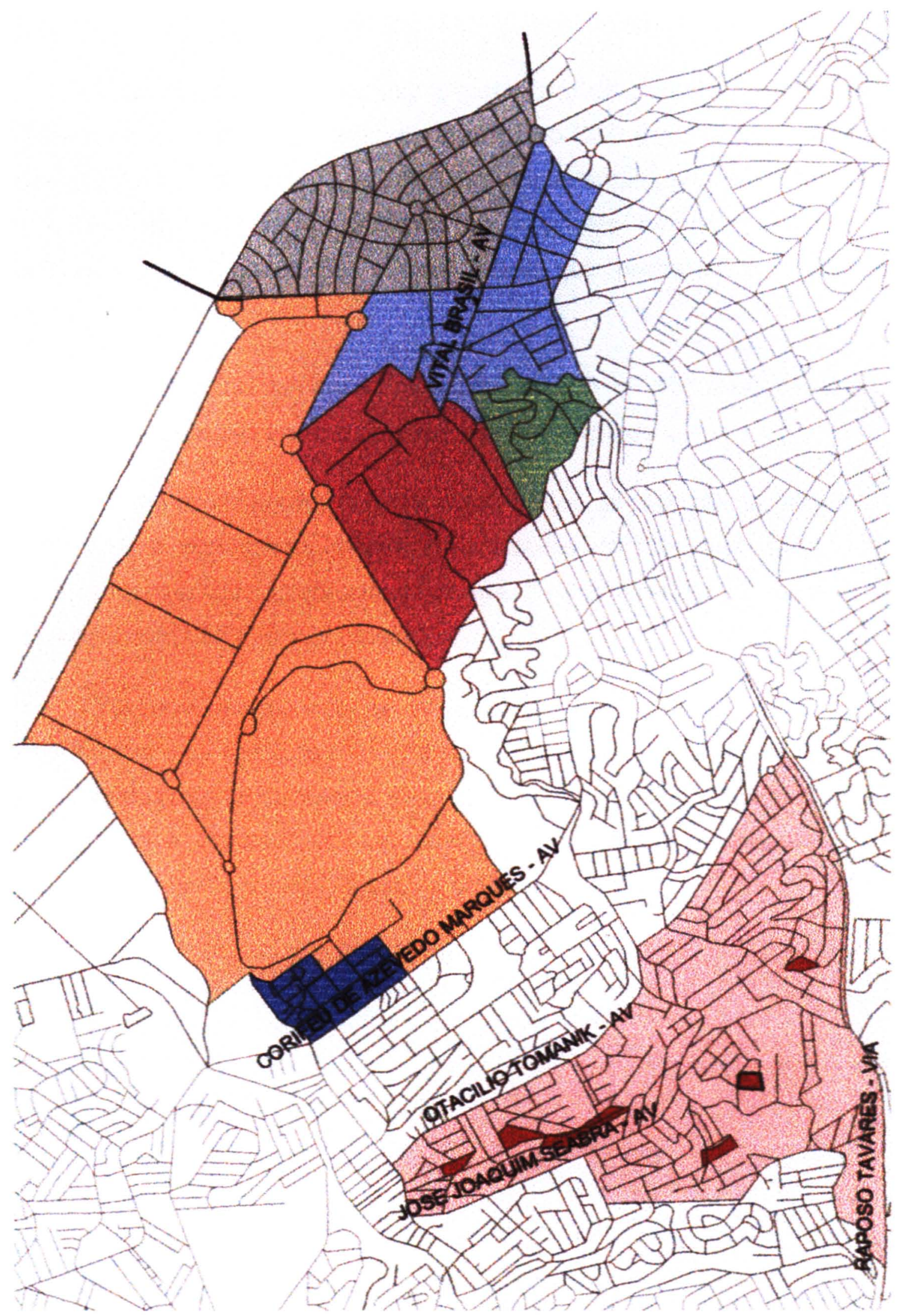

Figura I - Mapa da área de abrangência do Centro de Saúde Escola Butantã 


\subsection{SUJEITOS}

A população alvo do estudo foi composta de crianças de cinco anos a 11 anos e 11 meses de idade, atendidas pelo CSE Butantã no período de $1^{\circ}$ de agosto a 31 de outubro de 2000 . Em um levantamento prévio realizado no CSE Butantã foram encontrados os seguintes números relativos ao atendimento de crianças nesta faixa etária que passaram por consulta pediátrica agendada:

- Setembro, outubro e novembro de 1998 - 468 crianças

- Abril, maio e junho de $1999 \rightarrow 472$ crianças

Foram considerados sujeitos deste estudo as crianças na faixa etária estudada que procuraram atendimento através de consultas agendadas. Não foram analisadas as consultas tipo eventual/reavaliação. Os retornos da mesma criança não foram computados.

Também foram sujeitos os pediatras do CSE Butantã. Foram incluídos todos os médicos pediatras assistentes que, durante o período de estudo, realizaram ou supervisionaram o atendimento clínico das crianças da população alvo. Foram excluídos residentes, estagiários e pós-graduandos que freqüentavam o serviço durante o período estudado. 


\subsection{RELAÇÃO DOS INSTRUMENTOS UTILIZADOS}

Para a coleta das evidências no campo de estudo foram utilizados vários tipos de instrumentos, descritos a seguir.

$\checkmark$ Formulário para revisão do prontuário (Anexo 1)

As consultas realizadas no CSE Butantã são registradas em impressos padronizados específicos para cada tipo de consulta (Anexo 2). Existem os seguintes tipos de consultas:

- Caso novo - saúde da criança

- Retorno - saúde da criança

- Caso novo - saúde escolar

- Retorno - saúde escolar

- Eventual/reavaliação - saúde da criança

Os dados das consultas agendadas (todas acima, exceto a última) foram transcritos para um formulário, elaborado pela pesquisadora, que buscou resumir os dados de interesse da pesquisa.

$\checkmark$ Questionário de Capacidades e Dificuldades (Strengths and Difficulties Questionnaire) - SDQ (Anexo 3).

O SDQ é um questionário de triagem para problemas de saúde mental em crianças e adolescentes. É um questionário de fácil aplicação e fornece hipóteses diagnósticas de prováveis problemas de saúde mental. É composto de 25 questões das quais 20 correspondem a "dificuldades" ou sintomas de problemas de saúde mental e cinco questões sobre "capacidades" ou aspectos positivos da personalidade da criança (GOODMAN 1997, 2000, 2001; GOODMAN e col. 2000). Interroga também sobre o impacto que os sintomas relatados têm sobre a vida cotidiana das crianças e suas familias (GOODMAN 1999). A pontuação deste questionário 
fornece predições para três grupos de transtornos: transtornos de conduta, transtornos hipercinéticos e transtornos ansiosos/depressivos. Fornece também, através da combinação das respostas, a predição da presença ou ausência de algum tipo de problema de saúde mental. As três versões existentes (para pais, professores e jovens a partir de 11 anos) podem ser auto-aplicáveis (FLEITLICH e GOODMAN 2000). Apenas a versão para pais foi utilizada neste estudo. A versão original do SDQ tem propriedades psicométricas adequadas e comparáveis às do $\mathrm{CBCL}$ (ver a seguir) (GOODMAN e SCOTT 1999).

$\checkmark$ Inventário de Comportamento da Infância e Adolescência (Child Behavior Checklist) - CBCL (Anexo 4).

O CBCL (ACHENBACH e EDELBROCK 1981; ACHENBACH 1991; ACHENBACH 1993) foi criado em 1981 pelo psicólogo Thomas $M$. Achenbach e pelo psiquiatra infantil Craig Edelbrock em Vermont, Estados Unidos, e foi padronizado inicialmente para crianças de quatro a 18 anos. Possui 138 itens, sendo 20 destinados à avaliação da competência social da criança (perfil social) e 118 relativos à avaliação de problemas de comportamento (perfil comportamental). Apenas o perfil comportamental foi utilizado neste estudo. O princípio de construção do CBCL foi empírico, baseado na análise estatística de uma lista de queixas na área de saúde mental presentes nos prontuários médicos (DUARTE e BORDIN 2000). Este instrumento visa apenas detectar a presença ou não de problemas de comportamento, emocionais ou de relacionamentos e não fornece um diagnóstico de transtorno mental específico (BORDIN e col. 1995).

As 118 perguntas feitas durante o inventário referem-se a descrições de tipos de comportamento que os pais podem classificar como ausente, às vezes presente ou presente, recebendo pontuação de "0", "1" ou "2". 0 escore total obtido a partir da aplicação do CBCL determina três categorias: clínica, limítrofe e não clínica. O perfil comportamental é constituído de nove sub-escalas: 
(a) retraimento

(b) queixas somáticas

(c) ansiedade/depressão

(d) problemas com o contato social

(e) problemas com o pensamento

(f) problemas com a atenção

(g) comportamento delinqüente

(h) comportamento agressivo

(i) problemas sexuais (esta padronizada apenas para idade de quatro a 11 anos).

Quando agrupadas, as sub-escalas (a), (b) e (c) definem a escala de problemas "internalizing" e as sub-escalas $(g)$ e $(h)$ definem a escala de problemas "externalizing".

- $\mathrm{CBCL}$ é mundialmente utilizado para identificar prováveis problemas de saúde mental em crianças e adolescentes a partir de informações dos pais (BIRD 1996) e já foi traduzido e validado em mais de 50 idiomas. Na América Latina foi utilizado por BRALIO e col. (1987) e, no Brasil traduzido e validado por BORDIN e col. (1995). Tem sido utilizado em pesquisas epidemiológicas tanto como "screening" em estudos transversais em dois tempos quanto como preditivo de "outcomes" em estudos longitudinais (BARKLEY 1988). Também tem sido empregado em estudos com população pediátrica para avaliar impacto psico-afetivo de doenças crônicas. Além disso, tem demonstrado utilidade no ambiente clínico para diagnóstico precoce de prováveis transtornos mentais. As sub-escalas "problemas com a atenção" e "ansiedade/depressão" têm demonstrado melhor validade diagnóstica (BILENBERG 1999).

Além do inventário para os pais, outros dois instrumentos foram desenvolvidos por ACHENBACH (1993): um para professores (Teacher Report Form - TRF) e outro para adolescentes (Youth Self-Report Form YSR), já traduzidos para o português (DUARTE e BORDIN 2000). 
$\checkmark$ Ficha de identificação (Anexo 5).

Este formulário, elaborado pela pesquisadora para ser utilizado na entrevista domiciliar, tinha por objetivo, além de identificar a criança alvo da entrevista, obter informações sobre variáveis da criança e de sua familia que não constavam no prontuário do CSE Butantã. Foram inquiridas as seguintes variáveis:

- raça

- escolaridade (série cursada em 2000)

- idade dos pais

- escolaridade dos pais

- profissão e ocupação dos pais

- idade e sexo dos irmãos

- situação conjugal dos pais

Era também anotado o nome da pessoa que respondeu à entrevista.

\section{$\checkmark$ Questionário para pais sobre as preocupações relativas às dificuldades das crianças (Anexo 6).}

Este instrumento tinha o objetivo específico de captar a preocupação dos pais com os problemas de saúde mental detectados pelos questionários padronizados na entrevista domiciliar. Quando os pais manifestaram alguma preocupação era questionado se 0 assunto tinha sido abordado na consulta médica e o que aconteceu depois. No caso de haver preocupação mas o acompanhante não ter abordado o problema na consulta era perguntado o porquê. Este instrumento corresponde a uma adaptação feita pela pesquisadora de questionário elaborado por DULCAN e col. (1990).

\section{Roteiro da entrevista semi-estruturada com os pediatras (Anexo 7)}

As entrevistas realizadas com os médicos pediatras do CSE Butantã foram feitas a partir de um roteiro pré-definido pela pesquisadora. $O$ roteiro 
da entrevista é diferente de um questionário e, de acordo com MINAYO (1994), como visa:

"apreender o ponto de vista dos atores sociais previstos nos objetivos da pesquisa, (...) contém poucas questões. Instrumento para orientar uma "conversa com finalidade" que é a entrevista, ele deve ser o facilitador de abertura, de ampliação e de aprofundamento da comunicação" (p. 99).

Seguindo a abordagem de DENZIN (1989) as entrevistas partiram do roteiro inicial mas o desenrolar destas foi moldado a cada entrevistado, assumindo que significados, compreensões e interpretações não podem ser padronizados. A entrevista foi ajustada pela observação, estudo interacional e coleta das narrativas, transformando-se em uma "boa conversa", um processo no qual duas pessoas, criativa e abertamente, compartilham experiências.

A escolha da entrevista como técnica privilegiada para coleta de dados na abordagem qualitativa deu-se no sentido de buscar superar a limitação implícita da obtenção de dados que poderiam ser chamados de "objetivos", como de fontes como censos, estatísticas, registros e outros, e a possibilidade de acesso a dados de caráter subjetivo como "idéias, crenças, maneiras de pensar; opiniōes sentimentos, maneiras de sentir; conduta ou comportamento, presente ou futuro; razões, conscientes ou inconscientes de determinadas crenças, sentimentos, maneiras de atuar ou comportamentos" (MINAYO 1994; LEFÈVRE e col. 2000). 


\subsection{PROCEDIMENTOS METODOLÓGICOS}

\subsubsection{LEVANTAMENTO DOS DADOS}

O estudo foi realizado em dois momentos complementares, não seqüenciais, visando obter dados de fontes distintas para permitir uma análise mais aprofundada da atuação dos profissionais frente aos problemas de saúde mental na população pediátrica.

\section{$\checkmark$ PRIMEIRO MOMENTO - abordagem qualitativa.}

O primeiro momento do estudo consistiu na entrevista semiestruturada com os pediatras do CSE Butantã, partindo do pressuposto de que eles representam a porta de entrada do sistema de saúde para as crianças. Esta entrevista buscou obter, além da identificação em relação a idade, sexo e formação de cada profissional, a maneira como este percebe e valoriza os problemas de saúde mental, e que encaminhamento dá a eles (FONTANA e FREY 2000). Todas as entrevistas foram feitas pela pesquisadora.

$\checkmark$ SEGUNDO MOMENTO - abordagem quantitativa.

No segundo momento buscou-se encontrar, no universo das crianças estudadas, aquelas com PSM.

Para tanto a trajetória percorrida foi dividida em três etapas:

1. Foram levantados todos os prontuários de crianças na faixa etária estudada (cinco anos a 11 anos e 11 meses) que procuraram atendimento no decorrer de três meses consecutivos (01/08 a 31/10 de 2000). Apenas a consulta alvo da pesquisa foi analisada. Caso a criança tenha procurado atendimento mais de uma vez no período de estudo, apenas a primeira consulta foi levada em consideração. 
O objetivo desta busca foi o de localizar todas as crianças que tiveram alguma hipótese diagnóstica na área de saúde mental feita pelo pediatra durante a consulta médica.

As anotações do prontuário, a partir dos princípios da auditoria médica propostos por LEMBCKE (1967), foram consideradas retrato fiel da consulta. Esses princípios consideram que o que está escrito foi feito e o que não está escrito não foi feito. Os dados coletados desta fonte foram: idade, sexo, motivo da consulta (queixa), hipóteses diagnósticas realizadas (codificadas pela CID-10), condutas e encaminhamentos dados (tanto internos como externos à unidade). Este levantamento foi realizado pessoalmente pela pesquisadora.

2. Para localizar crianças com prováveis diagnósticos na área de saúde mental que tenham passado desapercebidas nas consultas clínicas, foi feito um rastreamento através do SDQ.

O SDQ foi aplicado ao acompanhante da criança no próprio CSE Butantã, logo depois da consulta médica (no mesmo periodo de 01/08 a $31 / 10$ de 2000). Após a aplicação do questionário, foi informado aos pais que alguns receberiam a visita de um entrevistador no domicilio para uma nova conversa, e que esta visita não significaria que a criança tivesse algum problema. Também foi oferecida possibilidade de orientação especializada para os pais que assim o desejassem. $O$ questionário foi aplicado por cinco entrevistadoras, funcionárias de nivel médio (auxiliares de enfermagem) do CSE Butantã com experiência em visitas domiciliares. A duração média deste procedimento foi de 15 minutos. Estas entrevistadoras não tinham conhecimento dos dados da consulta médica.

3. A partir da análise dos dados dos prontuários ( $1^{\natural}$ etapa) e dos resultados da aplicação do SDQ ( $2^{a}$ etapa) foram selecionadas as crianças para as visitas domiciliares $\left(3^{a}\right.$ etapa). 
Foram incluidas dois tipos de crianças: (a) as que tinham alguma hipótese diagnóstica do capítulo $V$ da CID-10 na consulta pediátrica (prontuário), ou com resultado do SDQ anormal, ou impacto limítrofe ou anormal e (b) um grupo de crianças sem alterações registradas no prontuário, e com SDQ e impacto sem anormalidades.

O objetivo dessa seleção era construir uma amostra intencional com alta concentração de crianças com problemas de saúde mental e um pequeno grupo controle de crianças aparentemente sem anormalidades, distribuídas igualmente por sexo e faixa etária (pré-escolar - cinco e seis anos e escolar - sete a onze anos).

A coleta dos dados na visita domiciliar foi realizada através dos seguintes instrumentos:

- Ficha de identificação (Anexo 5).

- SDQ (Anexo 3) - a repetição da aplicação do SDQ durante a entrevista domiciliar visava permitir a realização de um estudo posterior de confiabilidade do instrumento.

- CBCL (Anexo 4).

- Questionário para pais sobre as preocupações relativas às dificuldades dos filhos (Anexo 6).

A entrevista dos pais foi realizada no domicilio, entre sete e quinze dias após a consulta pediátrica (CARVALHEIRO 1975; TANAKA 1988), pelo mesmo grupo de entrevistadoras que aplicou o SDQ no Centro de Saúde. Estas entrevistadoras não tinham conhecimento dos dados do prontuário nem do resultado do SDQ. Na escolha da entrevistadora para cada visita, tomou-se o cuidado de que não fosse a mesma que havia aplicado o SDQ no CSE Butantã.

Antes do início do campo as entrevistadoras foram submetidas a um treinamento para conhecimento adequado dos instrumentos (SDQ e $C B C L$ ), 
esclarecimento de dúvidas e padronização da forma de preenchimento dos dados.

Um resumo das três etapas deste segundo momento encontra-se no Quadro 2.

Quadro 2 - Relação das fontes de dados. CSE Butantã, 2000.

\begin{tabular}{|c|c|c|c|}
\hline \multirow{2}{*}{ Fonte dos dados } & Planejado & \multicolumn{2}{|c|}{ Realizado } \\
\hline & $\mathrm{N}$ & $\mathrm{N}$ & $(\%)$ \\
\hline 1. Prontuários analisados & 411 & 411 & $(100,0)$ \\
\hline 2. Aplicação do SDQ & 411 & 353 & $(85,9)$ \\
\hline 3. Visitas domiciliares (amostra intencional) & 226 & 206 & $(91,5)$ \\
\hline
\end{tabular}

Em nenhuma etapa do estudo as crianças foram avaliadas diretamente. Por ocasião da visita domiciliar foi novamente oferecida à familia de todas as crianças a possibilidade de uma avaliação diagnóstica mais detalhada e eventual encaminhamento para tratamento.

\subsubsection{DESENHO DA ANÁLISE}

A forma como a questão da pesquisa foi formulada neste trabalho me levou a lançar mão tanto da técnica quantitativa quanto da qualitativa.

Neste sentido SPINK e MENEGON (2000) afirmam que:

"O método propriamente dito, uma vez definido o alinhamento epistemológico, pode ser único ou múltiplo, combinando estratégias quantitativas e qualitativas, como na triangulação metodológica" (p. 75).

TRIVIÑOS (1987) também discute esta dicotomia:

"Toda pesquisa pode ser, ao mesmo tempo, quantitativa e qualitativa. Na prática ocorre que toda a investigação baseada na estatística, que pretende obter resultados objetivos, fica exclusivamente no dado estatístico. Raramente o pesquisador aproveita essa informação para 
avançar numa interpretação mais ampla da mesma. Seu ideal é estabelecer que existe entre os fenômenos uma relação estatisticamente significativa ou não, verificar empiricamente suas hipóteses ou determinar que elas foram rejeitadas. Os investigadores pouco experientes, especialmente, que transformam a estatística num instrumento fundamental de busca, quando ela realmente deveria ser um elemento auxiliar do pesquisador, desperdiçam um material hipoteticamente importante. $E$ terminam seu estudo onde, verdadeiramente, deveriam começar" (p. 118).

Contribuindo para esta discussão, MINAYO e SANCHES (1993) referem que, apesar de suas naturezas distintas, elas não podem ser vistas como oposição contraditória; pelo contrário:

"é de se desejar que as relações sociais possam ser analisadas em seus aspectos mais 'ecológicos' e 'concretos' e aprofundadas em seus significados mais essenciais. Assim, o estudo quantitativo pode gerar questōes para serem aprofundadas qualitativamente, e vice-versa" ( $p$. 247).

Também na pesquisa avaliativa a combinação dos dois tipos de abordagem de pesquisa permite iluminar novos pontos de vista sobre o objeto de estudo, possibilitando conclusões mais abrangentes (PATTON 1990; TANAKA e MELO 2001).

Do ponto de vista quantitativo, inicialmente busquei explorar o máximo possivel os dados obtidos a partir dos prontuários. Planejei obter informações sobre a familia e outras variáveis sócio-demográficas a partir destes formulários, mas, após uma primeira exploração do material, foi possivel perceber que os dados anotados não permitiriam uma adequada avaliação dos mesmos. Não havia anotações atualizadas sobre a composição familiar ou situação sócio-econômica. Apenas idade, sexo e os elementos inerentes à consulta (queixas, hipóteses diagnósticas codificados de acordo com a CID-10 - e condutas) possibilitaram uma 
análise válida. Além da distribuição por sexo e idade, procurei analisar os diversos tipos de queixas (de saúde mental ou não) e, eventualmente, gravidade das mesmas.

Outro aspecto importante foi a análise da conduta do profissional: busquei elaborar um perfil de quais tipos de queixas permitem encaminhamentos mais efetivos ou determinam condutas mais expectantes.

Nesta etapa, para esta análise, os dados coletados foram transcritos para um banco de dados e trabalhados com o software "Statistical Package for the Social Sciences" (SPSS ${ }^{\circledR}$ for Windows ${ }^{\circledR}$ 1998).

A análise dos resultados do SDQ também foi realizada pelo software SPSS $^{\circledR}$, a partir de um banco de dados especialmente construído para esta finalidade e utilizando o algoritmo proposto por GOODMAN (2000).

Os dados obtidos a partir da aplicação do CBCL foram analisados inicialmente através de software especifico desenvolvido por ACHENBACH (1999). Este programa fornece perfis comportamentais clínico, limitrofe e não-clínico, além de outros tipos de categorizações: escalas de problemas "internalizing" e de problemas "externalizing" e agrupamentos de sintomas em sindromes: retraimento, queixas somáticas, ansiedade/depressão, problemas com o contato social, problemas com o pensamento, problemas com a atenção, comportamento delinqüente, comportamento agressivo e problemas sexuais. No Anexo 8 pode-se analisar um exemplo de como este programa produz estes perfis e escalas.

Nesta etapa também procurei aprofundar o conhecimento de algumas variáveis familiares que possam influir no aparecimento e evolução de problemas na área da saúde mental. Dados sobre a percepção pelas famílias das dificuldades enfrentadas pelas crianças também foram questionados para possibilitar a adequação da análise dos dados coletados. Caso as famílias não valorizem estas dificuldades ou não acreditem que os médicos possam ajudá-las, provavelmente não falarão delas nas consultas. 
A comparação entre os dados recolhidos dos prontuários e aqueles obtidos nas entrevistas domiciliares possibilitou uma compreensão de como se dá a articulação entre estas duas instâncias (família e atenção básica) no enfrentamento das questões relativas à saúde mental. Além de um grupo de crianças sem anormalidades, foram definidos três grupos:

1) crianças com hipóteses diagnósticas de PSM feitas pelos pediatras e também identificadas pelos instrumentos padronizados como portadoras de prováveis PSM,

2) crianças com prováveis PSM identificadas apenas pelos instrumentos padronizados e

3) crianças com hipóteses diagnósticas de PSM feitas apenas pelos pediatras.

Nesta etapa da análise quantitativa, quando necessário, utilizei o Teste Qui-Quadrado, adotando nivel de significância menor ou igual a $5 \%$.

Com o intuito de ampliar a compreensão dos determinantes das condutas dos médicos da atenção básica, busquei um aprofundamento da questão através das entrevistas realizadas com os pediatras que atenderam ou supervisionaram o atendimento das crianças estudadas (abordagem qualitativa).

O método utilizado para a análise das entrevistas tem como base a análise de conteúdo, conforme descrita por BARDIN (1977), que compreende as seguintes fases (p.102):

- Pré-análise - corresponde à fase de organização propriamente dita. Entre outras atividades inclui uma leitura "flutuante dos textos", buscando apreender as hipóteses emergentes e o estabelecimento de categorias empíricas. 
- Exploração do material - fase longa e fastidiosa, consiste essencialmente em operações de codificação ou enumeração, de acordo com regras previamente formuladas.

- Tratamento dos resultados obtidos e interpretação.

Como técnicas de análise foram utilizadas, de forma adaptada, a análise categorial (BARDIN 1977) e análise temática (MINAYO 1994).

A busca sistemática de aprofundamento do conhecimento das razões da atuação dos profissionais visou, além da compreensão ampliada desta questão, a possibilidade de proposição de projetos de capacitação ou de organização de serviços mais pertinentes e adequados, como também contribuir para a elaboração de políticas de saúde específicas e articuladas com o cotidiano dos serviços, que permitam o real enfrentamento deste problema.

Por fim, mas não menos importante, vale a pena referir uma questão metodológica que me acompanhou durante a elaboração deste estudo.

A escolha do estudo de caso e da abordagem qualitativa me fizeram recolocar a questão validade dos achados deste estudo. A pesquisa, da perspectiva realista, é regida por regras que visam superar a diferença entre nossas representações e a realidade (SPINK e MENEGON 2000). A perspectiva construcionista me permitiu ressignificar estes critérios, entendendo a realidade como um fenômeno histórico, cultural e dinâmico e a pesquisa como prática social. A preocupação com a replicabilidade dos resultados foi substituída pela explicitação da especificidade dos achados, tornando assim fundamental a descrição e exploração plena do contexto da pesquisa.

Sob esta ótica a opção por um Centro de Saúde Escola que, à primeira vista, colocaria em risco a possibilidade de generalizar os resultados encontrados, proporcionou a obtenção de um material extremamente rico e a análise de uma situação especifica com poder 
iluminador sobre o fenômeno em estudo. Como citam SPINK e MENEGON (2000):

"A generalização, vista como conteúdo, fica comprometida. Mas, em contraste, quando vista a partir da perspectiva dos processos de produção de sentidos, continua sendo possível, mesmo se reinterpretada como ilustração das inúmeras possibilidades de sentido". 


\subsection{ASPECTOS ÉTICOS}

Os aspectos éticos foram considerados em todo o desenrolar da pesquisa, conforme resolução n. ${ }^{\circ} 196$, de 10 de outubro de 1996 , do Conselho Nacional de Saúde.

O projeto de pesquisa foi aprovado pelo Comitê de Ética em Pesquisa da Faculdade de Saúde Pública da USP em 05/05/1999 (Of.COEP/44/99). Este projeto também foi submetido à apreciação do Conselho do Departamento de Pediatria da FMUSP, tendo sido aprovado em 05/03/1999. Foi também submetido à aprovação da direção do CSE Butantã antes do início da fase de campo.

Foram elaborados dois termos de responsabilidade da pesquisadora, um para os pais ou responsáveis pelas crianças e outro para os médicos pediatras (Anexos 9 e 10).

Nas entrevistas com os acompanhantes ou responsáveis pelas crianças, após a consulta médica no CSE Butantã, era explicado que se tratava de uma pesquisa sobre problemas de comportamento das crianças, que a participação era voluntária e que a recusa não interferiria no atendimento recebido pela criança no CSE Butantã. Após o consentimento verbal era entregue 0 termo de responsabilidade assinado pela pesquisadora e assegurado que qualquer dúvida seria esclarecida pela pesquisadora, tanto relativa à pesquisa, quanto aos problemas de saúde mental das crianças. Para tanto a pesquisadora tinha um plantão semanal no CSE Butantã para receber os responsáveis pelas crianças que assim desejassem. Também foi garantido 0 anonimato e que os dados obtidos somente seriam utilizados nesta pesquisa. Este aspecto foi importante pois, apesar do CSE Butantã ter área de abrangência bem definida, várias crianças moravam em outras regiões e os responsáveis ficaram com medo de serem "descobertos" e perderem o atendimento. Mesmo com essa 
garantia é possível que parte das perdas dos casos de visitas domiciliares tenha sido devida a esta questão.

No inicio das entrevistas com os médicos pediatras foi feito um relato sucinto da pesquisa e seus objetivos. Foi obtida a anuência do entrevistado e entregue 0 termo de responsabilidade assinado pela pesquisadora. Foram pactuadas a garantia do anonimato, a utilização responsável dos dados obtidos e a liberdade de participação ou não no estudo. Não houve nenhuma dificuldade em obter a colaboração dos médicos para as entrevistas, apenas algumas pequenas dificuldades para encontrar horários adequados para a realização das mesmas. 
Eu queria pentear o menino como os anjinhos de caracóis. Mas ele quer cortar o cabelo, porque é pescador e precisa de anzóis.

Eu queria calçar o menino com umas botinhas de cetim. Mas ele diz que agora é sapinho e mora nas águas do jardim.

Eu queria dar ao menino umas asinhas de arame e algodão. Mas ele diz que não pode ser anjo, pois todos já sabem que ele é índio e leão.

(Este menino está sempre brincando, dizendo-me coisas assim. Mas eu bem sei que ele é um anjo escondido, um anjo que troça de mim.)

Cecília Meireles 


\section{RESULTADOS E DISCUSSÃO}

\subsection{PRONTUÁRIOS}

Foram estudados os prontuários de 411 crianças de cinco anos a 11 anos e 11 meses de idade que compareceram a consultas agendadas no setor de Pediatria do CSE Butantã de 01 de agosto a 31 de outubro de 2000, perfazendo um total de 14 semanas de estudo. Este número correspondeu a todas as crianças nessa faixa etária atendidas em consultas agendadas no periodo estudado. A média de crianças consultadas foi de 29 por semana, variando de 18 a 42 crianças. A análise dos prontuários centrou-se na primeira consulta agendada dentro do período estudado.

Em relação ao tipo de consulta, houve predomínio das consultas de retorno* na saúde da criança, enquanto que na saúde escolar houve maior número de casos novos do que retorno, conforme Tabela 1.

Tabela 1 - Distribuição do número e percentagem das crianças segundo tipo de consulta. CSE Butantã, 2000.

\begin{tabular}{lcc}
\hline \multicolumn{1}{c}{ Tipo de consulta } & $\mathrm{N}$ & $(\%)$ \\
\hline Caso novo - saúde da criança & 36 & $(8,8)$ \\
Retorno - saúde da criança & 328 & $(79,8)$ \\
Caso novo - saúde escolar & 32 & $(7,8)$ \\
Retorno - saúde escolar & 15 & $(3,6)$ \\
\hline Total & 411 & $(100,0)$ \\
\hline
\end{tabular}

A distribuição das crianças por sexo foi equilibrada, com $50,4 \%$ do sexo feminino. Em relação à idade, houve tendência de redução no número de crianças atendidas com o aumento da idade.

\footnotetext{
* formulários dos diversos tipos de consulta no Anexo 2.
} 
Com o intuito de facilitar a análise, as crianças foram distribuídas em dois grupos etários: pré-escolar (cinco e seis anos) e escolar (sete anos a 11 anos e 11 meses) (Tabela 2).

Tabela 2 - Distribuição do número e percentagem das crianças segundo idade e sexo. CSE Butantã, 2000.

\begin{tabular}{lcccccc}
\hline \multirow{2}{*}{ Idade } & \multicolumn{4}{c}{ Sexo } & \multicolumn{3}{c}{ Total } \\
\cline { 2 - 6 } & $\mathrm{N}$ & $(\%)$ & $\mathrm{N}$ & $(\%)$ & $\mathrm{N}$ & $(\%)$ \\
\hline 5-6 (pré-escolar) & 91 & $(44,6)$ & 92 & $(44,4)$ & 183 & $(44,5)$ \\
$7-11$ (escolar) & 113 & $(55,4)$ & 115 & $(55,6)$ & 228 & $(55,5)$ \\
\hline Total & 204 & $(100,0)$ & 207 & $(100,0)$ & 411 & $(100,0)$ \\
\hline
\end{tabular}

A distribuição das crianças por idade em anos e sexo pode ser vista no Gráfico 1.

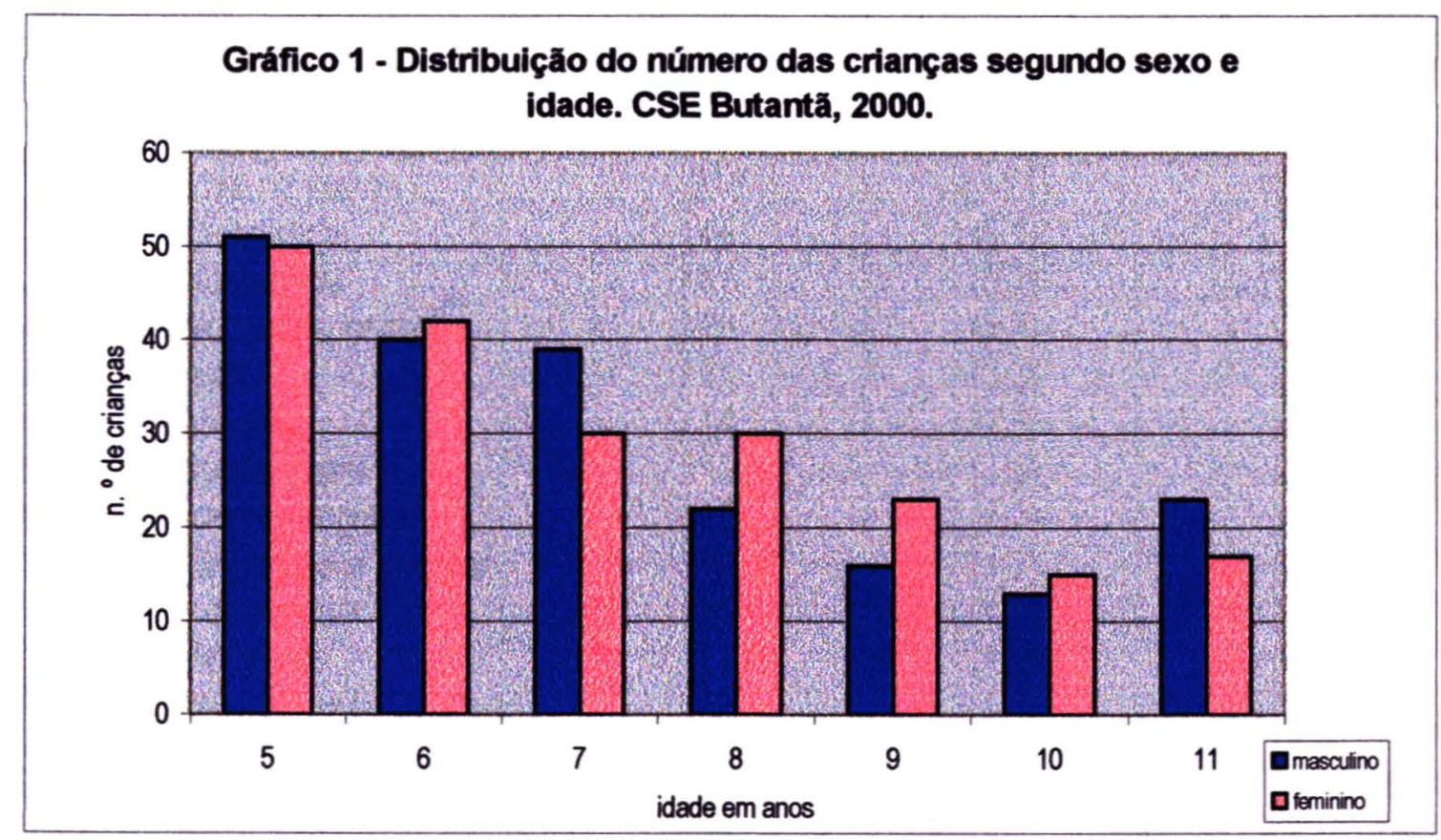

\subsubsection{QUEIXAS}

Foi realizado o levantamento das anotações feitas no campo MOTIVO DA CONSULTA dos impressos padronizados das consultas (Anexo 2). As queixas anotadas neste campo foram classificadas como queixas 
espontâneas, considerando que foram expressas diretamente como problemas percebidos pela mãe.

Foram encontradas 724 queixas espontâneas, variando de zero (84 crianças sem anotações) a quatro queixas por criança. Em 218 prontuários havia anotação de "controle de saúde, puericultura ou rotina", sozinha ou acompanhada de queixa(s) específica(s). Apesar deste tipo de anotação não ser de fato uma queixa, para fins operacionais foi considerada como tal. Inicialmente foi elaborada uma listagem completa de todas as queixas (Anexo 11).

A seguir estas anotações foram categorizadas em grupos de queixas afins, totalizando 159 grupos, e os 16 tipos mais freqüentes estão listados na Tabela 3.

Tabela 3 - Distribuição do número e percentagem das queixas segundo os 159 grupos. CSE Butantã, 2000.

\begin{tabular}{llccc}
\hline \multicolumn{2}{c}{ Tipo de queixa } & $\mathrm{N}$ & (\% de respostas) & (\% de casos) \\
\hline 1 & Controle de saúde & 218 & $(30,1)$ & $(53,0)$ \\
2 & Dor de cabeça & 44 & $(6,1)$ & $(10,7)$ \\
3 & Dor abdominal & 41 & $(5,7)$ & $(10,0)$ \\
4 & Tosse, coriza, rinorréia & 39 & $(5,4)$ & $(9,5)$ \\
5 & Enurese & 24 & $(3,3)$ & $(5,8)$ \\
6 & Prurido anal & 14 & $(1,9)$ & $(3,4)$ \\
7 & Obstrução nasal & 13 & $(1,8)$ & $(3,2)$ \\
8 & Corrimento vaginal & 12 & $(1,7)$ & $(2,9)$ \\
9 & Dificuldade para escutar & 12 & $(1,7)$ & $(2,9)$ \\
10 & Falta de apetite & 12 & $(1,7)$ & $(2,9)$ \\
11 & Dor de ouvido & 11 & $(1,5)$ & $(2,7)$ \\
12 & Dificuldade para enxergar & 10 & $(1,4)$ & $(2,4)$ \\
13 & Dor em membro inferior & 8 & $(1,1)$ & $(1,9)$ \\
14 & Prurido nasal & 8 & $(1,1)$ & $(1,9)$ \\
15 & Lesão de pele & 7 & $(1,0)$ & $(1,7)$ \\
16 & Dificuldade para falar & 7 & $(1,0)$ & $(1,7)$ \\
& Outras queixas & 244 & $(33,5)$ & $(59,6)$ \\
\hline & Total & 724 & $(100,0)$ & $-{ }^{\star}$ \\
\hline${ }^{\star}-$ respostas múltiplas - mais de uma queixa por criança) & &
\end{tabular}


Os grupos de queixas foram novamente reunidos, desta vez em sete grandes agrupamentos sintomáticos, conforme descrito na Tabela 4.

Tabela 4 - Distribuição do número e percentagem das queixas segundo agrupamentos sintomáticos. CSE Butantã, 2000.

\begin{tabular}{lccc}
\hline \multicolumn{1}{c}{ Grupos de queixas } & $N$ & (\% de respostas) & (\% de casos) \\
\hline Controle de saúde & 218 & $(30,1)$ & $(53,0)$ \\
Queixas respiratórias & 130 & $(18,0)$ & $(31,6)$ \\
Queixas inespecificas & 115 & $(15,9)$ & $(28,0)$ \\
Queixas comportamento & 60 & $(8,3)$ & $(14,6)$ \\
Queixas audição/visão & 33 & $(4,6)$ & $(8,0)$ \\
Queixas desenvolvimento & 17 & $(2,4)$ & $(4,1)$ \\
Outras queixas & 151 & $(20,7)$ & $(36,9)$ \\
\hline Total & 724 & $(100,0)$ & $-{ }^{*}$ \\
\hline
\end{tabular}

${ }^{\star}$ - respostas múltiplas - mais de uma queixa por criança)

Buscando ter uma compreensão mais completa das queixas, foram analisadas também as queixas que apareceram como resposta a questões predefinidas no prontuário (Anexo 2). Três campos foram cobertos por essa fonte: sono (condições atuais de vida), relacionamento familiar (aspectos sócio-econômicos), e desenvolvimento neuropsicomotor. Estas queixas foram denominadas queixas induzidas porque considerou-se que eram dirigidas por perguntas formuladas pelo médico.

\section{- Sono}

A queixa apareceu claramente registrada na consulta de retorno da saúde da criança, pois há um campo especifico para ser anotada. Nos outros tipos de consulta o médico anotava onde achava mais adequado, tornando mais difícil a coleta do dado. Em 178 casos $(43,3 \%)$ havia algum comentário qualitativo sobre o sono da criança; em $133(32,4 \%)$ havia sido anotado apenas a duração em horas, sem outro tipo de comentário; e em $100(24,3 \%)$ não havia anotação sobre o sono. Os comentários qualitativos podiam ser positivos (sono tranqüilo, dorme bem, sem alterações, sem queixas) ou negativos; neste último caso podiam ser divididos em dois grupos: as alterações relacionadas às obstruções de vias aéreas superiores (rinite, roncos, usa Afrin ${ }^{\circledR}$ ) e aquelas relacionadas às alterações do sono 
propriamente ditas (agitado, pesadelos, medos, não consegue dormir à noite, enurese).

- Relacionamento familiar

Os registros sobre o relacionamento familiar apresentavam a seguinte distribuição: em 218 prontuários $(53,0 \%)$ havia sido anotado bom ou adequado ou normal sem outras especificações; em 106 (25,8\%) não havia preenchimento do item; em $86(21,0 \%)$ havia descrição de algum aspecto do relacionamento familiar; e em um $(0,2 \%)$ estava anotado apenas inadequado. Nos casos em que havia alguma descrição anotada, a grande maioria estava relacionada com aspectos negativos do relacionamento (como, por exemplo, discussão entre os pais, pai não tem contato com a criança, brigas com irmãos).

- Desenvolvimento

Havia especificações quanto ao desenvolvimento da criança em 274 prontuários $(66,7 \%)$ Não constavam anotações sobre nenhum aspecto do desenvolvimento em 79 casos (19,2\%); em 57 (13,9\%) estava apenas anotado como bom ou adequado ou normal sem outras especificações; apenas em um caso $(0,2 \%)$ estava anotado como inadequado.

As anotações relativas ao desenvolvimento, tanto alterado como normal, foram categorizadas em quatro tipos: desenvolvimento físico/motor, desenvolvimento cognitivo, desenvolvimento da linguagem e desenvolvimento psicossocial (Quadro 3).

Quadro 3 - Distribuição do número e percentagem dos tipos de anotaçōes sobre desenvolvimento. CSE Butantã, 2000.

\begin{tabular}{lcc}
\hline \multicolumn{1}{c}{ Tipo de anotação* $^{*}$} & $\mathrm{~N}$ & $(\%)$ \\
\hline Desenvolvimento cognitivo & 232 & $(56,4)$ \\
Desenvolvimento psicossocial & 124 & $(30,2)$ \\
Desenvolvimento da linguagem & 100 & $(24,3)$ \\
Desenvolvimento físico/motor & 64 & $(15,6)$ \\
\hline
\end{tabular}

("- ocorre mais de um tipo de anotação por prontuário) 
É interessante ressaltar que, em muitos casos, principalmente nas consultas de casos novos, as anotações não correspondiam à idade cronológica atual da criança (por exemplo, em crianças de mais de cinco anos as anotações sobre o desenvolvimento motor iam somente até a aquisição da marcha). Além disso, várias anotações eram muito pouco especificas, não podendo ser traduzidas como indicadores do nível de desenvolvimento atual da criança, como por exemplo: gosta de conversar, criança ativa, conversa frases, esperta, brinca, vai na escola, criança chora bastante, gosta de fazer prova na escola, citação apenas da série freqüentada pela criança e outras.

É esperado que o principal tipo de anotação na área do desenvolvimento, na faixa etária estudada (cinco anos a 11 anos e 11 meses), seja o aspecto cognitivo, tendo em vista que a principal "tarefa" do desenvolvimento nesta faixa etária é a aquisição de habilidades nesta área.

As anotações de variáveis do desenvolvimento psicossocial foram as mais inespecíficas (como, por exemplo, brinca, tem amigos, é indisciplinado, teimoso, tímido, quase não manipula genitais), não podendo ser traduzidas em julgamentos mais acurados sobre a criança.

Baseado nas queixas espontâneas e induzidas encontradas no prontuário, foi formado um grupo de crianças com queixas que pudessem remeter a diagnósticos relacionados ao capítulo $\mathrm{V}$ da CID-10 (Transtornos mentais e comportamentais) (Anexo 12).

Do total das 411 crianças foram encontradas $92(22,4 \%)$ com queixas (espontâneas ou induzidas) relacionadas a PSM.

\subsubsection{DIAGNÓSTICOS}

Os formulários dos prontuários médicos das consultas de saúde da criança (tanto caso novo com retorno) apresentavam vários itens de diagnóstico, sendo sete deles predefinidos, que têm a finalidade de induzir o registro destes diagnósticos (Anexo 2). Nas consultas de saúde escolar 
(tanto caso novo como retorno) havia 13 diagnósticos predefinidos mas somente os sete diagnósticos predefinidos comuns aos quatro tipos de formulários foram analisados.

No grupo de diagnósticos predefinidos no prontuário foram encontrados os diagnósticos que serão sumariamente descritos nas Tabelas $5,6,7,8,9,10$ e 11 .

Tabela 5 - Distribuição do número e percentagem das crianças segundo diagnóstico nutricional. CSE Butantã, 2000.

\begin{tabular}{lcc}
\hline \multicolumn{1}{c}{ Diagnóstico nutricional } & $\mathrm{N}$ & $(\%)$ \\
\hline Eutrófico & 369 & $(89,8)$ \\
Distrófico & 31 & $(7,5)$ \\
Sem registro & 11 & $(2,7)$ \\
\hline Total & 411 & $(100,0)$ \\
\hline
\end{tabular}

Tabela 6 - Distribuição do número e percentagem das crianças segundo diagnóstico de crescimento. CSE Butantã, 2000.

\begin{tabular}{lcc}
\hline \multicolumn{1}{c}{ Diagnóstico de crescimento } & $\mathrm{N}$ & $(\%)$ \\
\hline Adequado & 382 & $(92,9)$ \\
Inadequado & 12 & $(2,9)$ \\
Sem registro & 17 & $(4,1)$ \\
\hline Total & 411 & $(100,0)$ \\
\hline
\end{tabular}

Tabela 7 - Distribuição do número e percentagem das crianças segundo diagnóstico alimentar. CSE Butantã, 2000.

\begin{tabular}{lcc}
\hline \multicolumn{1}{c}{ Diagnóstico alimentar } & $\mathrm{N}$ & $(\%)$ \\
\hline Adequado & 240 & $(58,4)$ \\
Inadequado & 158 & $(38,4)$ \\
Sem registro & 13 & $(3,2)$ \\
\hline Total & 411 & $(100,0)$ \\
\hline
\end{tabular}

Tabela 8 - Distribuição do número e percentagem das crianças segundo diagnóstico de vacinação. CSE Butantã, 2000.

\begin{tabular}{lcc}
\hline \multicolumn{1}{c}{ Diagnóstico de vacinação } & $N$ & $(\%)$ \\
\hline Completa & 341 & $(83,0)$ \\
Incompleta & 31 & $(7,5)$ \\
Sem registro & 39 & $(9,5)$ \\
\hline Total & 411 & $(100,0)$ \\
\hline
\end{tabular}


Tabela 9 - Distribuição do número e percentagem das crianças segundo diagnóstico do desenvolvimento neuropsicomotor. CSE Butantã, 2000.

\begin{tabular}{lcc}
\hline \multicolumn{1}{c}{ Diagnóstico de desenvolvimento } & $\mathrm{N}$ & $(\%)$ \\
\hline Normal & 388 & $(94,4)$ \\
Atrasado & 16 & $(3,9)$ \\
Sem registro & 7 & $(1,7)$ \\
\hline Total & 411 & $(100,0)$ \\
\hline
\end{tabular}

Tabela 10 - Distribuição do número e percentagem das crianças segundo diagnóstico do ambiente físico. CSE Butantã, 2000.

\begin{tabular}{lcc}
\hline \multicolumn{1}{c}{ Diagnóstico do ambiente físico } & $N$ & $(\%)$ \\
\hline Adequado & 298 & $(72,5)$ \\
Inadequado & 99 & $(24,1)$ \\
Sem registro & 14 & $(3,4)$ \\
\hline Total & 411 & $(100,0)$ \\
\hline
\end{tabular}

Tabela 11 - Distribuição do número e percentagem das crianças segundo diagnóstico do ambiente emocional. CSE Butantã, 2000.

\begin{tabular}{lcc}
\hline \multicolumn{1}{c}{ Diagnóstico do ambiente emocional } & $\mathrm{N}$ & $(\%)$ \\
\hline Adequado & 320 & $(77,9)$ \\
Inadequado & 75 & $(18,2)$ \\
Sem registro & 16 & $(3,9)$ \\
\hline Total & 411 & $(100,0)$ \\
\hline
\end{tabular}

No segundo grupo, em que o item do prontuário é aberto, as hipóteses diagnósticas foram codificadas segundo a CID-10.

Foram feitas 971 hipóteses diagnósticas, que estão listadas no Anexo 13. As 21 principais, que representam $67,5 \%$ do total de hipóteses diagnósticas $(\mathrm{N}=971)$, estão detalhadas na Tabela 12 .

Em 16 prontuários $(3,9 \%)$ não houve nenhuma hipótese diagnóstica anotada no grupo de diagnósticos não predefinidos. 
Tabela 12 - Distribuição do número e percentagem das hipóteses diagnósticas feitas pelos pediatras. CSE Butantã, 2000.

\begin{tabular}{|c|c|c|c|c|}
\hline & Hipóteses diagnósticas & $\mathrm{N}$ & $\begin{array}{c}\text { (\% de } \\
\text { respostas) }\end{array}$ & $\begin{array}{l}(\% \mathrm{de} \\
\text { casos) }\end{array}$ \\
\hline 1 & $\mathrm{~J} 30$ rinite alérgica & 90 & $(9,3)$ & $(21,9)$ \\
\hline 2 & K02 cáries dentárias & 63 & $(6,5)$ & $(15,3)$ \\
\hline 3 & B82 parasitose intestinal não especificada & 61 & $(6,3)$ & $(14,8)$ \\
\hline 4 & Z00.1 exame de rotina da saúde da criança & 53 & $(5,5)$ & $(12,9)$ \\
\hline 5 & D64.9 anemia não especificada & 52 & $(5,4)$ & $(12,6)$ \\
\hline 6 & R10 dor abdominal e pélvica & 32 & $(3,3)$ & $(7,8)$ \\
\hline 7 & J00 resfriado comum & 27 & $(2,8)$ & $(6,6)$ \\
\hline 8 & F98:0 enurese de origem não orgânica & 24 & $(2,5)$ & $(5,8)$ \\
\hline 9 & J39 outras doenças vias aéreas superiores & 24 & $(2,5)$ & $(5,8)$ \\
\hline 10 & R51 cefaléia & 24 & $(2,5)$ & $(5,8)$ \\
\hline 11 & N47 fimose & 22 & $(2,3)$ & $(5,4)$ \\
\hline 12 & R01 sopros cardiacos & 21 & $(2,2)$ & $(5,1)$ \\
\hline 13 & L85.3 xerose cutânea & 20 & $(2,1)$ & $(4,9)$ \\
\hline 14 & H53.9 distúrbio visual não especificado & 19 & $(2,0)$ & $(4,6)$ \\
\hline 15 & $\begin{array}{l}\text { F81 transtornos especificos do } \\
\text { desenvolvimento das habilidades escolares }\end{array}$ & 19 & $(2,0)$ & $(4,6)$ \\
\hline 16 & $\begin{array}{l}\text { N76 outras afecções inflamatórias da } \\
\text { vagina e da vulva }\end{array}$ & 19 & $(2,0)$ & $(4,6)$ \\
\hline 17 & $\begin{array}{l}\text { H66 otite média supurativas e as não } \\
\text { especificadas }\end{array}$ & 18 & $(1,9)$ & $(4,4)$ \\
\hline 18 & $\begin{array}{l}\text { J35 doenças crônicas das amigdalas e das } \\
\text { adenóides }\end{array}$ & 17 & $(1,8)$ & $(4,1)$ \\
\hline 19 & J45 asma & 16 & $(1,6)$ & $(3,9)$ \\
\hline 20 & $\begin{array}{l}\text { F80 transtornos especificos do } \\
\text { desenvolvimento da fala e da linguagem }\end{array}$ & 15 & $(1,5)$ & $(3,6)$ \\
\hline 21 & $\begin{array}{l}\text { H91.9 perda de audição não especificada } \\
\text { Outras hipóteses diagnósticas }\end{array}$ & $\begin{array}{c}15 \\
320 \\
\end{array}$ & $\begin{array}{l}(1,5) \\
(32,5)\end{array}$ & $\begin{array}{c}(3,6) \\
(77,6) \\
\end{array}$ \\
\hline & Total & 971 & $(100,0)$ & $-* \star$ \\
\hline
\end{tabular}

A seguir foram selecionadas, dentre 0 total de hipóteses diagnósticas, aquelas referentes ao capítulo $\mathrm{V}$ da CID-10 (Transtornos mentais e comportamentais).

No total de 411 prontuários foram identificadas $72(17,5 \%)$ crianças com hipóteses diagnósticas do capítulo $\mathrm{V}$ da CID-10, sendo 62 crianças com uma única hipótese diagnóstica, nove com duas hipóteses diagnósticas e uma com três hipóteses diagnósticas deste capítulo (num total de 83 hipóteses diagnósticas). 
As hipóteses diagnósticas do capitulo $\mathrm{V}$ da CID-10 encontradas estão na Tabela 13.

Tabela 13 - Distribuição do número e percentagem das hipóteses diagnósticas do capítulo V da CID-10. CSE Butantã, 2000.

\begin{tabular}{|c|c|c|c|c|}
\hline Hipóteses diagnósticas & $N$ & $\begin{array}{l}\text { (\% de } \\
\text { respostas) } \\
(\mathrm{N}=83)\end{array}$ & $\begin{array}{c}\text { (\% de casos } \\
\text { com HD do } \\
\text { cap. V da } \\
\text { CID-10*) } \\
(\mathrm{N}=72)\end{array}$ & $\begin{array}{l}\text { (\% do total } \\
\text { de casos) } \\
(\mathrm{N}=411)\end{array}$ \\
\hline F98.0 enurese de origem não orgânica & 24 & $(29,0)$ & $(33,3)$ & $(5,8)$ \\
\hline $\begin{array}{l}\text { F81 transtomos especificos do } \\
\text { desenvolvimento das habilidades escolares }\end{array}$ & 19 & $(22,9)$ & $(26,4)$ & $(4,6)$ \\
\hline $\begin{array}{l}\text { F80 transtornos especificos do } \\
\text { desenvolvimento da fala e da linguagem }\end{array}$ & 15 & $(18,1)$ & $(20,8)$ & $(3,6)$ \\
\hline F45.8 bruxismo & 5 & $(6,0)$ & $(6,9)$ & $(1,2)$ \\
\hline $\begin{array}{l}\text { F98.9 transtornos comportamentais e } \\
\text { emocionais não especificados com inicio } \\
\text { habitualmente na infância ou adolescência }\end{array}$ & 5 & $(6,0)$ & $(6,9)$ & $(1,2)$ \\
\hline $\begin{array}{l}\text { F91.9 transtorno não especificado de } \\
\text { conduta }\end{array}$ & 4 & $(4,8)$ & $(5,6)$ & $(1,0)$ \\
\hline $\begin{array}{l}\text { F90.9 transtorno hipercinético não } \\
\text { especificado }\end{array}$ & 3 & $(3,6)$ & $(4,2)$ & $(0,7)$ \\
\hline $\begin{array}{l}\text { F51 transtorno não-orgânico do sono } \\
\text { devido a fatores emocionais }\end{array}$ & 2 & $(2,4)$ & $(2,8)$ & $(0,5)$ \\
\hline F98.1 encoprese de origem não orgânica & 2 & $(2,4)$ & $(2,8)$ & $(0,5)$ \\
\hline $\begin{array}{l}\text { F45.9 transtorno somatoforme não } \\
\text { identificado }\end{array}$ & 1 & $(1,2)$ & $(1,4)$ & $(0,2)$ \\
\hline $\begin{array}{l}\text { F89 transtorno não especificado do } \\
\text { desenvolvimento psicológico }\end{array}$ & 1 & $(1,2)$ & $(1,4)$ & $(0,2)$ \\
\hline $\begin{array}{l}\text { F93.9 transtorno emocional de infância, não } \\
\text { especificado }\end{array}$ & 1 & $(1,2)$ & $(1,4)$ & $(0,2)$ \\
\hline F98.5 gagueira & 1 & $(1,2)$ & $(1,4)$ & $(0,2)$ \\
\hline Total & 83 & $(100,0)$ & $-\star \star$ & $-{ }^{* \star}$ \\
\hline
\end{tabular}

Como pode ser observado na tabela acima, a codificação das hipóteses diagnósticas de acordo com a CID-10 foi aproximada, pois as anotações no prontuário, na maioria das vezes, eram muito inespecíficas, com exceção de algumas poucas como enurese, encoprese e bruxismo. No 
decorrer da discussão dos resultados será utilizada a forma como o pediatra escreveu a hipótese diagnóstica no prontuário.

- Diagnóstico "ambiente emocional"

O diagnóstico do ambiente emocional é um dos diagnósticos predefinidos no prontuário e representa uma avaliação qualitativa do médico em relação às possíveis influências do meio, na área emocional, sobre a criança. É feito em analogia ao diagnóstico de ambiente físico e pode ser melhor compreendido como um conjunto de fatores de risco para problemas emocionais.

Nos 411 prontuários foram encontradas 75 crianças $(18,2 \%)$ com diagnóstico de ambiente emocional inadequado (Tabela 11). Este diagnóstico, por si só, não foi considerado como hipótese diagnóstica de PSM.

$\mathrm{Na}$ Tabela 14 encontram-se especificadas as anotações encontradas no prontuário nos casos de ambiente emocional inadequado. 
Tabela 14 - Distribuição do número e percentagem das crianças segundo especificações de ambiente emocional inadequado. CSE Butantā, 2000.

\begin{tabular}{lcc}
\hline Descrição do diagnóstico ambiente emocional inadequado & $\mathrm{N}$ & $(\%)$ \\
\hline Ausência do pai & 28 & $(37,5)$ \\
Ausência de pai e mãe & 8 & $(10,7)$ \\
Pais separados & 7 & $(9,4)$ \\
Alcoolismo pai elou mãe & 4 & $(5,3)$ \\
Ausência da mãe & 2 & $(2,7)$ \\
Dificuldade de relacionamento com o pai & 2 & $(2,7)$ \\
Criança sem limite* & 2 & $(2,7)$ \\
Mãe confusa/nervosa & 2 & $(2,7)$ \\
Criança introvertida* & 1 & $(1,3)$ \\
Briga entre os pais & 1 & $(1,3)$ \\
Dinâmica familiar inadequada & 1 & $(1,3)$ \\
Tio presidiário; uso de drogas por familiares & 1 & $(1,3)$ \\
Dependência da avó* & 1 & $(1,3)$ \\
Problemas financeiros & 1 & $(1,3)$ \\
Mãe adotiva quer levá-lo para a Bahia & 1 & $(1,3)$ \\
Mora em casa de apoio e è filho adotivo* & 1 & $(1,3)$ \\
Não está na escola* & 1 & $(1,3)$ \\
Distúrbio de comportamento* & 1 & $(1,3)$ \\
Padrasto, mãe omissa & 1 & $(1,3)$ \\
Inadequado sem outra especificação & 9 & $(12,0)$ \\
\hline Total & 75 & $(100,0)$ \\
\hline ("- descriçð̄es diretamente relacionadas à condição da criança) &
\end{tabular}

$\mathrm{Na}$ maior parte dos casos $(60,0 \%)$ o médico considerou a situação parental não tradicional (pai e/ou mãe genéticos não residindo mesmo domicilio da criança) como inadequada por si só, traduzindo uma relação direta entre este tipo de alteração e possiveis problemas emocionais na criança. Em 6 casos $(8,0 \%)$ são especificados atributos da criança como evidência do ambiente emocional inadequado.

\subsubsection{QUEIXA X DIAGNÓSTICO MÉDICO}

Para melhor compreender a relação entre as queixas, sejam elas espontâneas ou induzidas, e o diagnóstico médico, foram relacionados os casos com queixas de PSM ( $\mathrm{N}=92$ ) e os casos com hipóteses diagnósticas de PSM ( $N=72$ ) (Anexo 14) e realizadas análises comparativas destes dados. 
Entre as 92 crianças com queixas de PSM foi encontrado que em 27 casos $(29,3 \%)$ não havia registro de hipótese diagnóstica de PSM no prontuário. Por outro lado, entre as 319 crianças sem queixa de PSM havia sete casos $(2,2 \%)$ com registro de hipótese diagnóstica de PSM (Tabela 15).

Tabela 15 - Distribuição do número e percentagem das crianças segundo queixas e hipóteses diagnósticas de PSM. CSE Butantã, 2000.

\begin{tabular}{|c|c|c|c|c|c|c|}
\hline \multirow{3}{*}{$\begin{array}{l}\text { Hipótese diagnóstica de } \\
\text { 'PSM }\end{array}$} & \multicolumn{4}{|c|}{ Queixas de PSM } & \multirow{2}{*}{\multicolumn{2}{|c|}{ Total }} \\
\hline & \multicolumn{2}{|c|}{ Sim } & \multicolumn{2}{|c|}{ Não } & & \\
\hline & $\mathrm{N}$ & (\%) & $\mathrm{N}$ & $(\%)$ & $\mathrm{N}$ & (\%) \\
\hline Sim & 65 & $(70,6)$ & 7 & $(2,2)$ & 72 & $(17,5)$ \\
\hline Não & 27 & $(29,4)$ & 312 & $(97,8)$ & 339 & $(82,5)$ \\
\hline Total & 92 & $(100,0)$ & $\overline{319}$ & $(100,0)$ & 411 & $(100,0)$ \\
\hline
\end{tabular}

Fazendo o mesmo tipo de análise para problemas respiratórios, foram encontradas as seguintes relações (Tabela 16):

Tabela 16 - Distribuição do número e percentagem das crianças segundo queixas e hipóteses diagnósticas de problemas respiratórios. CSE Butantã, 2000.

\begin{tabular}{lcccccc}
\hline \multirow{2}{*}{$\begin{array}{l}\text { Hipóteses diagnósticas de } \\
\text { problemas respiratórios }\end{array}$} & \multicolumn{3}{c}{ Queixas de problemas respiratórios } & \multicolumn{3}{c}{ Total } \\
& $N$ & $(\%)$ & $N$ & $(\%)$ & $N$ & $(\%)$ \\
\hline Sim & 107 & $(87,0)$ & 65 & $(22,6)$ & 172 & $(41,8)$ \\
Não & 16 & $(13,0)$ & 223 & $(77,4)$ & 239 & $(58,2)$ \\
\hline Total & 123 & $(100,0)$ & 288 & $(100,0)$ & 411 & $(100,0)$ \\
\hline
\end{tabular}

Dos 123 casos com queixa de problemas respiratórios, apenas 16 $(13,0 \%)$ não tiveram hipótese diagnóstica de problemas respiratórios anotada no prontuário e foram feitas hipóteses diagnósticas de problemas respiratórios em 65 casos $(22,6 \%)$ dentre as 288 crianças sem queixa de problema respiratório registrada no prontuário.

Considerando as queixas, tanto as de problemas respiratórios como as de PSM, como critério de referência, foram calculadas a sensibilidade e a especificidade das hipóteses diagnósticas dos pediatras para ambos os tipos de problema (Quadro 4). 
Quadro 4 - Índices de "validade" das hipóteses diagnósticas dos médicos segundo critério de referência (queixas). CSE Butantã, 2000.

\begin{tabular}{lcc}
\hline \multirow{2}{*}{ Índices de "validade" } & \multicolumn{2}{c}{ Critério de referência (queixas) } \\
\cline { 2 - 3 } & PSM & Problemas respiratórios \\
\hline Sensibilidade & $70,6 \%$ & $87,0 \%$ \\
Especificidade & $97,8 \%$ & $77,4 \%$ \\
\hline
\end{tabular}

O raciocínio clínico do médico é diferente nos dois tipos de queixas.

Nos PSM há uma tendência de desvalorizar a queixa (sensibilidade de $70,6 \%$ ), isto é, há queixas que não se refletem em hipóteses diagnósticas. A especificidade das hipóteses diagnósticas dos médicos é alta $(97,8 \%)$ significando que quando não há queixa é pouco provável que haja hipótese diagnóstica.

Nos problemas respiratórios as queixas têm maior probabilidade de transformarem-se em hipóteses diagnósticas (sensibilidade de $87,0 \%$ ). No entanto, a especificidade é mais baixa $(77,4 \%)$, pois há hipóteses diagnósticas sem queixas anotadas no prontuário.

É importante considerar que os tipos de queixas são diferentes. No caso dos PSM a queixa é mais subjetiva e os instrumentos de observação objetiva do pediatra contribuem pouco para o aprofundamento do problema. Além disso, nem sempre a queixa na área da saúde mental corresponde a uma hipótese diagnóstica. Por exemplo uma queixa de fobia pode corresponder a uma característica de um estágio do desenvolvimento e não um sintoma patológico.

No caso dos problemas respiratórios, quando a queixa está presente, o pediatra se sente mais habilitado para aprofundar a investigação diagnóstica. A possibilidade de verificação dos sinais clínicos no exame físico e a confiança na própria capacidade de intervenção também propiciam a conduta de busca ativa do diagnóstico, até mesmo nos casos sem nenhuma queixa. 
Analisando os tipos de queixa de PSM (espontâneas ou induzidas) encontrou-se que, dos 92 casos com queixas, 65 corresponderam a queixas espontâneas e 27 a queixas induzidas. Dentre os casos com queixa espontânea foi feita hipótese diagnóstica de PSM em 53 crianças (81,5\%); dentre aqueles com queixa induzida a hipótese diagnóstica de PSM foi feita em 12 crianças $(44,4 \%)$. É interessante notar que a queixa induzida, apesar de aparecer em resposta a um questionamento do pediatra, tem menor probabilidade de resultar em hipótese diagnóstica de PSM.

Na Figura II pode ser melhor visualizada a relação entre os tipos de queixas de PSM durante a consulta e as hipótese diagnósticas de PSM realizados pelos pediatras. 


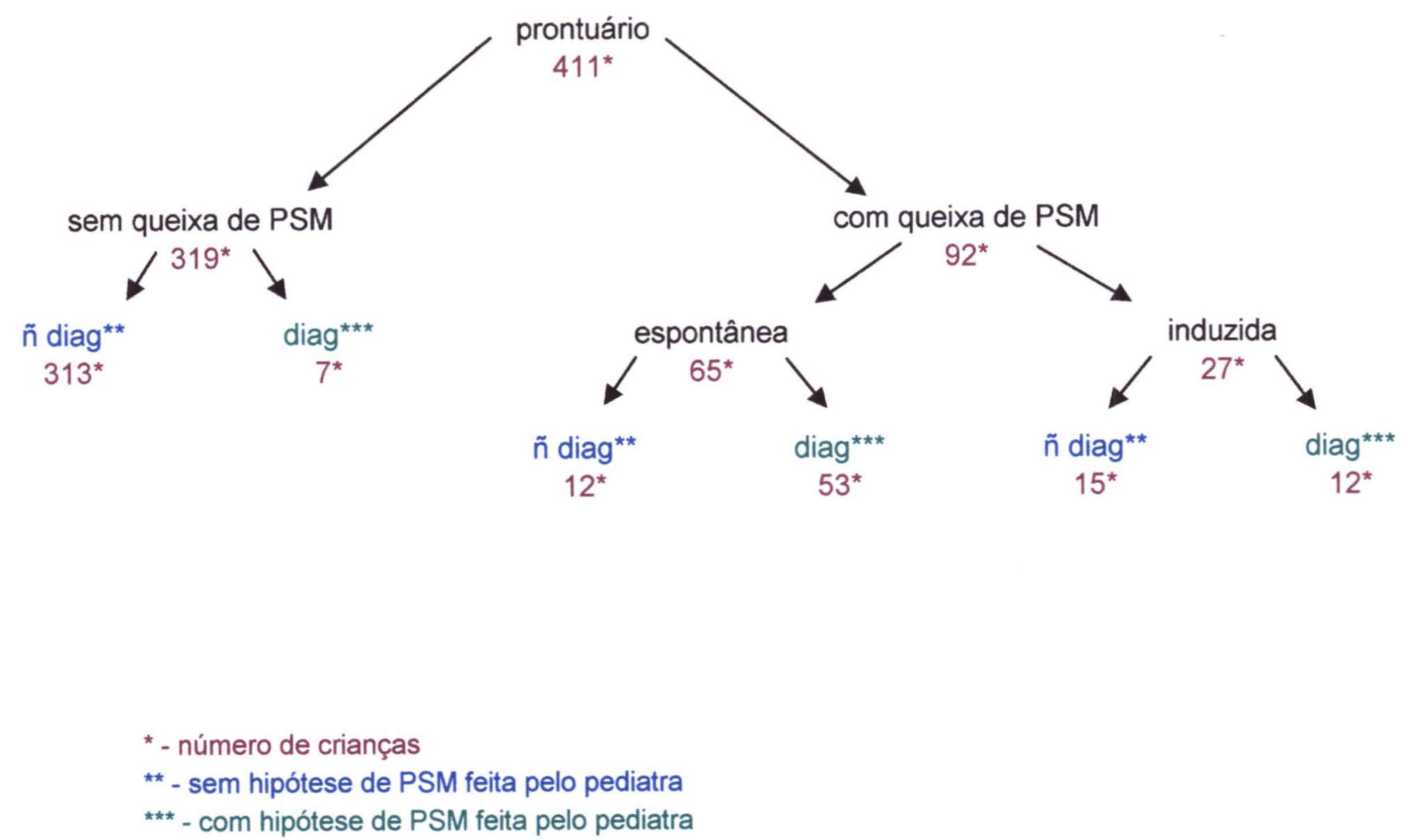

** - sem hipótese de PSM feita pelo pediatra

- com hipótese de PSM feita pelo pediatra

Figura II - "Árvore" da relação entre queixas e hipóteses diagnósticas de PSM feitas pelos pediatras 


\subsubsection{CONDUTAS}

Foram analisadas as condutas do pediatra anotadas nos prontuários das 72 crianças com hipótese diagnóstica do capítulo $V$ da CID-10. Os tipos de conduta encontrados estão listados na Tabela 17.

Tabela 17 - Distribuição do número e percentagem das crianças com diagnóstico de PSM segundo tipo de conduta do pediatra. CSE Butantã, 2000.

\begin{tabular}{lcc}
\hline \multicolumn{1}{c}{ Tipo de conduta } & $N$ & $(\%)$ \\
\hline Orientação & 13 & $(18,0)$ \\
Encaminhamento serviço de saúde mental & 6 & $(8,3)$ \\
Encaminhamento para fonoaudiologia & 5 & $(6,9)$ \\
Observação & 5 & $(6,9)$ \\
Relatório escolar & 5 & $(6,9)$ \\
Em acompanhamento de fonoaudiologia & 4 & $(5,6)$ \\
Encaminhamento para odontologia & 2 & $(2,8)$ \\
Exames + orientação & 2 & $(2,8)$ \\
Orientação/observação + avaliação saúde escolar & 2 & $(2,8)$ \\
Avaliação saúde escolar & 1 & $(1,4)$ \\
Em acompanhamento de psicologia & 1 & $(1,4)$ \\
Encaminhamento para oftalmologia & 1 & $(1,4)$ \\
Exames & 1 & $(1,4)$ \\
Exames + relatório escolar & 1 & $(1,4)$ \\
Encaminhamento para oftalmologia + exames & 1 & $(1,4)$ \\
Encaminhamento para oftalmologia + relatório escolar & 1 & $(1,4)$ \\
Sem registro no prontuário* & 21 & $(29,2)$ \\
\hline Total & 72 & $(100,0)$ \\
\hline I*-não foi possivel diferenciar se a conduta não foi tomada ou se apenas não foi registrada)
\end{tabular}

(" - não foi possivel diferenciar se a conduta năo foi tomada ou se apenas não foi registrada)

A conduta mais freqüente foi a orientação (em 18,0\% dos casos) sem outras especificações, que foi encontrada em tipos variados de hipóteses diagnósticas, desde enurese, distúrbio do sono até distúrbio de conduta e atraso do desenvolvimento neuropsicomotor.

O encaminhamento para fonoaudiologia (cinco crianças) ou em acompanhamento em fonoaudiologia (quatro crianças) referiam-se a casos com hipótese diagnóstica de transtornos específicos de linguagem.

As condutas de solicitação de relatório escolar e encaminhamento para oftalmologia estavam relacionadas com queixas escolares. 
Nenhum encaminhamento para psicologia foi feito nas crianças com hipótese diagnóstica isolada de transtorno de habilidades escolares.

Exames de laboratório foram solicitados em dois casos de enurese e em três casos de dificuldades escolares (timpanometria, acuidade ocular).

Os dois encaminhamentos para odontologia foram feitos em casos de bruxismo.

O encaminhamento para serviços especializados de saúde mental foi realizado em seis casos; um caso já estava em acompanhamento com psicóloga. Estes sete casos tinham as seguintes hipóteses diagnósticas:

- Distúrbio de comportamento (em dois casos)

- Déficit de atenção

- Distúrbio de conduta + Escolaridade atrasada

- Enurese + Síndrome da criança dolorosa

- Enurese + Distúrbio de conduta

- Enurese + Dificuldade de aprendizagem + Terror noturno

Nenhuma criança foi medicada.

Entre as 72 crianças com hipótese diagnóstica de PSM, havia 21 $(29,2 \%)$ sem conduta anotada no prontuário, não sendo possível saber se nenhuma conduta foi tomada ou se apenas não houve registro.

A relação completa das hipóteses diagnósticas de PSM e as condutas para cada caso está no Anexo 15. A análise mais detalhada dessa relação revela a heterogeneidade das condutas, com variados tipos de encaminhamentos para a mesma hipótese diagnóstica. 


\subsection{QUESTIONÁRIO DE CAPACIDADES E DIFICULDADES (SDQ)}

O Questionário de Capacidades e Dificuldades (SDQ) foi aplicado, após as consultas pediátricas, aos responsáveis pelas crianças. Foi planejado aplicar o SDQ em todos os acompanhantes das crianças $(\mathrm{N}=$ 411). Foram entrevistados 356 acompanhantes. Não foram entrevistados 55 acompanhantes devido a problemas na organização do processo de trabalho das entrevistadoras e pressa dos acompanhantes ao final de consultas demoradas.

Dos 356 questionários foram descartados três após a aplicação pois o preenchimento apresentava-se incompleto (a parte correspondente ao impacto dos sintomas estava em branco).

Foram comparados os grupos com aplicação do SDQ $(N=353)$ e sem aplicação do SDQ $(N=58)$ em relação às variáveis sexo, idade e hipótese diagnóstica de PSM feita pelo pediatra na consulta. Não foram encontradas diferenças estatisticamente significantes entre os dois grupos.

Os resultados obtidos a partir dos 353 questionários completos estão na Tabela 18.

Tabela 18 - Distribuição do número e percentagem das crianças segundo pontuação do SDQ e do impacto. CSE Butantã, 2000.

\begin{tabular}{|c|c|c|c|c|c|c|c|c|}
\hline \multirow{3}{*}{ Pontuação total do SDQ } & \multicolumn{6}{|c|}{ Impacto } & \multirow{2}{*}{\multicolumn{2}{|c|}{ Total }} \\
\hline & \multicolumn{2}{|c|}{ Normal } & \multicolumn{2}{|c|}{ Limitrofe } & \multicolumn{2}{|c|}{ Anormal } & & \\
\hline & $\mathrm{N}$ & (\%) & $\mathrm{N}$ & $(\%)$ & $\mathrm{N}$ & $(\%)$ & $\mathrm{N}$ & $(\%)$ \\
\hline Normal & 148 & $(42,0)$ & 4 & $(1,1)$ & 6 & $(1,7)$ & 158 & $(44,7)$ \\
\hline Limitrofe & 45 & $(12,7)$ & 3 & $(0,8)$ & 1 & $(0,3)$ & 49 & $(13,9)$ \\
\hline Anormal & 79 & $(22,4)$ & 26 & $(7,4)$ & 41 & $(11,6)$ & 146 & $(41,4)$ \\
\hline Total & 272 & $(77,1)$ & 33 & $(9,3)$ & 48 & $(13,6)$ & 353 & $(100,0)$ \\
\hline
\end{tabular}

Estas 353 crianças podem ser divididas em quatro grupos, incorporando-se os casos de SDQ limitrofes aos casos com SDQ normal e os casos com impacto limítrofe aos casos com impacto normal (Tabela 19). 
Tabela 19 - Distribuição do número e percentagem das crianças segundo pontuação do SDQ e do impacto (casos com SDQ/impacto limitrofes incorporados aos normais). CSE Butantã, 2000.

\begin{tabular}{|c|c|c|c|c|c|c|}
\hline \multirow{3}{*}{ Pontuação total do SDQ } & \multicolumn{4}{|c|}{ Impacto } & \multirow{2}{*}{\multicolumn{2}{|c|}{ Total }} \\
\hline & \multicolumn{2}{|c|}{ Normal $^{*}$} & \multicolumn{2}{|c|}{ Anormal } & & \\
\hline & $\mathrm{N}$ & (\%) & $\mathrm{N}$ & $(\%)$ & $\mathrm{N}$ & $(\%)$ \\
\hline Normal $^{*}$ & 200 & $(56,7)$ & 7 & $(2,0)$ & 207 & $(58,6)$ \\
\hline Anormal & 105 & $(29,7)$ & 41 & $(11,6)$ & 146 & $(41,4)$ \\
\hline Total & 305 & $(86,4)$ & 48 & $(13,6)$ & 353 & $(100,0)$ \\
\hline
\end{tabular}

$\left({ }^{*}\right.$ - inclui casos normais e casos limitrofes)

Note-se que, das 353 crianças avaliadas pelo SDQ, 41 crianças $(11,6 \%)$ apresentaram pontuação total do SDQ anormal e do impacto anormal, apontando para a presença de provável transtorno nas áreas abrangidas pelo questionário (sintomas emocionais, problemas de conduta, hiperatividade e problemas de relacionamento com os colegas). 


\subsection{SDQ X DIAGNÓSTICO DE PSM FEITO PELO PEDIATRA}

Foi realizada uma comparação entre os resultados da aplicação do SDQ e as hipóteses diagnósticas de PSM feito pelo pediatra.

Inicialmente, considerando os casos normais e limitrofes do SDQ como pontuação normal, foi comparado o resultado do SDQ sem o impacto com as hipóteses diagnósticas de PSM feitas pelo pediatra (Tabela 20).

Tabela 20 - Distribuição do número e percentagem das crianças segundo resultado total do SDQ (sem impacto) e hipótese diagnóstica de PSM feita pelo pediatra. CSE Butantã, 2000.

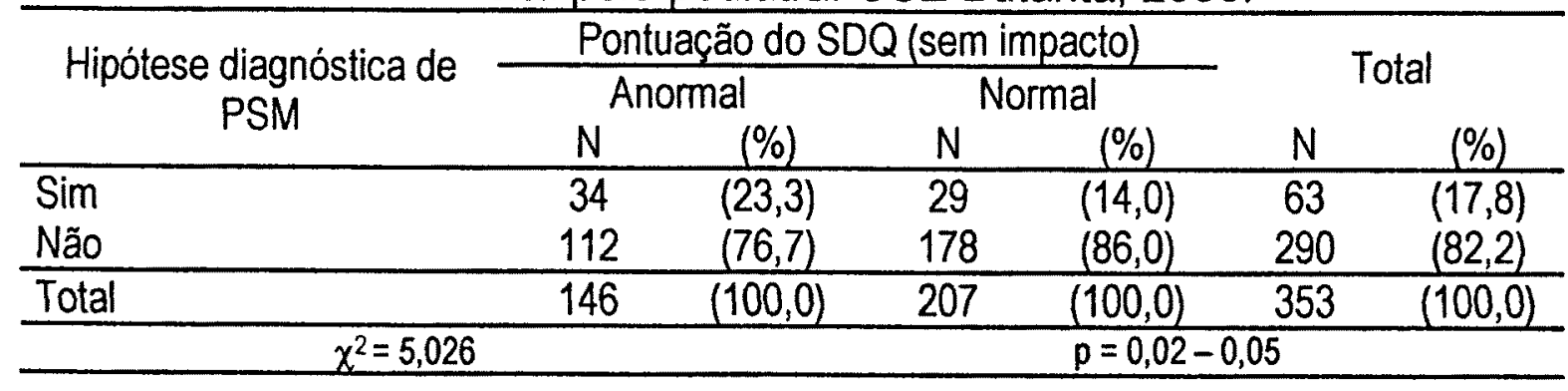

A seguir foi realizada a mesma comparação, agora levando em conta o impacto e considerando pontuação anormal apenas aqueles com pontuação total do SDQ anormal e impacto anormal (Tabela 21).

Tabela 21 - Distribuição do número e percentagem das crianças segundo resultado total do SDQ (com impacto) e hipótese diagnóstica de PSM feita pelo pediatra. CSE Butantã, 2000.

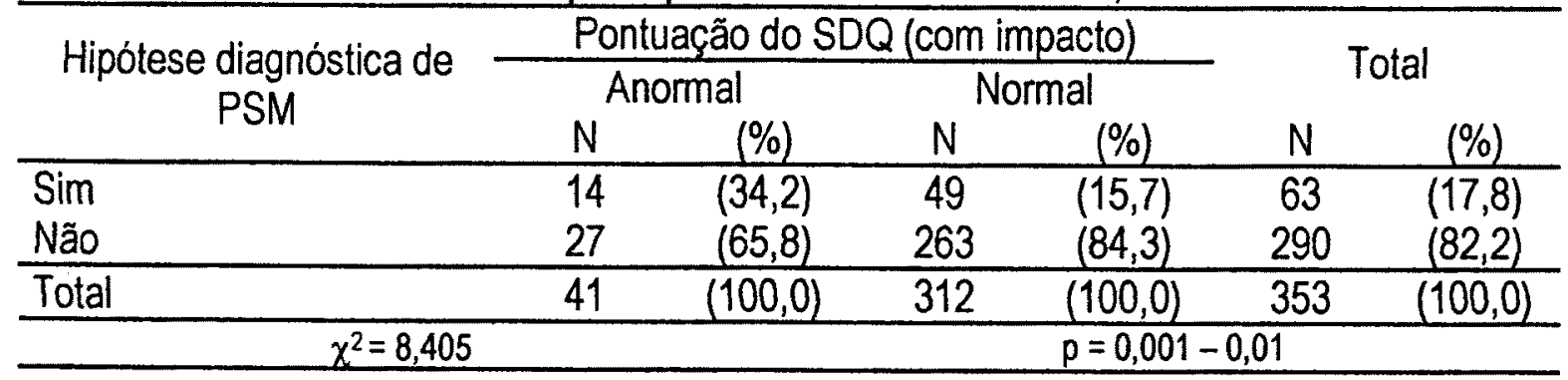

Considerando a aplicação do SDQ como teste de referência, foram calculadas a sensibilidade e especificidade das hipóteses diagnósticas de PSM feitas pelos pediatras nas duas situações (Quadro 5). 
Quadro 5 - Índices de validade das hipóteses diagnósticas dos médicos segundo critério de referência (SDQ). CSE Butantã, 2000.

\begin{tabular}{lcc}
\hline \multirow{2}{*}{ Indices de validade } & \multicolumn{2}{c}{ Critério de referência } \\
\cline { 2 - 3 } \multicolumn{1}{c}{ Sensibilidade } & SDQ sem impacto & SDQ com impacto \\
Especificidade & $23,3 \%$ & $34,1 \%$ \\
\hline
\end{tabular}

A sensibilidade das hipóteses diagnósticas dos pediatras em relação ao SDQ é baixa, mesmo com a inclusão do critério impacto, isto é, casos positivos pelo critério de referência não são diagnosticados pelos médicos.

Por outro lado, a especificidade é alta, mostrando que os pediatras são capazes de distinguir os verdadeiros negativos, não incluindo-os como casos positivos (independentemente da inclusão do critério impacto).

Para permitir melhor compreensão das relações entre as hipóteses diagnósticas de PSM feitas pelos pediatra e os resultados do SDQ, foi construído um esquema que pode ser visto na Figura III. 


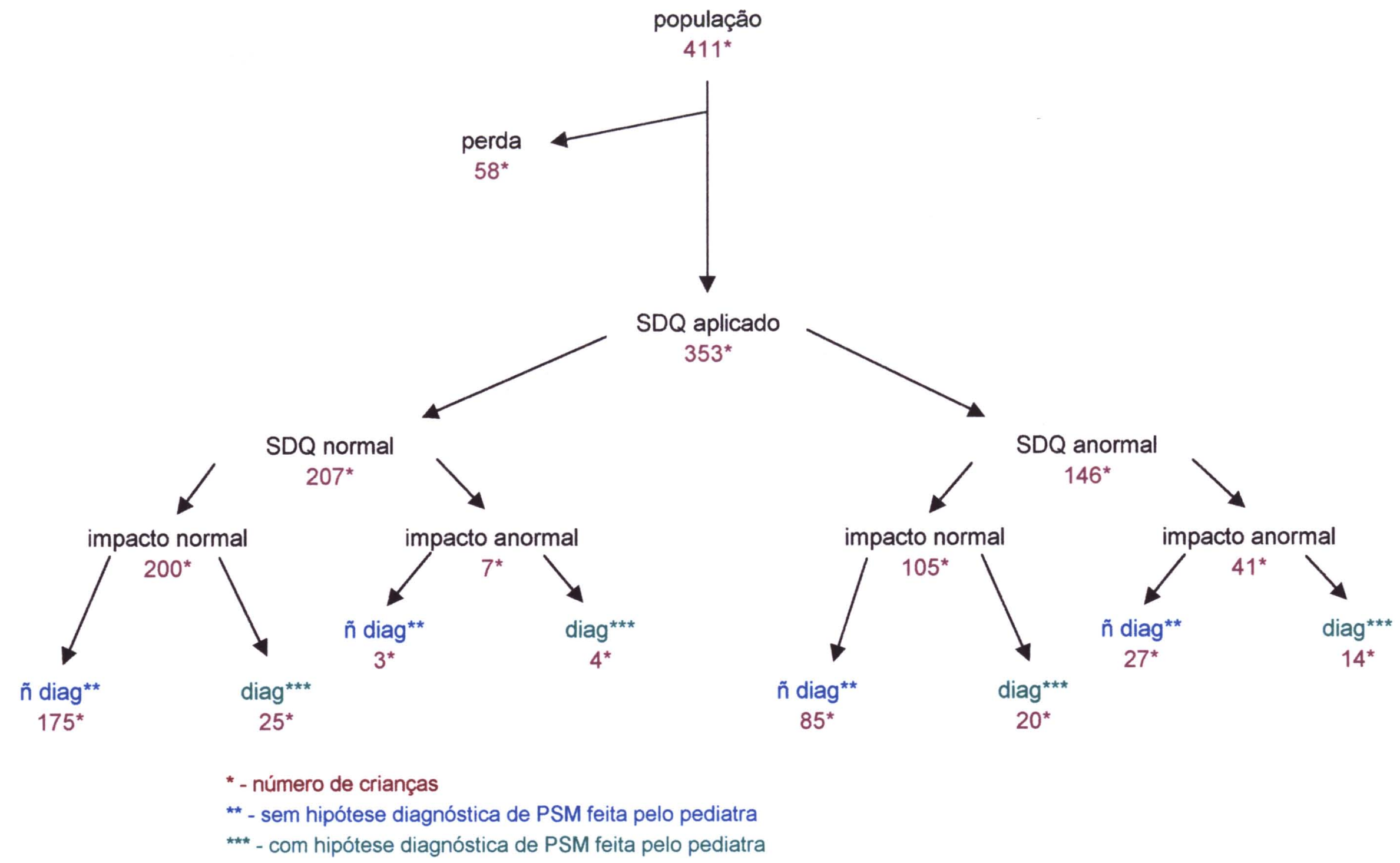

Figura III - "Árvore" da relação entre SDQ e hipóteses diagnósticas de PSM feitas pelos pediatras 
Das 41 crianças tidas como prováveis portadoras de transtornos psiquiátricos pelo SDQ, apenas 14 (34,2\%) foram identificadas pelos pediatras. Os diagnósticos destas crianças feitos pelos pediatras estão no Quadro 6. Das 27 crianças não identificadas pelos pediatras, oito $(29,6 \%)$ tinham queixas relacionadas a problemas de saúde mental anotadas no prontuário (Anexo 16).

Quadro 6 - Hipóteses diagnósticas feitas pelos pediatras em crianças com SDQ anormal e impacto anormal. CSE Butantā, 2000.

\begin{tabular}{|c|c|c|c|}
\hline & Primeiro diagnóstico & Segundo diagnóstico & Terceiro diagnóstico \\
\hline 1 & Enurese & $\begin{array}{l}\text { Distúrbio do } \\
\text { comportamento* }\end{array}$ & \\
\hline 2 & Fala infantilizada & Déficit de aprendizagem & \\
\hline 3 & Dislalia & & \\
\hline 4 & Dificuldade na escola & & \\
\hline 5 & Enurese & & \\
\hline 6 & Déficit de atenção* & & \\
\hline 7 & Escolaridade atrasada & & \\
\hline 8 & Enurese & $\begin{array}{l}\text { Dificuldade de } \\
\text { aprendizagem }\end{array}$ & Terror noturno \\
\hline 9 & Não sabe ler & & \\
\hline 10 & Não sabe ler & & \\
\hline 11 & Mau rendimento escolar & & \\
\hline 12 & Enurese & & \\
\hline 13 & $\begin{array}{l}\text { Dificuldade de } \\
\text { aprendizagem }\end{array}$ & & \\
\hline 14 & Distúrbio de atenção* & & \\
\hline
\end{tabular}

(" provável equivalência da hipotese diagnóstica do pediatra e do resultado do SDQ)

É necessário ressaltar que o SDQ não cobre as áreas de transtornos específicos do desenvolvimento (linguagem e habilidades escolares), nem enurese; deste modo em apenas três casos (destacados no Quadro 6) haveria equivalência entre as hipóteses diagnósticas dos médicos e aquelas do SDQ. É possivel que o pediatra apreenda apenas um aspecto da sintomatologia, não aprofundando a avaliação das questões emocionais envolvidas. 
É importante ressaltar que o SDQ também pode ter falsos positivos e falsos negativos, e que sua utilização como critério de referência busca criar um parâmetro de comparação para as hipóteses diagnósticas dos pediatras. A inclusão da medida de impacto provavelmente reduz a proporção de falsos positivos e permite a identificação dos casos prováveis sem muito erro.

Um grupo pequeno de crianças (quatro) apresentou hipótese diagnóstica de PSM feita pelo pediatra, SDQ normal e impacto anormal. Pela análise do prontuário foi possível verificar que se tratavam de casos com queixas importantes na consulta e hipóteses diagnósticas consistentes. Os casos estão descritos no Quadro 7.

Quadro 7- Hipóteses diagnósticas feitas pelos pediatras em quatro crianças com SDQ normal e impacto anormal. CSE Butantã, 2000.

\begin{tabular}{|c|c|c|}
\hline & Queixa & Hipótese diagnóstica \\
\hline 1 & $\begin{array}{l}\text { É muito rebelde; } \\
\text { Não sabe ler }\end{array}$ & $\begin{array}{l}\text { Distúrbio de conduta; Escolaridade } \\
\text { atrasada }\end{array}$ \\
\hline 2 & Não vai bem na escola & Dificuldade de alfabetização \\
\hline 3 & Nervosa, agitada & $\begin{array}{l}\text { Enurese; } \\
\text { Sindrome da criança dolorosa }\end{array}$ \\
\hline 4 & $\begin{array}{l}\text { Enurese; } \\
\text { Encoprese }\end{array}$ & $\begin{array}{l}\text { Enurese; } \\
\text { Encoprese }\end{array}$ \\
\hline
\end{tabular}

Foi possivel verificar que a avaliação do impacto aumenta a sensibilidade do SDQ em casos com sintomas isolados e significado clínico importante.

Por outro lado, o pediatra fez hipóteses diagnósticas de PSM em 25 crianças que tiveram SDQ normal e impacto normal. As hipóteses diagnósticas realizadas estão no Quadro 8. 
Quadro 8 - Hipóteses diagnósticas feitas pelos pediatras em crianças com SDQ normal e impacto normal. CSE Butantã, 2000.

\begin{tabular}{ll}
\hline & \multicolumn{1}{c}{ Primeira hipótese diagnóstica } \\
\hline 1 & Bruxismo \\
3 & Dificuldade da diç̧ão \\
4 & Distúrbio escolar \\
5 & Atraso de linguagem \\
6 & Dislalia \\
7 & Dislalia \\
8 & Eniançátese diagnóstica infantilizada \\
9 & Enurese \\
10 & Enurese \\
11 & Enurese \\
12 & Enurese \\
13 & Distúrbio de linguagem \\
14 & Bruxismo \\
15 & Enurese \\
16 & Dificuldade de fala \\
17 & Enurese \\
18 & Dislalia \\
19 & Dificuldade de aprendizagem \\
20 & Dificuldade de educar \\
21 & Gagueira \\
22 & Bruxismo \\
23 & Distúrbio de atenção \\
24 & Troca letras \\
25 & Enurese \\
\hline & \\
\hline
\end{tabular}

Entre os 25 casos nota-se um predomínio de hipóteses diagnósticas únicas, quase que exclusivamente na área do desenvolvimento: transtornos de linguagem em nove casos $(36,0 \%)$, enurese em oito $(32,0 \%)$, bruxismo em quatro $(16,0 \%)$ e dificuldade de aprendizagem em dois $(8,0 \%)$; corrobora-se assim o perfil do SDQ, que só seleciona casos com sintomas 
relacionados a transtornos emocionais, de conduta, de hiperatividade ou de relacionamentos.

Em dois casos foram anotadas hipóteses diagnósticas muito inespecificas ("criança infantilizada" e "dificuldade de educar"), o que parece apontar para a dificuldade do pediatra de transformar sinais e sintomas em diagnósticos. A criança que recebeu a hipótese diagnóstica de "dificuldade de educar" tinha queixa emocional (medos) e era adotada. 


\subsection{VISITA DOMICILIAR}

Após a consulta médica e a aplicação do SDQ, ainda no Centro de Saúde, o acompanhante da criança era avisado que haveria a possibilidade de uma visita domiciliar posterior para aprofundamento do estudo e que esta visita não significava que a criança tivesse algum problema. Depois da escolha dos casos para a realização das visitas domiciliares, as entrevistadoras entravam em contato com a familia solicitando autorização e marcando a data da entrevista. Nos casos selecionados para as visitas foram feitas até três tentativas de localização da residência, após as quais o caso era considerado perdido.

Como o objetivo era compor um grupo de crianças com PSM, foram selecionados os casos com SDQ anormal e/ou impacto anormal. Também foram incluídas aquelas com hipóteses diagnósticas de PSM feitos pelo pediatra, independente do resultado do SDQ. Além destas foram também entrevistados familiares de 45 crianças com SDQ normal e impacto normal e sem diagnóstico de PSM pelo pediatra para possibilitar um estudo posterior de comparação dos instrumentos padronizados utilizados.

Foram selecionadas 226 crianças e realizadas 206 visitas domiciliares $(91,2 \%)$. Em 20 casos não foi possivel contatar a familia ou houve recusa por parte desta. Foram comparados os grupos com visita domiciliar $(N=206)$ e sem visita domiciliar $(N=205)$ em relação às variáveis sexo e idade. Não foram encontradas diferenças estatisticamente significantes entre os dois grupos.

Segundo relato das entrevistadoras, a grande maioria das visitas transcorreu em clima de cordialidade, sem maiores problemas para obter as respostas para a longa seqüência de perguntas. A duração média da entrevista domiciliar completa foi de 90 minutos. Em muitos casos a entrevista transformava-se em uma boa conversa, com o entrevistado alongando-se em outras informações além das solicitadas pelo roteiro 
preestabelecido. O tempo máximo transcorrido entre a consulta pediátrica e a entrevista domiciliar foi de 15 dias.

Como referido na metodologia, a entrevista domiciliar era composta das seguintes partes:

\subsubsection{IDENTIFICAÇÃO (Anexo 5)}

Do total de 206 visitas realizadas, em $185(89,8 \%)$ as entrevistas foram respondidas pela mãe genética. Das crianças visitadas $103(50,0 \%)$ eram do sexo feminino e 92 (44,7\%) eram pré-escolares (cinco e seis anos), semelhante ao perfil do total de crianças estudadas (Tabela 22).

Tabela 22 - Distribuição do número e percentagem das crianças com visita domiciliar segundo idade e sexo. CSE Butantã, 2000.

\begin{tabular}{|c|c|c|c|c|c|c|}
\hline \multirow{3}{*}{ Idade (em anos) } & \multicolumn{4}{|c|}{ Sexo } & \multirow{2}{*}{\multicolumn{2}{|c|}{ Total }} \\
\hline & \multicolumn{2}{|c|}{ Masculino } & \multicolumn{2}{|c|}{ Feminino } & & \\
\hline & $\mathrm{N}$ & $(\%)$ & $\mathrm{N}$ & $(\%)$ & $\mathrm{N}$ & $(\%)$ \\
\hline 5-6 (pré-escolar) & 44 & $(42,7)$ & 48 & $(46,6)$ & 92 & $(44,7)$ \\
\hline 7-11 (escolar) & 59 & $(57,3)$ & 55 & $(53,4)$ & 114 & $(55,3)$ \\
\hline Total & 103 & $(100,0)$ & 103 & $(100,0)$ & 206 & $(100,0)$ \\
\hline
\end{tabular}

As principais características familiares das crianças estudadas estão descritas no Quadro 9.

Nota-se que $66,5 \%$ das crianças moravam com seus pais genéticos e $25,7 \%$ com apenas um deles. O número de irmãos era pequeno, sendo $16,5 \%$ das crianças filhos únicos e $67,5 \%$ tendo um ou dois irmãos. Configurou-se assim que ao redor de dois terços das crianças vinham de familias com proles pequenas, de dois ou três filhos, habitando o mesmo domicílio que seus pais genéticos.

Quanto à escolaridade, $7,3 \%$ das mães e $9,7 \%$ dos pais não freqüentaram escola. A grande maioria (73,8\% das mães e $61,6 \%$ dos pais) tinha até oito anos de estudo. É interessante notar que em 30 casos a mãe ou a pessoa entrevistada não sabia informar a escolaridade do pai. 
Quadro 9 - Características familiares das crianças entrevistadas. CSE Butantã, 2000.



\subsubsection{SDQ}

O SDQ foi aplicado novamente na entrevista domiciliar para permitir um estudo posterior de confiabilidade do instrumento. 


\subsubsection{CBCL}

O CBCL foi o principal instrumento aplicado na visita domiciliar. Foi planejada a aplicação em uma amostra intencional de 226 crianças. Houve perda de 20 crianças, tendo sido efetivamente realizado em 206 crianças.

Os resultados referentes ao perfil comportamental (Anexo 17) das crianças estudadas são apresentados na Tabela 23.

Tabela 23 - Distribuição do número e percentagem das crianças segundo perfil comportamental e escalas do CBCL. CSE Butantã, 2000.

\begin{tabular}{lcccccc}
\hline \multirow{2}{*}{ Perfil comportamental* } & \multicolumn{2}{c}{ Normal } & \multicolumn{2}{c}{ Limítrofe } & \multicolumn{2}{c}{ Clínico } \\
\cline { 2 - 7 } & $N$ & $(\%)$ & $N$ & $(\%)$ & $N$ & $(\%)$ \\
\hline Retraimento & 137 & $(66,5)$ & 25 & $(12,1)$ & 44 & $(21,4)$ \\
Queixas somáticas & 180 & $(87,4)$ & 13 & $(6,3)$ & 13 & $(6,3)$ \\
Ansiedade/depressão & 132 & $(64,1)$ & 25 & $(12,1)$ & 49 & $(23,8)$ \\
Problemas com o contato & 135 & $(65,5)$ & 27 & $(13,1)$ & 44 & $(21,4)$ \\
social & & & & & & \\
Problemas com o pensamento & 144 & $(69,9)$ & 35 & $(17,0)$ & 27 & $(13,1)$ \\
Problemas com a atenção & 108 & $(52,4)$ & 26 & $(12,6)$ & 72 & $(35,0)$ \\
Comportamento delinqüente & 131 & $(63,6)$ & 43 & $(20,9)$ & 32 & $(15,5)$ \\
Comportamento agressivo & 119 & $(57,8)$ & 33 & $(16,0)$ & 54 & $(26,2)$ \\
Problemas "internalizing" & 75 & $(36,4)$ & 30 & $(14,6)$ & 101 & $(49,0)$ \\
Problemas "externalizing" & 82 & $(39,8)$ & 21 & $(10,2)$ & 103 & $(50,0)$ \\
\hline Total de problemas de & 57 & $(27,7)$ & 19 & $(9,2)$ & 130 & $(63,1)$ \\
comportamento & & &
\end{tabular}

("- uma mesma criança pode apresentar mais de um tipo de problema)

Para permitir uma análise mais detalhada desta lista, e considerando as peculiaridades do $\mathrm{CBCL}$, os casos limitrofes foram incorporados aos normais. Assim, as análises se realizaram com dois grupos: o normal (englobando a classificação normal e a limítrofe do $\mathrm{CBCL}$ ) e o clínico.

Foram encontradas 130 crianças com escore clínico para total de problemas de comportamento, que correspondem a $63,1 \%$ das entrevistas domiciliares realizadas. A sub-escala com maior freqüência foi a de 
problemas de atenção $(35,0 \%)$ e a de menor freqüência foi a de queixas somáticas $(6,3 \%)$.

\subsubsection{QUESTIONÁRIO PARA PAIS SOBRE AS PREOCUPAÇÕES RELATIVAS ÀS DIFICULDADES DAS CRIANÇAS}

Na entrevista domiciliar, após a aplicação do $\mathrm{CBCL}$, era perguntado se algum dos problemas relatados preocupava especialmente os pais (Anexo 6).

Do total de 206 entrevistas foram obtidas 203 respostas com três perdas (1,5\%). Entre os 203 pais entrevistados, 102 (50,2\%) revelaram-se preocupados com as dificuldades dos filhos.

A seguir, para os 102 pais entrevistados e preocupados com os PSM dos filhos, foi perguntado se, durante a consulta pediátrica objeto deste estudo, a mãe ou o acompanhante da criança tinha falado sobre este problema com o médico.

Entre as 102 crianças com pais preocupados apenas 54 acompanhantes $(52,9 \%)$ revelaram ao médico, durante a consulta, suas queixas e/ou preocupações com o comportamento de seus filhos; quatro $(3,9 \%)$ entrevistados não souberam referir se o acompanhante tinha comentado com o pediatra o PSM da criança.

Os motivos pelos quais 44 acompanhantes $(43,1 \%)$ não falaram com o pediatra estão detalhados na Tabela 24: 
Tabela 24 - Distribuição do número e percentagem das crianças com preocupação dos pais com PSM segundo motivo de não comentar o problema com o pediatra. CSE Butantã, 2000.

\begin{tabular}{lcc}
\hline \multicolumn{1}{c}{ Porque não falou com o médico } & $N$ & $(\%)$ \\
\hline Médico não perguntou & 7 & $(15.9)$ \\
Esqueceu & 6 & $(13,6)$ \\
Criança com outros problemas clínicos & 6 & $(13,6)$ \\
Achou que não era necessário & 5 & $(11,4)$ \\
Já faz tratamento especializado & 5 & $(11,4)$ \\
Achou que não era coisa para médico & 4 & $(9,1)$ \\
Foi outra pessoa que levou à consulta & 3 & $(6,8)$ \\
Tem vergonha & 2 & $(4,5)$ \\
Não queria falar na frente da criança & 1 & $(2,3)$ \\
Outros & 5 & $(11,4)$ \\
\hline Total & 44 & $(100,0)$ \\
\hline
\end{tabular}

Quase metade dos acompanhantes à consulta médica não achou importante discutir com o médico suas preocupações a respeito dos PSM das crianças.

Dos motivos alegados mais freqüentes, chama atenção, em primeiro lugar, a falta de busca ativa do pediatra por estas questões: "médico não perguntou" e "esqueceu" são duas faces da mesma resposta, pois se o médico tivesse perguntado provavelmente 0 acompanhante não teria esquecido o problema.

Quando a criança tem outras queixas clínicas a probabilidade da queixa de PSM aparecer na consulta diminui, pois o médico e, provavelmente, também a familia, centram suas atençōes sobre estas outras questões, deixando para um segundo plano ou para outro momento o PSM. Esta foi uma das razões por que, nesta pesquisa, foram analisadas apenas consultas agendadas e não as "eventual/reavaliação".

Um terceiro grupo de respostas remete a um outro aspecto da questão. "Achou que não era necessário" e "achou que não era coisa de médico" podem significar que os pais não acreditam que o médico possa 
ajudá-los neste tipo de problema ou que acham que podem lidar sozinhos com as dificuldades da criança.

DULCAN e col. (1990), estudando os fatores parentais que influenciam o reconhecimento pelos pediatras dos problemas de saúde mental das crianças, encontraram que o nivel de estresse dos pais, a historia familiar de doença psiquiátrica e a discussão das preocupações dos pais com o pediatra são importantes para aumentar a capacidade de detecção destes problemas pelo médico. Os pais são informantes cruciais sobre problemas emocionais e de comportamento dos filhos, visto que, neste mesmo estudo, os pediatras não diagnosticaram $83,0 \%$ das crianças com problemas no total; porém, nos casos em que os pais relataram suas preocupações, a freqüência do não diagnóstico caiu para $67,0 \%$ e nos casos sem queixas dos pais a freqüência do não diagnóstico subiu para $87,0 \%$.

Num interessante trabalho de revisão de literatura sobre o papel dos pais na detecção de problemas de desenvolvimento e de comportamento, GLASCOE e DWORKIN (1995) estudaram os pais como fonte de informação e identificaram dois tipos principais de apreciações: avaliações incluindo preocupações, estimativas e predições, e descrições como lembranças e relatos. Em relação especificamente às preocupações, uma série de trabalhos referidos neste artigo mostra forte relação entre preocupação dos pais com problemas emocionais e de comportamento e a presença real de transtornos psiquiátricos.

É importante que, durante as consultas pediátricas, seja criado um ambiente propicio para o levantamento das queixas de problemas emocionais e de comportamento. SHARP e col. (1992) estudaram, através de fitas de vídeo, 34 consultas de avaliação de rotina de crianças de cinco a 12 anos. Em $88,0 \%$ das consultas foram criadas oportunidades tanto pelo pediatra como pela família para a abordagem de problemas psicossociais. Entretanto, somente em $40,0 \%$ dos casos os médicos responderam com informações, orientações ou encaminhamentos. 


\subsection{CBCL X DIAGNÓSTICO DE PSM FEITO PELO PEDIATRA}

Confrontando-se os casos com hipótese diagnóstica de PSM feita pelo pediatra e os resultados do $\mathrm{CBCL}$ realizado nas 206 crianças, foi obtida a seguinte distribuição (Tabela 25):

Tabela 25 - Distribuição do número e percentagem das crianças segundo escores das escalas do CBCL e hipótese diagnóstica de PSM feita pelo pediatra. CSE Butantã, 2000.

\begin{tabular}{lccccccc}
\hline \multirow{2}{*}{$\begin{array}{c}\text { Diagnóstico PSM pelo } \\
\text { pediatra }\end{array}$} & \multicolumn{3}{c}{ Clínico } & \multicolumn{3}{c}{ Normal $^{*}$} & \multicolumn{2}{c}{ Total } \\
\cline { 2 - 7 } & $N$ & $(\%)$ & $N$ & $(\%)$ & $N$ & $(\%)$ \\
\hline $\operatorname{Sim}$ & 33 & $(25,4)$ & 19 & $(25,0)$ & 52 & $(25,2)$ \\
Não & 97 & $(74,6)$ & 57 & $(75,0)$ & 154 & $(74,8)$ \\
\hline Total & 130 & $(100,0)$ & 76 & $(100,0)$ & 206 & $(100,0)$ \\
\hline & & & \multicolumn{5}{c}{$p=0,9-0,95$} \\
\hline
\end{tabular}

${ }^{*}$ - inclui casos normais e casos limitrofes)

Considerando a aplicação do $\mathrm{CBCL}$ como teste de referência, foram calculadas a sensibilidade e especificidade das hipóteses diagnósticas de PSM feitas pelos pediatras (Quadro 10).

Quadro 10 - Índices de validade das hipóteses diagnósticas de PSM segundo critério de referência (CBCL). CSE Butantã, 2000.

\begin{tabular}{lc}
\hline \multicolumn{1}{c}{ Índices de validade } & Critério de referência \\
\hline Sensibilidade & (CBCL) \\
Especificidade & $25,4 \%$ \\
\hline
\end{tabular}

A sensibilidade das hipóteses diagnósticas dos pediatras em relação ao CBCL é baixa, semelhante à encontrada quando foi utilizado como critério de referência o SDQ (Quadro 5).

Para aprofundar a análise dessa relação, as 206 crianças estudadas foram distribuídas em quatro grupos: 
A. CBCL clínico e com hipótese diagnóstica de PSM pelo pediatra, composto por 33 crianças $(16,0 \%)$.

B. CBCL normal e com hipótese diagnóstica de PSM pelo pediatra, composto por 19 crianças $(9,2 \%)$.

C. CBCL clínico e sem hipótese diagnóstica de PSM pelo pediatra, composto por 97 crianças $(47,1 \%)$.

D. CBCL normal e sem hipótese diagnóstica de PSM pelo pediatra, composto por 57 crianças $(27,7 \%)$.

Ao analisar os grupos com escore clínico do $\mathrm{CBCL}$ e/ou com hipótese diagnóstica de PSM feita pelo pediatra (grupos $A, B$ e $C$ ), foi possivel identificar as seguintes questões:

- O grupo $\mathrm{A}$ corresponde aos casos em que há concordância entre a hipótese diagnóstica do pediatra e a do instrumento. Analisando-se as sub-escalas do $\mathrm{CBCL}$, pode-se observar que a maior percentagem de diagnósticos do pediatras nos casos clínicos do $\mathrm{CBCL}$ concentram-se nas áreas de delinqüência $(48,3 \%)$ e queixas somáticas $(38,5 \%)$ e a menor na área de isolamento $(21,4 \%)$.

- O grupo B corresponde a hipóteses diagnósticas de PSM que o pediatra faz, em crianças, que não foram identificadas pelo instrumento do $C B C L$. $A$ análise mais aprofundada mostrou que se tratavam de crianças com queixas isoladas como enurese ou bruxismo ou queixas na área do desenvolvimento da linguagem.

- O grupo C, compreendendo 97 crianças, aponta que, dentre as 206 crianças estudadas nesta etapa da pesquisa, $47,1 \%$ têm sintomas e prováveis diagnósticos na área de saúde mental que não foram detectados pelos pediatras durante a consulta clínica. 
Relacionando-se os perfis comportamentais clínico e normal do CBCL com a presença de preocupação dos pais $(N=203$ pois houve três perdas na informação sobre preocupação dos pais), encontrou-se associação positiva entre perfil clínico e presença de preocupação dos pais (Tabela 26).

Tabela 26 - Distribuição do número e percentagem das crianças segundo escores das escalas do CBCL e preocupação dos pais com os PSM. CSE Butantã, 2000.

\begin{tabular}{|c|c|c|c|c|c|c|}
\hline \multirow{3}{*}{ Preocupação dos pais } & \multicolumn{4}{|c|}{ Escore CBCL } & & \\
\hline & \multicolumn{2}{|c|}{ Clinico } & \multicolumn{2}{|c|}{ Normal $^{*}$} & \multicolumn{2}{|c|}{ Total } \\
\hline & $N$ & $(\%)$ & $\mathrm{N}$ & $(\%)$ & $n$ & $\%$ \\
\hline $\operatorname{Sim}$ & 84 & $(65,1)$ & 18 & $(24,3)$ & 102 & $(50,2)$ \\
\hline Não & 45 & $(34,9)$ & 56 & $(75,7)$ & 101 & $(49,8)$ \\
\hline Total & 129 & $(100,0)$ & 74 & $(100,0)$ & 203 & $(100,0)$ \\
\hline$x^{2}=31,30$ & & & & $p<0, c$ & & \\
\hline
\end{tabular}

Quando existe preocupação dos pais o escore do $\mathrm{CBCL}$ é clínico em $82,4 \%$ das crianças; quando não existe preocupação o escore do CBCL é clínico em $44,6 \%$ das crianças.

Relacionando-se as três variáveis acima (resultado do $\mathrm{CBCL}$, presença de preocupação dos pais com os PSM e hipótese diagnóstica de PSM pelo pediatra), foi obtida uma "árvore" que busca ilustrar esta questão (Figura IV). 


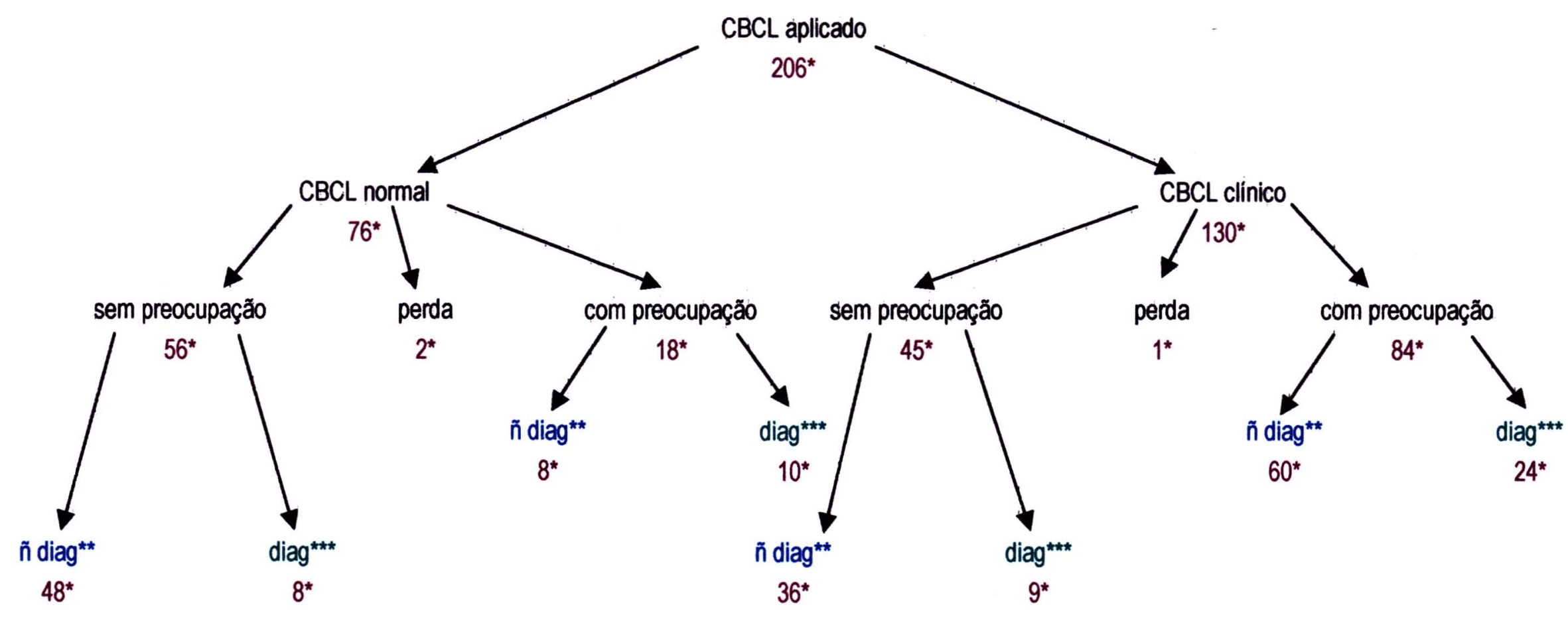

* - número de crianças

** - sem hipótese diagnóstica de PSM feita pelo pediatra

*** - com hipótese diagnóstica de PSM feita pelo pediatra 
Analisando mais detalhadamente as crianças com escore do $\mathrm{CBCL}$ clínico para total de problemas de comportamento $(N=129)$, foi relacionada a presença de preocupação dos pais com hipótese diagnóstica de PSM feita pelo pediatra (Tabela 27). Verificou-se que, mesmo nas crianças com provável diagnóstico de transtorno mental pelo $\mathrm{CBCL}$, a presença de preocupação dos pais não melhora a detecção dos PSM pelos pediatras.

Tabela 27 - Distribuição do número e percentagem das crianças com escore do CBCL clínico segundo hipótese diagnóstica de PSM feita pelo pediatra e preocupação dos pais. CSE Butantã, 2000.

\begin{tabular}{lccccccc}
\hline \multirow{2}{*}{ Preocupação dos pais } & \multicolumn{3}{c}{ Diagnóstico PSM pelo pediatra } & \multicolumn{2}{c}{ Total } \\
\cline { 2 - 8 } & \multicolumn{3}{c}{ Sim } & \multicolumn{3}{c}{ Não } & \\
\cline { 2 - 8 } & $\mathrm{N}$ & $(\%)$ & $\mathrm{N}$ & $(\%)$ & $\mathrm{N}$ & $(\%)$ \\
\hline \multirow{2}{*}{$\operatorname{sim}$} & 24 & $(72,7)$ & 60 & $(62,5)$ & 84 & $(65,1)$ \\
Não & 9 & $(27,3)$ & 36 & $(37,5)$ & 45 & $(34,9)$ \\
\hline Total & 33 & $(100,0)$ & 96 & $(100,0)$ & 129 & $(100,0)$ \\
\hline & & & \multicolumn{5}{c}{$p=0,2-0,3$} \\
\hline
\end{tabular}

Os casos com escore clínico do $\mathrm{CBCL}$ para total de problemas de comportamento foram classificados segundo as hipóteses diagnósticas de PSM feitos pelos pediatras e a preocupação dos pais com os PSM para cada sub-escala do $\mathrm{CBCL}$, com o intuito de verificar se haveria algum agrupamento específico de sintomas que propiciaria melhor deteç̧ão por parte dos pediatras (Gráfico 2). 


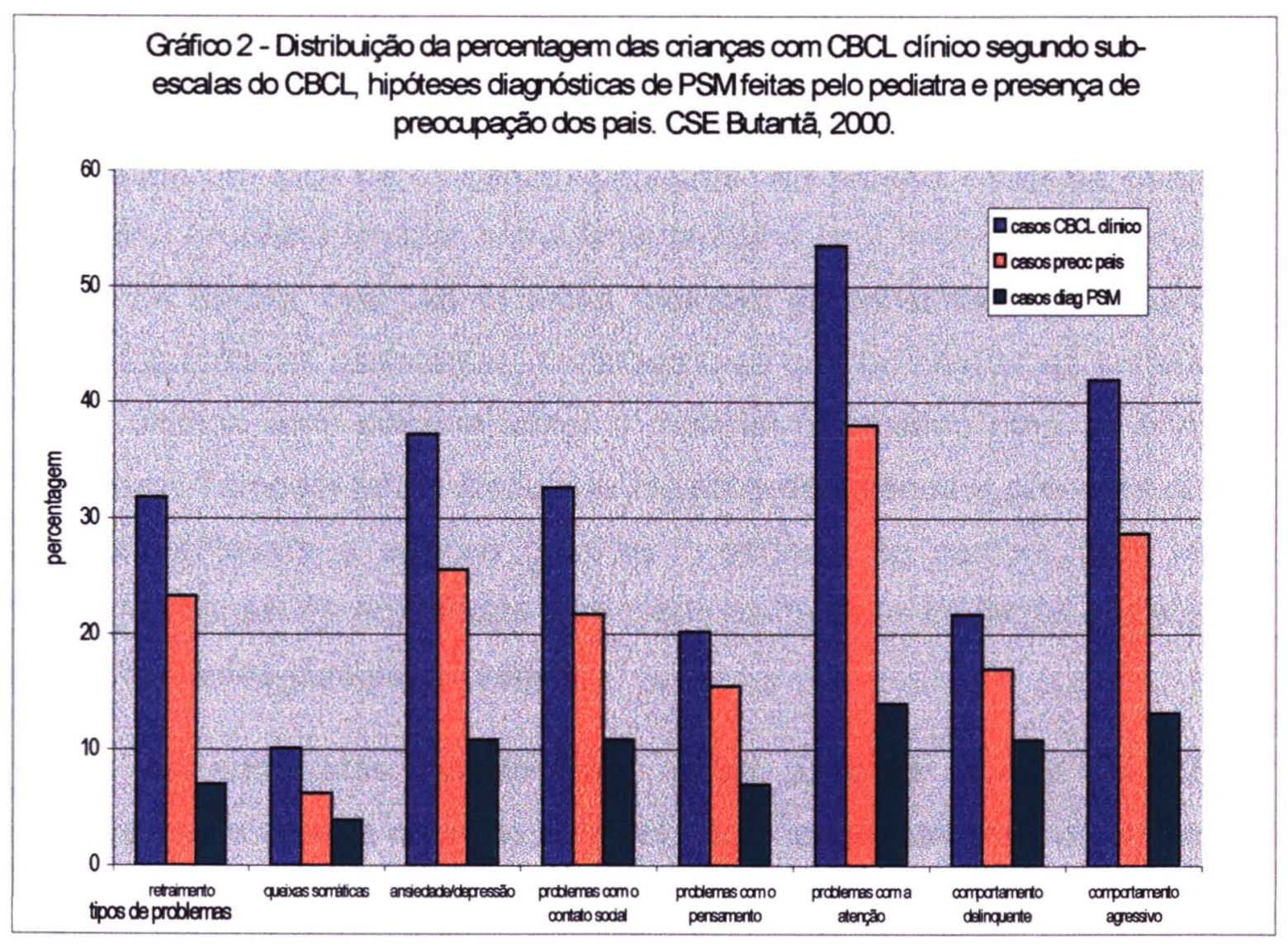

No Gráfico 2 pode-se observar que, em todas as sub-escalas, a percentagem dos casos com escore clínico do $\mathrm{CBCL}$ aproxima-se da percentagem dos casos com preocupação dos pais com os sintomas, com a tendência constante de haver sempre casos clínicos que não suscitam preocupação. Nota-se que a sub-escala onde há uma maior concordância entre a hipótese diagnóstica de PSM feita pelos pediatras, a detecção pelo CBCL e a preocupação dos pais é a da delinqüência. 


\subsection{ENTREVISTAS COM OS MÉDICOS PEDIATRAS}

Foram entrevistados todos os médicos assistentes que fazem a supervisão do atendimento que os alunos e residentes prestam às crianças, perfazendo um total de 11 (onze) pediatras. No projeto inicial da pesquisa havia sido proposto realizar entrevistas também com médicos residentes do Centro de Saúde, mas, como estes realizam as consultas sob supervisão direta dos médicos assistentes, considerou-se que ao centrar as entrevistas nestes últimos seria possível obter o material necessário para as análises desejadas. Também foram excluídos médicos estagiários e pós-graduandos que freqüentavam o serviço durante o período do campo. Não houve nenhuma recusa. As entrevistas com todos os médicos pediatras assistentes foram realizadas pela pesquisadora.

As entrevistas aconteceram entre julho e agosto de 2000, imediatamente antes e no início da coleta dos dados quantitativos referentes ao objeto em estudo. Como descrito na metodologia, foi utilizado um roteiro para a entrevista. Cada entrevista durou aproximadamente trinta minutos e, antes do início da entrevista, foi solicitada autorização para a gravação das mesmas em fita cassete. Nenhum entrevistado colocou impedimento à gravação.

As entrevistas iniciavam-se com a fala da pesquisadora, fornecendo uma explicação sobre a pesquisa e seus objetivos. A seguir, os aspectos éticos já mencionados eram cumpridos. A partir daí era solicitado ao médico que relatasse as suas atividades cotidianas no Centro de Saúde e de que forma as questões relacionadas à saúde mental permeavam estas atividades. Seguia-se então uma conversa, com a pesquisadora fazendo os ajustes necessários para que os objetivos da coleta de dados fossem cumpridos. O roteiro foi utilizado como fio condutor das hipóteses iniciais da pesquisa. À medida que as entrevistas se realizavam, novas perspectivas e questionamentos foram acrescentados e outros foram retirados, tendo em vista o esgotamento do seu papel iluminador devido à repetição do material 
coletado. A meta foi obter um material rico, denso, verdadeiramente interacional, que permitisse a realização do processo interpretativo (DENZIN 1989).

As entrevistas foram realizadas no próprio Centro de Saúde, durante o período de trabalho dos entrevistados, o que permitiu a observação do ambiente de trabalho e as interações entre alunos, residentes e os médicos assistentes. Estas observações feitas no campo da pesquisa permitiram a apreensão de muitos detalhes que também foram utilizados na análise das entrevistas.

Outro aspecto fundamental foi o contexto das entrevistas. Estas ocorreram dentro de um clima de muita cordialidade, aparentando desejo de colaboração por parte dos pediatras. $O$ fato da pesquisadora ser conhecida de alguns dos entrevistados teceu uma rede de confiança e cumplicidade que acabou transformando a entrevista numa "boa conversa", mais em alguns casos que em outros. Este contexto contribuiu para que as evidências coletadas fossem de alta confiabilidade, pois permitiu que a interação e o diálogo realmente acontecessem, evitando a artificialidade que pode ocorrer neste tipo de coleta de dados, quando o entrevistado responde aquilo que ele intui que o entrevistador quer como resposta.

Como já referido, foram entrevistados 11 médicos pediatras, sendo três do sexo masculino e oito do feminino, com idades variando de 36 a 58 anos. Todos trabalhavam há vários anos no serviço estudado.

As fitas foram transcritas para a linguagem escrita procurando-se preservar as pausas, interjeições, repetições e outros componentes da linguagem oral que pudessem contribuir para traduzir aspectos subjacentes às falas explícitas. Foram obtidas 77 páginas de material (espaçamento simples e letra corpo 12).

A seguir foi realizado um processo de "edição" do texto visando eliminar situações que pudessem identificar claramente os sujeitos das falas 
e as expressões mais típicas da linguagem coloquial, como "entendeu", "sabe", "né" e outras do gênero.

O momento seguinte constou da leitura exaustiva e repetida dos textos, buscando uma imersão no material e identificando o que surge de relevante, o que emerge do material coletado (BARDIN 1977). Buscou-se ao mesmo tempo apreender as representações que o grupo de pediatras tinha das questões abordadas sem deixar de examinar cada entrevista como um todo em si (SCHRAIBER 1995).

A partir de eixos temáticos (dois previamente selecionados e que direcionaram as entrevistas - reconhecimento dos PSM e ação dos pediatras frente aos PSM - e um que emergiu da análise preliminar concepção de PSM), os textos foram desmontados e recortados, sendo construído um mapa de verbalizações e explicações para cada entrevista (ANDRADE 2002). Estes mapas têm duplo objetivo (SPINK e LIMA 2000): dar subsídios ao processo de interpretação e facilitar a comunicação dos passos subjacentes ao processo interpretativo. Estes mapas se encontram no Anexo 18. Este processo de construção possibilitou identificar as interrelações nas verbalizações e explicações das diversas entrevistas, levando à construção de três novos mapas, desta vez por eixo temático.

Num momento posterior, a partir dos mapas por eixo temático, foram construídas "árvores" de produção de sentido para cada eixo temático, na tentativa de dar visibilidade ao conjunto global das verbalizações e explicações encontradas, as quais, por sua vez, apontaram novas categorias, num processo sempre inacabado de produção de sentidos.

Sempre buscando dar visibilidade às evidências coletadas no campo da pesquisa e ao processo de análise realizado, foram construídas matrizes para apresentação dos dados (YIN 1994; SPINK e LIMA 2000; TANAKA e MELO 2002). A seguir serão apresentadas as árvores de produção de sentido de cada um dos três eixos temáticos apreendidos, seguidas das análises realizadas. 


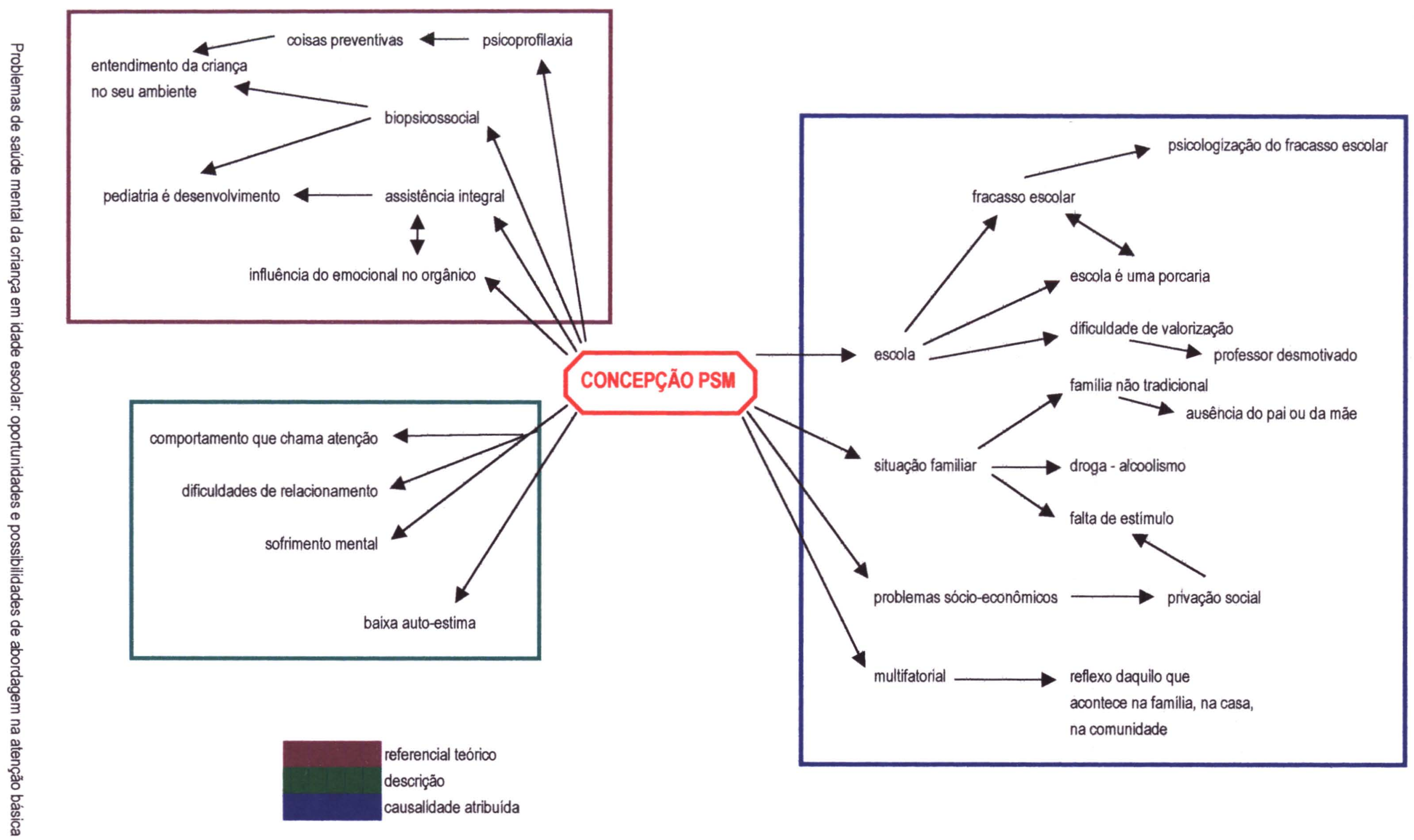

Figura V - "Árvore" das verbalizaçōes e explicaçōes do eixo temático CONCEPÇÃO DE PROBLEMA DE SAÚDE MENTAL 


\subsubsection{CONCEPÇÃO DE PROBLEMAS DE SAÚDE MENTAL}

A apreensão da concepção de problemas na área da saúde mental foi feita a partir do conjunto do material coletado, não tendo sido feita uma pergunta especifica para este fim.

Foi possivel distinguir três enfoques na abordagem do eixo temático concepção dos PSM.

O primeiro deles estava impregnado do referencial teórico próprio da Escola de Pediatria iniciada pelo professor Pedro de Alcântara na FMUSP (Matriz 1). MARCONDES (1973) escreveu:

"...do ponto de vista doutrinário, a Pediatria deve propiciar assistência integral à criança, sempre que for possível e na medida em que for possivel, abrangendo:

1. os problemas orgânicos e psiquicos

2. de modo preventivo e curativo

3. em sua totalidade e em suas mútuas dependências

4. de modo evolutivo, de acordo com as peculiaridades de cada fase de crescimento

5. à luz

a) da constituição da criança

b) das condições econômicas, sociais culturais, espirituais e de saúde da família e

c) das condições do ambiente físico" (p. 5).

Expressões como assistência integral, biopsicossocial, psicoprofilaxia, coisas preventivas remetem à construção cultural e acumulação teórica histórica da Pediatria. São evocadas logo no início das falas, principalmente daqueles ligados diretamente à Universidade e ao 
ensino de graduação. Pode-se dizer que são reflexos do tempo vivido' (SPINK e GIMENES 1994; SPINK e MEDRADO 2000), impregnando as falas dos entrevistados.

Matriz 1 - Ideário da Pediatria relacionado à Saúde Mental identificado pelos pediatras. CSE Butantã, 2000.

\begin{tabular}{|l|l|}
\hline Enfoque & Verbalização \\
\hline Integralidade & $\begin{array}{l}\text { O pediatra, eu acho que ele tem que ver a criança como um todo,... não só do } \\
\text { ponto de vista físico e tal... } \\
\ldots \text { uma herança do Pedro de Alcântara,... de certa forma ele que é o } \\
\text { responsável... por ter formado toda uma geração de pessoas que tivesse } \\
\text { preocupação com a questão da interferência do emocional no orgânico... } \\
\ldots \text { essa escola aqui sempre tentou fazer assistência integrada, biopsicossocial... } \\
\text {... sempre pregamos a atenção global, a atenção biológica, psicológica e social. }\end{array}$ \\
\hline Psicoprofilaxia & $\begin{array}{l}\text {... essa palavra psicoprofilaxia continua forte, então entender a criança no seu } \\
\text { ambiente é uma coisa que aqui é considerada... } \\
\text {...então é um espirito comum aqui, então vamos dizer assim, as coisas } \\
\text { preventivas... }\end{array}$ \\
\hline $\begin{array}{l}\text { Aspecto } \\
\text { evolutivo }\end{array}$ & $\begin{array}{l}\text {... em dúvida a pediatria é desenvolvimento... crescimento e desenvolvimento } \\
\text { sendo provavelmente o futuro da pediatria, }\end{array}$ \\
\hline
\end{tabular}

O segundo enfoque aparece ligado à descrição dos PSM. São definidos como comportamento que chama atenção, dificuldades de relacionamento, sofrimento mental. A descrição não se refere diretamente aos tipos de PSM, que serão vistos mais adiante, mas sim a uma forma de conceituar este tipo de dificuldade (Matriz 2). Tal enfoque se aproxima muito da atual forma de classificação dos Transtornos Mentais e Comportamentais, tanto na CID-10 como no DSM-IV. O foco dessas classificaçōes está mais centrado nas características descritivas dos transtornos do que nas supostas etiologias ou patogêneses (GOODMAN e SCOTT 1997).

\footnotetext{
${ }^{1}$ Segundo SPINK (2000) a dimensão tempo é fundamental para a abordagem do "paradoxo de enunciados que pertencem concomitantemente à ordem das regularidades possibilitando visualizar as permanências que sustentam o compartilhamento - e à polissemia dos repertórios, que sustenta a singularidade dos processos de produção de sentidos. O tempo longo marca os conteúdos culturais, definidos ao longo da história da civilização; o tempo vivido, das linguagens aprendidas pelos processos de socialização, e o tempo curto, marcados pelos processos."
} 
Matriz 2 - Concepção de PSM relacionada à descrição de comportamentos identificados pelos pediatras. CSE Butantã, 2000.

\begin{tabular}{|l|l|}
\hline Enfoque & Verbalização \\
\hline $\begin{array}{l}\text { Desvio do } \\
\text { padrão }\end{array}$ & $\begin{array}{l}\text { O que me vem à cabeça quando se fala em saúde mental (...) a gente encontra, de } \\
\text { desvios de comportamento, nas alterações que existem dentro do comportamento } \\
\text { da criança, (...), que causam uma certa apreensão. } \\
\text {... a criança apresenta um comportamento que chama a atenção (...) } \\
\text { comportamentos que fogem do esperado para sua faixa, ou da expressão do seu } \\
\text { sentimento às vezes estão exacerbados ou pouco demonstrados, de tal forma que } \\
\text { mostra que tem ali alguma questão que precisa ser revista. } \\
\text {... não sei se é isso que você está procurando ou se é mais o que a gente coloca } \\
\text { como problemas de comportamento, como dificuldades de relacionamento, ai mais } \\
\text { um sofrimento mental, se quiser chamar assim... }\end{array}$ \\
\hline
\end{tabular}

O terceiro enfoque, abordado de forma importante por quase todos os entrevistados, é a concepção de causalidade dos PSM. Há uma direcionalidade em implicar, de maneira mais intensa, o meio ambiente nas origens dos PSM das crianças, praticamente isentando-as, seja biológica ou psicologicamente, como co-participantes da gênese destas dificuldades.

Dois aspectos do predomínio do meio sobre a biologia puderam ser notados:

O primeiro se refere à forma como a conduta ou comportamento da criança é interpretado e valorizado perante o meio: o contexto familiar, escolar e cultural, moldando e definindo as fronteiras entre o normal e o patológico, e por vezes tendendo a banalizar e desvalorizar sinais e sintomas que indicam o sofrimento psíquico da criança (Matriz 3 ).

Matriz 3 - Concepção de PSM relacionada aos limites da patologia identificados pelos pediatras. CSE Butantã, 2000.

\begin{tabular}{|l|l|}
\hline Enfoque & Verbalização \\
\hline $\begin{array}{l}\text { Interpretação } \\
\text { do sintoma }\end{array}$ & $\begin{array}{l}\text { e a questão da importância do,... na verdade, do... de certa forma do ambiente de } \\
\text { vida, na verdade é tudo, quer dizer, desde,... tanto fisico quanto no ambiente afetivo } \\
\text { interferindo naquela avaliação que deveria fazer na criança no dia a dia. } \\
\text { Há necessidade muitas vezes de você interpretar ou procurar esclarecer o que é } \\
\text { normal ou esperado, dentro do desenvolvimento da criança. } \\
\text {... mas muitas vezes porque foi já algum problema que já veio anterior que a gente } \\
\text { não conseguiu perceber o que era, de auto-estima da própria criança... }\end{array}$ \\
\hline
\end{tabular}


O segundo, e talvez mais significativo, é que a causa dos PSM se remete diretamente ao meio ambiente, seja sob a forma de situação familiar irregular, meio escolar inadequado ou condições socio-econômicas desfavoráveis (Matriz 4).

Matriz 4 - Concepção de causalidade dos PSM identificada pelos pediatras. CSE Butantã, 2000.

\begin{tabular}{|c|c|}
\hline Enfoque & Verbalização \\
\hline Família & $\begin{array}{l}\text {... é uma coisa que a gente vé muito, quando a gente sente algum problema na área de } \\
\text { comportamento da criança, pode procurar na familia, a gente procura mesmo, e a coisa é } \\
\text { mais ampla, é um pouco por ai... } \\
\text {... saúde mental é... então é a familia,... é ambiente geralmente muito desestruturado } \\
\text { também, a criança acaba refletindo de alguma forma... } \\
\text { É um problema multifatorial, principalmente quando a gente lida com criança, a criança em } \\
\text { geral ela é um reflexo daquilo que acontece na sua familia, na sua casa, na comunidade... }\end{array}$ \\
\hline Escola & $\begin{array}{l}\text {... e que não necessariamente é uma dificuldade porque ela é incapaz de aprender (...) mas } \\
\text { é porque,... ai já entram também questões sociais, escola que é uma porcaria, professor } \\
\text { coitado que está desmotivado, não consegue... } \\
\text { O problema não é ela, o problema é que o pai é alcoólatra, a mãe é analfabeta, apanha em } \\
\text { casa, ou não tem vida nenhuma social... E ai na escola loggico que não vai estar rendendo. } \\
\text { A professora pegava a criança indo mal na escola, mau rendimento escolar, e a primeira } \\
\text { coisa que fazia era encaminhar para psicóloga. Então ela ficava rotulada desde cedo, } \\
\text { quando que a origem dos distúrbios de aprendizagem, mau rendimento escolar é totalmente } \\
\text { outra, na maior parte dos casos. }\end{array}$ \\
\hline Social & $\begin{array}{l}\text { Acho que são todos decorrentes... seguramente essa população acaba vivendo em } \\
\text { condiçōes piores em média, não dá para generalizar para todos, é claro,... do que aquelas } \\
\text { que não vivem em favela. Então está muito associado à privaçãa social, então a privação } \\
\text { económica, a privação do lazer. } \\
\text {... uma área que eu acho que é muito fruto do ambiente em que a criança vive, sem dúvida } \\
\text { alguma, eu sempre defendi essa... acredito mesmo no fato da criança ser fruto do ambiente } \\
\text { que ela vive, e consequentemente muito dos desvios, dos comportamentos, enfim, das } \\
\text { alterações que ela tem ocorrem em função dessa variação do ambiente. } \\
\text {... um plano geral da criança, quer dizer, vendo a criança não só como nosso paciente aqui, } \\
\text { mas como vivendo fora, vivendo... dentro da... da... da casa, dentro da família, e aí, sem } \\
\text { dúvida alguma, entram todas as... os problemas, que a gente pode estar relacionando em } \\
\text { termos de saúde mental. }\end{array}$ \\
\hline
\end{tabular}

Neste sentido MARCELLI (1998) comenta que:

"...não é fácil a avaliação da repercussão das condutas externas no seio da estrutura psicológica da criança. A noção de patologia reacional não deve levar a pensar que um sintoma possa responder total e permanentemente a um simples condicionamento, a uma reação linear do tipo estímulo-resposta (....). É a esse 
procedimento que correspondem os conceitos de distúrbio reativo, mas também as noções de vulnerabilidade e competência. Assim, querer definir uma criança normal e uma criança patológica em função do meio equivale, em parte, a definir um ambiente normal ou patológico, isto é, uma sociedade normal ou patológica..." (p. 53).

A Organização Pan-Americana da Saúde e a Organização Mundial de Saúde, no Relatório sobre a Saúde no Mundo - 2001 (OPAS/OMS 2001): Saúde Mental: Nova Concepção, Nova esperança, coloca da seguinte forma a questão da causalidade dos Transtornos Mentais:

"Por muitos anos os cientistas discutiram a importância relativa dos fatores genéticos versus fatores ambientais no desenvolvimento de transtornos mentais e de comportamento. A evidência científica moderna indica que os transtornos mentais e de comportamento resultam de fatores genéticos e ambientais, ou, noutras palavras, da interação da biologia com fatores sociais. O cérebro não reflete simplesmente 0 desenrolar determinista de complexos programas genéticos, nem é o comportamento humano mero resultado do determinismo ambiental. Já desde antes do nascimento e por toda a vida, os genes e o meio ambiente estão envolvidos numa série de complexas interações. Essas interações são cruciais para o desenvolvimento e a evolução dos transtornos mentais e comportamentais" (p. 35).

Esta concepção de causalidade, baseada na interação complexa de fatores biológicos, psicológicos e sociais, tem importância prática, pois evita responsabilizar exclusivamente pais e meio ambiente por sintomas apresentados pela criança, cujo exemplo histórico mais forte foi implicar diretamente as mães na gênese do autismo infantil (DUARTE 2000). Por outro lado, a importância dos cuidados providos pelo meio, dos quais a criança obviamente necessita, não deve ser minimizada, pois é fundamental tanto para otimização do desenvolvimento em criança sem grandes obstáculos biológicos, como para compensar possíveis desvantagens 
(doenças de outra ordem, internações, vulnerabilidade física e outras). A noção do vínculo com a figura cuidadora (a mãe, na grande maioria das vezes, mas que pode ser outra pessoa - noção de função materna), como um locus privilegiado da interação, deve ser valorizada e cuidada pelos profissionais da atenção primária como forma de promoção da saúde (RUTTER 1999). 


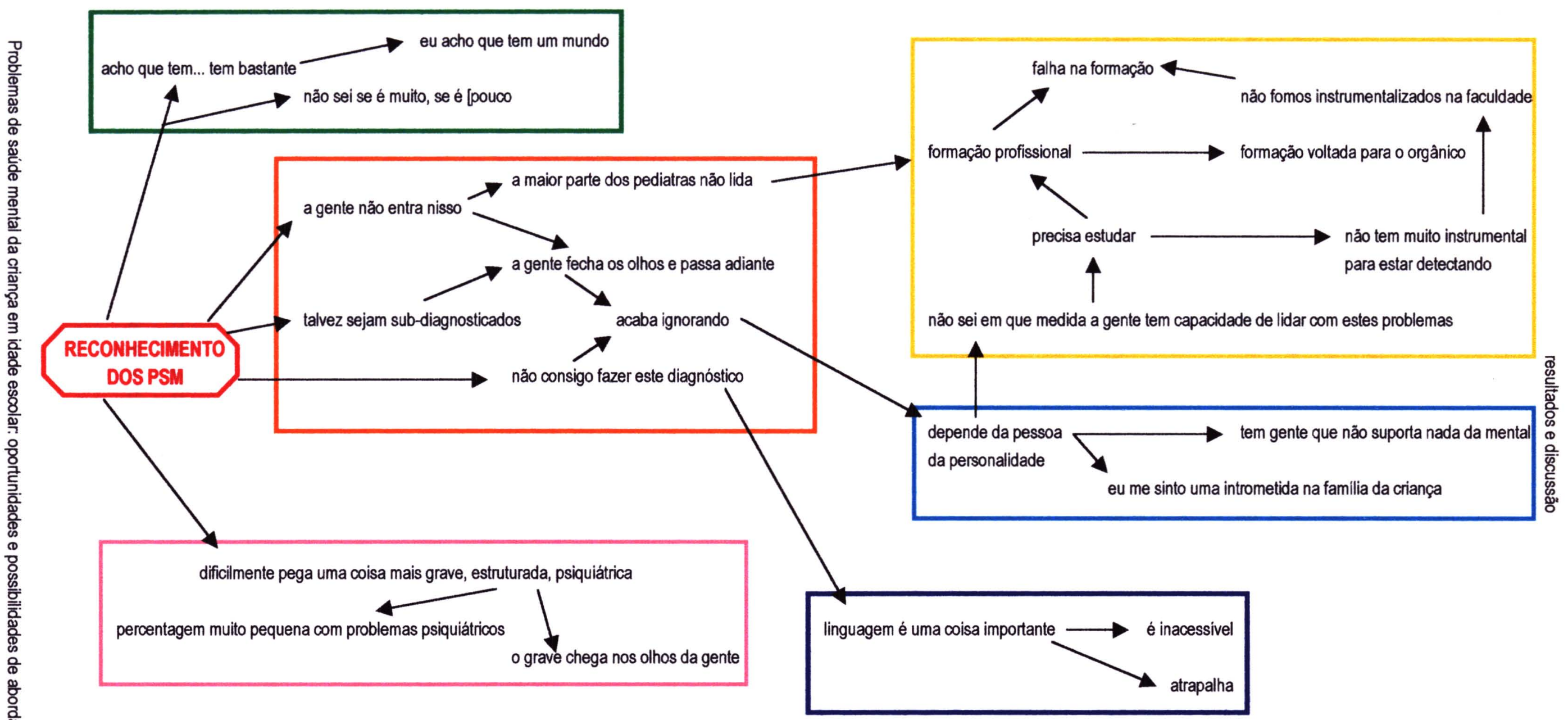

dimensão dos problemas

dificuldades

formação

avaliação da gravidade



Figura VI - "Ávore" das verbalizaçōes e explicações do eixo temático RECONHECIMENTO DOS PROBLEMAS DE SAÚDE MENTAL NA INFÂNCIA 


\subsubsection{RECONHECIMENTO DOS PROBLEMAS DE SAÚDE MENTAL}

Diferentemente da concepção dos PSM, foi possivel detectar grande variabilidade das falas na análise do eixo temático do reconhecimento dos PSM. Chama atenção a amplitude das opiniões. Sob este eixo temático foi possivel identificar várias subcategorias de análise:

\section{Magnitude e gravidade dos problemas de saúde mental na prática pediátrica}

Os médicos tiveram dificuldade em definir a magnitude dos problemas de saúde mental encontrados no cotidiano do trabalho. As opiniões variaram desde uma grande quantidade de problemas com limites não muito distintos atẻ a idéia de freqüência bem baixa (Matriz 5).

Matriz 5 - Magnitude dos PSM no cotidiano da Pediatria identificada pelos pediatras. CSE Butantã, 2000.

\begin{tabular}{|l|l|}
\hline Dimensão & Verbalização \\
\hline Muito & $\begin{array}{l}\text { Eu acho que tem um mundo, só que a gente não entra nisso... } \\
\ldots \text { mas que é um mundo, é, entendeu? é só questão de levantar, a gente } \\
\text { simplesmente fecha os olhos e passa adiante... } \\
\text { Eu acho que tem bastante,... eu acho que,... mas é, é como eu te falei, é dificil } \\
\text { dizer porque eu posso achar isso subjetivamente... } \\
\text {... eu sou partidária - toda vez que você procura, você acha (...) acho que } \\
\text { tem... tem bastante... }\end{array}$ \\
\hline Pouco & $\begin{array}{l}\text { Nessa população que a gente atende... tem uma porcentagem muito pequena } \\
\text { com problemas psiquiátricos ou psicológicos. Psiquiátricos eu diria assim } \\
\text { baixíssimo, certo? Psicológicos... alguns, e muito poucos necessários para } \\
\text { encaminhamento... }\end{array}$ \\
\hline Indefinido & $\begin{array}{l}\ldots \text { eu acho que é difícil dizer se é muito, se é pouco, porque a gente nunca fezz } \\
\text { nenhuma quantificação... } \\
\ldots \text { talvez sejam sub-diagnosticados ou quando são diagnosticados a gente } \\
\text { acaba não sabendo muito o que fazer. É que às vezes a gente até não sabe } \\
\text { nem dizer o nome da patologia direito... } \\
\text { Eu acho que muitas vezes passa desapercebido alguns aspectos. }\end{array}$ \\
\hline
\end{tabular}

$\mathrm{Na}$ maioria das entrevistas aparece uma demanda nebulosa, não bem definida, sendo impossível identificar sua magnitude. 
Uma das explicações para esta grande amplitude na percepção da dimensão dos problemas de saúde mental parece ser a variabilidade da definição e os limites não muito claros destes problemas. A prevalência geral dos transtornos mentais na infância tem sido alvo de inúmeras pesquisas nas últimas décadas, desde o trabalho pioneiro de RUTTER e col. (1970). Embora os resultados desses estudos variem consideravelmente, admite-se que entre 10 e $20 \%$ das crianças tenham um ou mais problemas de saúde mental (OPAS/OMS 2001; GOODMAN e SCOTT 1997; OFFORD e FLEMING 1996; BIRD 1996; BRANDENBURG e col. 1990; COSTELLO 1989b). Algumas características especificas da infância dificultam traçar os limites entre os fenômenos que fazem parte do desenvolvimento normal e aqueles que seriam anormais. Muitos dos sintomas dos problemas de saúde mental, como por exemplo medos ou ansiedade, podem fazer parte do desenvolvimento, sendo considerados normais em determinadas faixas etárias ou dentro de certos limites de intensidade (RUTTER 1988).

Mais recentemente tem sido utilizada a noção de impacto junto aos critérios de presença de sintomas para a realização de diagnósticos na área de saúde mental. Isto significa que não basta a criança apresentar um determinado sintoma para se fazer o diagnóstico; é necessário que este sintoma seja persistente e intenso o suficiente para "atrapalhar" a vida da criança ou da sua família. Este novo enfoque também agrega as representações sociais dos diversos problemas de saúde mental, pois trabalha com a subjetividade da criança e da familia, e pode adequar as classificações nosológicas internacionais aos diversos contextos culturais. 
Matriz 6 - Categorização das queixas durante $\circ$ atendimento pediátrico identificada pelos pediatras. CSE Butantã, 2000.

\begin{tabular}{|l|l|}
\hline Dimensão & Verbalização \\
\hline $\begin{array}{l}\text { Direcionalidade } \\
\text { da consulta }\end{array}$ & $\begin{array}{l}\text { Então os problemas variam muito, depende da faixa etária e depende daquilo } \\
\text { que você está buscando. } \\
\text {... quer dizer, se coloca até a questão da culpa e da responsabilidade do } \\
\text { médico, no sentido de que ele não pode falhar em estar detectando problemas } \\
\text { orgânicos, seja a nivel de prevenção ou seja a nível de diagnóstico precoce } \\
\text { de certa forma você acaba diminuindo essa responsabilidade no sentido da } \\
\text { questão do desenvolvimento, e da manutenção da saúde do indivíduo como } \\
\text { um todo, inclusive nos aspectos de saúde mental... }\end{array}$ \\
\hline $\begin{array}{l}\text { Valorização da } \\
\text { queixa }\end{array}$ & $\begin{array}{l}\text {... a gente não tem pernas, porque são tantos problemas de saúde que acaba } \\
\text { não chegando lá,... e então... a equipe... acaba talvez não priorizando isso... } \\
\text { porque a gente sabe que tem gente que olha para estas questões já torce o } \\
\text { nariz e não vai muito fundo... } \\
\text { Mas o que a gente vê geralmente é assim aquilo é um pouco menosprezado, } \\
\text { na própria discussão dos casos, nas reuniões clínicas, é colocado geralmente } \\
\text { em segundo mesmo, não é a coisa que faz todo mundo ferver na coisa do } \\
\text { diagnóstico. } \\
\text {... tem muitos problemas de maus tratos, de negligência, que ficam muitas } \\
\text { vezes, até a gente às vezes não se dá conta que ela pode ser que fosse um } \\
\text { problema de negligência, que fosse um problema até de maus tratos, que } \\
\text { passam como se fosse assim algum problema normal... }\end{array}$ \\
\hline
\end{tabular}

Existe uma percepção, mais uniforme, de que problemas muito graves são menos freqüentes e não aparecem no cotidiano do atendimento (Matriz 7).

Matriz 7 - Gravidade dos PSM identificada pelos pediatras. CSE Butantã, 2000.

\begin{tabular}{|l|l|}
\hline Dimensão & Verbalização \\
\hline Gravidade & $\ldots$ acho que dificilmente pega uma coisa mais grave, estruturada, psiquiátrica, \\
& é mais assim... um comportamento em casa, a criança de difícil controle, sem \\
limite, a criança agressiva, ou em casa ou na escola... \\
$\ldots$ mas a gente conta no dedo criança que eu peço psiquiatra infantil, sabe... \\
Eu acabo acionando o psicólogo, mas número de vezes muito pequeno... \\
\\
$\begin{array}{l}\text { O grave é... eu não precisei mais do que dois minutos para ver aquela menina } \\
\text { se comportando em crise na escola e dizer essa criança provavelmente vai } \\
\text { precisar de uma atenção especializada, certo? Quer dizer, o grave, ele chega } \\
\text { nos olhos da gente. Deve existir, eu acho... uma faixa que a gente segura com } \\
\text { a gente, que talvez beneficiasse mais do que um atendimento especializado. } \\
\text { E existe uma faixa que o pediatra toca muito bem... }\end{array}$ \\
\hline
\end{tabular}


De fato, os problemas graves de saúde mental na infância são pouco freqüentes; estima-se a prevalência dos transtornos globais do desenvolvimento em 2 por 1.000 crianças, sendo a de autismo infantil de 0,5 por 1.000 (GOODMAN e SCOTT 1997).

No entanto, uma possibilidade a ser considerada é que crianças com problemas mais graves não procurem o Centro de Saúde para atendimento rotineiro pois seus responsáveis sabem que não terão respostas para seus problemas, considerando que a oferta de serviços que o Centro de Saúde presta molda a demanda a ele referida (LEBRÃO 1997; TANAKA e MELO 2001).

\section{Tipos de problemas encontrados}

Para identificar o conhecimento dos pediatras sobre os PSM foi solicitado que especificassem quais os problemas mais comuns no dia a dia dos serviços de pediatria. Os médicos tiveram alguma dificuldade para nomear os tipos de problemas mais encontrados. Em uma das entrevistas a pergunta chegou a ser feita três vezes sem que fosse obtida uma resposta clara. Na maioria das vezes o problema é nomeado com as palavras da mãe, como a queixa trazida na consulta. Esta queixa não é trabalhada pelo conhecimento do médico e não se transforma em uma hipótese diagnóstica clínica. Nos problemas identificados predomina a idéia de problemas reativos ao ambiente, seja ele familiar ou escolar.

No Quadro 11 encontra-se a compilação dos PSM citados nas entrevistas e as explicações relacionadas. 
Quadro 11 - Descrição e explicação dos tipos de PSM citados pelos pediatras nas entrevistas. CSE Butantã, 2000.

\section{DESCRIÇÃO}

- comportamentos muito diferentes do que a gente espera para a idade

- atraso do desenvolvimento

- falta de estimulação

- crianças desadaptadas socialmente

- questão dos bicos, mamadeira, cólica crianças grandes que estão usando bicos

- questão do vínculo - falta de uma relação afetiva mais forte, problemas de vinculo com a mãe, com a famillia

- não consegue aleitar

- não ter alguém que seja exatamente responsável pelos cuidados da criança

- criança com dificuldade de relacionamento familiar

- crianças extremamente difíceis de você trabalhar, dificil de controle, questão da autoridade; questão do controle

- cólica

- anorexia; distúrbio de apetite, "meu filho não come"

- perda urinária; enurese

- obstipação

- asma

- dor recorrente

- distúrbio de sono

- distúrbio de linguagem dificuldade de articular palavras

- dificuldade escolar; distúrbios de aprendizagem, criança que precisa ou não ser matriculada em classe especial

\section{EXPLICAÇÃO}

comportamentos que chamam a atenção a relação dela com 0 ambiente sofre agressão em casa

ficam excessivamente introvertidas ou excessivamente agressivas "cinco chupetas penduradas"

isolamento afetivo

crianças em creches

tipo de cuidador

depressão pós-parto

questão da maternagem

crianças sem limites

aquilo é fisiológico, ela se desespera, o bebê se desespera

também importante, dependendo da idade

importante mas não é tanto

que se agrava, não é o único fator...

você não vai encontrar nada de orgânico

não tem diálogo

o problema não é ela (a criança)

demanda das escolas

dificuldade de valorização da escola 
(Continuação da página anterior)

Quadro 11 - Descrição e explicação dos tipos de PSM citados pelos pediatras nas entrevistas. CSE Butantã, 2000.

\section{DESCRIÇÃO}

- questão sexual

- maus tratos; negligência

- crianças agredidas

- agressividade; "o provocador"

violência da criança

distúrbios de conduta

conduta anti-social na escola

- agitada

- hiperatividade

- deprimida

- criança infeliz; criança que chora, chora, chora..

criança que acorda à noite chorando

- criança quieta, retraida demais

um pouco de ansiedade, pequenas ansiedades

- criança fóbica; às vezes um pouco de fobia

- distúrbio de sociabilidade grave

- distúrbios de comportamento sérios (drogas, gangues)

- problemas associados à privação social, privação econômica

- problemas relacionados à miséria

\section{EXPLICAÇĀO}

Meninos afeminados(...); questão da sexualização das meninas

tenho a impressão que é muito pouco

na escola não vai bem; não presta atenção

por circunstância familiar

contexto de violência

ambiente muito limitado

dificil aceitar este diagnóstico

constituição das famillias, a população das familias dessa área

parece normal na criança nessa idade mas que, por causa das circunstâncias em que eles estão, acabam se refletindo em situações de risco muito maiores...

essa população acaba vivendo em condiçōes piores em média

famílias desagregadas, crianças que sofrem 
A ênfase maior foi dada aos transtornos de aprendizagem. Essa ênfase não foi apenas numérica (geralmente um dos primeiros problemas citados), mas também qualitativa, servindo de exemplo da inadequação do ambiente escolar e desimplicando a criança da sua gênese. É importante ressaltar que, apesar do estudo ter focado a faixa etária escolar, a pergunta relacionada aos tipos de PSM foi dirigida à infância como um todo. A demanda escolar é vista como artificial e criada pela escola. No entanto, é importante ressaltar que a inserção da criança na escola amplia seu círculo social e pode explicitar problemas que antes vinham sendo desvalorizados pela familia. A escola traz novas tarefas para as crianças, como relacionamento grupal com seus pares, organização no tempo e no espaço e o aprendizado da leitura e escrita, que só serão bem sucedidas caso a criança tenha adquirido as aptidões necessárias anteriormente e tenha condições psíquicas adequadas para superar os desafios desta nova fase do desenvolvimento.

Problemas de vínculo da criança com a mãe ou cuidadores também foram valorizados, levando a reflexões sobre isolamento afetivo das crianças devido a ausências da mãe ou situações de cuidados inadequados, coerente com a concepção de PSM deste grupo de médicos.

Sintomas com conotação mais biológica também foram lembrados: dor recorrente, perda urinária, casos em que os aspectos emocionais surgem quando esgotam-se as possibilidades de intervenção mais conhecidas pelos pediatras. Provavelmente são, de fato, queixas mais comuns, pois os responsáveis pela criança sentem-se mais à vontade de comentar estas questões com o médico e fazem parte de um universo mais familiar ao campo da pediatria.

Questões relacionadas com atividades de prevenção, mais presentes no cotidiano da pediatria, também foram citadas: difícil controle, problema de limites, questão dos bicos, mamadeiras. 
Transtornos específicos da área psiquiátrica, como ansiedade e depressão, foram citados poucas vezes, o que aponta para a dificuldade em fazer este tipo de diagnóstico. Ficou patente a dificuldade de nomear as hipóteses diagnósticas da área de saúde mental. A hiperatividade chegou a ser contestada como quadro patológico.

O conhecimento que os pediatras revelaram sobre saúde mental é heterogêneo e, em alguns casos, pouco aprofundado, mostrando certa dificuldade em identificar os distintos campos de conhecimento relacionados com o problema (Matriz 8).

Matriz 8 - Dificuldades para detectar PSM identificadas pelos pediatras. CSE Butantã, 2000.

\begin{tabular}{|c|c|}
\hline $\begin{array}{l}\text { Tipos de } \\
\text { dificuldades }\end{array}$ & Verbalização \\
\hline $\begin{array}{l}\text { Desconhecimento } \\
\text { (cognitivo) }\end{array}$ & $\begin{array}{l}\text {... também (...) não deu nem para aprofundar, mas nem que eu conseguisse } \\
\text { ter o tempo todo que eu preciso, falta talvez algum instrumento melhor, uma } \\
\text { formação melhor para eu definir os casos, isso a gente não consegue, eu não } \\
\text { consigo... } \\
\text {... eu acho que talvez aqueles que... a gente coloca como sadio, talvez às } \\
\text { vezes a gente não conseguiu detalhar direito ou não chegou num... num... } \\
\text { num... a... a discutir alguns pontos... } \\
\text {... eu não sei em que medida a gente tem essa capacidade de lidar com esses } \\
\text { problemas, eu acho que a gente tem que estudar, discutir, tem que trabalhar } \\
\text { para lidar com isso, não é só meter as caras... } \\
\text {... não conhece exatamente uma coisa não dá para dizer nada, nem que é } \\
\text { mais fácil nem que é mais dificil, talvez fosse tão... não digo tão fácil, mas tão } \\
\text { natural quanto você analisar o crescimento, se você. tivesse, (...) o peso } \\
\text { adequado, está certo, acho que tem que, acho que uma coisa nem pode ser } \\
\text { maior ou menor, mas acho que ela tem que ter o peso adequado (...). Então } \\
\text { não sei dizer... sei dizer que existe uma deficiência, o quanto è deficiente } \\
\text { realmente não sei dizer... }\end{array}$ \\
\hline $\begin{array}{l}\text { Impotência } \\
\text { (afetivo) }\end{array}$ & $\begin{array}{l}\text {... acho que é mais ou menos por aí, dar o mesmo peso também para esses } \\
\text { aspectos, geralmente o problema é que às vezes não é dado o mesmo peso } \\
\text { porque também a gente não sabe diagnosticar mesmo, não sabe identificar o } \\
\text { que está ocorrendo... } \\
\text { Se for doença mental mesmo, ai realmente a gente... eu pelo menos, acho } \\
\text { que não consigo fazer algum diagnóstico. } \\
\text {... a gente simplesmente fecha os olhos e passa adiante... } \\
\text {... creio que a maior parte dos pediatras não lida, a maior parte eu acho... } \\
\text { ignorando... }\end{array}$ \\
\hline
\end{tabular}


De fato os pediatras, apesar de teoricamente considerarem as questões de saúde mental como parte integrante e importante do atendimento pediátrico, não conseguem, na prática, avaliar estas questões com a mesma destreza que as questões orgânicas. Mesmo queixas explicitas "desaparecem" no decorrer da consulta, não se convertendo em hipóteses diagnósticas e condutas, como foi visto na primeira parte deste estudo. Em várias das falas foram explicitadas as dificuldades de reconhecer e lidar com os PSM no cotidiano.

Os próprios pediatras, no decorrer das entrevistas, tentaram explicar estas dificuldades.

O primeiro aspecto a ser analisado nas verbalizaçōes dos pediatras é o referente às diferentes linguagens utilizadas nos dois campos de conhecimento envolvidos no problema (pediatria e psiquiatria) (Matriz 9). Esta disparidade aparece como um fator complicador da atuação, comprometendo a troca de informações entre os profissionais e o fluxo habitual das atividades durante o atendimento.

Matriz 9 - Diferenças entre as linguagens especificas da pediatria e da psiquiatria identificadas pelos pediatras. CSE Butantã, 2000.

\begin{tabular}{|l|l|}
\hline $\begin{array}{l}\text { Grau da } \\
\text { diferença }\end{array}$ & Verbalização \\
\hline Muito difícil & $\begin{array}{l}\text {... do jeito que eles falam, os psico... as psi... as psicanálises que eles falam para, } \\
\text { para, para o médico... para médico com formação em pediatria,... para pediatra, é } \\
\text { aversivo... } \\
\text {... porque os residentes chegavam aqui e cuspiam os textos... eles odiavam... que } \\
\text { esse cara isso... a criança expressa o desejo na terra, que loucura é esta, } \\
\text { entendeu? }\end{array}$ \\
\hline $\begin{array}{l}\text { Difícil mas } \\
\text { está } \\
\text { melhorando }\end{array}$ & $\begin{array}{l}\text {...mudou muito, hein, vem melhorando muito... e acho que tem uma coisa de } \\
\text { aproximação, isso, isso é uma coisa... é uma coisa que está começando agora... }\end{array}$ \\
\hline $\begin{array}{l}\text { Difícil mas gente... o A meu é o A deles, então já dá para gente... } \\
\text { superável }\end{array}$ & $\begin{array}{l}\text { (linguagem?) Eu acho um problema, mas eu pergunto: o que é isso, o que quer } \\
\text { dizer... eu me esclareço de alguma forma, então, imago... tem uns termos assim, } \\
\text { (...) não lembro agora, mas tem uns termos que eu não consigo, á eu falo, não, me } \\
\text { explica... aí eu entendo e ai tudo bem e vai, mas eu acho que é só questão de se } \\
\text { entender, não é uma coisa intransponivel, assim, não é uma coisa que... não é } \\
\text { impossivel... }\end{array}$ \\
\hline
\end{tabular}


Para alguns, a situação é entendida como algo que pode ser paulatinamente superado, na medida em que haja uma melhor compreensão dos códigos utilizados. Para outros, no entanto, são linguagens incompativeis, sendo a linguagem da área "psi" de difícil entendimento, que tem que ser decodificada para tornar-se inteligivel para os pediatras.

Um aspecto interessante é que, quando a pergunta sobre a linguagem foi feita diretamente (isto é, não surgiu espontaneamente na entrevista), foi respondida como uma dificuldade que poderia ser facilmente superada com boa vontade de ambas as partes. No entanto, quando emergiu naturalmente no meio da fala, a linguagem da área da saúde mental era algo muito complexo e difícil de ser compreendido e superado: "i-na-cessi-vel".

Outro aspecto importante são as falhas na formação profissional, que foram apontadas por quase todos os entrevistados (Matriz 10). Essas falhas foram identificadas tanto na formação básica na Faculdade de Medicina, quanto na especialização realizada na residência médica.

Aqui vale ressaltar a distinção feita entre informação e formação com uma conotação mais ampla, incluindo aspectos afetivos da incorporação de conhecimento. 
Matriz 10 - Falhas na formação profissional identificadas pelos pediatras. CSE Butantã, 2000.

\begin{tabular}{|c|c|}
\hline $\begin{array}{l}\text { Tipos de } \\
\text { falha }\end{array}$ & Verbalização \\
\hline $\begin{array}{l}\text { Formação } \\
\text { profissional }\end{array}$ & $\begin{array}{l}\text {... toda a formação do médico é voltada realmente para atender o orgânico. } \\
\text {... eu acho que falta formação nossa, lidar com isso,... e muitas vezes aparecem problemas } \\
\text { não sei,... não vou nem chamar assim de doença mental, nem sauude mental, mas são } \\
\text { problemas, digamos nessa área emocional... } \\
\text {... a informação você pode estar obtendo em qualquer lugar, a formação... tem muito a ver } \\
\text { no trabalho no cotidiano que vocé faz, então é... o quanto que uma queixa, aparentemente } \\
\text { objetiva, tem um contexto subjetivo... } \\
\text { O quanto existe de rigidez no médico, a di... da dificuldade de estar percebendo isso... isso } \\
\text { ai não é informação, eu acho que isso é formação... isso permeado pela saúde mental... } \\
\text { pelo universo da sauude mental... } \\
\text {... deveria ter bagagem tanto, principalmente a nivel de formação, porque se você não tem } \\
\text { uma formação adequada, como é que você vai ensinar, não é so ensinar, se você não tem } \\
\text { o instrumental adequado como é que você vai estar estruturando uma ação de saúde (...) } \\
\text { você vai falhar ou pecar por omissão... }\end{array}$ \\
\hline $\begin{array}{l}\text { ação } \\
\text { cífica na } \\
\text { lade }\end{array}$ & $\begin{array}{l}\text { Nos cursos de medicina, dificilmente se faz qualquer tipo de abordagem, quer dizer a } \\
\text { abordagem que é dada dentro do curso ela é muito... é... restrita à patologia já especifica, e } \\
\text { não e esse dia a dia que a gente tem... } \\
\text {... existe eu acho que falha na formação, e ai naturalmente não estou me referindo à nossa } \\
\text { escola que eu acho que ela acaba sendo assim um top de linha, tem várias também, mas } \\
\text { em comparação com outras escolas que existem por aí... } \\
\text {... a nossa escola ensinou é... uma, uma... cultura muito medica, muito medicalizada, a... é } \\
\text { muito simples catar uma receita e escrever... de que forma que o individuo lida com as } \\
\text { perguntas que a mãe traz, ou que a... a... ou com a... ou com aquilo que ela não pergunta, o } \\
\text { quanto ele faz aparecer a queixa, o quanto ele vai na busca ativa. } \\
\text {... vejo até pela carga horária, se você pegar programa de quarto ou de quinto ano,... que } \\
\text { onde a gente trabalha atenção básica. Ela é inteiramente voltada para a doença. }\end{array}$ \\
\hline $\begin{array}{l}\text { Formação na } \\
\text { residência } \\
\text { médica }\end{array}$ & $\begin{array}{l}\text {... na própria residência eu acho que falta um pouco de... de instrumental médico mesmo,... } \\
\text { de observar, o que eu tenho que observar, que nem a gente ensina assim o diagnóstico de } \\
\text { sarampo, você observa... assim, assim, assim,... para determinado problema mais na área } \\
\text { da higiene mental, que aspectos são importantes valorizar... } \\
\text { No segundo semestre o pessoal já vem de enfermaria,... UTI, ... berçário, e tal, do próprio } \\
\text { pronto socorro, então ele já vem com uma conotação assistencial de intervenção, de tentar } \\
\text { resolver o problema doença... não que piora,... muda,... muda o enfoque sabe, você tem } \\
\text { que puxar às vezes o cara para realidade, às vezes,... exemplificando,... vamos supor, } \\
\text { vamos pegar uma patologia que possa ter um efeito psicossomático de influência, na asma, } \\
\text { por exemplo, o asmático no primeiro semestre, acho que você pode até colocar todos os } \\
\text { fatores etiologicos da asma, até comportam um aspecto psicossomático, da dinâmica } \\
\text { familiar... às vezes pode desencadear até uma asma... no segundo semestre às vezes } \\
\text { esquece desse detalhe, eles imaginam muito mais o asmático como broncoespasmo com o } \\
\text { seu corticóide, com o seu ou betabloqueador, enfim, toda a interferência medicamentosa e } \\
\text { muitas vezes esquece, porque ele vem de uma área eminentemente assistencial a nivel de } \\
\text { unidade de internacão, de pronto socorro. }\end{array}$ \\
\hline
\end{tabular}


Um terceiro aspecto levantado foi que o interesse e a aptidão para reconhecer e lidar com as questões de saúde mental são inerentes à personalidade do médico. Também puderam ser identificadas dificuldades pessoais em trabalhar com questões que não são "objetivas" (Matriz 11).

Matriz 11 - Características de personalidade do médico identificadas pelos pediatras. CSE Butantã, 2000.

\begin{tabular}{|c|c|}
\hline Enfoque & Verbalização \\
\hline \multirow[t]{4}{*}{$\begin{array}{l}\text { Componente } \\
\text { da } \\
\text { personalidade }\end{array}$} & $\begin{array}{l}\text {... já percebe nitidamente que tem também um componente pessoal, quer dizer, } \\
\text { aquele que já está mais aberto, que levou a sementinha, ela vai crescer, e tem } \\
\text { aquele que já vem de base meio fechado e o terreno não é fértil, você joga a } \\
\text { sementinha não vai fertilizar de forma alguma. }\end{array}$ \\
\hline & $\begin{array}{l}\text {...tem gente que não suporta, isso,... é verdade, ... já vi, tem colegas... que não } \\
\text { suportam nada, só querem tudo preto no branco,... não querem saber, só querem } \\
\text { saber de coisa física mesmo, só curativa... }\end{array}$ \\
\hline & $\begin{array}{l}\text { Depende da formação, depende da pessoa... esse campo psiquico depende } \\
\text { muito da pessoa (...) mas tem um componente, tem uma variabilidade individual } \\
\text { muito grande... }\end{array}$ \\
\hline & $\begin{array}{l}\text {... médico não topa para isso, tem muita gente... é muito assustado... então... a } \\
\text { gente não está preparado, a gente inventa com uma onipotência danada e dai } \\
\text { toma um monte de medicamento na cabeça... ai sabe, (...) tem, tem que se haver } \\
\text { com coisa que você não vai dar conta... então todo dia você mexe com... é um } \\
\text { remexer de baú contínuo... }\end{array}$ \\
\hline
\end{tabular}

Esta avaliação remete ao espectro de impossibilidade de mudança, isto é, o profissional tem que trazer já em si, na sua personalidade, o potencial para trabalhar com questões da área da saúde mental. Caso isto não ocorra não adiantaria investir em formação, pois "não vai fertilizar de forma alguma". A possibilidade de adquirir competência para lidar com os problemas de saúde mental parece estar restringida por uma rigidez da estrutura da personalidade do profissional. 


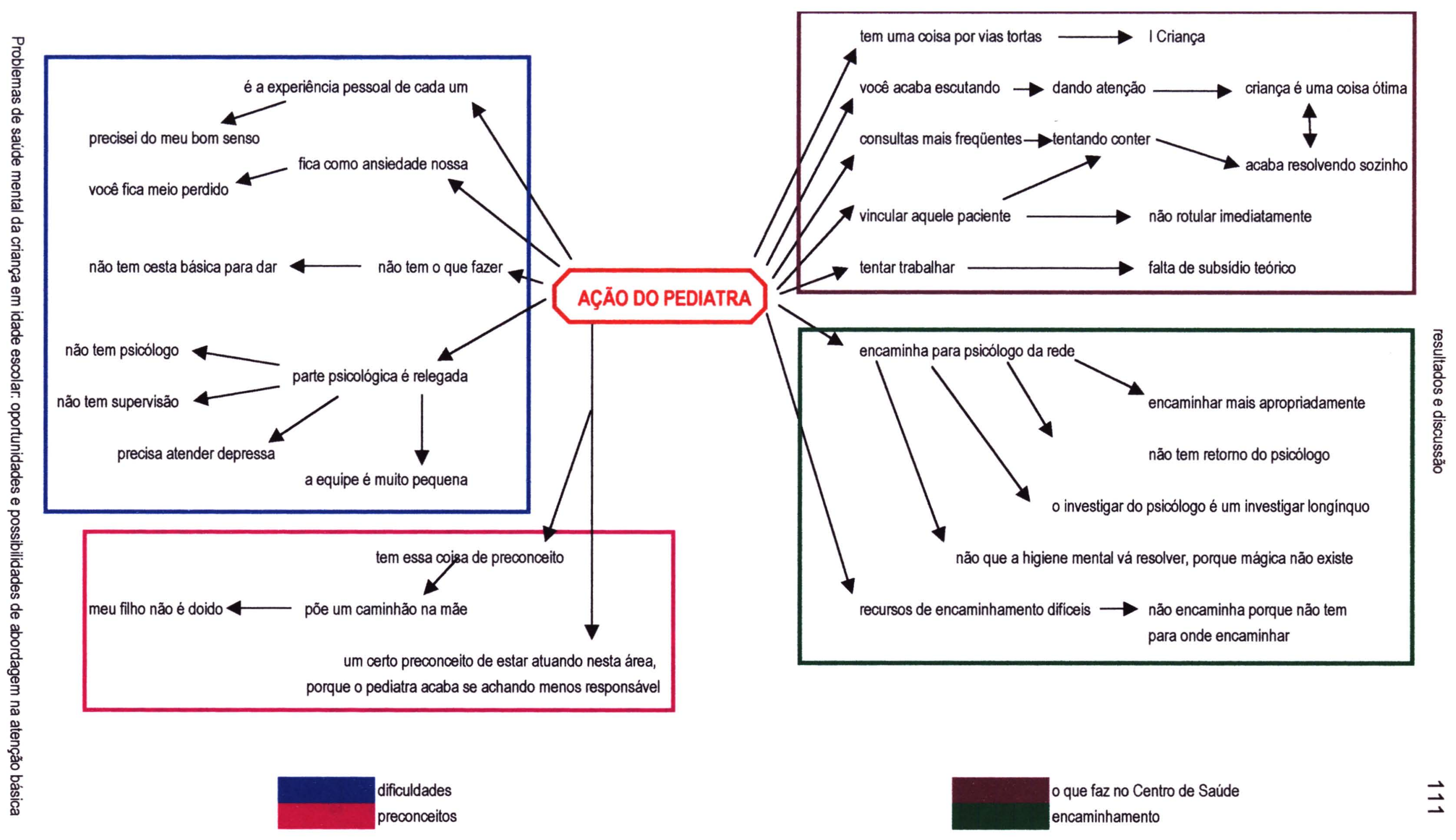

Figura VII - "Ánvore" das verbalizações e explicaçōes do eixo temático AÇÃo DOS PEDIATRAS FRENTE AOS PROBLEMAS DE SAÚDE MENTAL NA INFÂNCIA 


\subsubsection{AÇÃO DO PEDIATRA FRENTE AOS PROBLEMAS DE SAÚDE MENTAL}

A análise das falas relacionadas à ação dos pediatras frente aos problemas de saúde mental apontou uma dicotomia: o que é possível fazer e o que não é possivel fazer na atenção básica.

Os pediatras reconheceram que não dominam a área de saúde mental nem seus problemas e instrumental de intervenção com a mesma profundidade que outras especialidades da medicina. A dificuldade de se deparar com um problema que não sabem abordar ou não têm instrumentos claros de intervenção para lançar mão faz com que se mantenham longe destas questões, desvalorizando-as na prática clínica diária.

São repetidas as falas sobre não saber o que fazer e não ter instrumentos de intervenção. O desconhecimento de tecnologia apropriada imobiliza os pediatras, fazendo-os minimizar as queixas explícitas e não inquirir, durante a consulta, sobre questões de saúde mental (Matriz 12). Uma observação durante o campo, feita na sala dos assistentes do Centro de Saúde, descreve bem este aspecto. Uma residente aguardava para discutir com o assistente o caso que estava atendendo. Parecia ansiosa, manipulando constantemente o prontuário. A criança tinha uma queixa de comportamento. Num determinado momento explicita: "É melhor trabalhar no pronto socorro; lá, pelo menos, eu sei o que fazer!".

O enfoque privilegiado da formação médica contempla a utilização de tecnologias de intervenção dos tipos "dura" e "leve-dura" (MERHY e col. 2002) $)^{2}$, relegando para um segundo plano ou não considerando as intervenções na área da saúde mental, mesmo as mais elementares (acolhimento, vínculo), como atribuições do médico.

\footnotetext{
${ }^{2}$ MERHY e col. classificam as tecnologias envolvidas no trabalho em saúde como: "leve" (como no caso das tecnologias de relações do tipo produção de vínculo, autonomização, acolhimento, gestão como forma de governar processos de trabalho), "leve-dura" (como no casos de saberes bem estruturados que operam no processo de trabalho em saúde, como a clínica médica, a clínica psicanalítica, a epidemiologia, o taylorismo, o fayolismo) e "dura" (como no caso de equipamentos tecnológicos do tipo máquinas, normas, estruturas organizacionais).
} 
Observa-se um conflito entre 0 ideário da pediatria $e$ as possibilidades de intervenção do pediatra na atenção básica.

Matriz 12 - Tipos de tecnologia para abordar os PSM considerados ausentes pelos pediatras. CSE Butantã, 2000.

\begin{tabular}{|l|l|}
\hline $\begin{array}{l}\text { Tipos de } \\
\text { tecnologia }\end{array}$ & Verbalização \\
\hline $\begin{array}{l}\text { Falta de } \\
\text { instrumento } \\
\text { técnico }\end{array}$ & $\begin{array}{l}\text {... quando começa entrar na área, vamos falar mais em psicologia, para não } \\
\text { falar psiatria, acaba entrando outras ciências que a gente não tem um } \\
\text { instrumento técnico, digamos assim... } \\
\text { Infelizmente a gente não tem nenhum recurso técnico, primeira coisa,... a } \\
\text { gente torce... para num... a gente pede algumas, algumas ajudas... } \\
\ldots \text { acho que a instrumentalização do pediatra, que não está bem } \\
\text { instrumentalizado nessa parte, já te disse que com o bom senso a gente } \\
\text { consegue mesmo gritar e dizer não pode ficar (...) tem que ser encaminhado, } \\
\text { mas se existe uma faixa que é a faixa que você quer captar, que fica meio... } \\
\text { descoberto... } \\
\ldots \text {..porque não existe o instrumental. Quando você não tem definido o } \\
\text { instrumental, não tem definido o que é adequado e o que é inadequado. Não } \\
\text { existe essa definição em lugar nenhum, portanto, acho que cada um está } \\
\text { usando seus critérios próprios. É diferente, por exemplo, imunização,... existe } \\
\text { um calendário oficial, quem está dentro daquele calendário está correto, quem } \\
\text { está fora, estará incorreto... }\end{array}$ \\
\hline $\begin{array}{l}\text { Desconhecimento } \\
\text { das } \\
\text { possibilidades de } \\
\text { intervenção }\end{array}$ & $\begin{array}{l}\text {... não sabe o que fazer com isso... não tem uma cesta básica para dar, não } \\
\text { tem um psicólogo para ajudar a familia, fazer uma terapia familiar, então não } \\
\text { f.. apesar de que é isso que eu estou te falando, a gente acaba levantando a } \\
\text { lebre mas muitas vezes a gente não consegue dar vazão à isso, ás vezes fica } \\
\text { como ansiedade nossa, o que fazer com o pai alcoólatra, por exemplo... tenta } \\
\text { ter essa preocupação de levantar pelo menos e depois muitas vezes a gente } \\
\text { não consegue dar vazão a isso, a essa demanda... } \\
\ldots . \text { se eu soubesse minimamente, olha, que tipo de postura tem que ter, que } \\
\text { tipo de conduta tem que tomar, até onde eu posso ir, porque muitos } \\
\text { problemas às vezes você consegue com um mínimo de abordagem com a } \\
\text { mãe, fazer a mãe... acordar, ir atrás, correr... } \\
\ldots \text { quando a gente pensa em saúde mental acho que a gente pensa muito em } \\
\text { quanto você não sabe lidar com esse tipo de problema. }\end{array}$ \\
\hline
\end{tabular}


Dentre as possibilidades de atuar dos pediatras foram encontrados aspectos contraditórios (Matriz 13). Em muitas falas foram descritas situações de intervenções concretas que não são valorizadas pelos pediatras. Em uma das observações de campo foi registada uma passagem muito significativa. Após uma exposição sobre detecção precoce de transtornos globais do desenvolvimento realizada no Centro de Saúde, durante a discussão que se seguiu, um dos pediatras fez a seguinte observação: "quando a gente entra neste campo parece que a gente não é mais médico".

Estas atuações são remetidas ao senso comum, ao bom senso de cada um, deixando de serem vistas como procedimentos científicos, tecnologias de intervenção respaldadas pelo "saber oficial".

Intervenções do tipo ouvir mais, marcar consultas mais freqüentes, dar mais atenção, conversar com a criança, "tentar conter", por não fazerem parte do arsenal terapêutico clássico dos pediatras, não são entendidos como científicos. Desta forma eles acabam verbalizando que "criança é uma coisa ótima, (...) acaba resolvendo sozinha", após detalhar uma série de condutas e intervenções por eles realizadas. 
Matriz 13 - Tipos de intervenção do pediatra frente aos PSM identificados pelos pediatras. CSE Butantã, 2000.

\begin{tabular}{|c|c|}
\hline $\begin{array}{l}\text { Aspectos da } \\
\text { intervenção }\end{array}$ & Verbalização \\
\hline $\begin{array}{l}\text { Tipos de } \\
\text { intervenções }\end{array}$ & $\begin{array}{l}\text { Mas então algumas vezes você acaba escutando, dando atenção, e às vezes o } \\
\text { que você nota, principalmente em crianças maiores, e às vezes até em crianças } \\
\text { menores, que você dando uma atenção, fazendo consultas mais freqüentes, } \\
\text { escutando a queixa, tentando conter, elas melhoram espontaneamente... } \\
\text {... muitas vezes a gente acaba tentando resolver com os recursos próprios que } \\
\text { tem mesmo (...). O que a gente faz? Primeira coisa, vincular aquele paciente } \\
\text { com uma pessoa só que vai atender e tentar vincular com o assistente também, } \\
\text {... cria o vinculo terapêutico, eles se abrem muito mais, e ai você fica muito mais } \\
\text { exposto á essa realidade, e ele é mais confidente, ele conta mais, ai afloram as } \\
\text { queixas,... as angústias que tem, muitas vezes da... até do próprio... } \\
\text { responsáveis, vamos colocar assim,... e ai você passa a compreender a criança } \\
\text { dentro do contexto... } \\
\text { ter mais calma, ampliar a história, procurar escutar os pais, procurar escutar a } \\
\text { criança, certo? Quer dizer, não rotular imediatamente, não encaminhar } \\
\text { imediatamente, a não ser que seja alguma coisa que grite aos olhos da gente } \\
\text { (...) Então a gente descobrindo a raiz do problema, com calma, consegue } \\
\text { resolver a maior parte desses problemas, certo? } \\
\text {... você vai fazer aquilo que eu chamo de uma terapia (...) não deixa de ser, } \\
\text { aquilo que eu acho que o pediatra antigo, o médico de antigamente tinha um } \\
\text { enorme sucesso, ele tinha tempo para sentar, para conversar, para ver, para } \\
\text { entender algo mais do que a queixa do seu paciente. }\end{array}$ \\
\hline & $\begin{array}{l}\text {... e uma coisa que é ruim é você ficar trabalhando em cima só do seu... da } \\
\text { coisa do bom senso,... ai depende até, às vezes, um pouco até da } \\
\text { personalidade da pessoa, não é uma coisa muito... não sei que eficácia isto } \\
\text { pode ter para o paciente. } \\
\text {... mas eu acho que uma coisa que nos impulsionou a agir desse jeito, muitas } \\
\text { vezes até de uma forma intuitiva, muito mais ligado ao bom senso do que de } \\
\text { conhecimento profundo... } \\
\text { Tentando fazer a atenção global a gente começou a se auto-instrumentalizar e } \\
\text { seguramente usar o bom senso e o senso comum a maior parte das vezes. } \\
\text { Como pediatra, (...) eu sempre procurei encaminhar antes do aparecimento dos } \\
\text { problemas... } \\
\text { Então nós começamos a ficar muito auto-suficientes, sabe, mas auto-suficientes } \\
\text { no seguinte sentido, aqui não dá para dar cobertura. A rede, não só não dava } \\
\text { como quando dava era muito a desejar, muito a desejar... confesso para você } \\
\text { que muitas vezes eu precisei do meu bom senso, (...) procuro caminhar no } \\
\text { antes, sempre prevenindo. }\end{array}$ \\
\hline $\begin{array}{l}\text { Desqualificação } \\
\text { da intervenção }\end{array}$ & $\begin{array}{l}\text {... a criança é uma coisa ótima, você segura e tal e ai ela vai e passa o } \\
\text { problema entendeu? Então acaba se resolvendo sozinho, de alguma forma ela } \\
\text { acaba se ligando em alguma coisa... }\end{array}$ \\
\hline
\end{tabular}


Vários fatores relacionados à organização da assistência foram citados como problemáticos. O primeiro deles, apontado nas entrevistas, é a organização atual do processo de trabalho do médico na atenção básica, que não favorece a deteç̧ão de problemas que não sejam tipo "prontoatendimento" (Matriz 14).

Matriz 14 - Características da organização do processo de trabalho do médico identificadas como deficientes pelos pediatras. CSE Butantã, 2000.

\begin{tabular}{|c|c|}
\hline $\begin{array}{l}\text { Deficiências no } \\
\text { trabalho médico }\end{array}$ & Verbalização \\
\hline $\begin{array}{l}\text { Descaracterização } \\
\text { do vinculo médico- } \\
\text { paciente }\end{array}$ & $\begin{array}{l}\text {...é que não existe mais aquela coisa do vínculo, quer dizer, o paciente que } \\
\text { é seu. O paciente não é de ninguém, ele está uma hora no pronto socorro, } \\
\text { outra hora no centro de saúde, outra hora num outro, as mães que muitas } \\
\text { vezes estão trabalhando, estão correndo para lá e para cá, vão uma hora no } \\
\text { desespero, querem tudo muito rápido, essa demanda por remédios para } \\
\text { tudo... } \\
\text { A gente como médico perdeu muito a parte... formação humanística mesmo, } \\
\text { então a questão... é a arte, é a cultura, quer dizer, ficou tão tecnicista que } \\
\text { outras coisas parecem que não existem, e... a gente tem que estar } \\
\text { resgatando, o homem não é só uma maquininha... } \\
\text {... a gente quando as crianças param de ficar doentes, eu acho que, de um } \\
\text { modo geral o pediatra manda as crianças embora. }\end{array}$ \\
\hline $\begin{array}{l}\text { Pouco tempo de } \\
\text { consulta }\end{array}$ & $\begin{array}{l}\text {... porque na atenção primária, você precisa atender depressa os clientes. } 0 \\
\text { depressa não quer dizer } 10 \text { minutos, as consultas são longas, mas você não } \\
\text { pode fazer um interrogatório extremamente extenso, quer mesmo pela } \\
\text { demanda que a gente tem... na atenção primária não dá muito para esperar } \\
\text { pela solução dos problemas... } \\
\text {... acho que o pediatra antigo, o médico de antigamente tinha um enorme } \\
\text { sucesso, ele tinha tempo para sentar, para conversar, para ver, para } \\
\text { entender algo mais do que a queixa do seu paciente. } \\
\text { O pessoal quer ser rápido e fala sem escutar nada. Acho que o que falta,... } \\
\text { falta muita escuta mesmo }\end{array}$ \\
\hline $\begin{array}{l}\text { Consulta tipo } \\
\text { "pronto- } \\
\text { atendimento" }\end{array}$ & $\begin{array}{l}\text {... então são coisas que eu creio que passam muito batido porque, o } \\
\text { pessoal, chegou chiando,... prescreve, ai vai para outro, ninguém vê esta } \\
\text { criança como um todo, às vezes o pessoal não tem esse tipo de coisa,... } \\
\text {... não sei como é que anda a assistência em todos os lugares, mas } \\
\text { normalmente a parte psicológica é relegada... só é atendido esses curativos } \\
\text { mais direto, o que eles fazem no fim é dar receitinha e encaminhar. Então a } \\
\text { parte psicológica deve ficar prejudicada,... }\end{array}$ \\
\hline
\end{tabular}

O tempo de cada consulta e tipo de trabalho realizado na atenção básica também são considerados motivos para a pouca importância dada às 
questões de saúde mental. Aqui é importante salientar que a questão tempo da consulta, na maioria das vezes, é remetida para os atendimentos feitos em outros serviços que não o Centro de Saúde Escola. A observação do campo de estudo observou que as consultas são longas por causa do caráter didático do atendimento e do processo de supervisão realizado pelos médicos assistentes.

A falta de vínculo com o paciente foi citada como uma das dificuldades de aprofundar $\circ$ atendimento clínico. Aqui também a organização do atendimento no Centro de Saúde, tendo em vista o ensino, com o rodizio dos residentes e alunos, limitaria o estabelecimento de relações médico-paciente mais estáveis e que permitissem o desenvolvimento de ações na linha da prevenção e promoção na área de saúde mental. Os jovens residentes sentem-se inibidos para fazer perguntas nesta área e as mães, muitas vezes, acham que estes não são assuntos para médicos.

No entanto, apesar desta organização do atendimento ser típica de situações de ensino, as falas remeteram a dificuldades de estabelecimento do vínculo médico-paciente também para atendimentos nos serviços de atenção básica sem atividades didáticas. A falta de formação humanística dos estudantes de medicina e a utilização quase exclusiva de tecnologias "duras" (medicamentos e/ou exames) como técnicas possíveis de intervenção, além do curto tempo do atendimento na atenção básica, foram as causas citadas para explicar esta dificuldade.

Outro aspecto relacionado à organização da assistência referido foi a necessidade de profissionais de outras formações estarem presentes na atenção básica para possibilitar uma abordagem multiprofissional (Matriz 15). O papel destinado a estes profissionais é variável, dependendo do entrevistado, indo desde alguém para encaminhar o caso até a possibilidade do atendimento conjunto do paciente, contribuindo para a formação do pediatra no campo da saúde mental. 
Matriz 15 - Características da organização do processo de trabalho no Centro da Saúde identificadas como deficientes pelos pediatras. CSE Butantã, 2000.

\begin{tabular}{|l|l|}
\hline $\begin{array}{l}\text { Deficiência no } \\
\text { Centro de } \\
\text { Saúde }\end{array}$ & Verbalização \\
\hline $\begin{array}{l}\text { Falta de } \\
\text { profissionais }\end{array}$ & $\begin{array}{l}\text {... a gente é uma equipe muito pequena... então a gente acaba muitas vezes } \\
\text { cumprindo o papel de médico mesmo. }\end{array}$ \\
\hline $\begin{array}{l}\text { Falta de } \\
\text { profissionais da } \\
\text { área da saúde } \\
\text { mental }\end{array}$ & $\begin{array}{l}\text { O que a gente sente falta é de estar discutindo com pessoas da área mesmo de } \\
\text { mental para entender melhor os casos, para poder sistematizar melhor, então, } \\
\text { como a gente não tem esse contato, fica muito por conta de cada um... } \\
\text {... a gente não tem um serviço estruturado, serviço de saúde mental... é do } \\
\text { adulto, atende adolescentes e adultos, não atende criança. Então a gente não } \\
\text { tem esse serviço... a gente não tem esse profissional trabalhando } \\
\text { conjuntamente e nem supervisionando... } \\
\text { É isso que eu estava te falando, se tivesse alguém para gente discutir os casos } \\
\text { eu acho que ajuda, porque na hora que você discute eu acho que sempre você } \\
\text { acaba entendendo esse caso, aí o próximo fica um pouco mais fácil de você } \\
\text { lidar, então... acho que disso... se a gente tivesse aqui o pessoal da área de } \\
\text { mental, atendendo também crianças, ou discutindo os casos com a gente, } \\
\text { mesmo que não atendesse diretamente, isso facilitaria muito... }\end{array}$ \\
\hline $\begin{array}{l}\text { Organização } \\
\text { interna do } \\
\text { serviço }\end{array}$ & $\begin{array}{l}\text {... é uma experiência pessoal de cada um, não é uma coisa tão dirigida, e... faz } \\
\text { falta em vários aspectos, faz falta para equipe, faz falta para população } \\
\text { atendida, faz falta para o residente, então é uma necessidade do dia a dia, mas } \\
\text { ela não tem uma coisa muito estruturada, a gente nunca conseguiu organizar } \\
\text { mais esse serviço. } \\
\text { Então algumas tentativas que foram feitas de integração mais recentemente } \\
\text { não deram certo e a nossa expectativa que seria nos ajudar a ter um } \\
\text { instrumental de trabalhar a questão principalmente da prevenção que é muito } \\
\text { importante em termos de atenção primária, a gente acabou não tendo (...) a } \\
\text { gente não tem, dentro do próprio serviço condições de estar tendo um } \\
\text { resolutividade dos casos observados e até de um apoio em termos de } \\
\text { psicoprofilaxia }\end{array}$ \\
\hline
\end{tabular}

Outra possibilidade de atuação do pediatra é o encaminhamento das crianças com PSM para serviços especializados em saúde mental (Matriz 16). Existe um descrédito quanto à possibilidade de encaminhamento das crianças, tanto em relação ao número de serviços existentes quanto pelo fato de não conhecerem mais de perto estes serviços e não terem confiança no tipo de trabalho que será realizado lá. A pouca troca de informações entre os profissionais da atenção básica e os serviços especializados em saúde mental gera um sentimento de "perda do paciente". 
Matriz 16 - Características da organização do sistema de saúde identificadas como deficientes pelos pediatras. CSE Butantã, 2000.

\begin{tabular}{|c|c|}
\hline $\begin{array}{l}\text { Tipo de } \\
\text { deficiência }\end{array}$ & Verbalização \\
\hline $\begin{array}{l}\text { Pouco serviços } \\
\text { especializados }\end{array}$ & $\begin{array}{l}\text {... só que os encaminhamentos fora, geralmente você não tem muito para } \\
\text { onde encaminhar, ou então o tempo de espera é muito grande, e a mãe volta } \\
\text { e diz: ah, tem que ficar na fila de espera, não sei o quê,... então ela... } \\
\text { dificilmente a gente tem um retorno do seguimento, com psiquiatra, psicólogo, } \\
\text { coisa assim. Então é difícil... } \\
\text {... porque muitas vezes não é um caso que você precisa encaminhar } \\
\text { imediatamente para um acompanhamento com um psicólogo mesmo porque, } \\
\text { como eu falei, os recursos para encaminhamento são dificeis... } \\
\text {... muitas vezes não dispõe dos serviços e recursos, então você identifica, } \\
\text { essa criança precisaria de um encaminhamento, e busca, e você não } \\
\text { encontra, e você fica lidando com o problema, ou,... lidando com o problema } \\
\text { muito mal dentro do seu dia a dia, ou você passa a ignorar o problema, você } \\
\text { fala: bom, para isto eu não tenho uma solução e eu não tenho um sistema que } \\
\text { acolha esse problema. E isto é uma questão terrivel para nós. Se você hoje } \\
\text { aqui identificar uma criança que você acha que precisa de um apoio... } \\
\text { psicológico, ou precisa de uma avaliação especializada nessa área, você não } \\
\text { tem para onde encaminhar... }\end{array}$ \\
\hline $\begin{array}{l}\text { Descrédito no } \\
\text { serviço } \\
\text { especializado }\end{array}$ & $\begin{array}{l}\text {... mas você não sabe nem o que tem do outro lado do túnel... a pessoa que } \\
\text { vai atender... dá um certo receio. E eu tenho muito medo nessa área... } \\
\text {... mas, olha, eu não vi até hoje nenhum caso em que a gente tivesse um } \\
\text { relatório de psicólogo dizendo: olha, o... fazendo tal e tal abordagem, acho } \\
\text { que é isso, isso e isso, a gente não tem esse retorno, a mãe é que traz às } \\
\text { vezes a informação dela, e ás vezes é extremamente vaga porque ela } \\
\text { também não. } \\
\text {... solução do problema não muda muito mesmo, (...), eu digo: olha, esse } \\
\text { daqui vai ter que ir para higiene mental (...) mas assim,... não que eu ache que } \\
\text { a higiene mental vá resolver, porque mágica não existe em medicina... } \\
\text {... você manda, uns se perdem porque não conseguem marcar e os que } \\
\text { conseguem marcar você nem sabe muitas vezes o que tá acontecendo, você } \\
\text { perde, então eu não sinto que a gente refere muito... }\end{array}$ \\
\hline
\end{tabular}

As possibilidades de atuação do pediatra são marcadas pelo pessimismo. As intervenções realizadas no Centro de Saúde pelo médico são desvalorizadas por eles próprios, mesmo quando os resultados são positivos. O encaminhamento externo é visto com cautela: “... fica um vazio, é um túnel sem fim, sabe...". 
tema preconceito apareceu várias vezes durante as entrevistas. Por vezes referia-se ao preconceito por parte dos pais em relação aos psiquiatras e aos psicólogos. Em outras falas apareceu a idéia de que este tipo de preconceito já foi pior e que atualmente não seria um empecilho para este tipo de encaminhamento. Existe também o preconceito do próprio pediatra em relação a estas questões (Matriz 17).

Matriz 17 - Tipos de preconceitos identificados pelos pediatras nos distintos atores envolvidos. CSE Butantä, 2000.

\begin{tabular}{|l|l|}
\hline Imagem & Verbalização \\
\hline Da família & $\begin{array}{l}\text {.. existe um estigma na hora que você fala que a criança vai precisar ir para um } \\
\text { psicólogo... psiquiatra nem pensar você falar... então você acha que a criança } \\
\text { vai precisar fazer um acompanhamento, é até difícil porque às vezes não } \\
\text { consegue nem encontrar um termo, vai falar saúde mental a mãe arregala o } \\
\text { olho, psicólogo, psiquiatra então ela... quase infarta... } \\
\ldots \text { o encaminhamento, (...), por exemplo, para um psicólogo é... é uma questão } \\
\text { meio cultural também, acho que, por exemplo, quando você fala assim,... olha, } \\
\text { precisaria encaminhar para um psicólogo... você bota um caminhão na criança e } \\
\text { a mãe... tem muito essa coisa de preconceito, às vezes a mãe acaba não } \\
\text { levando... some,... às vezes a idéia que as pessoas tem è... ele está doido,... ou } \\
\text { então ele tem um problema muito grave... a expressão: são doidos, que as } \\
\text { pessoas usam,... o que é muito negativo... } \\
\text {... vou encaminhar você para um profissional da área de saúde mental, vamos } \\
\text { colocar, como se diz... genérico? a gente vai... psicólogo, psiquiatra... até } \\
\text { bonito, até dá status, imagina, fazer terapia, mas há anos atrás era o contrário, } \\
\text { você falava... vou mandar para o psiquiatra, coisa de louco, não quer nem } \\
\text { saber, e existe muitas vezes o receio também da própria familia de se } \\
\text { aprofundar nessas questōes que você pode detectar, que sabe lá o que vai } \\
\text { encontrar lá embaixo... }\end{array}$ \\
\hline Do médico & $\begin{array}{l}\text { Então a saúde escolar tem esse aspecto, existe até um certo preconceito às } \\
\text { vezes de estar atuando nessa área, porque o pediatra acaba às vezes se } \\
\text { achando menos responsável... }\end{array}$ \\
\hline
\end{tabular}

A maioria dos entrevistados descreveu suas atividades cotidianas e tentou explicar as dificuldades levantadas do ponto de vistas cognitivo, exemplificando com situações do dia a dia. No entanto, em vários momentos o aspecto afetivo do trabalho emergiu, tanto na forma auto-referida como em generalizações para fora do Centro de Saúde. O cunho emocional das colocações foi muito vivo, o que traduz a ansiedade subjacente ao fazer cotidiano nesta esfera do trabalho. 
Ansiedade e medo são as emoções que dão colorido ao atendimento rotineiro de pediatria quando o assunto em questão é da área emocional. $O$ sentimento de solidão e insegurança do pediatra frente às questões de saúde mental estão presentes por trás das vivas reclamações da falta da equipe multiprofissional atuando no Centro de Saúde. Chama atenção que apenas sentimentos de cunho negativo foram expressados durante as entrevistas, apontando que a tarefa de lidar com questões da área de saúde mental é extremamente penosa e difícil (Matriz 18).

As emoções que permeiam o atendimento parecem se centrar na impotência, no não ter o que fazer com aquela queixa, não saber como encaminhar. A formação focada no aspecto biológico, na patologia, e nas intervenções "duras" e com efeitos a curto prazo confronta-se, na prática cotidiana, com questões psíquicas e sociais que fogem a este padrão e necessitam de outras tecnologias de intervenção, não dominadas pelo médico. 
Matriz 18 - Sentimentos expressados pelos pediatras frente aos PSM. CSE Butantã, 2000.

\begin{tabular}{|c|c|}
\hline Sentimento & Verbalização \\
\hline Solidão & $\begin{array}{l}\text {... mas ele sozinho não vai fazer nada, } \\
\text {.. mas sozinho não... } \\
\text {... fica um vazio, é um túnel sem fim, sabe... }\end{array}$ \\
\hline Constrangimento & ... um certo constrangimento de dizer... \\
\hline Impotência & $\begin{array}{l}\text {... até a gente mesmo não consegue resolver... } \\
\text {... você não consegue fazer um acompanhamento mais adequado... } \\
\text {... eu não sei o que fazer... } \\
\text {... não tenho solução... não tenho um sistema que acolha este problema. E } \\
\text { isto é uma coisa terrivel para nós. } \\
\text { O quê que a gente percebe? Alterações de comportamento e de } \\
\text { relacionamento das crianças... Fiquei perdida... } \\
\text {... falta talvez algum instrumento melhor, uma formação melhor para eu } \\
\text { definir os casos, isso a gente não consegue, eu não consigo. }\end{array}$ \\
\hline Medo & $\begin{array}{l}\text {... tem ás vezes que dá medo, (...) se você começar cavocar esse negócio } \\
\text { você vai mexer em estruturas que podem abalar a base da pessoa,... e aí, o } \\
\text { quê que você faz? } \\
\text {... se você não sabe o que tem do outro lado do túnel (...) dá um certo receio. } \\
\text { E eu tenho muito medo nessa área. } \\
\text {... mas ele morre de medo de... de uma mãe que não consegue aleitar, ou de } \\
\text { uma mãe que está deprimida... } \\
\text {... então a gente fica meio de mãos atadas, então isso que eu falei, às vezes } \\
\text { a gente tem até medo de entrar nisso.... você dá umas orientadas e foge, é } \\
\text { mais fácil a gente lidar com a pneumonia... }\end{array}$ \\
\hline Intromissão & $\begin{array}{l}\text { Eu me sinto uma intrometida na família da criança. Esse diagnóstico ai me } \\
\text { faz intrometer mais ainda. E eu não vejo limites, só se desistir, só se desistir. }\end{array}$ \\
\hline Ansiedade & $\begin{array}{l}\text {... acaba não conseguindo trabalhar isso, então muitas vezes o que fica é o } \\
\text { profissional ansioso... } \\
\text {... a gente acaba levantando a lebre mas muitas vezes a gente não consegue } \\
\text { dar vazão à isso, ás vezes fica como ansiedade nossa. } \\
\text {... muitas vezes fica o profissional ansioso, a gente fica... não sabe o que } \\
\text { fazer com isso... não tem uma cesta básica para dar, não tem um psicólogo } \\
\text { para ajudar a família, fazer uma terapia familiar, então não tem o que fazer... }\end{array}$ \\
\hline
\end{tabular}


O conhecimento técnico na área de saúde mental, mesmo reconhecido pelos pediatras como não sendo adequado, não parece ser a questão mais importante. Um dos entrevistados fez a seguinte colocação:

"Agora, a solução é que não é fácil, se não, de repente você rotula alguém ... é o pediatra detecta, o pediatra não sabe detectar, eu acho que muitos sabem detectar, mas a abordagem é tremendamente dificultada por essa série de variáveis que a gente tem. (...) não dá para abordar de forma simplista esta 'questão, de forma alguma você tem que ter uma análise muito criteriosa, se não fica assim: ah, é o pediatra que não sabe nada. Cuidado, minha recomendação é que você tenha muito cuidado."

Mesmo quando explicitamente reconhecida a importância do atendimento integral, da influência do emocional sobre o orgânico, da psicoprofilaxia, como reza o ideário da pediatria, isto não é suficiente para transformar o saber, mesmo não aprofundado, em um fazer cotidiano. $O$ "desaparecimento" das queixas durante a consulta aponta para uma negação do problema, como "se eu não tenho instrumentos claros de intervenção, é melhor deixar isto para lá, não é da minha conta".

Quando existe a possibilidade de uma intervenção considerada efetiva pelo profissional ou um local de encaminhamento conhecido e confiável, isto é, o médico sente-se de fato no papel resolutivo do caso, as queixas tornam-se mais "visíveis" e passíveis de serem lidadas. Um exemplo deste tipo de situação foi explicitado em uma das entrevistas:

"... acho que a proximidade do profissional, e uma interface, um diálogo é que facilita isso. Aqui, por exemplo, no centro de saúde, pelo fato da gente ter um serviço de fono aqui do lado, que faz alguns testes audiométricos, audiometria e tudo o mais, comparado a outros locais, a gente tem uma facilidade muito grande (...) de fazer essa avaliação, então ao nivel de fono (...) você está mais atento a esse tipo de problema, pela facilidade de recurso que está ao lado..." 


\subsubsection{PROPOSTAS DE MUDANÇAS: UMA LUZ NO FIM DO TÚNEL}

Durante as entrevistas os próprios médicos pediatras, reconhecendo as dificuldades, apontaram várias sugestões para melhoria do atendimento na área de saúde mental. Uma das principais propostas foi um maior e melhor relacionamento com equipes de saúde mental (Matriz 19).

Esta retaguarda teria algumas características especiais como o trabalho em conjunto com profissionais especializados em saúde mental, a utilização de uma linguagem adequada, num contexto de parceria em que se buscaria respeitar a individualidade de cada profissional e aportar conhecimento condizente com a atuação profissional. 
Matriz 19 - Propostas para melhoria da assistência aos PSM identificadas pelos pediatras: Interação com profissionais de saúde mental. CSE Butantã, 2000.

\begin{tabular}{|c|c|}
\hline Propostas & Verbalização \\
\hline $\begin{array}{l}\text { Trabalho } \\
\text { conjunto }\end{array}$ & $\begin{array}{l}\text {... se vocé tem uma retaguarda eficiente, que vocé possa estar fazendo alguma coisa } \\
\text { em conjunto, eu acho que... melhoraria bastante a relação com o paciente, è... eu acho } \\
\text { que melhoraria em relação ao serviço, quer dizer, você conseguiria dar uma... uma } \\
\text { resolubilidade melhor, para o serviço, para nada se separar, tem que ser alguma coisa } \\
\text { em conjunto mesmo... } \\
\text {...se tivesse alguém para gente discutir os casos eu acho que ajuda, porque na hora } \\
\text { que vocé. discute eu acho que sempre vocé acaba entendendo esse caso, ai o próximo } \\
\text { fica um pouco mais fácil de você lidar... }\end{array}$ \\
\hline $\begin{array}{l}\text { Equipe } \\
\text { multiprofissional } \\
\text { na atenção } \\
\text { básica }\end{array}$ & $\begin{array}{l}\text {... o ideal é que a gente tivesse uma pessoa que pudesse resolver as nossas dúvidas } \\
\text { (...) o ideal é que tivesse psicólogo em toda a parte, quer dizer, dai, com certeza ia } \\
\text { haver um espaço, o entendimento seria possivel, porque hoje não se pode, se não tem } \\
\text { interlocutor... não pode começar nem o diálogo, } \\
\text {... precisaria ter um assistente social (...), precisaria ter sem dúvida um psicólogo na } \\
\text { unidade básica de saúde para, até para você ter um dimensionamento adequado do } \\
\text { que é o papel do médico, o que é o papel do psicólogo, o que é o papel do enfermeiro } \\
\text { dentro da saúde mental, porque é impossivel que um único profissional consiga fazer a } \\
\text { profilaxia, o diagnóstico precoce de problemas referenciais a essa área, se deveria } \\
\text { instrumentalizar a equipe como um todo para que vocé tivesse um sucesso maior no na } \\
\text { abordagem desses problemas }\end{array}$ \\
\hline $\begin{array}{l}\text { Criação de } \\
\text { novas formas de } \\
\text { trabalhar }\end{array}$ & $\begin{array}{l}\text {... precisa ter a criação de um grupo especialmente voltado para o desenvolvimento ou } \\
\text { para saúde mental, porque de certa forma há uma deficiéncia do serviço básico... } \\
\text {... com contexto voltado para pediatra. Não querer adaptar o que é para psiquiatra para } \\
\text { pediatra, porque não tem nada que ver... }\end{array}$ \\
\hline $\begin{array}{l}\text { Retaguarda } \\
\text { eficiente }\end{array}$ & $\begin{array}{l}\text {... facilitaria muito... ã... se a gente, por exemplo, pudesse ter um contato maior, onde } \\
\text { vocé pudesse, como eu falei, de repente detectar precocemente e estar podendo saber } \\
\text { que vocé vai encaminhar e aquela criança vai ser atendida... }\end{array}$ \\
\hline
\end{tabular}

A utilização de instrumentos padronizados para o diagnóstico precoce de problemas de saúde mental, aplicados à pratica pediátrica, também foi apontada como necessária para a melhoria da qualidade do trabalho (Matriz 20). As falas indicaram um movimento pró-ativo dos próprios pediatras por, uma vez mobilizados por este tipo de demanda, fazer uma busca desses instrumentos e de novas alternativas de intervenção. 
Matriz 20 - Propostas para melhoria da assistência aos PSM identificadas pelos pediatras: Utilização de instrumentos adequados. CSE Butantã, 2000.

\begin{tabular}{|l|l|}
\hline \multicolumn{1}{|c|}{ Instrumentos } & Verbalização \\
\hline $\begin{array}{l}\text { Criação de } \\
\text { parâmetros }\end{array}$ & $\begin{array}{l}\text {... ou então, nesse caso, por exemplo de autismo, se eu tivesse algum } \\
\text { instrumento que me dissesse: olha, suspeite quando, isso, isso, isso... ai } \\
\text { também facilita... a falta de formação, de não saber assim alguns } \\
\text { parâmetros mais confiáveis, mais sistematizados... }\end{array}$ \\
\hline $\begin{array}{l}\text { Assessoria versus } \\
\text { iniciativas } \\
\text { particulares }\end{array}$ & $\begin{array}{l}\text {... mas precisa uma melhor instrumentalização do próprio pediatra, certo?. E } \\
\text { que se houver alguma assessoria (...), mas antes escuta o que nós } \\
\text { pretendemos, e o que ela pretende da gente, se não, não dá certo outra vez. } \\
\text { E naturalmente iniciativas particulares do próprio pediatra, cuidando dessa } \\
\text { parte. }\end{array}$ \\
\hline Estudar casos & $\begin{array}{l}\text { Acho que num primeiro momento seria isso, estudar alguns casos... e num } \\
\text { segundo momento talvez levantar essa morbidade, à medida que vai se } \\
\text { estudando esses casos, se amadurece a idéia do problema, e depois } \\
\text { começar a se trabalhar a morbidade... mas eu tenho a impressão que seria, } \\
\text { num primeiro momento, seria a discussão de casos interessantes para } \\
\text { despertar um interesse na equipe... }\end{array}$ \\
\hline
\end{tabular}

A importância de rever aspectos da formação médica também foi citada como elemento fundamental na melhoria da intervenção do pediatra na área de saúde mental.

Matriz 21 - Propostas para melhoria da assistência aos PSM identificadas pelos pediatras: Mudanças na formação médica. CSE Butantã, 2000.

\begin{tabular}{|l|l|}
\hline $\begin{array}{l}\text { Nivel de } \\
\text { formação }\end{array}$ & Verbalização \\
\hline $\begin{array}{l}\text { Formação na } \\
\text { faculdade }\end{array}$ & $\begin{array}{l}\text {... que os alunos viessem melhor instrumentalizados para nós em relação às } \\
\text { questões da mente,... de fases anteriores inclusive. E que aqui na pediatria, } \\
\text { nós tivéssemos pessoas, que com uma linguagem adequada, conseguisse } \\
\text { atingir já o aluno,... terceiro,... quarto ano,... a entender os problemas mais } \\
\text { freqüentes que podem acometer a criança... }\end{array}$ \\
\hline $\begin{array}{l}\text { Formação na } \\
\text { residência }\end{array}$ & $\begin{array}{l}\text {... quando ele tem um... um... embasamento importante, eu acho que ele é... } \\
\text { ele é... uma... uma... è... uma... personagem extremamente importante } \\
\text { nesse... no acompanhamento da criança, ã... mas ele sozinho não vai fazer } \\
\text { nada, então eu acho que é importante a, a... penso que assim, eu acho que } \\
\text { as escolas deveriam estar a... a... ampliando um pouco a parte de... de } \\
\text { prevenção, de promoção da, da, da saúde mental para que isso fosse, è... } \\
\text { fizesse parte do curriculo do pediatra... }\end{array}$ \\
\hline
\end{tabular}




\subsubsection{O PAPEL DO PEDIATRA}

Grande parte dos entrevistados verbalizou qual seria o papel do pediatra na atenção aos problemas de saúde mental na infância. Esta opinião não foi resposta a uma pergunta feita diretamente, mas sim uma construção feita durante a interação da entrevista (Matriz 22). As falas remeteram, quase todas, ao ideário da escola de Pediatria da FMUSP, fundada pelo professor Pedro de Alcântara.

Matriz 22 - O papel identificado para o pediatra no atendimento dos PSM na atenção básica. CSE Butantã, 2000.

\begin{tabular}{|c|c|}
\hline Papéis & Verbalização \\
\hline $\begin{array}{l}\text { Visão integral da } \\
\text { criança }\end{array}$ & $\begin{array}{l}\text {... eu, eu não tenho dúvida que eu acho que onde você mais faz saúde mental é na } \\
\text { pediatria... } \\
\text { O pediatra tem que assumir coisas assim, você entende?, E na atenção primária esse } \\
\text { que é o grosso das coisas, são coisas que o pediatra, com uma visão global... tem } \\
\text { intenções de amparar afetivamente. } \\
\text {... verificar quais são os problemas, se eles não conseguem entender, encaminhar, eu } \\
\text { acho que o pediatra tem que ter responsabilidade global da criança, biopsicossocial } \\
\text { mesmo... }\end{array}$ \\
\hline Filtro & $\begin{array}{l}\text {... eu acho que ele é uma figura super importante porque ele é um filtro... então quer } \\
\text { dizer, quando ele tem um... um... embasamento importante, eu acho que ele é... ele } \\
\text { é... uma... uma... é... uma... personagem extremamente importante nesse... no } \\
\text { acompanhamento da criança, ã... mas ele sozinho não vai fazer nada, então eu acho } \\
\text { que é importante a, a... penso que assim, eu acho que as escolas deveriam estar a... } \\
\text { a... ampliando um pouco a parte de... de prevenção, de promoção da, da, da saúde } \\
\text { mental para que isso fosse, é... fizesse parte do currículo do pediatra. } \\
\text { acho que o pediatra tem que ser um sensor geral. Ele tem que estar aberto e... claro... } \\
\text { e alerta... para detectar tudo isso, tem que saber de uma certa forma, interferir da } \\
\text { melhor forma possivel, é dificil... }\end{array}$ \\
\hline Prevenção & $\begin{array}{l}\text { Como pediatra, (...) eu sempre procurei encaminhar antes do aparecimento dos } \\
\text { problemas... } \\
\text {... acho que o pediatra tem uma atuação mais clara na psicoprofilaxia, realmente se } \\
\text { antecipando aos problemas, e mostrando, e discutindo com a familia ou com as } \\
\text { creches. }\end{array}$ \\
\hline $\begin{array}{l}\text { Detectar } \\
\text { precocemente os } \\
\text { problemas }\end{array}$ & $\begin{array}{l}\text {... porque, por exemplo, quando se tem um caso de uma doença crônica, você não } \\
\text { fica segurando o caso com você encaminha para o especialista e o especialista } \\
\text { intervém, porque aquilo é a área dele. Acho que é a mesma coisa na área da higiene } \\
\text { mental, você saber detectar precocemente onde é que estão os problemas, saber até } \\
\text { onde eu como pediatra posso agir, então onde nåo devo mais me meter... } \\
\text {... eu acho que ele (o pediatra) é importante na hora de detectar, de descobrir que } \\
\text { existe um problema e de que forma estar encaminhando melhor essa criança (...) não } \\
\text { é a função dele estar, estar fazendo toda esse... ã... o acompanhamento, o } \\
\text { tratamento, não... }\end{array}$ \\
\hline
\end{tabular}




\section{POEMA ENJOADINHO}

Filhos... Filhos?

Melhor não tê-los!

Mas se não os temos

Como sabê-lo?

Se não os temos

Que de consulta

Quanto silêncio

Como os queremos!

Banhos de mar

Diz que é um porrete...

Cônjuge voa

Transpõe o espaço

Engole água

Fica salgada

Se iodifica

Depois, que boa

Que morenaço

Que a esposa fica!

Resultado: filho.

E então começa

A aporrinhação:

Cocô está branco

Cocô está preto

Bebe amoníaco

Comeu botão.
Filhos? Filhos

Melhor não tê-los

Noites de insônia

Cãs prematuras

Prantos convulsos

Meu Deus, salvai-o!

Filhos são o demo

Melhor não tê-los...

Mas se não os temos

Como sabê-lo?

Como saber

Que maciez

Nos seus cabelos

Que cheiro morno

Na sua carne

Que gosto doce

Na sua boca!

Chupam gilete

Bebem xampu

Ateiam fogo

No quarteirão

Porém, que coisa

Que coisa louca

Que coisa linda

Que os filhos são!

Vinícius de Moraes 


\section{CONCLUSÕES E COMENTÁRIOS FINAIS}

A presente pesquisa buscou avaliar como o atendimento rotineiro das crianças na faixa etária de cinco anos a 11 anos e 11 meses, pelos pediatras da atenção básica, enfoca os problemas de saúde mental (PSM). Para tanto, lançou mão de diversas fontes de evidências: análise de prontuários, utilização de questionário padronizado e entrevistas, visando abordar a questão de ângulos distintos e permitir uma triangulação das informações obtidas.

Este estudo encontrou que os pediatras apresentam baixa sensibilidade para reconhecer Problemas de Saúde Mental em crianças da faixa etária estudada atendidas em um Centro de Saúde da região urbana do município de São Paulo. Esta baixa capacidade de reconhecimento dos PSM pelos pediatras é bastante semelhante à encontrada por outros autores na literatura (BRIGGS-GOWAN e col. 2000; COSTELLO e col. 1988b; GARRALDA e BAILEY 1986; GIEL e col. 1981), indicando a dificuldade destes profissionais nessa área específica, mesmo considerando as diferenças de contexto social.

O levantamento realizado em 411 prontuários, correspondente a todas as crianças de cinco anos a 11 anos e 11 meses com consulta agendada de 01/08/00 a 31/10/00, mostrou que os pediatras fizeram hipóteses diagnósticas do capítulo $V$ da CID-10 (Transtornos Mentais e Comportamentais) em 72 crianças, que representavam $17,5 \%$ do total dos prontuários analisados.

Este trabalho utilizou o CBCL ("Child Behavior Checklist') para a deteç̧ão de casos com diagnóstico provável de transtorno mental e comparou esses achados às hipóteses diagnósticas anotadas nos prontuários. Assim, do total de 411 crianças pesquisadas, foram realizadas 206 entrevistas com o $\mathrm{CBCL}$, nas quais foram encontradas 130 crianças 
com escore clínico. Dentre as 130 crianças com escore clínico do CBCL, os pediatras identificaram como portadoras de PSM apenas 33 crianças $(25,3 \%)$; as outras 97 crianças com escore clínico não foram detectadas pelos médicos.

Ao analisar o conjunto de hipóteses diagnósticas de PSM realizadas pelos pediatras, foi possivel identificar as seguintes caracteristicas:

- Hipóteses diagnósticas de PSM relacionadas à área dos transtornos especificos do desenvolvimento (linguagem, por exemplo) ou à área somática (enurese, bruxismo) são mais comumente realizadas durante as consultas pediátricas, indicando maior facilidade na identificação destes diagnósticos.

- Chama atenção não haver hipóteses diagnósticas de transtornos ansiosos nem depressivos, que na literatura internacional correspondem a uma prevalência média, nesta faixa etária, de aproximadamente 10,0\% (COSTELLO 1989b; GOODMAN e SCOTT 1997; CASSIDY e JELLINEK 1998).

- A hipótese diagnóstica de transtorno hipercinético também é pouco utilizada, tendo sido feita em apenas três casos $(0,7 \%)$. Estudos nacionais e internacionais apontam uma prevalência destes transtornos de 1,0\% a 3,0\% (GOODMAN e SCOTT 1997). Um aspecto importante é que existe uma "descrença" neste diagnóstico, como se este fosse um construto teórico da literatura internacional, principalmente a norte-americana, não aplicável às nossas crianças.

- A hipótese diagnóstica de distúrbio de conduta não é utilizada segundo as normas preconizadas pela CID-10. Parece mais uma hipótese diagnóstica genérica de qualquer problema na área do comportamento ou, em outros casos, hipótese diagnóstica que remete aos distúrbios reativos de conduta 
segundo critérios diagnósticos de classificações não mais utilizadas.

É importante ressaltar que o $\mathrm{CBCL}$ não faz diagnósticos definitivos de transtornos mentais. Seu escore clínico apenas aponta um diagnóstico provável (presença de sintomas), o que explica, em parte, a alta percentagem de casos clínicos detectados por este instrumento. Este questionário foi utilizado justamente porque tem alta sensibilidade como poder-se-ia desejar da consulta pediátrica. O papel do pediatra, apontado nas entrevistas, de fazer psicoprofilaxia, prevenção e diagnóstico precoce exige a predisposição de captar sintomas sutis ou iniciais das patologias para que sua intervenção possa ser efetiva. Este aspecto aponta para um paradoxo pois, apesar de presente nas falas, esta predisposição não aparece na prática.

Estudando a preocupação dos pais em relação aos PSM dos filhos, foi encontrada associação positiva significativa entre escore clínico do $\mathrm{CBCL}$ e preocupação dos pais, indicando boa sensibilidade dos pais em relação à presença de sintomas de PSM nos filhos. Por outro lado, a presença de preocupação dos pais não aumenta a capacidade de diagnóstico de PSM pelos pediatras, o que aponta para problemas de troca de informações entre os pais e os pediatras, ou desvalorização das queixas explicitadas durante a consulta.

A conduta mais freqüente do pediatra anotada nos prontuários frente aos problemas detectados foi a orientação $(23,6 \%)$. Foram encaminhadas para serviços de saúde mental seis crianças. Uma já estava em acompanhamento. Supondo que as crianças encaminhadas seriam, de fato, atendidas nos serviços especializados, $1,7 \%$ do total das crianças estudadas recebiam ou estavam para receber assistência especializada em saúde mental. Também vale ressaltar que, dentre as 72 crianças com hipótese diagnóstica de PSM feita pelo pediatra, $21(29,2 \%)$ ficaram sem nenhum tipo de conduta registrada no prontuário, o que poderia estar indicando deficiência na formação profissional ou carências do próprio serviço. 
Vários aspectos apontaram para deficiências na formação dos pediatras para o enfrentamento das questōes de saúde mental. As deficiências estão presentes desde a formação básica (Faculdade de Medicina), onde os aspectos psicológicos e emocionais da prática médica são relegados a um segundo plano. Por outro lado, as tecnologias de intervenção frente aos problemas detectados privilegiam medicamentos e intervenções "armadas", e valorizam pouco outros tipos de abordagens. A questão da linguagem diversa das áreas "psi" também foi citada como problema, mas possivel de ser contornado por aproximações sucessivas de ambas as partes, desde que intencionalmente planejadas para tal fim.

Durante a residência médica de pediatria estas questões da formação profissional se acentuam. A avaliação do desenvolvimento, próxima da área da saúde mental e tão importante na Pediatria (poder-se-ia dizer um dos fundamentos da especialidade), privilegia as áreas motoras (marcos básicos das fases iniciais da infância). Na idade escolar alguma ênfase é dada ao aspecto cognitivo, via questōes escolares, porém com pouca precisão na avaliação e baixa capacidade de intervenção. Em relação aos aspectos emocionais há um grande vazio, identificado pelo baixo registro nos prontuários; mesmo quando há queixa explícita na consulta nota-se que ela é "esvaziada" durante o atendimento.

Um aspecto interessante citado nas entrevistas é que a sensibilidade para detecção dos PSM seria "inato" no profissional, isto é, a priori alguns seriam capazes de fazê-la e outros não, o que pode levar a uma idéia pessimista de que não é possivel fazer nada para melhorar este tipo de atuação.

A organização do processo de trabalho dos médicos também foi apontada como obstáculo para a detecção destes problemas. Duas foram as principais justificativas levantadas: o curto tempo das consultas (apesar disto não ser problema na prática cotidiana do CSE Butantã) e a falta de profissionais especializados (ou equipes multiprofissionais) que pudessem servir de retaguarda no caso de dificuldades durante o atendimento. 
A falta de instrumentos que facilitem a deteç̧ão dos sintomas na área do desenvolvimento emocional e da saúde mental, e que permitam a realização de avaliações mais precisas (em analogia com a curva padronizada para alterações do crescimento, por exemplo), também pode dificultar este tipo de abordagem. Muitas vezes o profissional percebe que algo não está evoluindo bem mas, como não sabe avaliar adequadamente ou acha que não tem instrumentos para intervenção, acaba desvalorizando seu achado clínico ou apenas anotando no prontuário dados inespecíficos que não levam a uma intervenção efetiva.

O encaminhamento para serviços especializados também é visto como algo problemático, difícil, com baixo retorno e não confiável.

A reorganização dos serviços pode ajudar muito o médico, ou outro profissional que atenda crianças na atenção básica, no trabalho de detecção precoce das alterações na área de saúde mental. A proximidade de profissionais especializados pode enriquecer a prática diária tanto na forma de uma equipe multiprofissional atuante como na forma de apoio para discussão de casos. A questão da proximidade, tanto no espaço quanto no tempo, é importante pois aumenta a legitimidade do processo. A atuação no "aqui e agora" permite uma troca viva e eficiente de conhecimento pois, além de ser importante que o pediatra conheça questōes de saúde mental, é necessário que o profissional da saúde mental compreenda a pediatria e a forma de trabalhar do pediatra; é preciso um trabalho de parceria no qual nenhum dos dois lados se coloque como detentor de todo o conhecimento.

O conhecimento e a atitude do pediatra durante a consulta são fundamentais para levantar a suspeita diagnóstica de problemas na área do desenvolvimento e de saúde mental, observar a persistência das alterações e fazer o encaminhamento no momento oportuno, levando em conta sua estratégica posição no acompanhamento clínico periódico durante toda a infância. Dificilmente um profissional da área da saúde mental (psiquiatra infantil, psicólogo, terapeuta ocupacional, fonoaudiólogo ou outro) teria as mesmas condições de fazer diagnóstico precoce de patologias graves como 
transtornos globais do desenvolvimento, nos quais a intervenção precoce é de fundamental importância para o prognóstico.

Os profissionais que lidam com a infância precisam estar atualizados com as novas abordagens na área da psiquiatria infantil tanto na área do diagnóstico (as alterações nosográficas trazidas pela CID-10 e pelo DSM-IV) quanto na área das intervenções possíveis. Conhecer a gama das intervenções existentes e sua efetividade permite adequada orientação da família e melhor acompanhamento do caso.

Manter-se prudentemente entre o alarmismo ou a "psicologização" de variações da normalidade e o "deixa que com o tempo vai passar" com desvalorização do sofrimento psíquico da criança exige do profissional que trabalha com a infância, principalmente na atenção básica, conhecimento técnico, arte e sensibilidade, para que a detecção precoce seja efetiva.

Os resultados encontrados neste estudo apontam que as ações destinadas à melhoria da assistência à saúde mental da infância, na atenção básica, devem incluir mudanças na formação profissional do médico, otimizando sua capacidade de fazer diagnósticos precoces e encaminhamentos oportunos, e também possibilitar o aperfeiçoamento da organização do trabalho, tanto no atendimento em si como na articulação entre as várias instâncias do sistema de saúde.

Vale ressaltar que este estudo foi realizado em um Centro de Saúde Escola no qual trabalham profissionais altamente capacitados e que dispõem de condições para atividades de ensino e pesquisa. Desta forma, estes achados apontam para a necessidade de serem reavaliados o conteúdo e a forma das disciplinas relacionadas ao desenvolvimento e à saúde mental infantil, tanto nos currículos de graduação como nos de residência de pediatria. Em relação à forma, é importante que a linguagem utilizada seja adequada e compreensivel para os alunos, evitando-se falas muitos especializadas que possam induzir a mal-entendidos ou mesmo 
brincadeiras e chacotas, não redundando em aprendizagem ou até suscitando posições de aversão ao tema. 
Depois fugiu para o sol E desceu pelo primeiro raio que apanhou. Hoje vive na minha aldeia comigo. É uma criança bonita de riso e natural.

Limpa o nariz ao braço direito. Chapinha nas poças de água, Colhe as flores e gosta delas e esquece-as. Atira pedras aos burros, Rouba a fruta dos pomares $E$ foge a chorar e a gritar dos cães. $E$, porque sabe que elas não gostam E que toda a gente acha graça, Corre atrás das raparigas Que vão em ranchos pelas estradas Com as bilhas às cabeças E levanta-lhes as saias.

A mim ensinou-me tudo.

Ensinou-me a olhar para as coisas. Aponta-me todas as coisas que há nas flores. Mostra-me como as pedras são engraçadas

Quando a gente as tem na mão

E olha devagar para elas. (excerto)

Fernando Pessoa

\section{REFERÊNCIAS}




\section{REFERÊNCIAS}

Achenbach TM, Edelbrock CS. Behavioral problems and competencies reported by parents of normal and disturbed children aged four to sixteen. Monographs of Society for Research in Children Development 46 (serial n. ${ }^{\circ} 188$ ); 1981.

Achenbach TM. Manual for the Child Behavior Checklist/4-18 and 1991 profile. Burlington, VT: University of Vermont, Department of Psychiatry: 1991.

Achenbach TM. Empirically based taxonomy: How to use syndromes and profile types derived from CBCL/4-18, TRF and YSR. Burlington, VT: University of Vermont, Department of Psychiatry: 1993.

Achenbach TM. Assesment Data Manager $\left(\mathrm{ADM}^{\circledR}\right)$ Achenbach System of Empirically Based Assessment (ASEBA ${ }^{\circledR}$ ) - CBCL (Child Behavior Checklist). [computer program]. Version1.10. Vermont; 1999.

Almeida Filho N. Estudo de prevalência de desordens mentais na infância em uma zona urbana de Salvador. J Bras Psiquiatr 1982; 31: 114554.

Almeida Filho N. Epidemiologia das doenças mentais na infância. Salvador, Centro Editorial e Didático da Universidade da Bahia, 1985.

Almeida Filho N, Mari JJ, Coutinho E, França JF, Fernandes JG, Andreoli $B$, Busnello $D$. Estudo multicêntrico de morbidade psiquiátrica em áreas urbanas brasileiras (Brasília, São Paulo e Porto Alegre). Revista ABP. APAL 1992; 14: 93-104.

Almeida Filho N, Rouquayrol $M Z$. Introdução à epidemiologia moderna. $2^{a}$ ed. Belo Horizonte: COOMED/APCE/ABRASCO, 1992. 
American Psychiatric Association. Diagnostic and Statistical Manual of Mental Disorders. Fourth edition. Washington, DC: American Psychiatric Association, 1994.

Andrade LHS, Gentil Filho V, Lólio CA, Laurenti R. Epidemiologia dos transtornos mentais em uma área definida de captação da cidade de São Paulo, Brasil. In: Organização Mundial de Saúde/Divisão de Saúde Mental e Prevenção de Toxicomanias. O uso racional de medicamentos psiquiátricos. [Relatório do encontro dos centros colaboradores da OMS no Brasil para o ensino e pesquisa em saúde mental; Rio de Janeiro 22-23 de novembro de 1997]. Genebra,1998. p. $37-41$.

Andrade SMO. A avaliação qualitativa sob a perspectiva do interacionismo simbólico: o caso da AIDS. São Paulo; 2002. [Tese de Doutorado - Faculdade de Saúde Pública da USP].

Assumpção Jr FB. Psiquiatria infantil brasileira: um esboço histórico. São Paulo: Lemos Editorial; 1995.

Bailey D, Garralda ME. Referral to child psychiatry: parent and doctor motives and expectations. J Child Psychol Psychiat 1989; 30(3): 44958.

Bardin L. Análise de conteúdo. Lisboa: Edições 70; 1977.

Barkley RA Child behavior rating scales and checklists. In: Rutter M, Tuma $\mathrm{AH}$, Lann IS. Assessment and diagnosis in child psychopathology. New York: The Guilford Press; 1988. p. 113-55.

Bilenberg $N$. The child behavior checklist (CBCL) and related material: standardization and validation in Danish population based and clinically based samples. Acta Psychiatr Scand 1999; 100 (Suppl): 2-52.

Bird HR. Epidemiology of childhood mental disorders in a cross-cultural context. J Child Psychol Psychiat 1996; 37: 35-49.

Bordin IAS, Mari JJ, Caeiro MF. Validação de versão brasileira do "Child Behavior Checklist" (CBCL) (Inventário de comportamentos da infância 
e adolescência): dados preliminares. Revista ABP-APAL 1995; 17: 5566.

Bralio SE, Seguel XR, Montenegro HA. Prevalência de transtornos psiquicos en la poblacion escolar de Santiago de Chile. Acta Psiquiatr Psicol Am Lat 1987; 33: 316-25.

Brandenburg NA, Friedmen R, Silver SE. The epidemiology of childhood psychiatric disorders: prevalence findings from recent studies. J Am Acad Chid Adolesc Psychiatry 1990; 29: 76-83.

Briggs-Gowan MJ, Horwitz SM, Schwab-Stone ME, Leventhal JM, Leaf PJ. Mental health in pediatric setting: distribution of disorders and factors related to service use. J Am Acad Chid Adolesc Psychiatry 2000; 39: 841:49.

Cantwell DP, Rutter M. Classification: conceptual issues and substantive findings. In: Rutter M; Taylor $E$; Hersov I, ediitors. Child and adolescent psychiatry: modern approaches. 3rd ed. Oxford: Blackwell Science; 1994. p. 3-21.

Cantwell DP. Psiquiatria infantil: introdução e panorama. In: Kaplan HI e Sadock BJ, editores. Tratado de psiquiatria. Trad. D Batista. $6^{a}$ ed. Porto Alegre: Artes Médicas Sul Ltda; 1999. p. 2345.

Carvalheiro JR. Levantamento de condiçōes de saúde por entrevistas domiciliares. Ribeirão Preto; 1975 [Tese de Livre-Docência Faculdade de Medicina de Ribeirão Preto da USP].

Cassidy LJ, Jellinek MS. Approaches to recognition and management of childhood psychiatric disorders in pediatric primary care. Pediatr Clin North Am 1998; 45(5): 1037-52.

Chang G, Warner V, Weissman MM. Physicians' recognition of psychiatric disorsders in children and adolescent. AJDC 1988; 142: 736-9.

Chiesa AM. A eqüidade como princípio norteador da identificação de necessidades relativas ao controle dos agravos respiratórios na 
infância. São Paulo; 1999. [Tese de Doutorado - Faculdade de Saúde Pública da USP].

Costello EJ. Primary care pediatrics and child psychopathology: a review of diagnostic, treatment and referral practices. Pediatrics 1986; 78(6): 1044-51.

Costello EJ, Burns BJ, Costello AJ, Edelbrock C, Dulcan M, Brent D. Service utilization and psychiatric diagnosis in pediatric primary care: the role of gatekeeper. Pediatrics 1988(a); 82: 435-41.

Costello EJ, Edelbrock C, Costello AJ, Dulcan M, Burns B, Brent D. Psychopathology in pediatric primary care: the new hidden morbidity. Pediatrics 1988(b); 82:415-2.

Costello EJ. Child psychiatric disorders and their correlates: a primary care pediatric sample. J Am Acad Chid Adolesc Psychiatry 1989(a); 29: 851-5.

Costello EJ. Developments in child psychiatric epidemioloy. J Am Acad Chid Adolesc Psychiatry 1989(b); 29: 836-41.

Denzin NK. Interpretive interactionism. Newboury Park: SAGE Publications, Inc; 1989.

Diaz RF Psicanálise e instituição. [Texto realizado para a Mesa Redonda intitulada "Psicanálise e Instituição" promovida pela Escrita Freudiana; 1991 jun 20].

Duarte CS. Características de personalidade de mães de crianças com diagnóstico de autismo infantil: um estudo comparativo. São Paulo; 2000. [Tese de Doutorado - Escola Paulista de Medicina da UNIFESP].

Duarte CS, Bordin IAS. Instrumentos de avaliação. Rev Bras Psiquiatr 2000; 22(Supl II):55-8.

Dulcan M, Costello EJ, Costello AJ, Edelbrock C, Brent D, Janiszewiski S. The pediatrician as gatekeeper to mental health care for children: do 
parents' concerns open the gate? J Am Acad Child Adolesc Psychiatry 1990; 29:453-58.

Fleitlich BW, Goodman R. Epidemiologia. Rev Bras Psiquiatr 2000; 22(Supl II):2-6.

Fleitlich BW, Goodman R. Social factors associated with child mental health problems in Brazil: cross sectional survey. BMJ 2001; 323: 599600 .

Fontana $A$, Frey $\mathrm{JH}$. The interview: from structured questions to negotiated text. In: Denzin NK, Lincoln YS. Ed. The handbook of qualitative research. $2^{\text {nd }}$. ed. Thousand Oaks: Sage Publications; 2000.

Fundação IBGE. Contagem populacional. Região Metropolitana da Grande São Paulo [CD-ROM]. Rio de Janeiro; 1996.

Fundação IBGE. Censo demográfico 2000 - resultados do universo (São Paulo; São Paulo) [CD-ROM]. Rio de Janeiro; 2002.

Garralda ME, Bailey D. Children with psychiatric disorders in primary care. J Child Psychol Psychiat 1986; 27: 611-24.

Garralda ME, Bailey D. Child and family factors associated with referral to child psychiatrist. Brit J Psychiatry 1988; 153: 81-9.

Giel R, Arango MV, Climent CE, Harding TW, Ibrahim HA, Ladrigo-Ignacio L, Srinivasa Murthy R, Salazar MC, Wig NN, Younis YOA. Childhood mental disorders in primary health care: results of observations in four developing countries. Pediatrics 1981; 68: 677-83.

Giordano Jr S, Pereira LMF. Saúde mental. In: Schraiber e col. organizadores. Saúde do adulto: programas e ações na unidade básica. São Paulo: Hucitec; 1996.

Glascoe FP, Dworkin HD. The role of parents in the detection of developmental and behavioral problems. Pediatrics 1995; 95(6): 82936. 
Goldberg D, Huxley P. Mental illness in the community - the pathway to psychiatric care. London: Tavistock Publications Ltd, 1980.

Goldberg D. Epidemilogy of mental disorders in primary care settings. Epidemiol Rev 1995;17:182-90.

Goodman R. The strengths and difficulties questionnaire: a research note. J Child Psychol Psychiat 1997; 38(5): 581-6.

Goodman R, Scott S. Child Psychiatry. Oxford: Blackwell Science; 1997.

Goodman R. The extended version of the strengths and difficulties questionnaire as a guide to child psychiatric caseness and consequent burden. J Child Psychol Psychiat 1999; 40(5): 791-9.

Goodman R, Scott S. Comparing the Strenghts and Difficulties Questionnaire and the Child Behavior Checklist: is small beautiful? J Abnorm Child Psychol 1999; 27: 17-24.

Goodman R. The strengths and difficulties questionnaire [documento on line] 2000; disponível em <http://www.sdqinfo.com>.

Goodman R, Ford T, Simmons H, Gatward R, Meltzer H. Using the Strengths and Difficulties Questionnaire (SDQ) to screen for psychiatric disorders in a community sample. Bristish Journal of Psychiatry 2000; 177: 534-9.

Goodman R. Psychometric properties of the strengths and difficulties questionnaire. J Am Acad Child Adolesc Psychiatry 2001; 40(11): 1337-45.

Horwitz SM, Leaf PJ, Leventhal JM, Forsyth B, Speechley KN. Identication and management of psychosocial and developmental problems in community-based, primary care pediatric practices. Pediatrics 1992; 89(3): $480-5$.

Lauridsen EPPL. Atenção à saúde mental infantil: um desafio às praticas de saúde - um olhar epidemiológico. São Paulo; 1998. [Dissertação de Mestrado - Faculdade de Saúde Pública da USP]. 
Lavigne LV, Binns HJ, Christoffel KK, Rosenbaun D, Arend R, Smith K, Hayford JR, Mcguire PA. Behavioral and emotional problems among preschool children in pediatric primary care: prevalence and pediatricians' recognition. Pediatrics 1993; 91:649-55.

Lebrão ML. Estudos de morbidade. São Paulo: Edusp, 1997.

Lefèvre $\mathrm{F}$, Lefèvre AMC, Teixeira JJV. $\mathrm{O}$ discurso do sujeito coletivo: uma nova abordagem metodológica em pesquisa qualitativa. Caxias do Sul: EDUCS, 2000.

Lembcke PA. Evolution of the medical audit. JAMA 1967; 199: 543-50.

Leone C, Yamanoto RM, Mascaretti LAS, Valente MH, Terra VM, Leal MM, Douek PC, Gomes FMS, Santos JM. Pesquisa em assistência primária: instrumento de ensino-aprendizagem na residência básica de pediatria. Pediatria (São Paulo) 1995; 17(4): 165-9.

Marcelli D. Manual de psicopatologia da infância de Ajuriaguerra. $5^{\mathrm{a}}$ edição. Trad. de PC Ramos. Porto Alegre: ArtMed; 1998.

Marcondes E. Pediatria doutrina e ação. São Paulo: Sarvier; 1973.

Mascaretti LAS. O ensino de saúde escolar no Centro de Saúde Escola "Prof. Samuel B. Pessoa" da Faculdade de Medicna da USP Departamento de Pediatria. Pediatria (São Paulo) 1997; 19: 234-40.

Mascaretti LAS, Fahl K, Tenório PB. Morbidade em escolares (1996) Centro de Saúde Escola "Prof. Samuel B. Pessoa"- Departamento de Pediatria da Faculdade de Medicina da Universidade de São Paulo. Pediatria (São Paulo) 1998; 20:75-82.

Merhy EE, Chakkour M, Stéfano E, Stéfano ME, Santos CM, Rodrigues RA, Oliveira PCP. Em busca de ferramentas analisadoras das tecnologias em saúde: a informação e o dia a dia de um serviço. Interrogando e gerindo trabalho em saúde. In Merhy EE, Onoko $R$ organizadores. Agir em saúde: um desafio para o público. $2^{a}$ ed. São Paulo: Hucitec, 2002. 
Minayo MCS, Sanches O. Quantitativo-qualitativo: oposição ou complementaridade. Cad Saúde Pública 1993; 9(3): 239-48.

Minayo MCS. O desafio do conhecimento: pesquisa qualitativa em saúde. $3^{\mathrm{a}}$ ed. São Paulo:Hucitec-Abrasco; 1994.

Ministério da Saúde. Assistência integral à saúde da criança: açōes básicas. Brasília, Centro de documentação do Ministério da Saúde, 1984.

Offord DR, Fleming JE. Epidemiology. In: Lewis $M$, ed. Child and adolescent psychiatry: a compreensive textbook. 2nd ed. Baltimore, Willians \& Wilkins, 1996. p. 1166-78.

OPAS/OMS. Relatório sobre a saúde no mundo - 2001 - Saúde mental: nova concepção, nova esperança. Genebra: 2001.

Organization Mundial de la Salud. La introducción de un componente de salud mental en la atención primaria. Ginebra: 1990.

Organização Mundial da Saúde. CID-10 Classificação estatística internacional de doenças e problemas relacionados à saúde. Trad. Centro Colaborador da OMS para a Classificação de Doenças em Português. $8^{\circ}$ ed. São Paulo: Editora da Universidade de São Paulo; 2000.

Patton MQ. Qualitative evaluation and research methods. $2^{\text {nd }}$ ed. Newbury Park: Sage Publications; 1990.

Pavuluri MN, Attikisson CC, Rosenblatt A. Help-seeking for behavior prolems by parents of preschool children: a community study. J Am Acad Chid Adolesc Psychiatry 1995; 35: 215-22.

Pedreira JL, Sánchez B. Sardineiro E, Martín L, Martín P. Aplicación del método epidemiológico para la detección de transtornos mentales en la infancia y la adolescencia. In: Revuelta JLGR, Pulido FR, López AS.EI método epidemiológico en salud mental. Barcelona: Masson; 1993. p. 215-38. 
Pickles A, Rowe R, Siminoff E, Foley D, Rutter M, Silberg J. Child psychiatric symptons and psychosocial impairment: relationship and prognostic significance. Brit J Psychiatry 2001; 179: 230-35.

Regier DA, Burke JD. Métodos quantitativos e experimentais em psiquiatria. In: Kaplan HI, Sadock BJ. Tratado de psiquiatria. Trad. Andrea Callef e col. $6^{2}$ ed. Porto Alegre; Artmed; 1999. p. 424-44.

Roberts ER, Attkisson CC, Rosenblatt A. Prevalence of psychopathology among children and adolescents. Am J Psychiatry 1998; 155: 715-25.

Robins CLN, Regier DA ed. Psychiatric disorders in América: the epidemiologic catchment area study. New York: Maxwell Macmillan International; 1991.

Rutter M, Tizard J, Whitmore K. Education, health and behaviour: a psychological and medical study of childhood development. London: Longman; 1970.

Rutter M. Epidemiological approaches to developmental psychopatholgy. Arch Gen Psychiatry 1988; 45: 486-95.

Rutter M. Isle of Wight revisited. Twenty-five years of child psychiatric epidemiology. J Am Acad Chid Adolesc Psychiatry 1989; 28: 633-53.

Rutter M. Psychosocial adversity and child psychopathology. Bristish Journal of Psychiatry 1999; 174: 480-93.

Sala A, Kon R. Informações sócio-econômicas de usuários em centro de saúde: perfis de vida e uso de serviço. In: $O$ sujeito na saúde coletiva - VI Congresso Brasileiro de Saúde Coletiva [CD-ROM]. 2000.

Saraceno B, Asioli A, Tognoni G. Manual de saúde mental. São Paulo: Ed. Hucitec; 1994.

Satorius N, Graham P. Child mental health: experience of eight countries. WHO Chronicle 1984; 38: 208-11. 
Schraiber LB. Pesquisa qualitativa em saúde: reflexões metodológicas do relato oral e produção de narrativas em estudo sobre a profissão médica. Rev Saúde Pública 1995; 29(1): 63-74.

Shaffer D, Fisher P, Dulcan M, Davies M, Piacentini J, Schwab-Stone M, Lahey BB, Bourdon K, Jensen PS, Bird HR, Canino G, Regier DA. The NIMH diagnostic interview schedule for children version 2.3 (DISC-2.3): descrition, acceptability, prevalence rate and performance in the MECA study. J Am Acad Chid Adolesc Psychiatry 1996; 35: 865-77.

Sharp L, Pantell RH, Murphy LO, Lewis CC. Psychosocial problems during child health supervision visits: eliciting, then what? Pediatrics 1992; 89(4): 619-23.

Spink MJ, Gimenes MGG. Práticas discursivas e produção de sentido: apontamentos metodológicos para a análise de discursos sobre a saúde e a doença. Saúde e Sociedade 1994; 3(2): 149-71.

Spink MJ (Org). Práticas discursivas e produção dos sentidos no cotidiano - aproximações teóricas metodológicas. 2 a ed. São Paulo: Cortez; 2000.

Spink MJ, Medrado B. Produção dos sentidos no cotidiano: uma abordagem teórico-metodológica para análise das práticas discursivas. In: Spink MJ (Org.). Práticas discursivas e produção dos sentidos no cotidiano - aproximaçōes teóricas metodológicas. $2^{a}$ ed. São Paulo: Cortez; 2000. p. 41-62.

Spink MJ, Menegon BVM. A pesquisa como prática discursiva: superando os horrores metodológicos. In: Spink MJ (Org.). Práticas discursivas e produção dos sentidos no cotidiano - aproximações teóricas metodológicas. $2^{a}$ ed. São Paulo: Cortez; 2000. p. 63-92.

Spink MJ, Lima H. Rigor e visibilidade: a explicitação dos passos da pesquisa. In: Spink MJ (Org.). Práticas discursivas e produção dos sentidos no cotidiano - aproximações teóricas metodológicas. $2^{\text {a }}$ ed. São Paulo: Cortez; 2000. p. 93-122. 
SPSS $^{\circledR}$ Inc. SPSS ${ }^{\circledast}$ for Windows ${ }^{\circledR}$ - Statistical Package for Social Science. [computer program]. Release 9.00 (18 Dec 1998). Standard Version; 1999.

Tanaka OY. Análise da utilização dos serviços do posto de assistência médica e do pronto atendimento do Jardim São Jorge no município de São Paulo, por meio de estudo da clientela usuária. São Paulo; 1988 [Tese de Doutoramento - Faculdade de Saúde Pública da USP].

Tanaka OY, Melo C. Avaliação de programas de saúde do adolescente: um modo de fazer. São Paulo: Editora da Universidade de São Paulo; 2001.

Tanaka OY, Melo C. Inovação e gestão - a organização social no setor saúde. São Paulo: Annablume/Fapesp; 2002.

Triviños ANS. Introdução à pesquisa en ciências sociais - a pesquisa qualitativa em educação. São Paulo: Editora Atlas S. A.; 1987.

Yin RK. Case study research - design and methods. $2^{\text {nd }}$ ed. Thousand Oaks: Sage Publications; 1994. 
ANEXO 1

FORMULÁRIO PARA REVISÃO DO PRONTUÁRIO 


\section{QUESTIONÁRIO PARA ANÁLISE DO PRONTUÁRIO}

Número de ordem:

Número do prontuário:

Nome:

Idade:

Data de nasc.: .................. Sexo: masc. fem.

Data da consulta:

Tipo cons.: CN Ret CNEsc RetEsc

Nome da mãe:

Nome do pai:

\section{Queixas/motivos da consulta:}

1.

2.

3.

4.

5.

6.

Sono:

Relacionamento Familiar:

DNPM:

\section{OBSERVAÇÕES:}




\section{Diagnósticos realizados:}

1. NUTRICIONAL: eutrófico distrófico

2. CRESCIMENTO: adequado inadequado

3. DNPM: normal atrasado

4. ALIMENTAR: adequado inadequado

5. ESCOLARIDADE: adequada atrasada não se aplica

6. SINAIS PUBERTÁRIOS: presentes ausentes não se aplica

7. EDUCAÇÃO SEXUAL: presente ausente não se aplica

8. VACINAÇÃO: completa incompleta

9. SITUAÇÃO SÓCIO-ECONÔMICA: adequada inadequada não se aplica

10. AMBIENTE Físico: adequado inadequado

11. LAZER: presente ausente não se aplica

12. AMBIENTE EMOCIONAL: adequado inadequado

13. DISTÚRBIOS DE FALAAUDIÇÃONISÃO: presente ausente não se aplica DRI:

14.

15.

\section{OUTROS DIAGNÓSTICOS:}

16.

17.

18.

19.

20

\section{Condutas:}

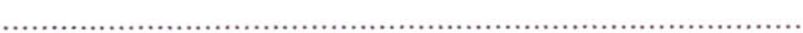
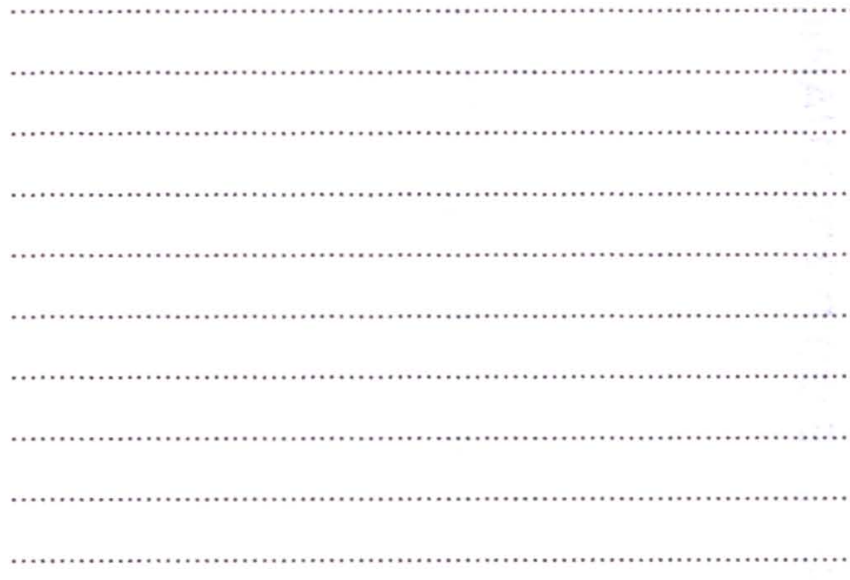

\section{EXAMES PEDIDOS:}

\section{ENCAMINHAMENTOS:}

Parte integrante do projeto de pesquisa: "O PAPEL DA ATENÇÃO PRIMÁRIA NA DETECÇÃO E ENCAMINHAMENTO DOS TRANSTORNOS MENTAIS NA CRIANÇA EM IDADE ESCOLAR". E Lauridsen, 2000; Departamento de Saúde Materno-Infantil, Faculdade de Saúde Pública - USP. 
ANEXO 2

FORMULÁRIOS DAS CONSULTAS DO CSE BUTANTÃ 


\begin{tabular}{|c|c|}
\hline \multirow{5}{*}{ CSE SAMUEL B. PESSOA } & Tipo de Consulta: \\
\hline & Pediatria/Programa : SAÚDE DA CRIANCAA \\
\hline & Tipo Profissional: \\
\hline & IDADE \\
\hline & ALTURA \\
\hline NOME & MATRICULA \\
\hline NFORMANTE ( parentesso): & PERIOODO: \\
\hline \multicolumn{2}{|l|}{ PRE-CONSULTA: } \\
\hline \multicolumn{2}{|l|}{ MOTTVO DA CONSULTA (HMA): } \\
\hline \multicolumn{2}{|c|}{$\begin{array}{l}\text { ISDA GERAL E ESPECIFICO ( APARELHOS: Digestivo, Respiratório, Cardio-Vascular, Locomotor, Genito- } \\
\text { Urinário, Nervoso, Pele e Anexos): }\end{array}$} \\
\hline I-ANTECEDEN? & TES \\
\hline \multicolumn{2}{|l|}{ A. FAMILLARES/ HEREDITÁRIOS } \\
\hline \multirow{2}{*}{\multicolumn{2}{|c|}{ 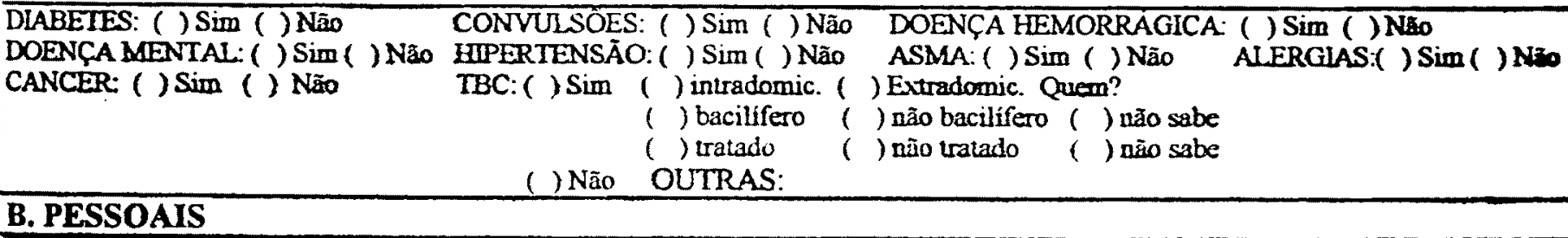 }} \\
\hline & \\
\hline \multicolumn{2}{|l|}{ B.1 PERINATALS: CONCEPGÃO, GESTAGÃO, PARTOE NASCIMENTO: } \\
\hline \multicolumn{2}{|c|}{$\begin{array}{l}\text { PESO NASC: } \\
\text { INTERCORRENCIAS NO BLTURA NASC: _ cm DARIO: }\end{array}$} \\
\hline \multicolumn{2}{|c|}{ B.2 MÓRBIDOS (Doenças, intermação, acidentes, cirurgias): ___ _ _ ALTA:___ DIAS _ } \\
\hline \multicolumn{2}{|c|}{$\begin{array}{l}\text { B.3 ALMMERTARES: } \\
\text { B.3.1. RECEBEU LEITE MATERNO AO NASCIMENTO? ( ) SIM ( ) NÃO MOTIVO: }\end{array}$} \\
\hline B.3.2. DESMAME (idade em dias) $:$ & $\begin{array}{l}\text { B.3.3. INICIO DA OFERTA DE OUTROS ALIMENTOS: REFEIÇÃO DE SAL: } \\
\text { OUTROS: }\end{array}$ \\
\hline \multicolumn{2}{|l|}{ OUTROS: } \\
\hline \multicolumn{2}{|c|}{ B.4 DNPM pregresso e atual ( motor, linguagem, pessoal-social e adaptativo): } \\
\hline \multicolumn{2}{|c|}{ II - CONDICÓEES ATUAIS de VIDA } \\
\hline \multicolumn{2}{|l|}{ A.HABITAÇÃO } \\
\hline 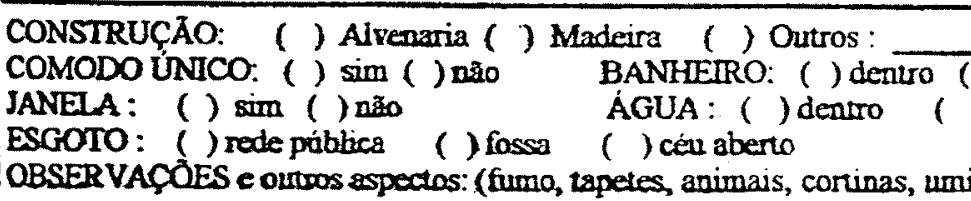 & 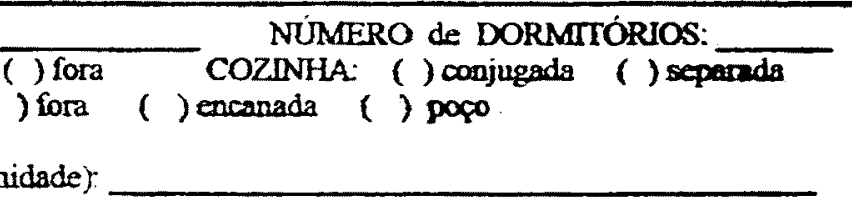 \\
\hline
\end{tabular}




\section{B. DINÁMICA FAMILIAR e SÓCIO-ECONÓMICO-CULTURAL \\ B. 1. COMPOSIÇÃO FAMLLIAR: ( $n^{\circ}$ de pessoas na casa, idade/saúde dos pais, irmãos e agregados)}

\section{B.2. RELACIONAMENTO FAMILIAR:}

R. ESCOLARIDADE dos PAIS ( $n^{\circ}$ de anos cursados e ultima série cursada):

PAI

$M \bar{A} \bar{E}$ anos

anos

série

B. $\div$ OCUPAÇÃO dos PAIS:

PAl (tipo de ocupação):

classificação: Eautônomo empregado desempregado patrão -aposentado I nào se aplica

MÄE (tipo de ocupação):

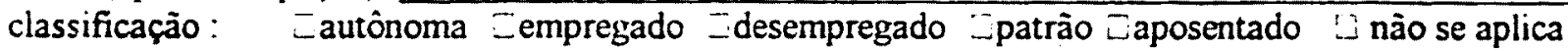

3.5. RENDA ( salários minimos):

FAMILIAR:

RENDA per capta:

\section{ALIMENTAÇÃO}

\section{C.1. TIPO DE ALEITAMENTO ATUAL:}

1( ) Aleitamento Materno Exclusivo

( com vitaminas,gts,xaropes, sais minerais)

2 ( ) Aleitamento Matemo Predominante

( com água, suco, chá)

3 ( ) Aleitamento Misto ( L.M.+ L.A)

4 ( ) Aleitamento complementado SEM outros leites)

5 ( ) Aleitamento complementado COM outros leites ( L.M.+L.A. +alim. sólidos ou semi-sólidos)

6 ( ) Criança Desmamada

( < de 2 anos que não recebe leite materno)

7 ( ) NÃO SE APLICA

( $>$ de 2 anos que não recebe leite materno)

(L.M.+alim.sólidos ou semi-sólidos)

C.2. TIPO DE ALIMENTAÇÃO - DLA ALIMENTAR:

1' Refeição:

Intervalo:

Aimoso:

Lanche da tarde:

Jantar.

Lanche da noite

Leite ( tipo, técnica de preparo e administraçào, horários):

Carnes:__ Ovos:____ Vegetais:___ Massas ( pães, biscoitos e doces):

Refrigerantes: __ Frutas e Sucos:___ Complem.Vitam

OBS:

III - VACINAS (numero de doses aplicadas)

BCG:

SABIN:

DPT:

ANTI-SARAMPO

TRIPLICE VIRAL

dT:

OUTRAS

Teve reação a alguma vacina 


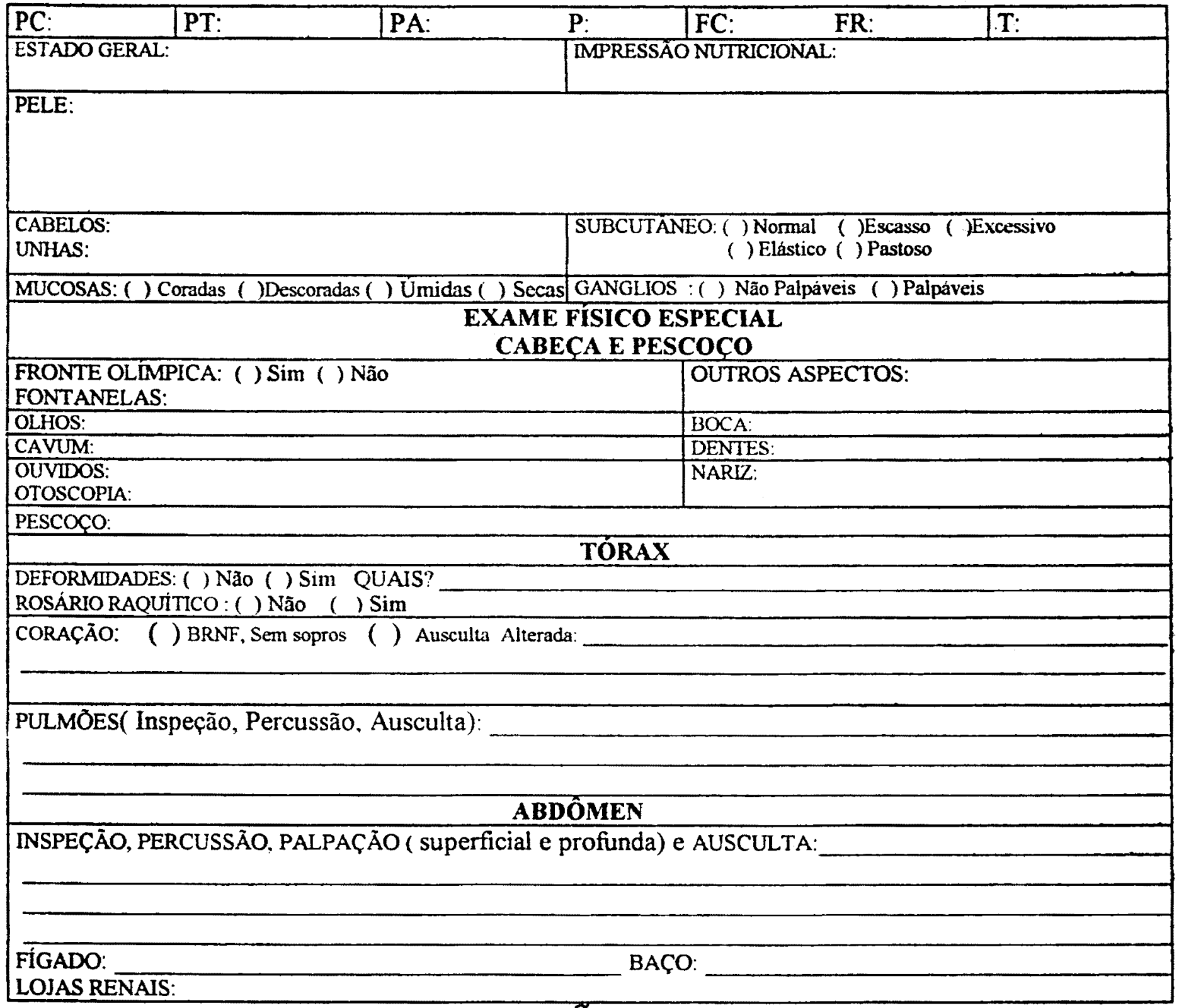

GENITAIS:

REGIẤO PERINEAL

PERÍNEO:

\section{MEMBROS}

DEFORMIDADES: ( ) Não ( ) Sim

ORTOLANI: ( ) Negativo ( ) Positivo ( ) NÃO SE APLICA

REFLEXOS: ( ) Normais QUAIS?

( ) Anormais QUAIS?

OUTROS DADOS RELEVANTES: 







\begin{tabular}{|c|c|}
\hline CSE SAMUEL B. PESSOA & 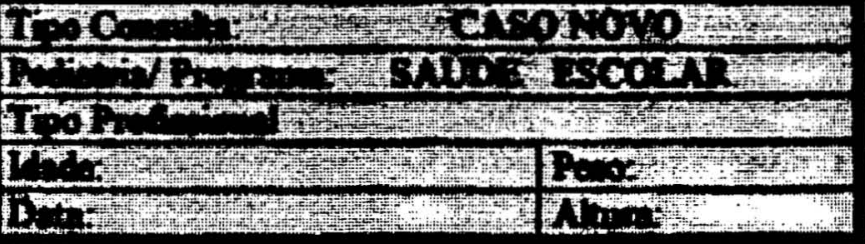 \\
\hline Pore & Matricula: \\
\hline $\begin{array}{l}\text { WORMANTE (parenteseo): } \\
\text { WE-CONSULTA: }\end{array}$ & PERTODO: \\
\hline \multicolumn{2}{|l|}{$\begin{array}{l}\text { DITHYO DA CONSULTA } \\
\text { WRAS: }\end{array}$} \\
\hline \multicolumn{2}{|c|}{ ISDA (investigar sobre dificuldades auditivas e ou viswais) } \\
\hline \multicolumn{2}{|l|}{ Antacedentes pré e peri-natais: } \\
\hline \multicolumn{2}{|l|}{ - Antecedentes mórbidos: } \\
\hline \multicolumn{2}{|l|}{ - Antecedento vacinal: } \\
\hline \multicolumn{2}{|l|}{ - Antecedentes familiares: } \\
\hline \multicolumn{2}{|l|}{ ALIMENTACAO (anterior $\theta$ atual): } \\
\hline \multicolumn{2}{|c|}{ DNPM (realizar desenho livro o completar o desenho do boneco na follha anera): } \\
\hline \multicolumn{2}{|l|}{ LNGUAGEM: } \\
\hline \multicolumn{2}{|l|}{ ESCOLARDDADE (anterios $\theta$ atnal): } \\
\hline DISCIPLNA: & \\
\hline
\end{tabular}


SOCLAIUDAD:

P्XUNWDA:

ROTINA DE VIDA:

\section{HABTACAR:}

Exome Fisico: PA:

FC:

FR:

$T^{\circ}$

EXNNEGSAL:

\section{Exome Especint:}

- Danios

- Orocopia: OD:

OE:

- Acuidado Viend

OD.

OE:

AO.

EXANE DELNGUAGEN: 
AVALIAÇÃo do DESENVOLVIMENTO NEURO PSICO MOTOR

COMPLETAR O DESENHO da FIGURA HUMANA



MEMÓRIA VISUAL das FIGURAS

IDADE da CRIANÇA segundo a avaiiação realizada: 







\section{I - CONDICOOES ATUAIS DE VIDA}

A. NIMUNIACXO

A.1 TIPOS DE ALEITAMENTO ATUAL.

1 ( ) Aleitamento Materno Exclusivo ( com vitaminas, gts. Naropes, sais mincrais)

2 ( ) Aleitamento Materno Predominante ( com água, suco. chá)

3 ( ) Aleitamento Misto ( L.M + L.A)

4 ( ) Aleitamento complementado SEM outros leites) ( L.M. +alim sólidos ou semi-sólidos)

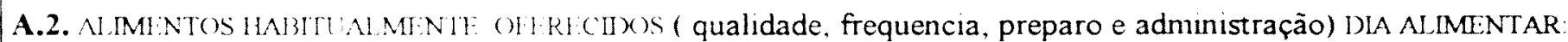

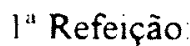

Intervalo

Almoço

Lanche da tarde

Jantar

Lanche da noite

Leite ( tipo, tecnica de preparo e adnınıstração, horarios)

Carnes Ovos Vegetais

Refrigerantes:
5 ( ) Aleitamento complementado COM outros leites ( L.M.+L.A. +alim. sólidos ou semi-sólidos)

6 ( ) Criança Desmamada

( $<$ de 2 anos que não recebe leite matemo)

7 ( ) NÃO SE APLICA

( $>$ de 2 anos que nao recebe leite materno)

B. HABTIOS

B.1. Higiene Pessoal (banho, sol, dentes)

B.2 Sono Funçòes Fisiológicas:

\section{B.3. Quem cuida/Creche ou Escola}

\section{II - ASPECTOS SOCIO-ECONÔMICOS}

\section{A Habulação e ocupaçào dos pans (anotar alleraçós)}

13. Relacionamento $\mathrm{H}$ amiliar

III - D.N.P.M. ATUAL ( motor. linguagem, pessoal social e adaptativo)

\begin{tabular}{|c|c|}
\hline & IV - VACINAS (número de doses aplicadas) \\
\hline $\begin{array}{l}\text { BCG } \\
\text { OUTRAS }\end{array}$ & $\begin{array}{l}\text { Anti-Sarampo: } \\
\text { Teve reação a alguma vacina ? }\end{array}$ \\
\hline
\end{tabular}




\begin{tabular}{|c|c|c|c|}
\hline ESTADO GERAL: & $T^{0}$ & PC: & ESTADO NUTRICIONAL: \\
\hline
\end{tabular}

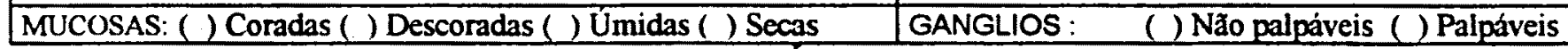

EXAME FISICO ESPECIAL

CABEÇA e PESCOÇo

TÓRAX e ABDÔMEN

REGIÃo PERINEAL e GENITAL

OUTROS DADOS RELEVANTES

DIAGNOSTICOS GERAIS

CONDUTAS E/OU TRATAMENTO

1. NUTRICIONAL: ( ) Eutrófico ( ). Distrófico

Tipo: () Obesidade () DPC () Anemia () Raquitismo () Outros

Percentil de peso:

2. CRESCIMENTO: ( ) Adequado ( ) Inadequado

Mudança de Canal de Crescimento: ( ) sim ( ) não

Percentil de altura:

3. DNPM: () Normal () Atrasado

4. ALIMENTAR: ( ) Adequada ( ) Inadequada

Tipo de inadequaçãa:

5. VACINAČÃ: ( ) Completa ( ) Incompleta

6. AMBIENIE FísICO: ( ) Adequado ( ) Inadequado

Tipo de inadequação:

7. AMBIFNTE EMOCIONAL: ( ) Adequado ( ) Inadequado

Justiticativa:

DOENÇA RESPIRATÓRIA da INFANCIA (DRI)

8.

9.

10

OUTROS DIAGNÓSTICOS: (inclusive patologia nutricional)

11.

12 .

13.

14.

15 .

16.

EXAMES PEDIDOS:

ENCAMINHAMENTOS

PRÓXIMA CONSULTA: ITPO ___ Data __ _

MEDICO/ACADÊMICO:

POS-CONSULTA.

Periodo ( IM( )T SAI.A MEDLCO

ASSISIT:NTE: ASSINAT

RF:SULTADO de EXAMES 


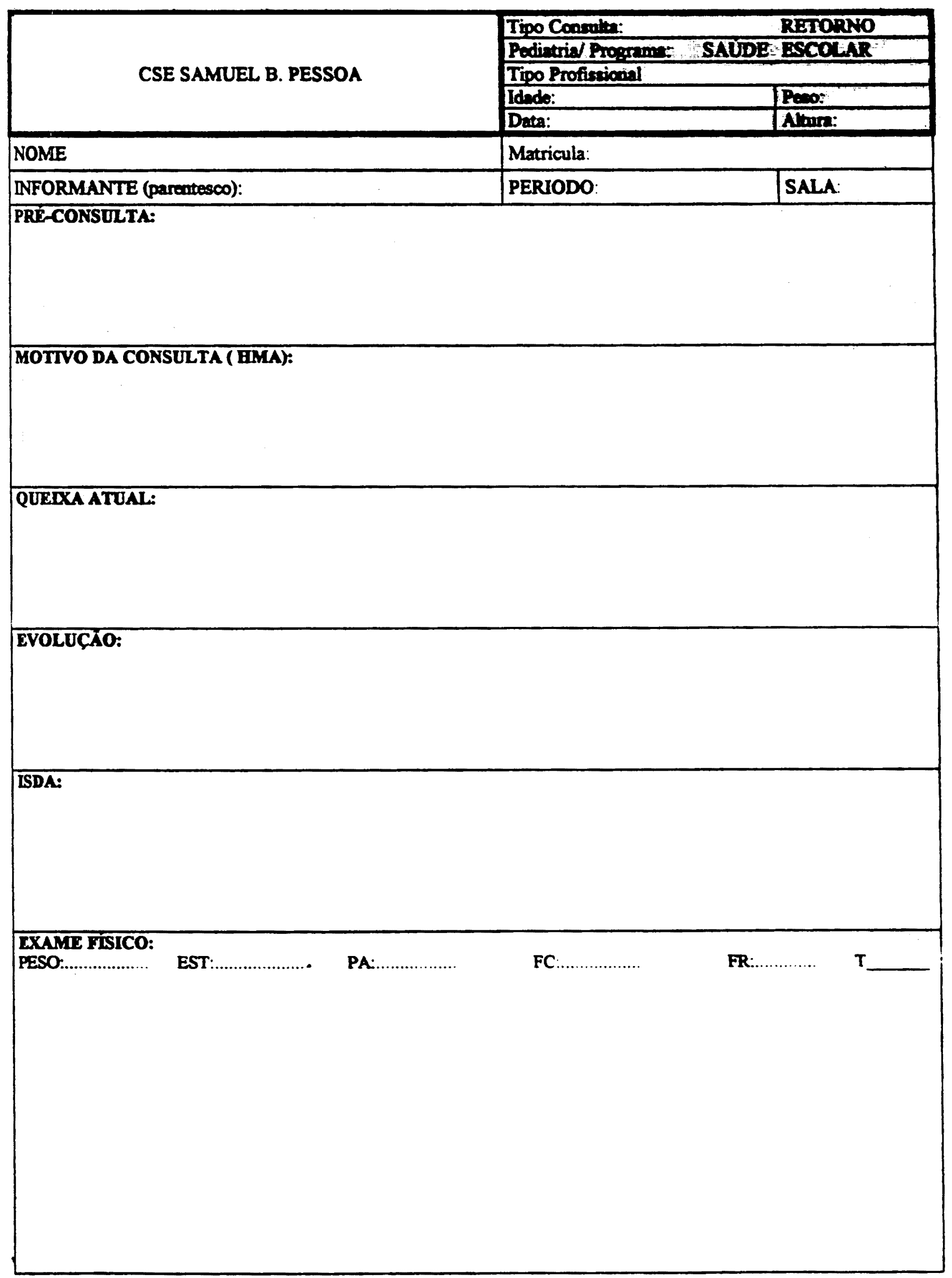




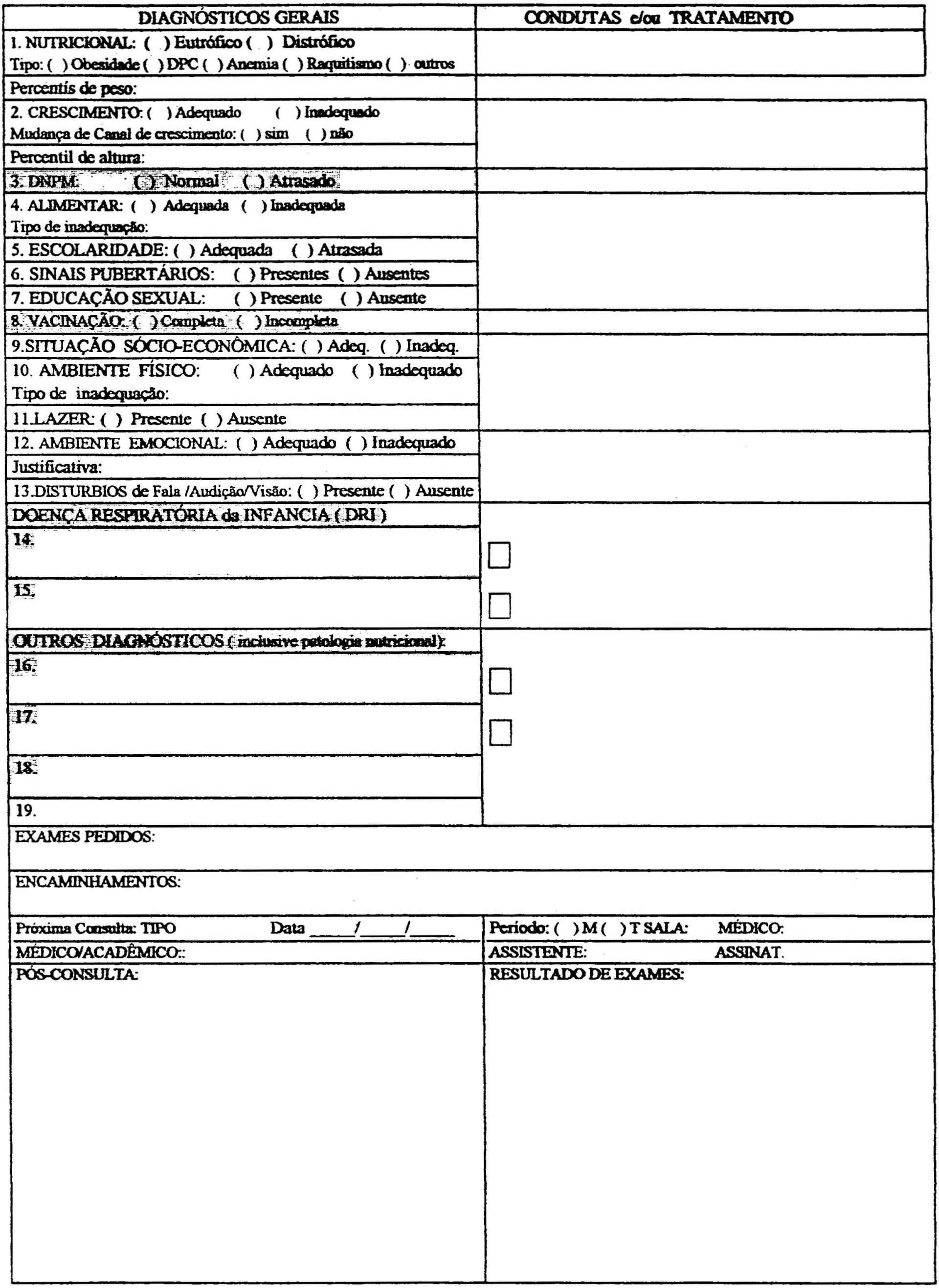




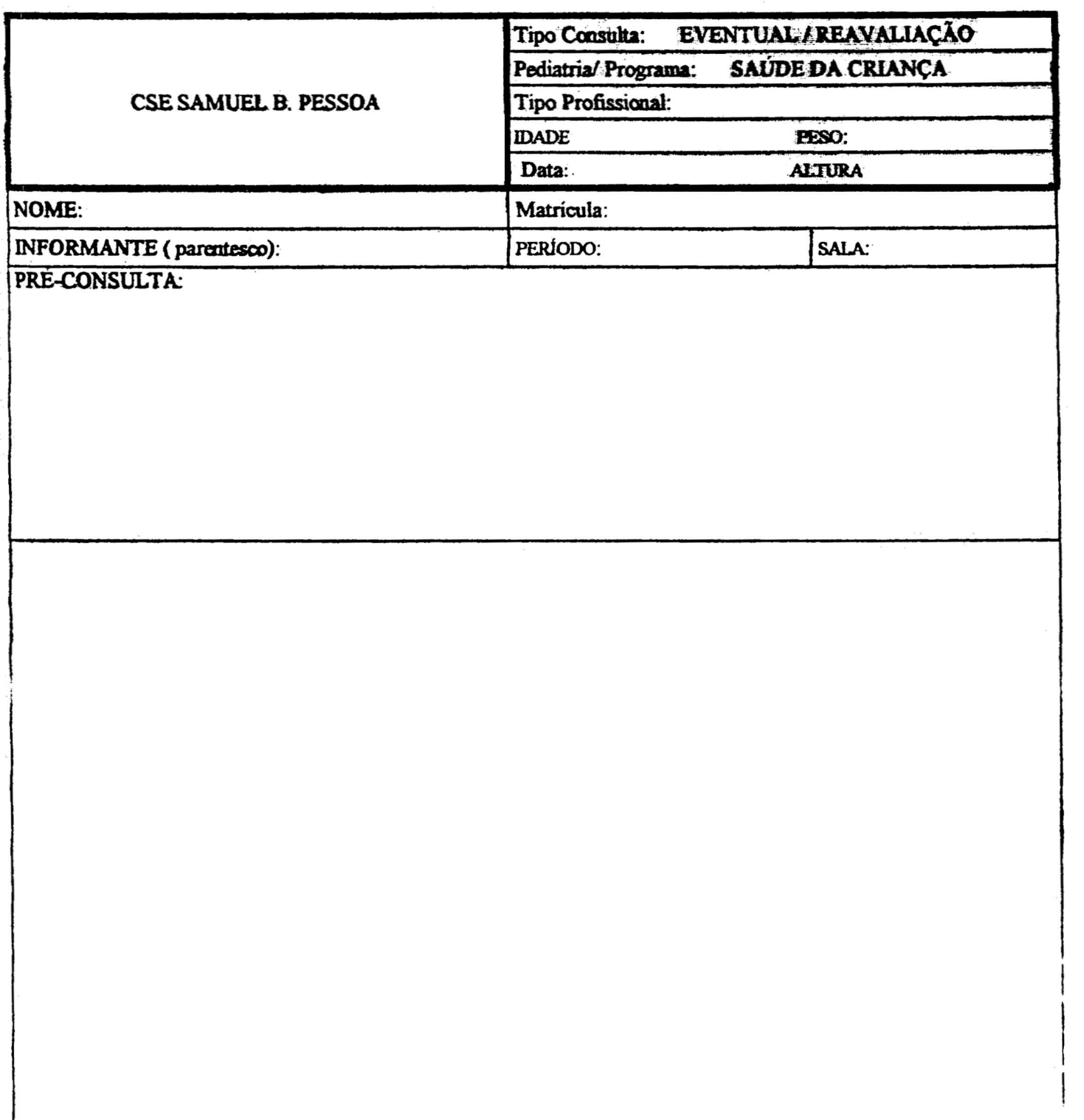




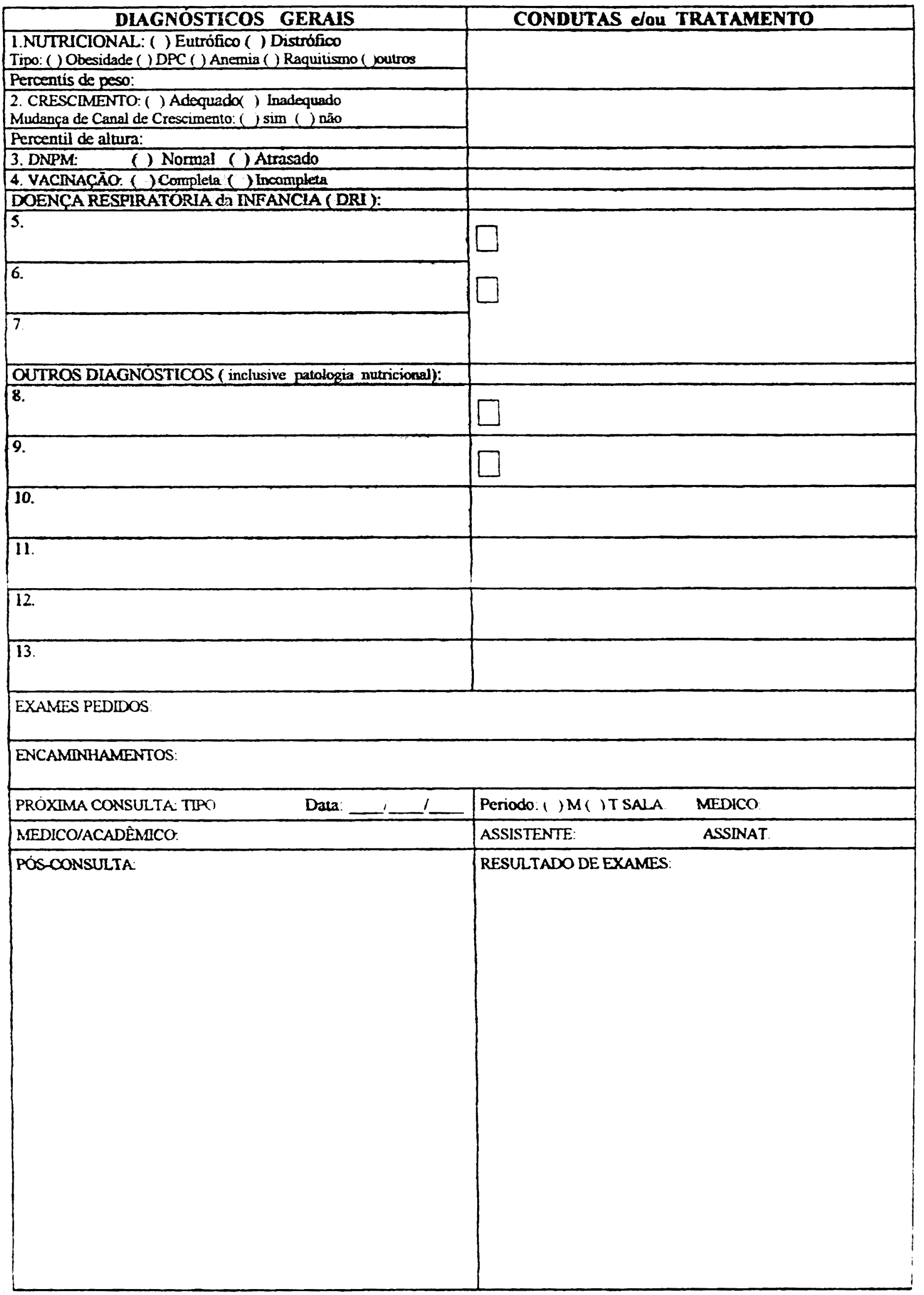


ANEXO 3

QUESTIONÁRIO DE CAPACIDADES E DIFICULDADES - SDQ 
Instruçōes: Por favor, em cada item marque com uma cruz o quadrado que melhor descreva a criança.

"Responda a todas as perguntas da melhor maneira possivel, mesmo que você não tenha certeza absoluta ou se a pergunta lhe pareça estranha. Dê suas respostas com base no comportamento da criança nos últimos seis meses".

Nümero de ordem:

Número do prontuário:

\begin{tabular}{|c|c|c|c|c|}
\hline & & Falso & $\begin{array}{c}\text { Mais ou menos } \\
\text { verdadeiro }\end{array}$ & Verdadeiro \\
\hline 1 & Tem consideração pelos sentimentos de outras pessoas. & $\square$ & $\square$ & $\square$ \\
\hline 2 & $\begin{array}{l}\text { Náo consegue parar sentado quando tem que fazer a liçáo ou comer; } \\
\text { mexe-se muito, esbarrando nas coisas, derrubando as coisas. }\end{array}$ & $\square$ & $\square$ & $\square$ \\
\hline 3 & Muitas vezes se queixa de dor de cabeça, dor de bariga ou de enjô. & $\square$ & $\square$ & $\square$ \\
\hline 4 & $\begin{array}{l}\text { Tem boa vontade em compartilhar doces, brinquedos, lápis... } \\
\text { com outras crianças. }\end{array}$ & $\square$ & $\square$ & $\square$ \\
\hline 5 & Freqüentemente tem acessos de raiva ou crises de birra. & $\square$ & $\square$ & $\square$ \\
\hline 6 & É solitário, prefere brincar sozinho. & $\square$ & $\square$ & $\square$ \\
\hline 7 & Geralmente é obediente e faz normaimente o que os adultos the pedem. & $\square$ & $\square$ & $\square$ \\
\hline 8 & Tem muitas preocupaçōes, muitas vezes parece preocupado com tudo. & $\square$ & $\square$ & $\square$ \\
\hline 9 & Tenta ser atencioso se alguém parece magoado, aflito ou se sentindo mal. & $\square$ & $\square$ & $\square$ \\
\hline 10 & Está sempre agitado, balançando as pernas ou mexendo as måos. & $\square$ & $\square$ & $\square$ \\
\hline 11 & Tem pelo menos um bom amigo ou amiga. & $\square$ & $\square$ & $\square$ \\
\hline 12 & Freqüentemente briga com outras crianças ou as amedronta. & $\square$ & $\square$ & $\square$ \\
\hline 13 & Freqüentemente parece triste, desanimado ou choroso. & $\square$ & $\square$ & $\square$ \\
\hline 14 & Em geral é querido por outras crianças. & $\square$ & $\square$ & $\square$ \\
\hline 15 & Facilmente perde a concentraçăo. & $\square$ & $\square$ & $\square$ \\
\hline 16 & $\begin{array}{l}\text { Fica inseguro quando tem que fazer alguma coisa pela primeira vez, } \\
\text { facilmente perde a confiança em si mesmo. }\end{array}$ & $\square$ & $\square$ & $\square$ \\
\hline 17 & É gentil com criança mais novas. & $\square$ & $\square$ & $\square$ \\
\hline 18 & Frequientemente engana ou mente. & $\square$ & $\square$ & $\square$ \\
\hline 19 & Outras crianças "pegam no pe" ou atormentam-no. & $\square$ & $\square$ & $\square$ \\
\hline 20 & $\begin{array}{l}\text { Freqüentemente se oferece para ajudar outras pessoas (pais, } \\
\text { professores, outras crianças). }\end{array}$ & $\square$ & $\square$ & $\square$ \\
\hline 21 & Pensa nas coisas antes de faze-las. & $\square$ & $\square$ & $\square$ \\
\hline 22 & Rouba coisas de casa, da escola ou de outros lugares. & $\square$ & $\square$ & $\square$ \\
\hline 23 & Se dá melhor com adultos do que com outras crianças. & $\square$ & $\square$ & $\square$ \\
\hline 24 & Tem muitos medos, assusta-se facilmente. & $\square$ & $\square$ & $\square$ \\
\hline 25 & Completa as tarefas que começa, tem boa concentraçăo. & $\square$ & $\square$ & $\square$ \\
\hline
\end{tabular}

Por favor, vire a página. Há mais perguntas no outro lado. 
Pensando no que acabou de responder, você acha que seu filho/filha tem alguma dificuldade? Pode ser uma dificuldade emocional, de comportamento, pouca concentração ou para se dar bem com as outras pessoas.

\begin{tabular}{l|l|l|l}
\hline Não & $\begin{array}{l}\text { Sim- } \\
\text { pequenas } \\
\text { dificuldades }\end{array}$ & $\begin{array}{l}\text { Sim- } \\
\text { dificuldades } \\
\text { bem definidas }\end{array}$ & $\begin{array}{l}\text { Sim- } \\
\text { dificuldades } \\
\text { graves }\end{array}$ \\
\hline$\square$ & $\square$ & $\square$ & $\square$ \\
\hline
\end{tabular}

Se você respondeu "sim", por favor responda às seguintes questōes sobre estas dificuldades:

- Há quanto tempo estas dificuldades existem?

\begin{tabular}{l|l|l|l}
$\begin{array}{l}\text { Menos de } \\
1 \text { mês }\end{array}$ & $\begin{array}{l}1 \text { a } 5 \\
\text { meses }\end{array}$ & $\begin{array}{l}6 \text { a } 12 \\
\text { meses }\end{array}$ & $\begin{array}{l}\text { Mais de } \\
1 \text { ano }\end{array}$ \\
\hline$\square$ & $\square$ & $\square$ & $\square$ \\
\hline
\end{tabular}

- Estas dificuldades incomodam ou aborrecem seu filho/filha?

\begin{tabular}{l|l|l|l} 
Nada & Um pouco & Muito & Mais que muito \\
\hline$\square$ & $\square$ & $\square$ & $\square$ \\
\hline
\end{tabular}

- Estas dificuldades atrapalham o dia-a-dia do seu filho em alguma das situações abaixo?

\begin{tabular}{l|l|l|l|l}
\hline & Nada & Um pouco & Muito & Mais que multo \\
\hline Dia-a-dia em casa & $\square$ & $\square$ & $\square$ & $\square$ \\
\hline Amizades & $\square$ & $\square$ & $\square$ & $\square$ \\
\hline Aprendizado escolar & $\square$ & $\square$ & $\square$ & $\square$ \\
\hline Atividades de lazer (passeios, esportes) & $\square$ & $\square$ & $\square$ & $\square$ \\
\hline
\end{tabular}

- Estas dificuldades são um peso para você ou para a familia como um todo?

\begin{tabular}{l|l|l|l} 
Nada & Um pouco & Muito & Mais que muito \\
\hline$\square$ & $\square$ & $\square$ & $\square$ \\
\hline
\end{tabular}

\section{Muito obrigado pela sua colaboração}


ANEXO 4

INVENTÁRIO DE COMPORTAMENTOS DA INFÂNCIA E ADOLESCÊNCIA - CBCL 


\title{
INVENTÁRIO DE COMPORTAMENTOS DA INFÂNCIA E ADOLESCÊNCIA \\ (Versão brasileira do "CHILD BEHAVIOR CHECKLIST" - CBCL) \\ (Para a faixa etária de 4 a 18 anos)
}

Número de ordem:

Número do prontuário:

\begin{abstract}
A lista abaixo é composta de itens que descrevem comportamentos de crianças e adolescentes.
Considere seu filho ATUALMENTE e NOS ÚLTIMOS 6 MESES e classifique os itens da lista abaixo conforme três possibilidades:
\end{abstract}

0. Item falso ou comportamento ausente.

1. Item parcialmente verdadeiro ou comportamento as vezes presente.

2. Item bastante verdadeiro ou comportamento freqüentemente presente.

Para cada item, faça um circulo ao redor do número 0,1 ou 2.

Favor responder todos os itens, mesmo aqueles que parecem não ter nenhuma relação com o comportamento de seu filho.

012 1. Comporta-se de modo infantil, como se tivesse menos idade.

\section{2. Tem alergia.}

Descreva:

012 3. Argumenta muito (apresenta argumentos para não fazer o que deveria fazer).

012 4. Tem asma ou bronquite.

012 5. Comporta-se como se fosse do sexo oposto.

012 6. Faz cocô na calça ou fora do vaso sanitário (ou fora do penico).

012 7. É convencido, gaba-se de si mesmo.

012 8. É distraido, não consegue prestar atenção por muito tempo.

012 9. Não consegue tirar certos pensamentos da cabeça (obsessōes).

Descreva:

012 10. É agitado, não para quieto.

012 11. Fica grudado nos adultos, é muito dependente.
0112 12. Queixa-se de solidão.

012 13. Parece estar confuso, atordoado.

012 14. Chora muito.

012 15. É cruel com os animais.

012 16. É cruel, maltrata as pessoas.

012 17. Fica no "mundo da lua", perdido nos próprios pensamentos (devaneios).

012 18. Machuca-se de propósito ou já tentou suicidar-se.

012 19. Exige que prestem atenção nele.

012 20. Destrói as próprias coisas.

012 21. Destrói as coisas de sua familia ou de outras crianças (ou adolescentes).

01222 . É desobediente em casa.

0122 23. É desobediente na escola.

012 24. É dificil para comer (não quer se alimentar direito).

012 25. Não se dá bem com outras crianças (ou adolescentes). 
012 26. Falta de arrependimento, não se sente culpado após ter se comportado mal.

Descreva:

012 27. Fica com ciúmes facilmente.

012 28. Come ou bebe coisas que não servem para ser comidas ou bebidas.

Descreva:

012 29. Tem medo de certos animais, situações ou lugares (não inclui a escola).

Descreva:

01230 . Tem medo de ir à escola.

012 31. Tem medo de cometer algum ato destrutivo (contra si ou contra outros).

\section{32. Tem "mania de perfeição".}

012 33. Acha que ninguém gosta dele.

012 34. Acha que os outros o perseguem.

012 35. Sente-se desvalorizado, inferior.

01236 . Machuca-se com freqüência, tem tendência a sofrer acidentes.

012 37. Entra em muitas brigas.

012 38. É alvo de gozaçōes freqüentemente.

012 39. Anda em más companhias.

012 40. Escuta sons ou vozes que não existem. Descreva:

012 41. É impulsivo, age sem pensar.

012 42. Prefere ficar sozinho do que na companhia de outros.

012 43. Mente ou engana os outros.

012 44. Rói unhas.
012 45. É nervoso, tenso.

012 46. Tem "tique nervoso".

Descreva:

012 47. Tem pesadelos.

012 48. As outras crianças (ou adolescentes) não gostam dele.

012 49. Tem prisão de ventre, intestino preso.

01250 . É medroso ou ansioso demais.

012 51. Tem tonturas.

012 52. Sente-se excessivamente culpado.

012 53. Come exageradamente.

012 54. Sente-se cansado demais.

01255 . Está gordo demais.

56. Na sua opiniäo, apresenta queixas físicas por "nervoso"( sem causa médica):

012 a. Dores (diferentes das citadas abaixo).

012 b. Dores de cabeça.

012 c. Náuseas, enjôos.

012 d. Problemas com os olhos.

Descreva:

012 e. Problemas de pele.

012 f. Dores de estômago ou de barriga.

012 g. Vômitos.

012 h. Outras queixas.

Descreva:

012 57. Ataca fisicamente as pessoas.

012 58. Fica cutucando o nariz, a pele ou outras partes do corpo.

Descreva:

012 59. Mexe nas partes íntimas em público.

01260 . Mexe demais nas partes intimas.

012 61. Não vai bem na escola.

Copyright 1991 TM Achenbach University of Vermont, 1 S. Prospect St., Burlington, VT 05401, USA. Tradução e reprodução autorizadas. Versäo brasileira IAS Bordin, 1992, Departamento de Psiquiatria, Escola Paulista de Medicina. 
012 62. É desastrado, desajeitado (tem má coordenação motora).

012 63. Prefere brincar com crianças (ou adolescentes ) mais velhas.

012 64. Prefere brincar com crianças (ou adolescentes ) mais novas.

\section{65. Recusa-se a falar.}

012 66. Repete certos atos várias vezes seguidas (compulsões).

Descreva:

\section{67. Foge de casa.}

012 68. Grita muito.

012 69. É reservado, fechado, não conta suas coisas para ninguém.

01270 . Vê coisas que não existem.

Descreva:

012 71. Fica sem jeito na frente dos outros com facilidade, preocupado com o que as pessoas possam achar dele.

012 72. Põe fogo nas coisas.

012 73. Tem problemas sexuais.

Descreva:

D 12 74. Fica se mostrando ou fazendo palhaçadas para chamar atenção.

012 75. É tímido.

0 12 76. Dorme menos que a maioria das crianças (ou adolescentes).

012 77. Dorme mais que a maioria das crianças (ou adolescentes) durante 0 dia ou à noite.

Descreva:

012 78. Lambuza-se ou brinca com as próprias fezes.
012 79. Tem problemas de fala.

Descreva:

012 80. Fica com o olhar parado, "olhando o vazio".

012 81. Rouba em casa.

012 82. Rouba fora de casa.

012 83. Junta coisas das quais não necessita, nem utiliza.

Descreva:

012 84. Tem comportamento estranho.

Descreva:

012 85. Tem idéias estranhas.

Descreva:

012 86. Fica de cara amarrada, mal humorado, irritase com facilidade.

012 87. Tem mudanças repentinas de humor ou de sentimentos.

012 88. Fica emburrado facilmente.

01289. É desconfiado.

011290. Xinga.

012 91. Fala que vai se matar.

012 92. Fala ou anda dormindo.

Descreva:

012 93. Fala demais.

012 94. Gosta de "gozar da cara "dos outros.

012 95. É esquentado, faz birra, tem acessos de raiva.

012 96. Pensa demais em sexo.

012 97. Ameaça as pessoas.

Copyright 1991 TM Achenbach University of Vermont, 1 S. Prospect St, Burlington, VT 05401, USA. Traduçáo e reprodução autorizadas. Versžo brasileira IAS Bordin, 1992, Departamento de Psiquiatria, Escola Paulista de Medicina. 
012 98. Chupa dedo.

01299 . É preocupado demais com ordem ou limpeza.

012 100. Tem problemas com o sono. Descreva:

012 101. Cabula as aulas.

O 12 102. É pouco ativo, movimenta-se vagarosamente ou falta-the energia.

012 103. E infeliz, triste ou deprimido.

012 104. É baruhento demais.

012105 Faz uso de drogas ou de bebidas alcóolicas. Descreva:

113.Favor anotar abaixo outros problemas de seu filho que năo foram abordados nos itens acima.
012 106. Estraga ou destroi coisas públicas (vandalismo).

Descreva:

012 107. Faz xixi na roupa durante o dia.

012 108. Faz xixi na cama.

012 109. Fica choramingando, fazendo manha.

012 110. Gostaria de ser do sexo oposto.

012 111. É retraido, não se relaciona com os outros.

012 112. É muito preocupado.

Descreva: 


\section{ANEXO 5}

FICHA DE IDENTIFICAÇÃO DA VISITA DOMICILIAR 


\section{ENTREVISTA DOMICILIAR FICHA DE IDENTIFICAÇÃO}

Número de ordem:

Número do prontuário:

Data do SDQ:

Examinador do SDQ no Centro de Saúde: :

SDQ respondido por:

Entrevista entregue à:

Entrevista feita por:

ENDEREÇO: na última folha

Nome da criança:

Data de nascimento:

Idade:

Sexo: masculino feminino

Grupo étnico ou raça:

Escolaridade (série cursada no ano 2000):

NÃO FREQÜENTA ESCOLA

Nome da mãe: Idade da mãe:

Escolaridade da mãe (última série cursada completa):

Profissão da mãe:

Ocupação atual da mãe:

Nome do pai:

Idade do pai:

Escolaridade do pai (última série cursada completa):

Profissão do pai:

Ocupação atual do pai:

Irmãos (sexo e idade):

Situação conjugal dos pais: criança mora com 2 pais biológicos
criança mora só com mãe biológica
criança mora com mãe biológica e pai substituto
criança mora só com pai biológico.
criança mora com pai biológico e mãe substituta
outra situação (especificar)

Razão da situação conjugal anormal: pais separados ou divorciados

falecimento de um ou ambos os pais

outra razão (especificar)

ESTA ENTREVISTA ESTÁ SENDO RESPONDIDA POR (nome e parentesco com a criança):

\section{APLICAR O SDQ E O CBCL}


ANEXO 6

QUESTIONÁRIO PARA OS PAIS SOBRE AS PREOCUPAÇÕES RELATIVAS ÀS DIFICULDADES DAS CRIANÇAS 


\section{ENTREVISTA DOMICILIAR}

\section{QUESTIONÁRIO PARA PAIS SOBRE AS PREOCUPAÇÕES RELATIVAS ÀS}

DIFICULDADES DAS CRIANÇAS (adaptado de Dulcan e col., 1989)

\section{AO TERMINAR O CBCL:}

1 "Nós falamos sobre muitos tipos de problemas que as crianças podem ter. Algum dos problemas citados tem preocupado especialmente o(a) $\operatorname{Sr}(a)$ ?"

não

sim $\square$ "Qual é este problema?"

2 "Durante a consulta do dia o(a) $\operatorname{Sr}(a)$ falou sobre este problema com o médico?" não $\square \quad$ Por que não falou com o médico?" (Descrever)

sim $\square \quad$ "O que aconteceu quando o(a) Sr(a) falou sobre este problema com o médico?" (Descrever)

"Ficou satisfeito(a) com a maneira com que o problema foi tratado pelo médico? Por que?" 
ANEXO 7

ROTEIRO DAS ENTREVISTAS COM OS PEDIATRAS 


\section{Roteiro de entrevista para técnicos de atenção primária}

Número de ordem:

Idade:

Sexo:

Formação completa:

Ano de formatura:

Tempo de trabalho na unidade:

Jornada de trabalho:

Função na unidade:

1. Descreva suas atividades na unidade.

2. Quais são as atividades que você realiza, nas consultas de rotina, relacionadas ao desenvolvimento e às questões de saúde mental?

3. Poderia descrever-me estas atividades?

4. Considerando o número de casos que você encontra, o que facilitaria estas atividades?

5. E quais as dificuldades encontradas?

6. Quando encontra alterações, o que faz?

7. Se encaminha, para onde?

8. Tem dificuldade para encaminhar estas crianças?

9. Quais soluções você acha mais efetivas para melhorar a qualidade do atendimento na área de saúde mental? 
ANEXO 8

EXEMPLO DE PERFIL GERADO PELO CBCL 







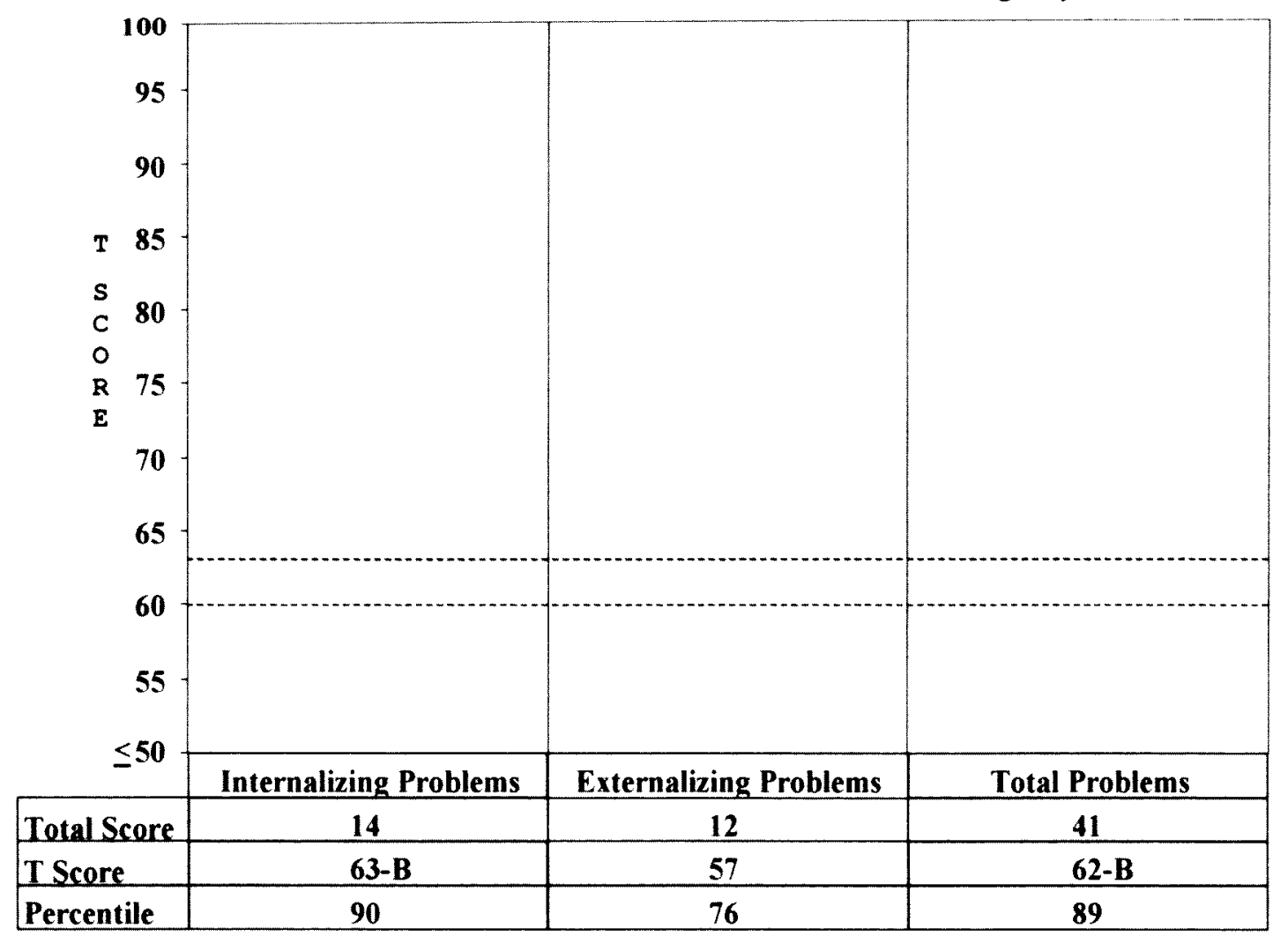

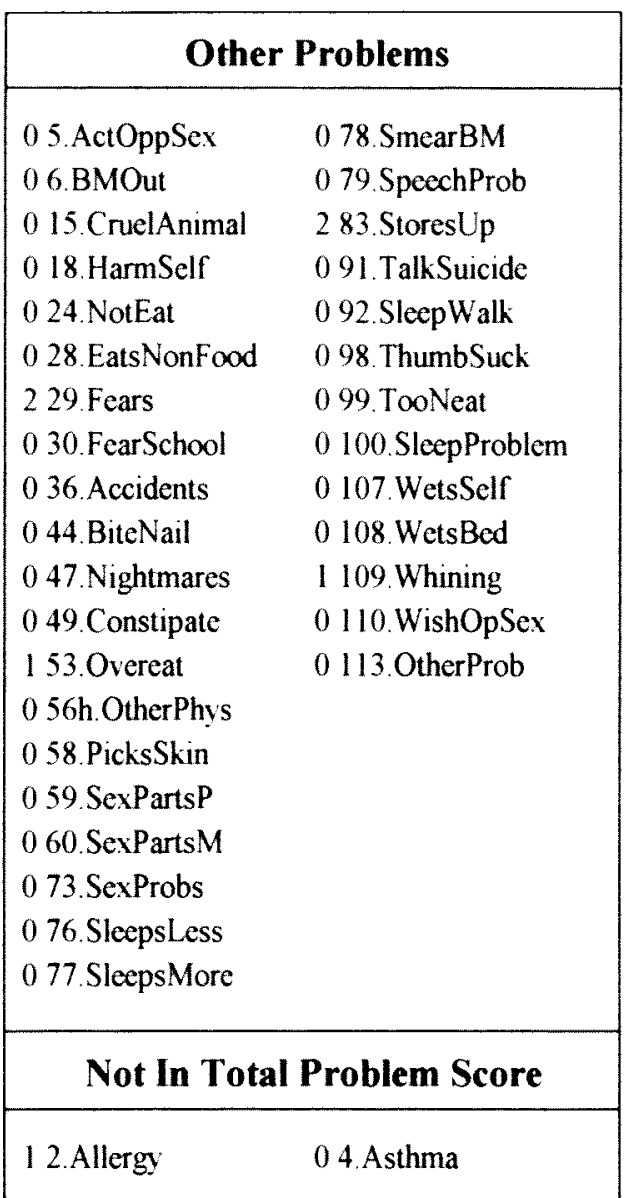

Copyright 1999 by T.M. Achenbach

\begin{tabular}{|l|c|c|}
\hline \multicolumn{3}{|c|}{ Cross-Informant Profile Types } \\
\hline & $\begin{array}{c}\text { Intraclass } \\
\text { Corr. (ICC) }\end{array}$ & $\begin{array}{l}\text { Significant } \\
\text { Similarity }\end{array}$ \\
\hline Withdrawn & -0.132 & No \\
\hline Somatic Complaints & 0.294 & No \\
\hline Social Problems & -0.471 & No \\
\hline Delinquent-Aggressive & -0.553 & No \\
\hline
\end{tabular}

\begin{tabular}{|l|c|c|}
\hline \multicolumn{3}{|c|}{ Profile Types Specific to CBCL } \\
\hline & $\begin{array}{c}\text { Intraclass } \\
\text { Corr. (ICC) }\end{array}$ & $\begin{array}{l}\text { Significant } \\
\text { Similarity* }\end{array}$ \\
\hline Delinquent & -0.553 & No \\
\hline & & \\
\hline & & \\
\hline & & \\
\hline
\end{tabular}

*Intraclass correlations $>0.444$ indicate statistically significant similarity between a child's profile and previously identified profile types.

\begin{tabular}{|l|c|c|c|c|c|c|c|}
\hline Withdrawn & $\begin{array}{c}\text { Somatic } \\
\text { Complaints }\end{array}$ & $\begin{array}{c}\text { Anxious/ } \\
\text { Depressed }\end{array}$ & $\begin{array}{c}\text { Social } \\
\text { Problems }\end{array}$ & $\begin{array}{c}\text { Thought } \\
\text { Problems }\end{array}$ & $\begin{array}{c}\text { Attention } \\
\text { Problems }\end{array}$ & $\begin{array}{c}\text { Delinquent } \\
\text { Behavior }\end{array}$ & $\begin{array}{c}\text { Aggressive } \\
\text { Behavior } \\
\text { clinical sample }\end{array}$ \\
\cline { 2 - 8 }
\end{tabular}


ANEXO 9

TERMO DE RESPONSABILIDADE DO PESQUISADOR

PAIS 


\section{TERMO DE RESPONSABILIDADE DO PESQUISADOR}

Prezado(a) Senhor(a)

Estamos fazendo um estudo sobre o comportamento das crianças, que freqüentam este Centro de Saúde e gostariamos de poder contar com a sua colaboração respondendo a um pequeno questionário.

Seus dados pessoais e as informações obtidas serão mantidas em segredo profissional e somente utilizadas para a finalidade de pesquisa.

A sua participação ou não nesta pesquisa não interferirá no seu atendimento ou no de sua familia pelos profissionais do Centro de Saúde.

Esperando poder contar com sua colaboração

Antecipadamente agradeço

Atenciosamente

Edith Lauridsen Ribeiro

São Paulo, agosto de 2000 
ANEXO 10

TERMO DE RESPONSABILIDADE DO PESQUISADOR

PEDIATRAS 


\section{TERMO DE RESPONSABILIDADE DO PESQUISADOR}

Prezado(a) doutor(a)

Estamos realizando um estudo para o qual pedimos sua colaboração respondendo a uma entrevista sobre como as questões de saúde mental são avaliadas nas Unidades Básicas de Saúde.

Não há necessidade que o(a) senhor(a) se identifique e as informações obtidas serão utilizadas exclusivamente para fins da pesquisa.

Esperando poder contar com sua colaboração

Antecipadamente agradeço

Atenciosamente

São Paulo, agosto de 2000

Edith Lauridsen Ribeiro 
ANEXO 11

LISTA COMPLETA DAS QUEIXAS 
Multiple Response

Group \$QUEIXAS Queixas categorizadas

Category label Code

puericultura; controle de saúde; rotina adenopatia retroauricular

aftas em lábio

agitada

alergia na pele

alteração da dinâmica familiar

amarela e equimoses

anemia

antecedentes de maus tratos

asma

atrofia cortical e hidrocefalia

aumento de gânglios

baixa estatura

baixo peso

balanopostite

broncopneumonia

bronquite, broncoespasmo

bruxismo, range os dentes

cansaço e palpitação; cansaço fácil

cáries, dentes furados

caroços no pescoço; caroços no pescoço

ceceio

cheiro ruim no ouvido

chiado tosse e dispnéia, crise de chiado

chupa o dedo

coceira nos ouvidos

coriza, rinorréia e tosse

corrimento e prurido vaginal; secreção $p$

cospe muito

crescimento de mama

crise convulsiva

desligada na escola; não presta atenção;

diarréia

dificuldade de aprendizagem; não vai bem

dificuldade de leitura

dificuldade de subir escadas e de correr

dificuldade, problemas na escola; não qu

dificuldade para enxergar, não enxerga d

dificuldade para escutar, não escuta bem

dificuldade para falar, problemas de fal

dispnéia aos médios esforços

disúria; dor para urinar

dor abdominal

dor de cabeça, cefaléia

dor de dente

dor de garganta

dor de ouvido, otalgia
0

1

2

3

4

5

6

7
Pct of Pct of Count Responses Cases

218
1
1
1
1
1
1
1
1
2

30,

, 1

53,0

, 2

, 2

, 2

, 1

, 1

, 1

, 1

, 1

, 1

, 3

, 1

, 1

, 1

, 4

, 3

, 1

, 4

, 6

.6

, 3

, 3

, 1

, 1

, 3

, 1

, 1

2,2

1,7

, 1

, 1

, 3

, 7

, 6

, 4

, 1

, 1

, 4

1,4

1,7

1,0

, 1

5,4

6,1

, 4

, 4

1,5 


\section{Category label}

dor em membro inferior

dor nas costas

dor no pé

dor torácica

edema de face

emagrecimento

encoprese

enurese, escapes de urina na roupa e na

escoliose, lordose e cifose

espirros frequentes

estrabismo

falta de apetite; não come bem; hiporexi

falta de ar à noite

febre, tosse e rinorréia

fimose

furúnculo genital

gagueira

gripes; gripes de repetição

hidrocele

hiperatividade

hipertrofia de adenóide

hipogonadismo

infecção urinária

inquieto

irritação

irritação na garganta

IVAS; resfriado

lesão de pele

lesão dedo do pé

lesões eritematosas

lesões hipocrômicas e lesões eritematosa

lesões hipocrômicas na face; manchas bra

lesões micropapulares

lesōes pruriginosas

lesões região perilabial

mancha na axila

manchas esbranquiçadas, hipocrômicas na

manchas roxas em membros

mau comportamento

mau hálito

miopia

não consegue fazer dieta; não quer fazer não participa da aula, não conversa com não quer comer

náuseas

nervoso

nódulo parede abdominal
Pet of Pct of

Code

48

49

50

52

53

54

55

56

57

58

59

61

62

64

65

66

67

68

69

70

71

72

73

74

76

77

78

79

80

81

82

83

84

85

86

87

88

89

90

91

92

94

95

96

97

98

99

Count Responses Cases

$1,1 \quad 1,9$

$, 1 \quad, 2$

$, 1 \quad, 2$

, $1 \quad-, 2$

$, 1 \quad, 2$

$, 1 \quad, 2$

$, 4 \quad, 7$

$3,3 \quad 5,8$

$, 3 \quad, 5$

, 3

, 3

1,7

, 1

, 6

, 3

, 3

, 1

, 7

, 1

, 1

, 1

, 1

, 1

, 1

, 1

, 1

1,7

1,0

, 1

, 3

, 3

, 3

, 1

, 3

, 1

, 1

, 6

, 1

, 1

, 1

, 1

, 4

, 1

, 1

, 1

, 3

, 1 
Group \$QUEIXAS Queixas categorizadas

Category label

Code

obesidade

obstipação intestinal

100

obstrução de vias aéreas; respira pela b 102

obstrução nasal

odinofagia

otite média serosa

otite, infecção no ouvido

pálida e aarela

pápulas eritematosas

pele seca

piscando olho quando vê TV

pitiriase alba

polaciúría, poliúria

pontada no peito

precisa escola especial e fisioterapia

preocupação com o comportamento da crian

problema de comportamento

problema de adaptação na escoal

problemas de alfabetização

problemas escolares e de comportamento

prurido anal

prurido nasal

prurido nos olhos

prurido; quadro pruriginoso pelo corpo

quadro sindrômica: hidrocele, fenda pala

quebrou vidro de medicação

queda do desempenho, rendimento escolar 128

queda, ueda com dormência, queda sobre $\circ \quad 129$

queimadura

reavaliação uadro respiratória

respiração bucal; respiração ruidosa

rinite

roncos noturnos e respiração bucal

sangramento nasal; epistaxe

sindrome de Down

sinusite

sinusopatia

sono agitado

sopro no coração

teimosa

tontura

tosse

tosse e crise de falta de ar

tremores e vômitos

urgência urinária

usa chupeta e mamadeira

usa óculos; óculos errados; óculos quebr
Pct of Pct of Count Responses Cases

1
4
4
13
1
1
3
1
1
2
1
1
2
1
1
1
1
1
1

$\begin{array}{rr}, 1 & 1, \\ , 6 & 1, \\ 16 & 3, \\ 1,8 & \end{array}$

$, 1 \quad, 2$

$12 \quad, 2$

$, 4 \quad, 7$

$, 1 \quad, 2$

$, 1 \quad, 2$

$, 3 \quad, 5$

$, 1 \quad, 2$

$, 1 \quad, 2$

$, 3 \quad, 5$

$, 1 \quad, 2$

$, 1 \quad, 2$

$, 1 \quad, 2$

$, 1 \quad, 2$

$, 1 \quad, 2$

$, 1 \quad, 2$

$, 1 \quad, 2$

$1,9 \quad 3,4$

$1,1 \quad 1,9$

$, 3,5$

$, 8 \quad 1,5$

$, 1 \quad, 2$

$, 1 \quad, 2$

$, 4 \quad, 7$

$, 4 \quad, 7$

$, 1 \quad, 2$

$, 1 \quad, 2$

$, 61,0$

$, 7 \quad 1,2$

$, 4 \quad, 7$

$, 4 \quad, 7$

$, 1 \quad, 2$

$, 3 \quad, 5$

$, 1 \quad, 2$

$, 1 \quad, 2$

, $4 \quad 7$

$, 1 \quad, 2$

$, 6 \quad 1,0$

$3,2 \quad 5,6$

$, 3 \quad, 5$

$, 1 \quad, 2$

$, 1 \quad, 2$

, $1 \quad 2$

$, 7 \quad 1,2$ 
Group \$QUEIXAS Queixas categorizadas

Category label

varicela

ver resultados de exames

vermes; eliminação de vermes

verrugas

vesiculas na boca

vulvovaginite

zumbido nos ouvidos

$\begin{array}{crrr}\text { Code } & \text { Count } & \begin{array}{r}\text { Pct of } \\ \text { Responses }\end{array} & \begin{array}{r}\text { Pct of } \\ \text { Cases }\end{array} \\ 151 & 1 & , 1 & , 2 \\ 153 & 1 & 1 & , 2 \\ 154 & 2 & , 3 & , 5 \\ 155 & 3 & , 4 & , 7 \\ 156 & 1 & , 1 & , 2 \\ 157 & 1 & , 1 & , 2 \\ 158 & 1 & , 1 & , 2 \\ & ---1 & -1 & -17 \\ \text { Total responses } & 724 & 100,0 & 176,2\end{array}$

0 missing cases; 411 valid cases 
ANEXO 12

CID-10 CAPÍTULO V

TRANSTORNOS MENTAIS E COMPORTAMENTAIS (F00-F99) 
Capitulo V Transtornos mentais e comportamentais (F00-F99)

Versão $1.6 \mathrm{C}-\mathrm{C} 1993$ by CBCD e DATASUS

F00-F09 Transtornos mentais orgânicos, inclusive os sintomáticos

F00* Demência na doença de Alzheimer (G30.- $t$ )

F01 Demência vascular

F02* Demência em outras doenças classificadas em outra parte

F03 Demência não especificada

F04 Síndrome amnésica orgânica não induzida pelo álcool ou por outras substâncias psicoativas

F05 Delírium não induzido pelo álcool ou por outras substâncias psicoativas

F06 Outros transtornos mentais devidos a lesão e disfunção cerebral e a doença física

F07 Transtornos de personalidade e do comportamento devidos a doença, a lesão e a disfunção cerebral

F09 Transtorno mental orgânico ou sintomático não especificado

F10-F19 Transtornos mentais e comportamentais devidos ao uso de substância psicoativa

F10 Transtornos mentais e comportamentais devidos ao uso de álcool

F11 Transtornos mentais e comportamentais devidos ao uso de opiáceos

F12 Transtornos mentais e comportamentais devidos ao uso de canabinóides

F13 Transtornos mentais e comportamentais devidos ao uso de sedativos e hipnóticos

F14 Transtornos mentais e comportamentais devidos ao uso da cocaína

F15 Transtornos mentais e comportamentais devidos ao uso de outros estimulantes, inclusive a cafeina

F16 Transtornos mentais e comportamentais devidos ao uso de alucinógenos

F17 Transtornos mentais e comportamentais devidos ao uso de fumo

F18 Transtornos mentais e comportamentais devidos ao uso de solventes voláteis

F19 Transtornos mentais e comportamentais devidos ao uso de múltiplas drogas e ao uso de outras substâncias psicoativas

F20-F29 Esquizofrenia, transtornos esquizotipicos e transtornos delirantes

F20 Esquizofrenia

F21 Transtorno esquizotipico

F22 Transtornos delirantes persistentes 
F23 Transtornos psicóticos agudos e transitórios

F24 Transtorno delirante induzido

F25 Transtornos esquizoafetivos

F28 Outros transtornos psicóticos não-orgânicos

F29 Psicose não-orgânica não especificada

F30-F39 Transtornos do humor [afetivos]

F30 Episódio maníaco

F31 Transtorno afetivo bipolar

F32 Episódios depressivos

F33 Transtorno depressivo recorrente

F34 Transtornos de humor [afetivos] persistentes

F38 Outros transtornos do humor [afetivos]

F39 Transtorno do humor [afetivo] não especificado

F40-F48 Transtornos neuróticos, transtornos relacionados com o "stress" e transtornos somatoformes

F40 Transtornos fóbico-ansiosos

F41 Outros transtornos ansiosos

F42 Transtorno obsessivo-compulsivo

F43 Reaçōes ao "stress" grave e transtornos de adaptação

F44 Transtornos dissociativos [de conversão]

F45 Transtornos somatoformes

F48 Outros transtornos neuróticos

F50-F59 Síndromes comportamentais associadas a disfunções fisiológicas e a fatores físicos

F50 Transtornos da alimentação

F51 Transtornos não-orgânicos do sono devidos a fatores emocionais

F52 Disfunção sexual, não causada por transtorno ou doença orgânica

F53 Transtornos mentais e comportamentais associados ao puerpério, não classificados em outra parte

F54 Fatores psicológicos ou comportamentais associados a doença ou a transtornos classificados em outra parte

F55 Abuso de substâncias que não produzem dependência

F59 Síndromes comportamentais associados a transtornos das funções fisiológicas e a fatores físicos, não especificadas

F60-F69 Transtornos da personalidade e do comportamento do adulto

F60 Transtornos especificos da personalidade

F61 Transtornos mistos da personalidade e outros transtornos da personalidade 
F62 Modificações duradouras da personalidade não atribuiveis a lesão ou doença cerebral

F63 Transtornos dos hábitos e dos impulsos

F64 Transtornos da identidade sexual

F65 Transtornos da preferência sexual

F66 Transtornos psicológicos e comportamentais associados ao desenvolvimento sexual e à sua orientação

F68 Outros transtornos da personalidade e do comportamento do adulto F69 Transtorno da personalidade e do comportamento do adulto, não especificado

F70-F79 Retardo mental

F70 Retardo mental leve

F71 Retardo mental moderado

F72 Retardo mental grave

F73 Retardo mental profundo

F78 Outro retardo mental

F79 Retardo mental não especificado

F80-F89 Transtornos do desenvolvimento psicológico

F80 Transtornos específicos do desenvolvimento da fala e da linguagem

F81 Transtornos específicos do desenvolvimento das habilidades escolares

F82 Transtorno especíico do desenvolvimento motor

F83 Transtornos específicos misto do desenvolvimento

F84 Transtornos globais do desenvolvimento

F88 Outros transtornos do desenvolvimento psicológico

F89 Transtorno do desenvolvimento psicológico não especificado

F90-F98 Transtornos do comportamento e transtornos emocionais que aparecem habitualmente durante $a$ infância ou a adolescência

F90 Transtornos hipercinéticos

F91 Distúrbios de conduta

F92 Transtornos mistos de conduta e das emoções

F93 Transtornos emocionais com início especificamente na infância

F94 Transtornos do funcionamento social com início especificamente durante a infância ou a adolescência

F95 Tiques

F98 Outros transtornos comportamentais e emocionais com início habitualmente durante a infância ou a adolescência

F99 Transtorno mental não especificado

F99 Transtorno mental não especificado em outra parte 
ANEXO 13

LISTA COMPLETA DOS DIAGNOSTICOS 
Group SDIAGCID Diagnósticos categorizados pela CID-10

Category label

Code

A06 - amebiase

A07.1 - giardíase

A09 - diarréia e gastroenterite de orige

A50.9 - sifilis congênita não especifica

BOO - infecção pelo virus do herpes simp

B01 - varicela

B07 - verrugas de origem viral

B08.1 - molusco contagioso

B35 - dermatofitose

B82 - parasitose intestinal não especifi

B86 - escabiose

D64.9 - anemia não especificada

D57 - transtornos falciformes

D72.1 - eosinofilia

D84.9 - imunodeficiência não especificad

E29.1 - hipofunção testicular

E30 - transtornos da puberdade não class

E30.1 - puberdade precoce

E34.3 - nanismo não classificado em o. p

E46 - desnutrição proteico calórica não

E66 - obesidade

F45 - transtornos somatoformes

F45.8 - bruxismo

F51 - transt. não orgânicos do sono

F80 - transt. espec. do desenv. da fala

F81 - transt. espec. do desenv. das habi

F89 - transt. não especificado do desenv

F90.9 - transtorno hipercinético não esp

F91.9 - transtorno não especificado de C

E93.9 - transtorno emocional da infância

F98.0 - enurese

F98.1 - encoprese

E98.5 - gagueira

F98.9 - transt. comportamentais e emocio

G31.9 - doença degenerativa do sistema $n$

G43 - enxaqueca

G47.3 - apnéia do sono

H02.4 - ptose palpebral

HlO - conjuntivite

HI - outros transtornos da conjuntiva

H50.9 - estrabismo não especificado

H52 - transtornos da refração e da acomo

H52.1 - miopia

H53.9 - distúrbio visual não especificad

H61.2 - outros transtornos do ouvido ext

H65 - otite média não supurativa

H66 - otite média supurativa e as não es
Pet of Pet of Count Responses Cases
1

3

4

5

6

7

8

9

10

11

12

13

14

15

16

17

18

19

20

21

22

23

24

25

28

29

30

31

32

33

34

35

36

37

38

39

40

42

43

44

45

46

47

48

49

50




Category label

Code

H69 - outros transtornos da trompa de Eu

H74.0 - timpanoesclerose

H83.0 - labirintite

H91.9 - perda de audição não especificad

H92 - otalgia e secreção auditiva

I38 - transtorno de valva cardíaca nảo e

I49.9 - arritmia cardíaca não especifica

I83 - varizes de membros inferiores

J00 - resfriado comum

J01 - sinusite aguda

J03 - amigdalite aguda

J11 - gripe

J30 - rinite alérgica e vasomotora

J31 - rinite crônica

J32 - sinusite crônica

J35 - doenças crônicas de amigdalas e ad

J38 - doenças das cordas vocais e da lar

J39 - outras doenças das vias aéreas sup

J40 -bronquite não especificada como agu

J45 - asma

J98.9 - transtorno respiratório não espe

K02 - cáries dentárias

K06.1 - hiperplasia gengival

K07 - anomalias dentofaciais

K12 - estomatite

K29 - gastrite e duodenite

$\mathrm{K} 40$ - hernia inguinal

K42 - hernia umbelical

K43 - hernia ventral

K59.0 - obstipação intestinal

K92.1 - melena

L01 - impetigo

L02 - abscesso cutâneo, furúnculo

L03 - celulite

L20 - dermatite atópica

L21 - dermatite seborréica

L28.2 - estrófulo

L29 - prurido

L30.5 - pitiriase alba

L68 - hipertricose

L72 - cistos foliculares de pele e tecid

L73 - outras afecções foliculares

L80 - vitiligo

L81 - outros transtornos de pigmentação

L85.3 - xerose cutânea; dermatite po: pe

L98.9 - afecções da pele e do tecido sub

M21 - outras deformidades adquiridas dos
Pct of Pct of Count Responses Cases $\begin{array}{ll}.2 & , 5 \\ , 1 & , 3 \\ 1 & 3\end{array}$

$1,5 \quad 3,8$

$, 1 \quad, 3$

$, 1 \quad, 3$

, 3

, 1

2,8

, 8

, 2

, 3

9,3

, 2

1,2

, 1

2,5

, 8

1,6

, 2

6,5

, 1

, 5

, 1

, 1

, 1

, 1

, 1

1,2

, 1

, 1

, 2

1

1,3

, 2

, 1

, 2

1,4

, 2

, 1

, 1

, 1

2,1

2,

, 4
5
3
3
8
3
3
8

, 8

6,8

2,0

, 5

22,7

, 5

, 5

, 3

6,1

2,0

4,0

, 5

15,9

, 3

1,3

, 3

, 3

, 3

, 3

, 3

3,0

, 3

, 3

, 5

, 3

3,3

, 5

, 3

, 5

3,5

, 5

, 3

, 3

, 3

, 5

5,1

1,0

1,8 
Category label

Code

M21.9 - deformidade não especificada de

M25.5 - dor articular

M40 - cifose e lordose

M41 - escoliose

M43.9 - vicio de postura

M79.6 - dor em membro

M89.8 - outros transtornos especificado

N39.0 - infecção do trato urinário de lo

N43 - hidrocele e espermatocele

N47 - hipertrofia de prepúcio, fimose

N48.1 - balanopostite

N50 - outros transtornos dos orgãos geni

N76 - outras afecções inflamatórias da $v$

N90.9 - transt. não inflam. e não espec.

P07.3 - prematuridade

Q17 - outras malformações congênitas da

Q20 - malformações congênitas das câmara

Q38.1 - lingua presa; anquiloglossia

Q54 - hipospádia

Q55.2 - testiculo retrátil

Q82.2 - mastocitose

Q87.8 - outras sindromes com malformaçõe

Q90 - sindrome de Down

R00 - anomalias do batimento cardíaco

R01 - sopros e outros ruidos cardiacos

R04.0 - epistaxe

R05 - tosse

R10 - dor abdominal

R22 - tumefação, massa ou tumoração loca

R23.3 - equimoses espontâneas

R29 - outros sintomas e sinais rel.aos s

R30 - dor associada à micção

R47 - distúrbios da fala não classificad

R49 - distúrbios da voz

R51 - cefaléia

R56 - convulsões

R58 - hemorragia não classificada em out

R59 - adenomegalia

S09.0 - traumatismo não especificado na

T11 - traumatismo não especificado de me

T16 - corpo estranho no ouvido

T25 - queimadura no pé

T78.4 - atopia; alergia não especificada

200.1 - exame de rotina de saúde da cria

Z11 - exame especial de rastreamento

z20.1 - contato com e exposição à tuberc

220.6 - contato com e exposição ao HIV
101

102

103

104

105

106

107

108

110

111

112

113

114

115

116

117

118

119

120

121

122

123

124

125

126

127

128

129

131

133

134

135

136

137

138

139

140

141

142

143

144

145

147

148

149

150

151
Pct of Pct of Count Responses Cases

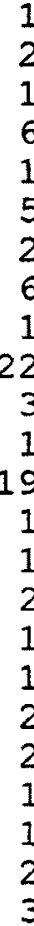

1

$, 1 \quad, 3$

$, 2 \quad, 5$

$, 1 \quad, 3$

$, 6 \quad 1,5$

$, 1,3$

, 5

1,3

, 5

1,5

, 3

5,6

, 8

, 3

4,8

, 3

, 3

, 5

, 3

, 3

, 5

, 5

, 3

, 3

, 5

, 8

5,3

, 5

, 5

8,1

, 5

, 3

, 5

, 8

, 3

, 3

6,1

1,0

, 3

1,0

, 3

, 3

, 3

, 3

, 5

13,4

, 3

1,0

, 3 
Group \$DIAGCID Diagnósticos categorizados pelo CID-10

$\begin{array}{lrrrr}\text { Category label } & \text { Code } & \text { Count } & \begin{array}{r}\text { Pct of Pct of } \\ \text { Responses Cases }\end{array} \\ 261 \text { - problemas relacionados com eventos } & 152 & 1 & 1 & , 3 \\ 262.4 \text { - negligência emocional da criança } & 153 & 1 & 1 & , 3 \\ & \text { Total responses } & 971 & 100,0 & 245,2\end{array}$

15 missing cases; 396 valid cases 
ANEXO 14

CASOS COM QUEIXAS E/OU HIPÓTESES DIAGNÓSTICAS DE PSM 
CASOS COM QUEIXAS EJOU HIPÓTESES DIAGNÓSTICAS DE PSM (continua na próxima página)

\begin{tabular}{|c|c|c|c|c|c|}
\hline & Queixa espontânea & Queixa espontảnea & Queixa induzida & Diagnóstico PSM & Diagnóstico PSM \\
\hline & é desligada na escola & $\mathrm{X}$ & $\mathrm{X}$ & $x$ & $\mathrm{X}$ \\
\hline 2 & $x$ & $x$ & sono agitado & $x$ & $x$ \\
\hline & fugia da escola, chorava & $x$ & $x$ & dificuldade na escola & $x$ \\
\hline 4 & $x$ & $x$ & $x$ & ceceio & $x$ \\
\hline 5 & $x$ & $x$ & range os dentes & bruxismo & $x$ \\
\hline 6) & $\bar{x}$ & $\bar{x}$ & acorda durante a noite & $x$ & $x$ \\
\hline & enurese & $x$ & $x$ & enurese & dist de comportamento \\
\hline 8 & $\mathrm{X}$ & $x$ & não sabe cores; não conta números & atraso na escola & $\mathrm{X}$ \\
\hline 9 & $\bar{x}$ & $x$ & dificuldades na escola & dificuldade de aprendizagem & \\
\hline 10 & $x$. & $x$ & bruxismo & bruxismo & $x$ \\
\hline 11 & $x$ & $x$ & $x$ & dificuldade de diç̧ão & $x$ \\
\hline 12 & & $x$ & dificuldades aprendizagem & fala infantilizada & déficit de aprendizagem \\
\hline 13 & & $x$ & $\bar{x}$ & enurese & $x$ \\
\hline 14 & faz acompanhamento psicológico & $x$ & $x$ & distúrbio de conduta & escolaridade atrasada \\
\hline 15 & é muito rebelde & $x$ & não sabe ler & distúrbio de conduta & escolaridade atrasada \\
\hline 16 & S. de Down & $\bar{x}$ & năolês & encoprese & \\
\hline 17 & dificuldade na escola & é inquieto & $x$ & distưrbio escolar & $x$ \\
\hline 18 & fala errado, toca letra & $x$ & $x$ & dislalia & $x$ \\
\hline 19 & criança irritada & dificuldade de fala & $x$ & atraso de linguagem & \\
\hline 20 & & $x$ & troca letras & dislalia & $x$ \\
\hline 21 & tem medo das pessoas & $x$ & $x$ & $x$ & $x$ \\
\hline 22 & dificuldade de aprendizagem & $x$ & $x$ & distúrbio de aprendizagem & $x$ \\
\hline 23 & problema de comportamento & $\bar{x}$ & pesadelos & distúrbio de comportamento & $X$ \\
\hline 24 & & $x$ & $x$ & mau rendimento escolar & $x$ \\
\hline 25 & troca letra & $x$ & $x$ & dislalia & $x$ \\
\hline 26 & $x$ & $\bar{x}$ & $\bar{x}$ & criança infantilizada & $x$ \\
\hline 27 & & $\bar{x}$ & $x$ & distúrbio de fala & $\bar{x}$ \\
\hline 28 & sono agitado & bruxismo & $x$ & distúrbio do sono & $x$ \\
\hline
\end{tabular}


CASOS COM QUEIXAS EJOU HIPÓTESES DIAGNOSTICAS DE PSM (continua na próxima pégina)

\begin{tabular}{|c|c|c|c|c|c|}
\hline & Queixa espontânea & Queixa espontánea & Queixa induzida & Diagnóstico PSM & Diagnóstico PSM \\
\hline 29 & necessidade escola esp. & toma Neuleptil & pouco contato & dislalia & X \\
\hline 30 & enurese & & $\mathrm{X}$ & enurese & \\
\hline 31 & & $x$ & não articula bem as palavras & $\bar{x}$ & $\bar{x}$ \\
\hline 32 & é teimosa, irrequieta & $\bar{x}$ & $x$ & $\bar{x}$ & $\bar{x}$ \\
\hline 33 & enurese & $x$ & $x$ & enurese & $x$ \\
\hline 34 & enurese & mau comport na escola & $\bar{x}$ & enurese & $x$ \\
\hline 35 & dificuldade na escola & apanha na escola & agitado & dificuldade na escola & \\
\hline 36 & queda desempenho esc. & $X$ & $x$ & $\mathrm{X}$ & $\mathrm{x}$ \\
\hline 37 & & $x$ & gagueira & $x$ & $\mathrm{X}$ \\
\hline 38 & medos & $\bar{x}$ & $x$ & dist neurovegetativo & $\bar{x}$ \\
\hline 39 & enurese & $\bar{x}$ & $\bar{x}$ & enurese & x \\
\hline 40 & & $x$ & levanta e conversa no sono & $x$ & $x$ \\
\hline 41 & não presta atenção na aula & enurese & $x$ & enurese & $x$ \\
\hline 42 & enurese & $x$ & $x$ & enurese & $x$ \\
\hline 43 & ceceio & $x$ & $x$ & $x$ & $x$ \\
\hline 44 & năo vai bem na escola & $\bar{x}$ & $x$ & dificuldade de alfabetizaçăo & $x$ \\
\hline 45 & medos & agressivo & $\bar{x}$ & déficit atençăáo & $x$ \\
\hline 46 & enurese & $\mathrm{X}$ & X & enurese & $\mathrm{X}$ \\
\hline 47 & queda desempenho escolar & $x$ & nåo consegue dormir à noite & $x$ & $x$ \\
\hline 48 & & $\bar{x}$ & range os dentes & $x$ & $x$ \\
\hline$\overline{49}$ & dispersa na aula & dificuldade de leitura & $x$ & $\bar{x}$ & $x$ \\
\hline 50 & & $x$ & mau rendimento escolar & escolaridade atrasada & $x$ \\
\hline 51 & nervosa, agressiva & $x$ & $x$ & enurese & sind. crianca dolorosa \\
\hline 52 & enurese & $\bar{x}$ & $\bar{x}$ & enurese & $\bar{x}$ \\
\hline 53 & faz tratamento de fono & $\bar{x}$ & $x$ & disturbio de linguagem & $x$ \\
\hline 54 & problema de fala & $\bar{x}$ & $\bar{x}$ & $x$ & $x$ \\
\hline 55 & $x$ & $\bar{x}$ & não sabe ler nem escrever & $x$ & $x$ \\
\hline 56 & $x$ & $\mathrm{x}$ & nåo obedece, chora & $x$ & $x$ \\
\hline 57 & range os dentes & $x$ & $x$ & bruxismo & $x$ \\
\hline 58 & enurese & $x$ & $\sqrt{x}$ & enurese & $x$ \\
\hline
\end{tabular}


CÁSOS COM QUEIXAS EJOU HIPÓTESES DIAGNÓSTICAS DE PSM (continua na próxima pägina)

\begin{tabular}{|c|c|c|c|c|c|}
\hline & Queixa espontânea & Queixa espontânea & Queixa induzida & Diagnóstico PSM & Diagnóstico PSM \\
\hline 59 & $X$ & $\mathrm{X}$ & ainda não lề & $\mathrm{X}$ & $\mathrm{X}$ \\
\hline 60 & enurese & $\mathrm{X}$ & $\mathrm{X}$ & Jenurese & $x$ \\
\hline 61 & năo fala direito & $\bar{x}$ & $\mathrm{x}$ & dificuldade na fala & $\bar{x}$ \\
\hline 62 & morte avô; nervoso & $\bar{x}$ & $\bar{x}$ & $\bar{x}$ & $x$ \\
\hline 63 & $x$ & $x$ & $x$ & fala palavras erradas & $x$ \\
\hline 64 & enurese & $\bar{x}$ & $x$ & enurese & $x$ \\
\hline 65 & enurese & $x$ & $x$ & enurese & $x$ \\
\hline 66 & enurese & $\mathrm{x}$ & $x$ & enurese & $x$ \\
\hline 67 & $X$ & $x$ & dislalia & dislalia & $\bar{x}$ \\
\hline 68 & não aprende & $\mathrm{X}$ & IX & dificuldade de aprendizagem & $\mathrm{X}$ \\
\hline 69 & enurese & problemas escolares & $x$ & enurese / terror noturno & dificuldade de aprendizagem \\
\hline 70 & $x$ & $x$ & bruxismo & $x$ & $x$ \\
\hline 71 & $X$ & $\mathrm{X}$ & medos & dificuldade de educar & $\mathrm{x}$ \\
\hline 72 & gagueira & bruxismo & $x$ & gagueira & bruxismo \\
\hline 73. & nåo presta atenção na aula & $X$ & $\mathrm{X}$ & distürbio de comportamento & $\mathrm{X}$ \\
\hline 74. & $x$ & $x$ & não sabe ler & Inão sabe ler & $\mathrm{x}$ \\
\hline 75 & dificuldade na escola & $x$ & $x$ & $x$ & $x$ \\
\hline 76 & disartria & $\mathrm{X}$ & $\mathrm{X}$ & disartria & \\
\hline 77 & $x$ & $\mathrm{X}$ & não sabe ler & não sabe ler & $\mathrm{X}$ \\
\hline 78 & hiperatividade & $x$ & escreve com dificuldade & distúrbio de conduta & \\
\hline 79 & range os dentes & $x$ & $\mathrm{x}$ & bruxismo & $x$ \\
\hline 80 & problema com alfabetização & $x$ & $x$ & mau rendimento escolar & $x$ \\
\hline 81 & & $\mathrm{IX}$ & aérea na escola; não vai bem & $\mathrm{X}$ & $\mathrm{X}$ \\
\hline 82 & enurese & $x$ & $x$ & enurese & \\
\hline 83 & mau rendimento escolar & $x$ & $x$ & distúrbio de atençẵo & X \\
\hline 84 & enurese & $\bar{X}$ & $\mathrm{X}$ & troca letras & $\mathrm{x}$ \\
\hline 85 & $x$ & $x$ & não sabe ler & dificuldade de aprendizagem & $x$ \\
\hline 86 & $x$ & $x$ & range cs dentes & $x$ & $x$ \\
\hline 87 & enurese & dificuldade para ler & $\mathrm{IX}$ & não sabe ler & enurese \\
\hline 88 & enurese & $\bar{x}$ & mau rendimento escolar & enurese & $\mathrm{X}$ \\
\hline
\end{tabular}


CASOS COM QUEIXAS EJOU HIPOTESES DIAGNOSTICAS DE PSM (continuaçäo da pógina anterior)

\begin{tabular}{|c|c|c|c|c|c|}
\hline & Queixa espontånea & Queixa espontânea & Queixa induzida & Diagnóstico PSM & Diagnostico PSM \\
\hline 89 & falta de atençåo & agitada & $x$ & distúrbio de atençăo & $x$ \\
\hline 90 & enurese & usa chupeta e mamadeira & $x$ & enurese & distúrbio de conduta \\
\hline 91 & & $x$ & pesadelos & $\bar{x}$ & $\bar{x}$ \\
\hline 92 & enurese & encoprese & $\bar{x}$ & enurese & encoprese \\
\hline 93 & enurese & $\bar{x}$ & $\bar{x}$ & enurese & $x$ \\
\hline 94 & bruxismo & $x$ & $x$ & $x$ & $x$ \\
\hline 95 & & $x$ & sono: gemidos; agitado & $x$ & $x$ \\
\hline 96 & alteração comportamento & $\mathrm{X}$ & sono agitado & distúrbio de comportamento & $\mathrm{x}$ \\
\hline 97 & enurese & $x$ & $x$ & enurese & $\bar{x}$ \\
\hline 98 & enurese & encoprese & $\mathrm{X}$ & $\mathrm{X}$ & $\mathrm{X}$ \\
\hline 99 & & $x$ & sono agitado & $x$ & $x$ \\
\hline
\end{tabular}


ANEXO 15

CASOS COM HIPÓTESES DIAGNÓSTICAS DE PSM E CONDUTA DO PEDIATRA 
CASOS COM HIPÓTESES DIAGNÓSTICAS DE PSM E CONDUTAS DOS PEDIATRAS (continua na página seguinte)

\begin{tabular}{|c|c|c|c|}
\hline & Diagnóstico PSM & Diagnóstico CID-10 & Conduta \\
\hline & dificuldade na escola & F81 & solicitada avaliaçăo escolar \\
\hline 2 & ceceio & F80 & encaminhamento para fonoaudiologia \\
\hline 3 & bruxismo & F45.8 & sem registro \\
\hline 4 & enurese; distúrbio de comportamento & F98.0; F98.9 & orientação + observaçăo \\
\hline 5 & atraso na escola & F81 & sem registro \\
\hline 6 & dificuldade de aprendizagem & F81 & encaminhamento para fonoaudiologia e oftalmologia \\
\hline 7 & bruxismo & F45.8 & orientação \\
\hline 8 & dificuldade de dicção & F80 & encaminhamento para fonoaudiologia \\
\hline 9 & fala infantilizada; déficit de aprendizagem & F80; F81 & orientaçāo + relatório escolar + avaliação de fonoaudiologia \\
\hline 10 & enurese & F98.0 & orientação \\
\hline 11 & distúrbio de conduta; escolaridade atrasada & F91.9; F81 & em acompanhamento com psicóloga \\
\hline 12 & distúrbio de conduta; escolaridade atrasada & F91.9;F81 & orientação \\
\hline 13 & encoprese & F98.1 & orientaçăo \\
\hline 14 & distúrbio escolar & F81 & exames de laboratório \\
\hline 15 & dislalia & F80 & sem registro \\
\hline 16 & atraso de linguagem & F80 & encaminhamento para fonoaudiologia \\
\hline 17 & dislalia & F80 & encaminhamento para fonoaudiologia \\
\hline 18 & distúrbio de aprendizagem & F81 & relatório escolar + timpanometria \\
\hline 19 & distúrbio de comportamento & F98.9 & encaminhamento para psicologia \\
\hline 20 & mau rendimento escolar & F81 & sem registro \\
\hline 21 & dislalia & F80 & encaminhamento para fonoaudiologia \\
\hline 22 & criança infantilizada & F89 & sem registro \\
\hline 23 & distứrbio de fala & F80 & sem registro \\
\hline 24 & distúrbio do sono & F51 & orientaçåo \\
\hline$\frac{27}{25}$ & dislalia & F80 & sem registro \\
\hline 26 & enurese & F98.0 & sem registro \\
\hline 27 & enurese & F98.0 & sem registro \\
\hline 28 & enurese & F98.0 & exames de laboratório + orientaçẵo \\
\hline 29 & dificuldade na escola & F81 & relatório escolar + observaçăo + encaminhamento para oftalmologia \\
\hline 30 & distúrbio neurovegetativo & F93.9 & orientação \\
\hline 31 & enurese & F98.0 & sem registro \\
\hline 32 & enurese & F98.0 & exames \\
\hline 33 & enurese & F98.0 & observaçăo \\
\hline 34 & dificuldade de alfabetizaçăo & F81 & orientaçắo \\
\hline 35 & déficit atençào & F90.9 & encaminhamenlo para psicologia infantil \\
\hline 36 & enurese & F98.0 & orientaçåo \\
\hline
\end{tabular}


CASOS COM HIPÓTESES DIAGNÓSTICAS DE PSM E CONDUTAS DOS PEDIATRAS (continuaçăo da płgina anterlor)

\begin{tabular}{|c|c|c|c|}
\hline & Dlagnóstico PSM & Dlagnóstico CID-10 & Conduta \\
\hline 37 & escolaridado atrasada & F81 & relatório escolar \\
\hline 38 & enurese; sindrome da criança dolorosa & F98.0; F45 & encaminhamento para psicologia infantil \\
\hline 39 & enurese & F98.0 & sem registro \\
\hline 40 & distúrbio de linguagem & F80 & encaminhamento para fonoaudiologia \\
\hline 41 & bruxismo & F45.8 & encaminhamento para odontologia \\
\hline 42 & enurese & F98.0 & sem registro \\
\hline 43 & enurese & F98.0 & sem registro \\
\hline 44 & dificuldade na fala & F80 & encaminhamento para fonoaudiologia \\
\hline 45 & fala palavras erradas & F80 & orientaçăo \\
\hline 46 & enurese & F98.0 & orientaçāo \\
\hline 47) & enurese & F98.0 & orientaçăo \\
\hline 48 & enurese & F98.0 & orientação \\
\hline 49 & dislalia & F80 & acompanhamento em fonoaudiologia \\
\hline 50 & dificuldade de aprendizagem & F81 & audiometria + acuidade visual \\
\hline 51 & enurese; terror noturno; dificuldade de aprendizagem & F98.0;F51; F81 & encaminhamento para psicologia infantil \\
\hline 52 & dificuldade de educar & F98.9 & orientaçáo \\
\hline 53 & gagueira; bruxismo & F98.5; F45.8 & sem registro \\
\hline 54 & distúrbio de comportamento & F98.9 & sem registro \\
\hline 55 & não sabe ler & F81 & sem registro \\
\hline 56 & disartria & F80 & acompanhamento em fonoaudiologia \\
\hline 57 & năo sabe ler & F81 & sem registro \\
\hline 58 & distúrbio de conduta & F91.9 & sem registro \\
\hline 59 & bruxismo & F45.8 & sem registro \\
\hline 60 & mau rendimento escolar & F81 & sem registro \\
\hline 61 & enurese & F98.0 & visita domiciliar \\
\hline 62 & distúrbio de atençåa & F90.9 & relatório da escola \\
\hline 63 & troca letras & F80 & observação \\
\hline 64 & dificuldade de aprendizagem & F81 & relatório da escola + encaminhamento para oftalmologia \\
\hline 65 & năo sabe ler; enurese & F81; F98.0 & relatório da escola \\
\hline 66 & enurese & F98.0 & orientaçăo \\
\hline 67 & distúrbio de atençăo & F90.9 & encaminhamento para oftalmologia \\
\hline 68 & enurese; distúrbio de conduta & F98.0; F91.9 & encaminhamento para psicologia infantil \\
\hline 69 & enurese; encoprese & F98.0; F98.1 & observaçăo \\
\hline 70 & enurese & F98.0 & sem registro \\
\hline 71 & distúrbio de comportamento & F98.8 & encaminhamento para psicologia infantil \\
\hline 72 & enurese & F88.0 & sem registro \\
\hline
\end{tabular}




\section{ANEXO 16}

CASOS COM SDQ ANORMALE IMPACTO ANORMAL 
CASOS COM IMPACTO E SDQ ANORMAIS

\begin{tabular}{|c|c|c|}
\hline & Queixa PSM & Diagnóstico PSM \\
\hline 1] & é desligada na escola & $\mathrm{x}$ \\
\hline 2 & $x$ & $x$ \\
\hline 3$)$ & $x$ & $x$ \\
\hline 4 & enurese & enurese; distúrbio de comportamento \\
\hline 5 & $\mathrm{X}$ & $x$ \\
\hline 6) & $x$ & $x$ \\
\hline 7 & dificuldade de aprendizagem & atraso da fala; déficit de aprendizagem \\
\hline 8 & fala errado; troca letra & dislalia \\
\hline 9 & $x$ & $x$ \\
\hline 10 & $x$ & $\mathrm{x}$ \\
\hline 11) & $x$ & $x$ \\
\hline 12 & $x$ & $x$ \\
\hline 13 & $x$ & $x$ \\
\hline 14 & dificuldade de aprendizagem, agitado, apanha & dificuldade na escola \\
\hline $15 \mid$ & não presta atenção na aula; enurese & enurese \\
\hline 16 & medos; agressivo & déficit de atenção \\
\hline 17 & queda desempenho na escola; nāo dorme & $x$ \\
\hline 18 & $x$ & $x$ \\
\hline 19 & mau rendimento escolar & escolaridade atrasada \\
\hline $20 \mid 1$ & não sabe ler nem escrever & $x$ \\
\hline 21 & ainda nåo lê & $x$ \\
\hline 22 & $\mathrm{X}$ & $x$ \\
\hline 23 & morte do avô, nervoso & $x$ \\
\hline 24 & enurese; problemas escolares & enurese; terror noturno; dificuldade de aprendizagem \\
\hline 25 & $x$ & $x$ \\
\hline 26 & não sabo ler & não sabe ler \\
\hline 27 & $x$ & $x$ \\
\hline 28 & dificuldade na escola & $x$ \\
\hline 29 & não sabo ler & atrasado; não sabe ler \\
\hline 30 & $\mathrm{X}$ & $x$ \\
\hline 31 & $x$ & $x$ \\
\hline 32 & problema de alfabetização & mau rendimento escolar \\
\hline 33 & aérea na escola; nāo vai bem & $x$ \\
\hline 34 & enurese & enurese \\
\hline 35 & não sabe ler & dificuldade de aprendizagem \\
\hline 36 & range os dentes & $x$ \\
\hline 37 & & $x$ \\
\hline 38 & & $x$ \\
\hline 39 & falte de atenção; agitada & distúrbio de atenção \\
\hline 40 & $\mathrm{X}$ & $\mathrm{x}$ \\
\hline 41] & & $x$ \\
\hline
\end{tabular}


ANEXO 17

ESCORES DO CBCL 
Isolamento - total em categorias

\begin{tabular}{|c|c|c|c|c|c|}
\hline & & Frequency & Percent & $\begin{array}{l}\text { Valid } \\
\text { Percent }\end{array}$ & $\begin{array}{l}\text { Cumulativ } \\
\text { e Percent }\end{array}$ \\
\hline \multirow[t]{4}{*}{ Valid } & Normal & 137 & 66,5 & 66,5 & 66,5 \\
\hline & Bordertine & 25 & 12,1 & 12,1 & 78,6 \\
\hline & Clinico & 44 & 21,4 & 21,4 & 100,0 \\
\hline & Total & 206 & 100.0 & 100,0 & \\
\hline
\end{tabular}

Queixas somáticas - total em categorias

\begin{tabular}{|c|c|c|c|c|c|}
\hline & & Frequency & Percent & $\begin{array}{l}\text { Valid } \\
\text { Percent }\end{array}$ & $\begin{array}{l}\text { Cumulativ } \\
\text { e Percent }\end{array}$ \\
\hline \multirow[t]{4}{*}{ Valid } & Normal & 180 & 87,4 & 87,4 & 87,4 \\
\hline & Borderline & 13 & 6,3 & 6,3 & 93,7 \\
\hline & Clínico & 13 & 6,3 & 6,3 & 100,0 \\
\hline & Total & 206 & 100,0 & 100,0 & \\
\hline
\end{tabular}

Ansiedade/depressăo - total em categorias

\begin{tabular}{|c|c|c|c|c|c|}
\hline & & Frequency & Percent & $\begin{array}{l}\text { Valid } \\
\text { Percent }\end{array}$ & $\begin{array}{l}\text { Cumulativ } \\
\text { e Percent }\end{array}$ \\
\hline \multirow[t]{4}{*}{ Valid } & Normal & 132 & 64,1 & 64,1 & 64,1 \\
\hline & Bordertine & 25 & 12,1 & 12,1 & 76,2 \\
\hline & Clínico & 49 & 23,8 & 23,8 & 100,0 \\
\hline & Total & 206 & 100,0 & 100,0 & \\
\hline
\end{tabular}

Problemas sociais - total em categorias

\begin{tabular}{|c|c|c|c|c|c|}
\hline & & Frequency & Percent & $\begin{array}{l}\text { Valid } \\
\text { Percent }\end{array}$ & $\begin{array}{l}\text { Cumulativ } \\
\text { e Percent }\end{array}$ \\
\hline \multirow[t]{4}{*}{ Valid } & Normal & 135 & 65,5 & 65,5 & 65,5 \\
\hline & Borderline & 27 & 13,1 & 13,1 & 78,6 \\
\hline & Clínico & 44 & 21,4 & 21,4 & 100,0 \\
\hline & Total & 206 & 100,0 & 100,0 & \\
\hline
\end{tabular}

Problemas de pensamento - total em categorias

\begin{tabular}{|c|c|c|c|c|c|}
\hline & & Frequency & Percent & $\begin{array}{c}\text { Valid } \\
\text { Percent }\end{array}$ & $\begin{array}{l}\text { Cumulativ } \\
\text { e Percent }\end{array}$ \\
\hline \multirow[t]{4}{*}{ Valid } & Normal & 144 & 69,9 & 69,9 & 69,9 \\
\hline & Borderline & 35 & 17,0 & 17,0 & 86,9 \\
\hline & Clinico & 27 & 13,1 & 13,1 & 100,0 \\
\hline & Total & 206 & 100,0 & 100,0 & \\
\hline
\end{tabular}

Problemas de atenção - total em categorias

\begin{tabular}{|c|c|c|c|c|c|}
\hline & & Frequency & Percent & $\begin{array}{l}\text { Valid } \\
\text { Percent }\end{array}$ & $\begin{array}{l}\text { Cumulativ } \\
\text { e Percent }\end{array}$ \\
\hline \multirow[t]{4}{*}{ Valid } & Normal & 108 & 52,4 & 52,4 & 52,4 \\
\hline & Bordertine & 26 & 12,6 & 12,6 & 65,0 \\
\hline & Clinico & 72 & 35,0 & 35,0 & 100,0 \\
\hline & Total & 206 & 100,0 & 100.0 & \\
\hline
\end{tabular}


Delinquência - total em categorias

\begin{tabular}{|c|c|c|c|c|c|}
\hline & & Frequency & Percent & $\begin{array}{l}\text { Valid } \\
\text { Percent }\end{array}$ & $\begin{array}{l}\text { Cumulativ } \\
\text { e Percent }\end{array}$ \\
\hline \multirow[t]{4}{*}{ Valid } & Normal & 131 & 63,6 & 63,6 & $\overline{63,6}$ \\
\hline & Borderline & 43 & 20,9 & 20,9 & 84,5 \\
\hline & Clinico & 32 & 15,5 & 15,5 & 100,0 \\
\hline & Total & 206 & 100,0 & 100,0 & \\
\hline
\end{tabular}

Agressividade - total em categorias

\begin{tabular}{|c|c|c|c|c|c|}
\hline & & Frequency & Percent & $\begin{array}{c}\text { Valid } \\
\text { Percent }\end{array}$ & $\begin{array}{l}\text { Cumulativ } \\
\text { e Percent }\end{array}$ \\
\hline \multirow[t]{4}{*}{ Valid } & Normal & 119 & 57,8 & 57,8 & 57,8 \\
\hline & Borderline & 33 & 16,0 & 16,0 & 73,8 \\
\hline & Clinico & 54 & 26,2 & 26,2 & 100,0 \\
\hline & Total & 206 & 100,0 & 100,0 & \\
\hline
\end{tabular}

Problemas internos - total em categorias

\begin{tabular}{|ll|r|r|r|r|}
\hline & & Frequency & Percent & $\begin{array}{c}\text { Valid } \\
\text { Percent }\end{array}$ & $\begin{array}{c}\text { Cumulativ } \\
\text { e Percent }\end{array}$ \\
\hline Valid & Normal & 75 & 36,4 & 36,4 & 36,4 \\
& Borderline & 30 & 14,6 & 14,6 & 51,0 \\
& Clínico & 101 & 49,0 & 49,0 & 100,0 \\
& Total & 206 & 100,0 & 100,0 & \\
\hline
\end{tabular}

Problemas extemos - total em categorias

\begin{tabular}{|c|c|c|c|c|c|}
\hline & & Frequency & Percent & $\begin{array}{l}\text { Valid } \\
\text { Percent }\end{array}$ & $\begin{array}{l}\text { Cumulativ } \\
\text { e Percent }\end{array}$ \\
\hline \multirow[t]{4}{*}{ Valid } & Normal & 82 & 39,8 & 39,8 & 39,8 \\
\hline & Borderline & 21 & $-10,2$ & 10,2 & 50,0 \\
\hline & Clínico & 103 & 50,0 & 50,0 & 100,0 \\
\hline & Total & 206 & 100,0 & 100,0 & \\
\hline
\end{tabular}

Total do CBCL em categorias

\begin{tabular}{|c|c|c|c|c|c|}
\hline & & Frequency & Percent & $\begin{array}{c}\text { Valid } \\
\text { Percent }\end{array}$ & $\begin{array}{l}\text { Cumulativ } \\
\text { e Percent }\end{array}$ \\
\hline \multirow[t]{4}{*}{ Valid } & Normal & 57 & 27,7 & 27,7 & 27,7 \\
\hline & Borderline & 19 & 9,2 & 9,2 & 36,9 \\
\hline & Clínico & 130 & 63,1 & 63,1 & 100,0 \\
\hline & Total & 206 & 100,0 & 100,0 & \\
\hline
\end{tabular}




\section{ANEXO 18}

MAPAS DAS ENTREVISTAS COM OS PEDIATRAS 


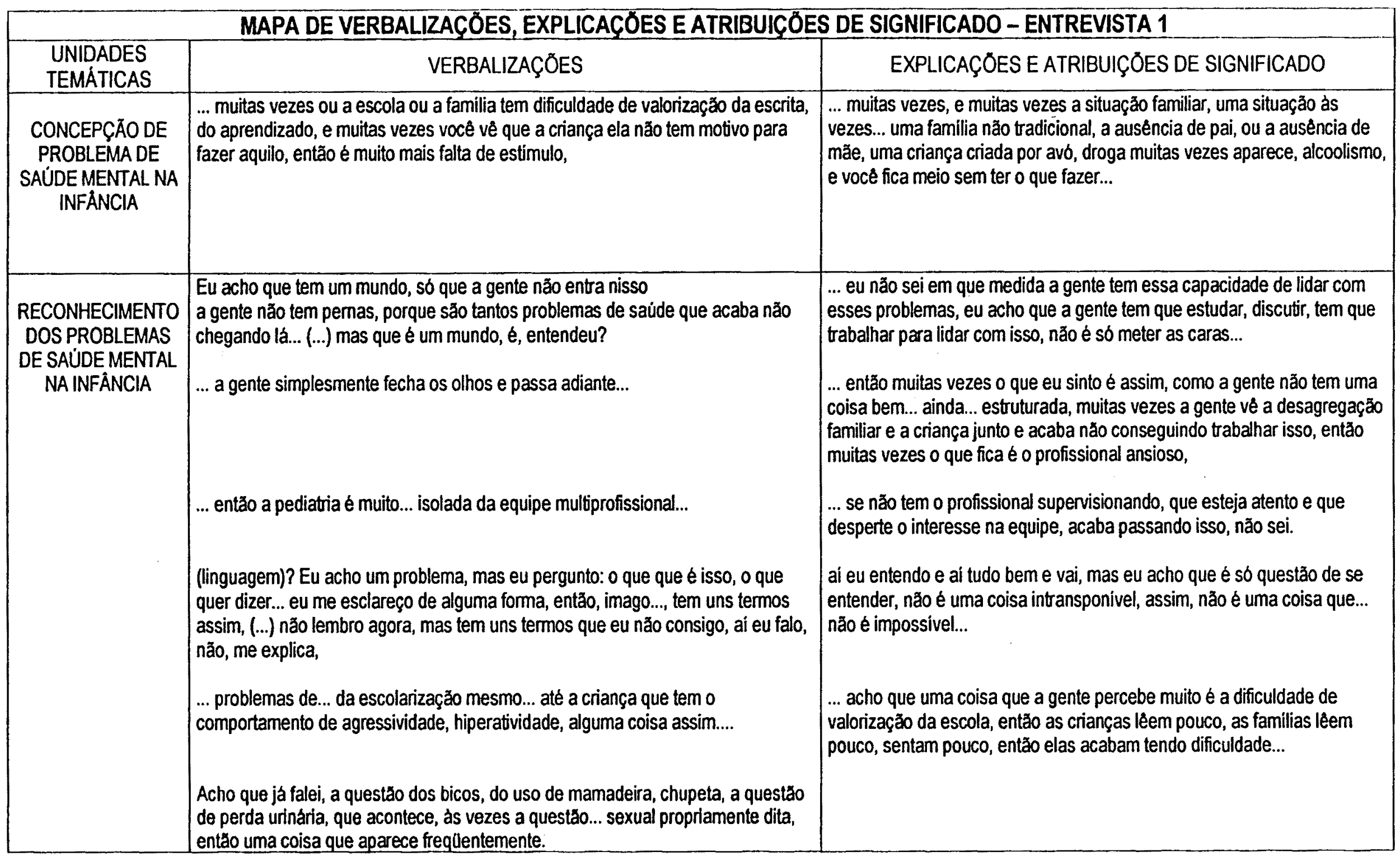




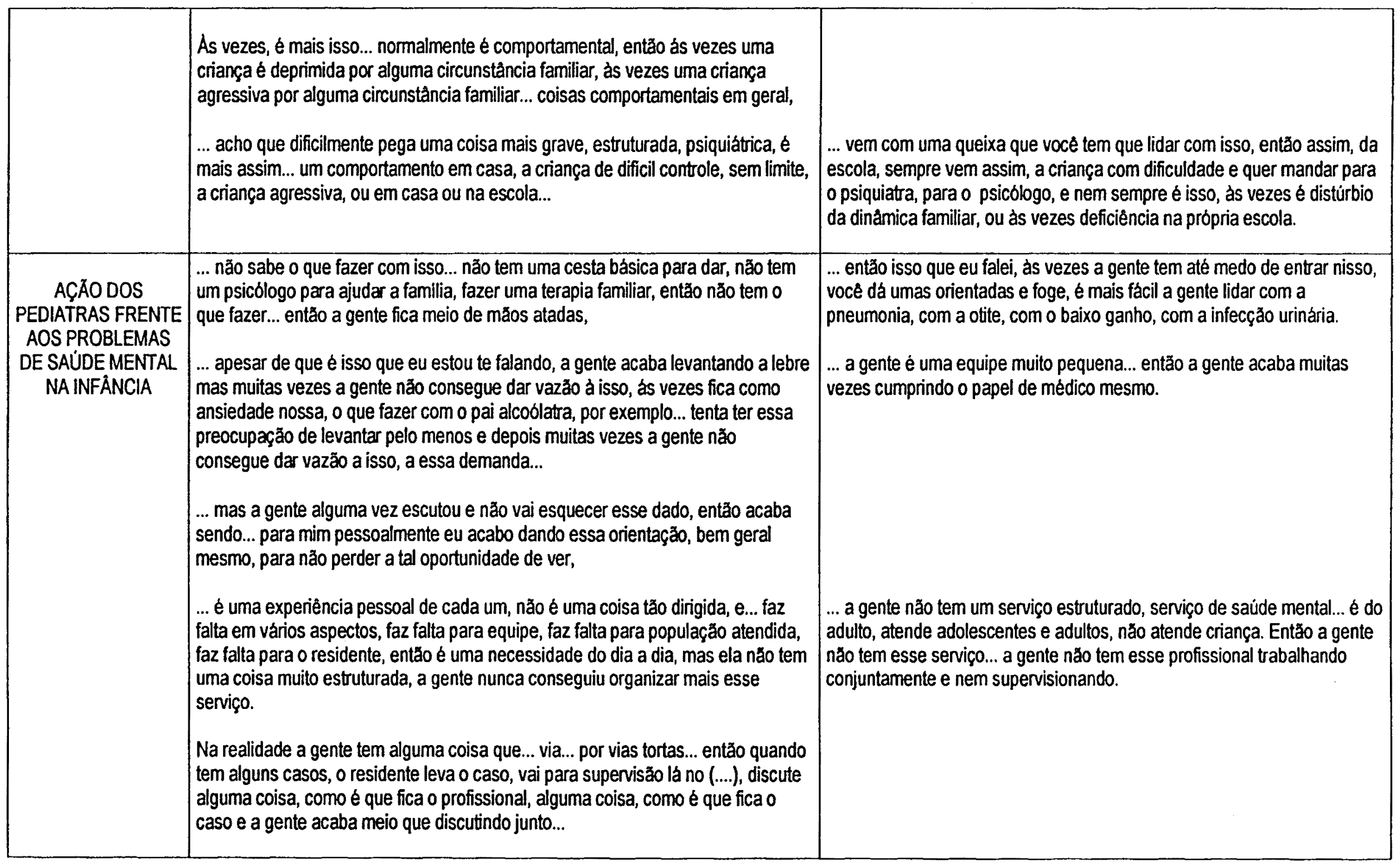




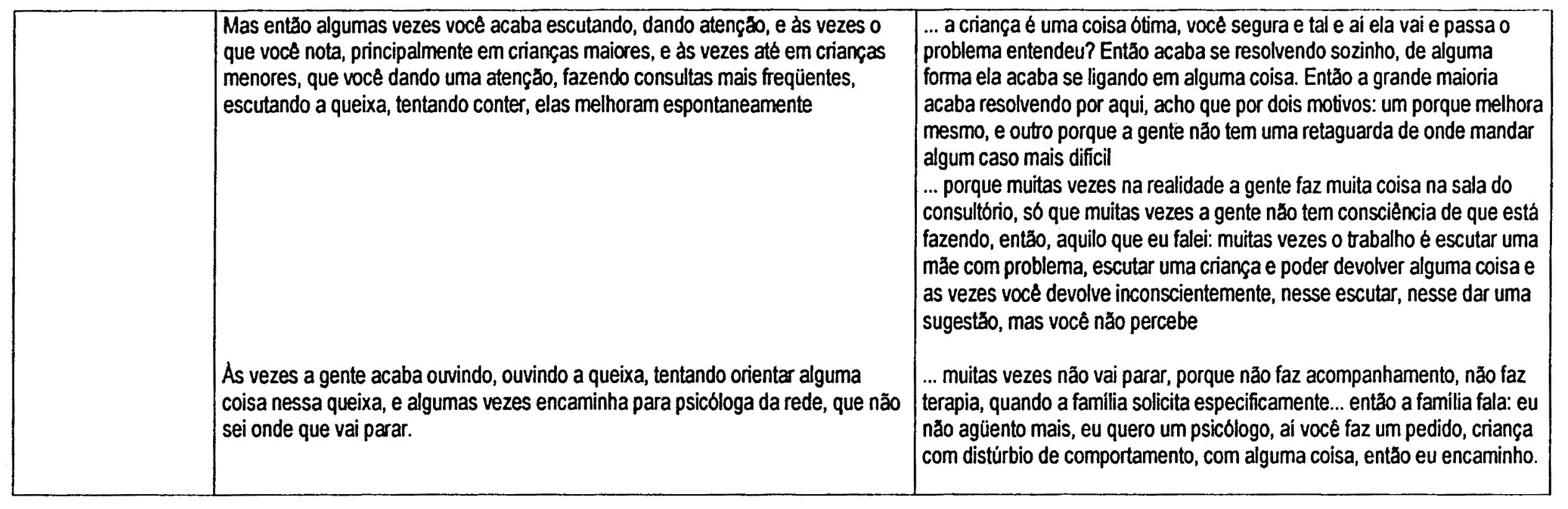




\begin{tabular}{|c|c|c|}
\hline \multicolumn{3}{|c|}{ MAPA DE VERBALIZAÇŎES, EXPLICAÇŐES E ATRIBUIÇŐES DE SIGNIFICADO - ENTREVISTA 2} \\
\hline $\begin{array}{l}\text { UNIDADES } \\
\text { TEMÁTICAS }\end{array}$ & VERBALIZAÇÕES & EXPLICAÇŐES E ATRIBUIÇÕES DE SIGNIFICADO \\
\hline $\begin{array}{l}\text { CONCEPÇÃO DE } \\
\text { PROBLEMA DE } \\
\text { SAÚDE MENTAL NA } \\
\text { INFANCIA }\end{array}$ & $\begin{array}{l}\text {... essa escola aqui sempre tentou fazer assistência integrada, biopsicossocial. } \\
\text { Entåo nós temos o aspecto psicologico, a Dra Dulce foi a pioneira aqui e tal, } \\
\text { até hoje o pessoal lá...psicoprofilaxia é uma coisa que é considerada... as } \\
\text { coisas que a gente tem feito, essa palavra psicoprofilaxia continua forte, então } \\
\text { entender a criança no seu ambiente é uma coisa que aqui é considerada... } \\
\\
\text {... então é um espirito comum aqui, então vamos dizer assim, as coisas } \\
\text { preventivas, o entendimento da criança no seu ambiente, o respeito que se } \\
\text { deve à criança, o espaço da criança, é uma coisa aqui é... habitualmente é } \\
\text { considerada, faz parte do nosso objetivo geral, no sentido do entendimento da } \\
\text { realidade da criança. }\end{array}$ & \\
\hline $\begin{array}{c}\text { RECONHECIMENTO } \\
\text { DOS PROBLEMAS } \\
\text { DE SAUUDE MENTAL } \\
\text { NA INFÄNCIA }\end{array}$ & 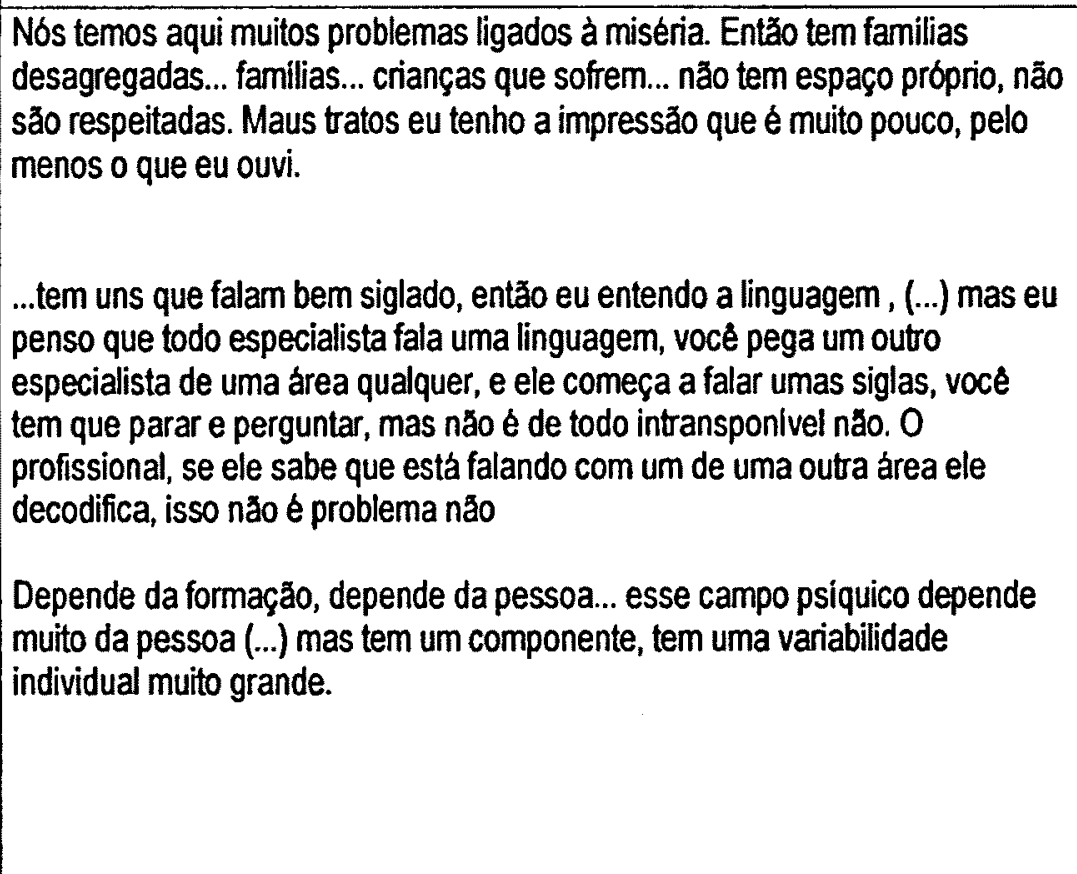 & $\begin{array}{l}\text { Mas numa realidade de sofrimento, a criança, ela... freqüentemente ela não é } \\
\text { bem atendida, no espaço que a criança tem em casa... o apoio que tem em } \\
\text { casa para estudar... para desenvolver as suas atividades... eu tenho a } \\
\text { impressão que muito daqui decorre de carência, essa carência social desta } \\
\text { população. } \\
\text {... acho que isso ai pode parecer um empecilho, mas eu acho que não é um } \\
\text { empecilho real não, se as pessoas querem conversar não vai ser isso que vai } \\
\text { impedir nåo... } \\
\text { Não såo todas, mas existem pessoas que tem mais facilidade, outras que não, } \\
\text { tem gente que não suporta, isso... é verdade... já vi, tem colegas (....) que não } \\
\text { suportam, nada, da mental só querem tudo preto no branco... não querem } \\
\text { saber, só querem saber de coisa fisica mesmo, só curativa... e até } \\
\text { profissionais consideráveis. Existem... a interpretação disso é muito diferente } \\
\text { conforme a escola, conforme a pessoa, conforme o lugar, eu acho com } \\
\text { certeza isso deve estar trazendo realidades muito diferentes... }\end{array}$ \\
\hline
\end{tabular}




\begin{tabular}{|c|c|c|}
\hline $\begin{array}{c}\text { AÇÃO DOS } \\
\text { PEDIATRAS FRENTE } \\
\text { AOS PROBLEMAS } \\
\text { DE SAÚDE MENTAL }\end{array}$ & 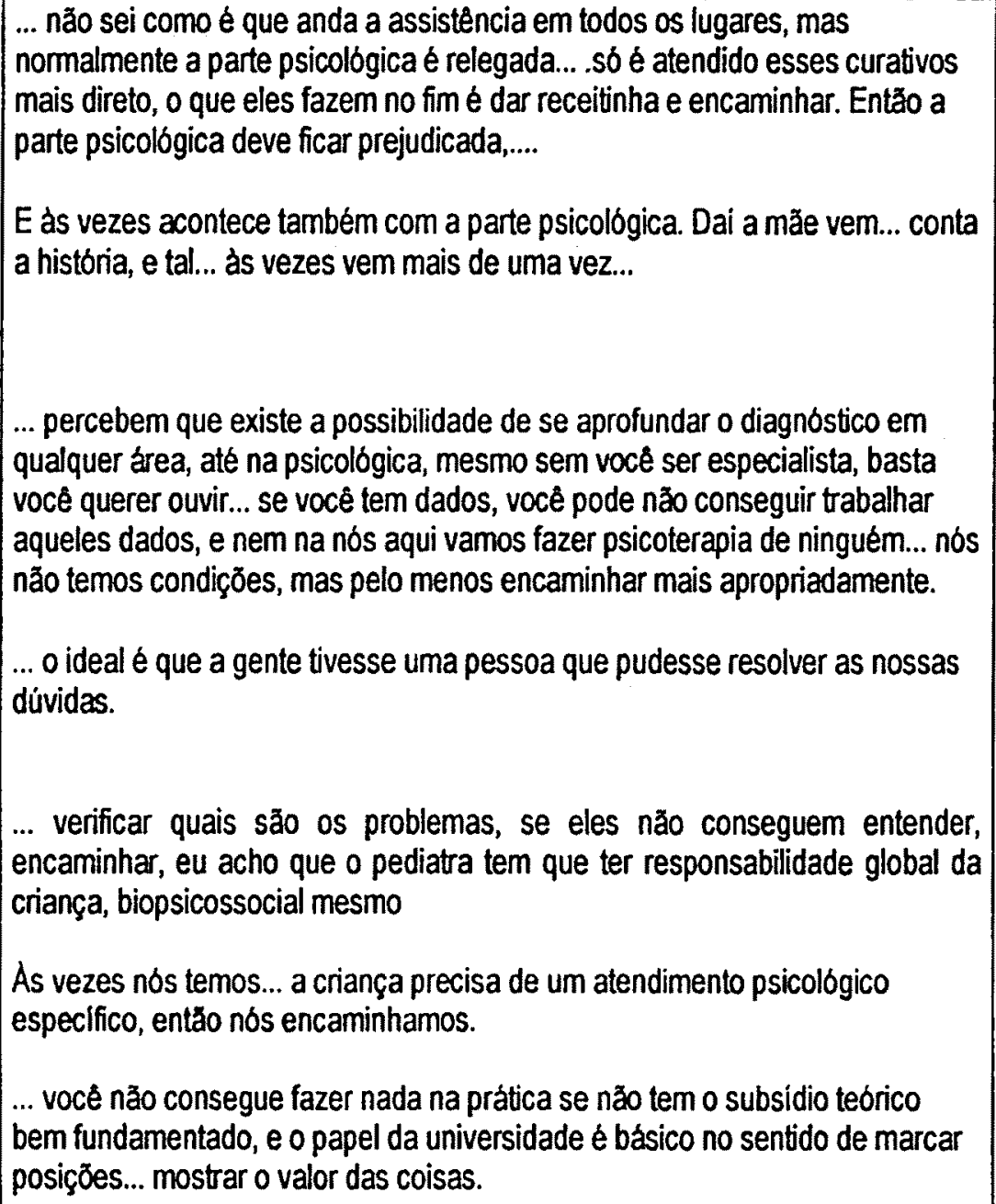 & $\begin{array}{l}\text { Assuntos psicológicos são assim, quando começa a sair, dai sai... é um mar, } \\
\text { está certo? e dai, se o rendimento do colega aqui percebe que aquilo era } \\
\text { muito para ele, mas pelo menos houve entendimento do problema e dai se } \\
\text { encaminha de um modo mais apropriado. } \\
\text {.. o ideal é que tivesse psicólogo em toda a parte, quer dizer, dai, com certeza } \\
\text { ia haver um espaço, o entendimento seria possivel, porque hoje não se pode, } \\
\text { se não tem interlocutor... não pode começar nem o diálogo, } \\
\text {... eu acho isso mesmo, você tem que entender... encaminhar, que o que seria } \\
\text { possivel resolver que o resolva. }\end{array}$ \\
\hline
\end{tabular}




\begin{tabular}{|c|c|c|}
\hline \multicolumn{3}{|c|}{ MAPA DE VERBALIZAÇÕES, EXPLICACŌES E ATRIBUICOOEES DE SIGNIFICADO - ENTREVISTA 3} \\
\hline $\begin{array}{l}\text { UNIDADES } \\
\text { TEMÁTICAS }\end{array}$ & VERBALIZAÇŐES & EXPLICAÇŌES E ATRIBUIÇŌES DE SIGNIFICADO \\
\hline $\begin{array}{l}\text { CONCEPÇÃO DE } \\
\text { PROBLEMA DE } \\
\text { SAÚDE MENTAL NA } \\
\text { INFÁNCIA }\end{array}$ & $\begin{array}{l}\text {... porque são problemas de saúde importantes... porque às vezes na } \\
\text { pediatria, por exemplo, começam como coisas muito ... aparentemente banais } \\
\text { e comuns, como uma criança que você não consegue segurar dentro do } \\
\text { consultório, depois quando cresce... } \\
\\
\text {... criança com dificuldade de aprendizagem, e que não necessariamente é } \\
\text { uma dificuldade porque ela é incapaz. de aprender... } \\
\text {... mas muitas vezes porque foi já algum problema que já veio anterior que a } \\
\text { gente não conseguiu perceber o que que era, de autoestima da própria } \\
\text { criança, }\end{array}$ & $\begin{array}{l}\text {... mas é porque,... ai já entram também questōes sociais, escola que é uma } \\
\text { porcaria, professor coitado que está desmotivado, não consegue... } \\
\text {... que acaba se refletindo nessa coisa, não aprende ou não consegue aderir, } \\
\text { não fica na escola, não vai para a escola, tem distúrbios de comportamento às } \\
\text { vezes sérios, às vezes rebeldes e que começam a ter envolvimento com } \\
\text { drogas, envolvimento com as gangues... }\end{array}$ \\
\hline $\begin{array}{c}\text { RECONHECIMENTO } \\
\text { DOS PROBLEMAS } \\
\text { DE SAUUDE MENTAL } \\
\text { NA INFANCIA }\end{array}$ & $\begin{array}{l}\text {... eu acho que é dificil dizer se é muito, se é pouco, porque a gente nunca fez } \\
\text { nenhuma quantificaçăo... } \\
\text { Eu acho que tem bastante, ... eu acho que,... mas é, é como eu te falei, é } \\
\text { difícil dizer porque eu posso achar isso subjetivamente... } \\
\text {... talvez sejam sub-diagnosticados ou quando são diagnosticados a gente } \\
\text { acaba não sabendo muito o que fazer. É que às vezes a gente até não sabe } \\
\text { nem dizer o nome da patologia direito... } \\
\text {... acho que é mais ou menos por ai, dar o mesmo peso também para esses } \\
\text { aspectos, geralmente o problema é que às vezes não é dado o mesmo peso } \\
\text { porque também a gente não sabe diagnosticar mesmo, não sabe identificar o } \\
\text { que que está ocorrendo ... } \\
\text { Mas o que a gente vé geralmente é assim aquilo é um pouco menosprezado, }\end{array}$ &  \\
\hline
\end{tabular}




\begin{tabular}{|c|c|c|}
\hline & $\begin{array}{l}\text { na própria discussão dos casos, nas reuniōes clinicas, é colocado geralmente } \\
\text { em segundo mesmo, nåo é a coisa que faz todo mundo ferver na coisa dos } \\
\text { diagnóstico. } \\
\text {.. eu acho que é o tipo de população também que a gente atende população } \\
\text { muito carente, uma situação socioeconómica e cultural muito desprivilegiada, } \\
\text {... tem muitos problemas de maus tratos, de negligência, que ficam muitas } \\
\text { vezes, até a gente às vezes não se dá conta que ela pode ser que fosse um } \\
\text { problema de negligência, que fosse um problema até de maus tratos, que } \\
\text { passam como se fosse assim algum problema normal, } \\
\text {... tem distürbios de comportamento às vezes sérios, às vezes rebeldes e que } \\
\text { começam a ter envolvimento com drogas, envolvimento com as gangues... }\end{array}$ & $\begin{array}{l}\text {... vamos dizer assim, de criança que apanhou do pai..., mas você vai ver por } \\
\text { trás tem toda uma situação de dinåmica familiar, que se um começa a puxar } \\
\text { (...), você começa a puxar e começa a levantar um monte de outras coisas... } \\
\text {... o que me vem à mente assim agora acho que mais è essa coisa mesmo do } \\
\text { vinculo afetivo da mãe com a criança } \\
\text {.. que parece normal na criança nessa idade mas que, por causa das } \\
\text { circunstancias onde eles estão, acabam se refletindo em situaç̋̋es de risco, } \\
\text { muito maiores do que se fosse uma criança que talvez tivesse uma condição } \\
\text { de vida melhor. }\end{array}$ \\
\hline
\end{tabular}




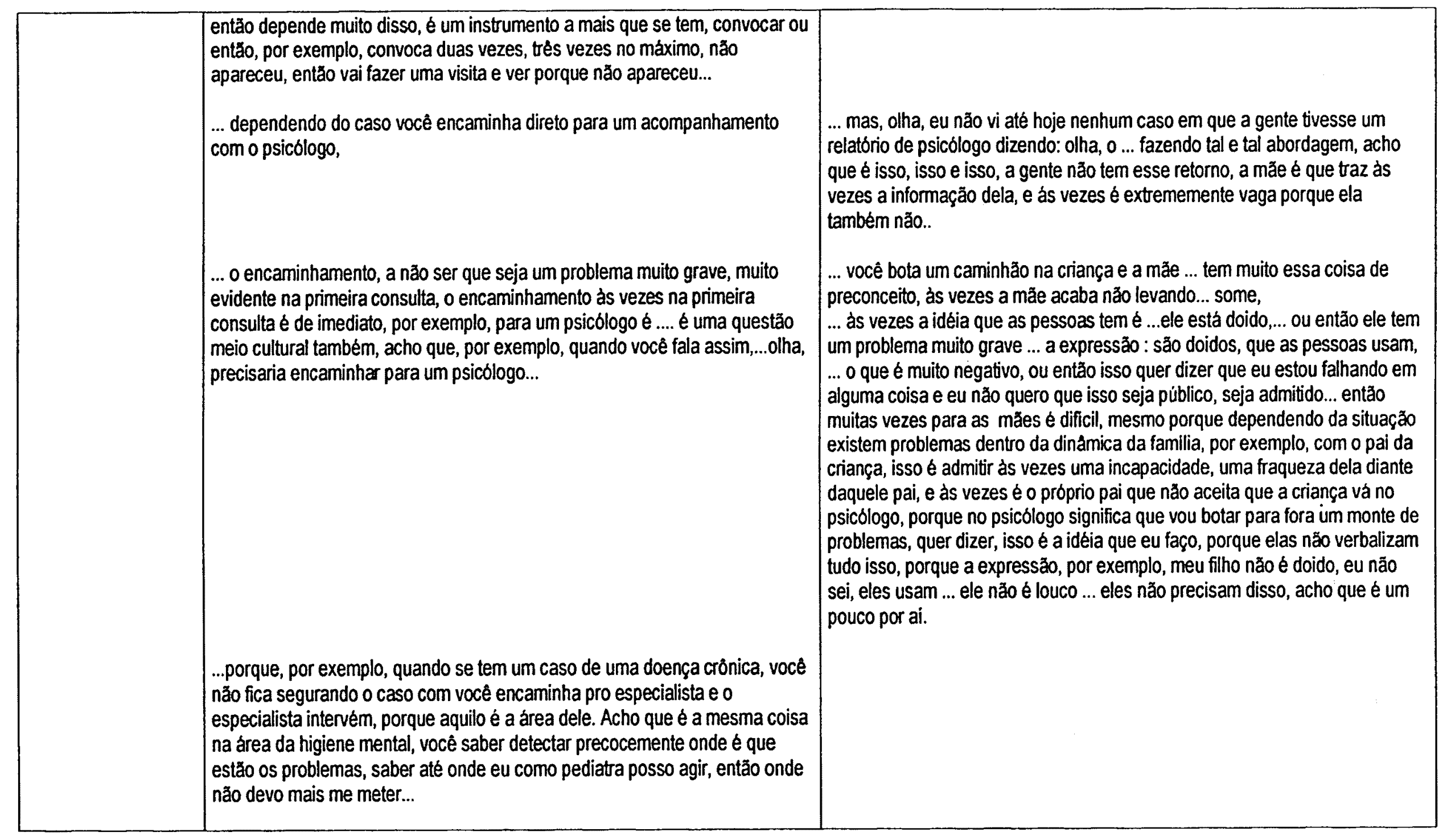




\begin{tabular}{|c|c|c|}
\hline \multicolumn{3}{|c|}{ MAPA DE VERBALIZAÇÕES, EXPLICAÇÕES E ATRIBUICOÓES DE SIGNIFICADO - ENTREVISTA 4} \\
\hline $\begin{array}{l}\text { UNIDADES } \\
\text { TEMÁTICAS }\end{array}$ & VERBALIZAÇÕES & EXPLICAÇŐES E ATRIBUIÇŌES DE SIGNIFICADO \\
\hline $\begin{array}{l}\text { CONCEPÇÄO DE } \\
\text { PROBLEMADE } \\
\text { SAÚDEMENTAL NA } \\
\text { INFANCIA }\end{array}$ & $\begin{array}{l}\text { É um problema multifatorial, principalmente quando a gente lida com criança, } \\
\text { a criança em geral ela é um reflexo daquilo que acontece na sua familia, na } \\
\text { sua casa, na comunidade. Então muitas vezes são questōes dificeis de serem } \\
\text { abordadas... }\end{array}$ & $\begin{array}{l}\text { A demanda da população é trazer a criança como sendo um problema, } \\
\text { sempre em busca de um remédio ou uma solução rápida para problemas que } \\
\text { em geral não estão na própria criança mas são fruto de um relacionamento ou } \\
\text { de uma falta de relacionamento, a uma abordagem bastante complexa, } \\
\text { porque é muito mais dificil você estar mexendo em comportamentos, em } \\
\text { coisas que envolvem outras pessoas que não a criança, e que com certeza } \\
\text { não vão se resolver com remédinhos, ... é o que todo mundo procura, a } \\
\text { solução mágica, fácil e rápida. }\end{array}$ \\
\hline $\begin{array}{l}\text { RECONHECIMENTO } \\
\text { DOS PROBLEMAS } \\
\text { DE SAÜDE MENTAL } \\
\text { NA INFÁNCIA }\end{array}$ & $\begin{array}{l}\text {... creio que a maior parte dos pediatras não lida, a maior parte eu acho que } \\
\text { acaba ignorando... } \\
\\
\text {.. existe eu acho que falha na formação, e ai naturalmente não estou me } \\
\text { referindo à nossa escola que eu acho que ela acaba sendo assim um top de } \\
\text { linha, tem várias também, mas em comparaçăo com outras escolas que } \\
\text { existem por al... }\end{array}$ & 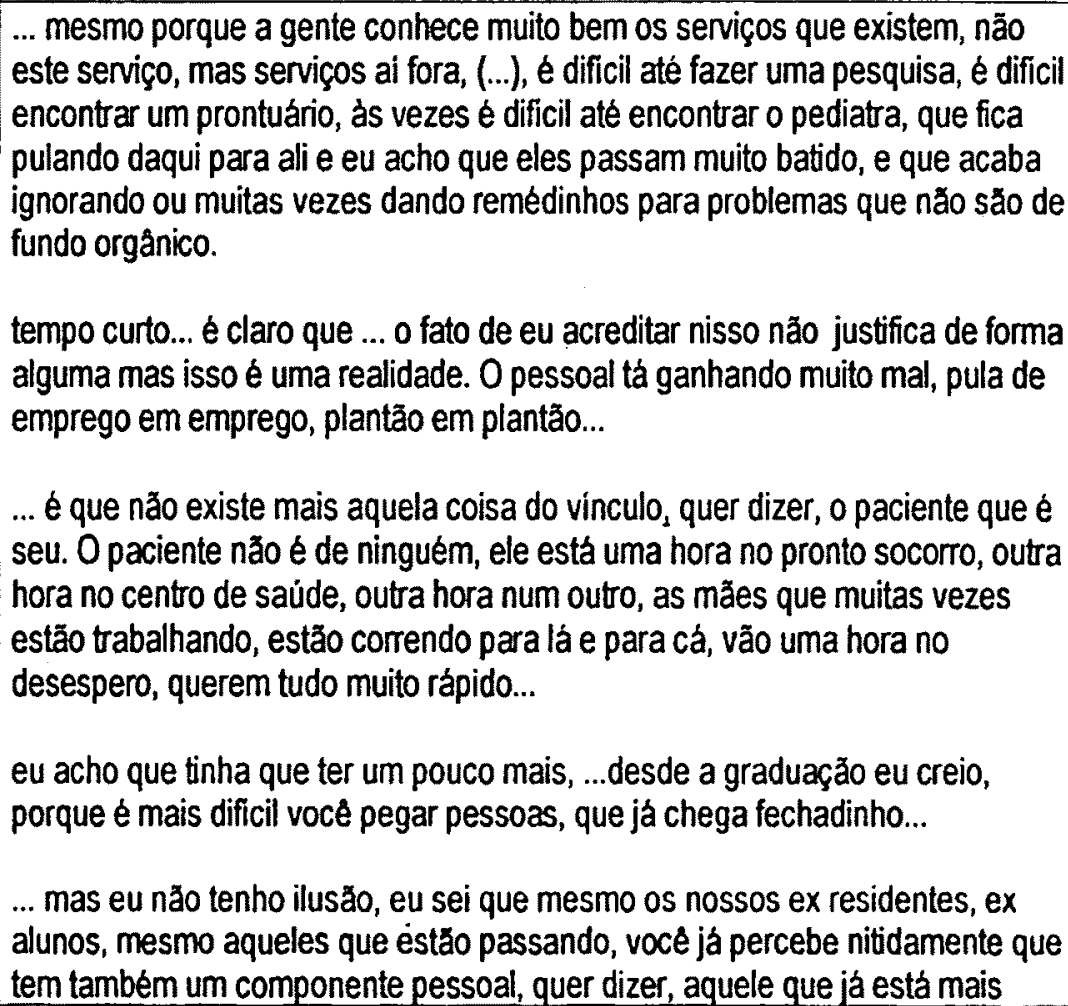 \\
\hline
\end{tabular}


Agora, a soluçăo é que não é fácil, se não, de repente vocẻ rotula alguém, ... é o pediatra detecta, o pediatra năo sabe detectar, eu acho que muitos sabem detectar, mas a abordagem é tremendamente dificultada por essa série de variáveis que a gente tem.

(linguagem?) Não sei the dizer se atrapalha ou não, eu acho que assim... seria desnecessário... pediatra na maior parte dos casos ter uma... um

entendimento tão... da coisa que se... se tivesse apenas um bom fundamento ele resolveria $99 \%$ dos casos.

Então os problemas variam muito, depende da faixa etária e depende daquilo que vocé está buscando.

Săo vários (problemas de saúde menta), então depende muito da faixa etária, ....no bebê? 0 distúrbio alimentar, ...

Sai um pouquinho da cólica, do distúrbio alimentar no bebê, você pode começar a ter o distúrbio do sono, o pré escolar, dor recorrente, seja qual for, então muita dor abdominal, dor na perninha.

No maiorzinho você sabe que tem a asma ... brônquica, que se agrava não é o fator certamente, mas pode estar se agravando com problemas ... de stress mesmo, sabe, tem criança que chia, ... está stressado, está chiando,

... dificuldade escolar, você vai ver, a criança está com dificuldade escolar. aberto, que levou a sementinha, ela vai crescer, e tem aquele que já vem de base meio fechado e o terreno năo é fértil, vocé joga a sementinha não vai fertilizar de forma algum....

... não dá para abordar de forma simplista esta questão, de forma alguma vocé tem que ter uma análise muito criteriosa, se não fica assim: ah, é o pediatra que não sabe nada. Cuidado, minha recomendação é que vocé tenha muito cuidado.

então são coisas que eu creio que passam muito batido porque, o pessoal, chegou chiando, ... prescreve, ai vai para outro, ninguém vé esta criança como um todo, às vezes o pessoal nåo tem esse tipo de coisa, ...

O problema não é ela, o problema é que o pai é alcoólatra, a mãe é analfabeta, apanha em casa, ou não tem vida nenhuma social .... E ai na escola lógico que não vai estar rendendo. 


\begin{tabular}{|c|c|c|}
\hline $\begin{array}{c}\text { AÇÃO DOS } \\
\text { PEDIATRAS FRENTE } \\
\text { AOS PROBLEMAS } \\
\text { DE SAUUDE MENTAL } \\
\text { NA INFÂNCIA }\end{array}$ & $\begin{array}{l}\text { O pessoal quer ser rápido e fala sem escutar nada. Acho que o que falta,... } \\
\text { falta muita escuta mesmo } \\
\text {... solução do problema não muda muito mesmo, porque quando eu digo aos } \\
\text { meus residentes, eu digo: olha, esse daqui vai ter que ir para higiene mental... }\end{array}$ & $\begin{array}{l}\text { não deixa de ser, aquilo que eu acho que o pediatra antigo, o médico de } \\
\text { antigamente tinha um enorme sucesso, ele tinha tempo para sentar, para } \\
\text { conversar, para ver, para entender algo mais do que a queixa do seu paciente. } \\
\text { Então no meu modo de entender a medicina tem que ter muito tempo, muita } \\
\text { disponibilidade e muito... olhar aberto. } \\
\text { A gente como médico perdeu muito a parte... formação humanistica mesmo, } \\
\text { então a questão... é a arte, e a cultura, quer dizer, ficou tão tecnicista que } \\
\text { outras coisas parecem que năo existem, e... a gente tem que estar } \\
\text { resgatando, o homem não é só uma maquininha... } \\
\text { mas assim, ... não que eu ache que a higiene mental vá resolver, porque } \\
\text { mágica năo existe em medicina e vocé sabe tão bem quanto... }\end{array}$ \\
\hline
\end{tabular}




\begin{tabular}{|c|c|c|}
\hline \multicolumn{3}{|c|}{ MAPA DE VERBALIZAÇŌES, EXPLICAÇÕES E ATRIBUIÇŌES DE SIGNIFICADO - ENTREVISTA 5} \\
\hline $\begin{array}{l}\text { UNIDADES } \\
\text { TEMÁTICAS }\end{array}$ & VERBALIZAÇÕES & EXPLICAÇÕES E ATRIBUIÇÕES DE SIGNIFICADO \\
\hline $\begin{array}{l}\text { CONCEPÇÃO DE } \\
\text { PROBLEMA DE } \\
\text { SAUUDE MENTAL NA } \\
\text { INFÂNCIA }\end{array}$ & $\begin{array}{l}\text {... sempre pregamos a atenção global, a atenção biológica, psicológica e } \\
\text { social, } \\
\text {... diante da criança, procurando encontrar alguma raiz da parte orgânica, } \\
\text { algum problema, mas nunca esquecendo de olhar a parte de equilibrio que } \\
\text { essa criança tem com a sua familia, com a sua escola, com o seu grupo de } \\
\text { amigos, com a creche, parquinho, etc. } \\
\text {... psicologização em relação ao fracasso escolar. }\end{array}$ & $\begin{array}{l}\text { A professora pegava a criança indo mal na escola, mau rendimento escolar, e } \\
\text { a primeira coisa que fazia era encaminhar para psicóloga. Entăo ela ficava } \\
\text { rotulada desde cedo, quando que a origem dos distúrbios de aprendizagem, } \\
\text { mau rendimento escolar é totalmente outra, na maior parte dos casos. }\end{array}$ \\
\hline $\begin{array}{c}\text { RECONHECIMENTO } \\
\text { DOS PROBLEMAS } \\
\text { DE SAÚDE MENTAL } \\
\text { NA INFANCIA }\end{array}$ & $\begin{array}{l}\text { Nessa população que a gente atende, eu tenho até dados definidos sobre } \\
\text { isso... tem uma porcentagem muito pequena com problemas psiquiátricos ou } \\
\text { psicológicos. Psiquiátricos eu diria assim baixissimo, certo? Psicológicos } \\
\text {...alguns, e muito poucos necessários para encaminhamento. } \\
\text { A gente considera que os problemas sócioeconômicos e culturais são os } \\
\text { mais prevalentes em nosso meio. } \\
\text { o grave é ... eu não precisei mais do que dois minutos para ver aquela menina } \\
\text { se comportando em crise na escola e dizer essa criança provavelmente vai } \\
\text { precisar de uma atenção especializada, certo? Quer dizer, o grave, ele chega } \\
\text { nos olhos da gente. Deve existir, eu acho ... uma faixa que a gente segura } \\
\text { com a gente, que talvez beneficiasse mais do que um atendimento } \\
\text { especializado. E existe uma faixa que o pediatra toca muito bem... } \\
\text {... a gente realmente não que vá dizer que tenha conhecimento profundo } \\
\text { sobre isso que realmente nåo tem, năo fomos nem instrumentalizados na } \\
\text { faculdade para isso. Aqui em pós graduação fomos um pouco }\end{array}$ & $\begin{array}{l}\text { Então, tem a sua afetividade, o seu equilibrio nessas relações, a sua reação } \\
\text { nessas relaçōes, a reação dos pais em relação à criança, a relação da escola } \\
\text { junto à criança e a própria criança na escola,... acho que uma coisa que nos } \\
\text { impulsionou a agir desse jeito, muitas vezes até de uma forma intuitiva, muito } \\
\text { mais ligado ao bom senso do que de conhecimento profundo... }\end{array}$ \\
\hline
\end{tabular}




\begin{tabular}{|c|c|c|}
\hline & $\begin{array}{l}\text { instrumentalizados, tentaram nos instrumentalizar um pouco mais no campo e } \\
\text { não deu certo, e existe uma iniciativa própria de cada um de nós, a minha } \\
\text { também existe, mas eu confesso para vocés que muito do bom senso e do } \\
\text { senso comum acaba sendo usado por todos nós e não só por mim ... } \\
\text {... e a linguagem é uma coisa importante também. } \\
\text {... primeira coisa que eu gostaria, é que os alunos viessem melhor } \\
\text { instrumentalizados para nós em relaçăo à (...) da mente, ...de fases anteriores } \\
\text { inclusive.. } \\
\text { Em relação aos professores (da Faculdade de Medicina), eu acho que eles } \\
\text { precisariam ser melhor instrumentalizados, eu acho que os professores } \\
\text { precisam estudar, precisam estudar urgente, e falar a mesma lingua da gente } \\
\text { Eu me sinto uma intrometida na família da criança. Esse diagnóstico ai me faz } \\
\text { intrometer mais ainda. E eu não vejo limites, só se desistir, só se desistir }\end{array}$ & $\begin{array}{l}\text { Porque a linguagem (...) e i-na-ce-ssi-vel para o melhor dos pediatras } \\
\text { presentes. Nós chegamos a dizer, mas vocé precisa falar de acordo com o } \\
\text { que nós podemos entender, (...). Isso é fundamental, aprender a falar com o } \\
\text { pediatra também, a linguagem nós conhecemos, certo?, então a nossa } \\
\text { instrumentalizaçăo açabou sendo muito deficiente, muito deficiente... } \\
\\
\text { E que aqui na pediatria, nós tivéssemos pessoas, que com uma linguagem } \\
\text { adequada, conseguisse atingir já o aluno, ..terceiro, ...quarto ano, ...a } \\
\text { entender os problemas mais freqüentes que podem acometer a criança, e que } \\
\text { devam ser encaminhados, e aqueles que não são tão freqüentes mas que tem } \\
\text { o papel do pediatra, bem instrumentalizado ele conseguiria resolver o } \\
\text { problema. }\end{array}$ \\
\hline \multirow{2}{*}{$\begin{array}{c}\text { AÇÃO DOS } \\
\text { PEDIATRAS FRENTE } \\
\text { AOS PROBLEMAS } \\
\text { DE SAÚDE MENTAL } \\
\text { NA INFÂNCIA }\end{array}$} & $\begin{array}{l}\text { Tentando fazer a atenção global a gente começou a se auto-instrumentalizar e } \\
\text { seguramente usar o bom senso e o senso comum a maior parte das vezes. } \\
\text { Como pediatra, (...) eu sempre procurei encaminhar antes do aparecimento } \\
\text { dos problemas }\end{array}$ & $\begin{array}{l}\text {...qual era a nossa abordagem? Trabalhar a familia, conversar com os pais, } \\
\text { separados ou juntos, conforme a necessidade, com a proppria criança, toda a } \\
\text { vez que for preciso, e usávamos de recursos assim os mais diversos } \\
\text { possiveis, }\end{array}$ \\
\hline & $\begin{array}{l}\text { Então nós começamos a ficar muito auto-suficientes, sabe, mas auto- } \\
\text { suficientes no seguinte sentido, aqui năo dá para dar cobertura. A rede, não }\end{array}$ & $\begin{array}{l}\text { O pediatra tem que assumir coisas assim, vocé entende?, E na atenção } \\
\text { primária esse que é o grosso das coisas, são coisas que o pediatra, com uma }\end{array}$ \\
\hline
\end{tabular}




\begin{tabular}{|c|c|c|}
\hline & 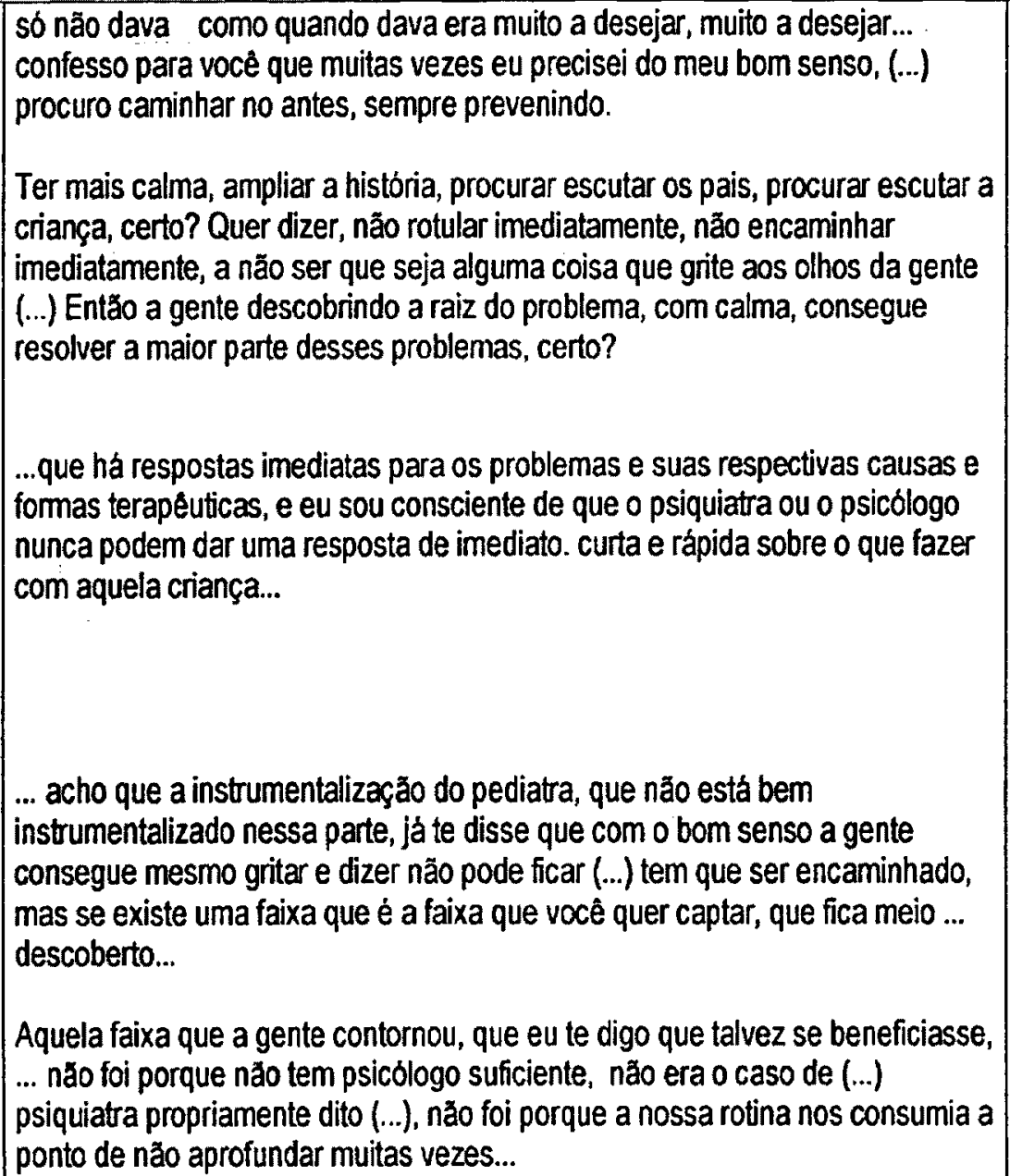 & $\begin{array}{l}\text { Por exemplo, a professora encaminhar uma criança dizendo que é problema, } \\
\text {.. que está com problema, o comportamento, e a criança simplesmente } \\
\text { estava abafada na sua casa, fazendo trabalhos de casa para mãe, } \\
\text { cozinhando, lavando, passando, hâ, hã, hâ, e quando ela chega aqui ela quer } \\
\text { brincar, năo quer aprender coisissima nenhuma. Isso merece um atendimento } \\
\text { psiquiátrico? Claro que não. } \\
\text { Porque na atenção primária, você precisa atender depressa os clientes. o } \\
\text { depressa não quer dizer } 10 \text { minutos, as consultas são longas, mas você não } \\
\text { pode fazer um interrogatório extremamente extenso... (...) e o investigar do } \\
\text { psicólogo, do psiquiatra é um investigar longinquo, não é um investigar } \\
\text { imediato. Então na atenção primária, que a gente lida com alunos, um número } \\
\text { grande de casos, existe uma rotina para tocar, uma demanda para resolver, } \\
\text { não ficava prático, não ficava prático } \\
\text { mas precisa uma melhor instrumentalização do próprio pediatra, certo?. E que } \\
\text { se houver alguma assessoria (...), mas antes escuta o que nós pretendemos, } \\
\text { e o que ela pretende da gente, se não, não dả certo outra vez. E naturalmente } \\
\text { iniciativas particulares do próprio pediatra, cuidando dessa parte. }\end{array}$ \\
\hline
\end{tabular}




\begin{tabular}{|c|c|c|}
\hline \multicolumn{3}{|c|}{ MAPA DE VERBALIZAÇŌES, EXPLICACOŌES E ATRIBUICOÕES DE SIGNIFICADO - ENTREVISTA 6} \\
\hline $\begin{array}{l}\text { UNIDADES } \\
\text { TEMÁTICAS }\end{array}$ & VERBALIZAÇÕES & EXPLICAÇÕES E ATRIBUIÇÕES DE SIGNIFICADO \\
\hline $\begin{array}{l}\text { CONCEPCCAO DE } \\
\text { PROBLEMA DE } \\
\text { SAÜDE MENTAL NA } \\
\text { INFANCIA }\end{array}$ & $\begin{array}{l}\text {... tudo isso é permeado eu acho que pela,... pela saúde mental... do... de } \\
\text { quem atende e de quem vem na consulta. } \\
\text { com entendimento dessas coisas dentro da... da questão da... da saúde } \\
\text { mental como um todo, da criança como um todo. } \\
\\
\text {... com um grupo que referende que ela está criando o filho dela bem, eu acho } \\
\text { que é a chave para saúde mental... ela está contente... e fica contente com o } \\
\text { filho dela. }\end{array}$ & $\begin{array}{l}\text {... eu, eu não tenho dúvida que eu acho que onde você mais faz saúde mental } \\
\text { é na pediatria. }\end{array}$ \\
\hline $\begin{array}{c}\text { RECONHECIMENTO } \\
\text { DOS PROBLEMAS } \\
\text { DE SAUUDE MENTAL } \\
\text { NA INFANCIA }\end{array}$ &  & $\begin{array}{l}\text { O quanto existe de rigidez no médico, a di... da dificuldade de estar } \\
\text { percebendo isso... isso al não é informaçăa, eu acho que isso é formação.... } \\
\text { isso permeado pela saúde mental... pelo universo da saúde mental. Todo, é... } \\
\text { eu acho que em toda consulta de pediatria, é... a nossa escola ensinou é... } \\
\text { uma, uma... cultura muito médica, muito medicalizada, a... é muito simples } \\
\text { catar uma receita e escrever... de que forma que o individuo lida com as } \\
\text { perguntas que a mãe traz, ou que a... a.... ou com a... ou com aquilo que ela } \\
\text { não pergunta, o quanto ele faz aparecer a queixa, o quanto ele vai na busca } \\
\text { ativa. } \\
\\
\text { na e... primeiro estar chamar a atenção para esse tipo de coisa... năo ficar... } \\
\text { não tornar o individuo tão hipócrita..... as residências médicas têm muito } \\
\text { pouca preocupação com o subjetivo, com o... achar que o individuo suporta... } \\
\text { aquele tipo de... de, de profissão que ele tá escolhendo. }\end{array}$ \\
\hline
\end{tabular}


... eu não acho basta aprender... tem vezes que vocé pode... tem vezes que... porque... veja... a... o... a... hora que se trabalha com essa área al, n... não... adianta... se não é intermediado com esteto, (...)... é uma coisa muito subjetiva... a única coisa que... que..., que te permite escutar ou não escutar uma coisa, é,... de como você é, de como a sua cabeça, de como valoriza aquilo lá... entendeu... que tipo de... qual teu tipo de formação...

0 pessoal da mental, (...) do jeito que eles falam, os psico... afins... as psicanálises que eles falam para, para médico a... para médico com formação em pediatria,.. para pediatra, é aversivo assim... mudou muito, hein, vem melhorando muito.

... primeiro de tudo... o que a gente encontra... problema de alimentação... muitos, muitos..., depressão pós-parto, muita..., depressão pós-parto adoidado... criança com muita dor... às pencas... distúrbio de sono em seguida, é a mesma criança, assim, uma teia, distúrbio de sono muito, muito... dis... é... distúrbio de, de linguagem... a criança... al vai entrando pela questăo da... a ques... a questăo da... da... e a coisa de todas, todas essas coisas, só văo mudando a área da mesma criança...

... cólica (...), crescimento, , é... a partir do primeiro ano de vida, hora que a criança começa a andar, a criança é infeliz... a criança que chora, chora, chora, chora...

... distürbios de linguagem muito assim...

... acho que tem muita depressão, ...eu acho que tem... distúrbio da sociabilidade muito grave...

... rendimento escolar é... é... deixa muito a desejar, vocé vai ver isso ai... tem
... a informaçăo você pode estar obtendo em qualquer lugar, a formação... tem muito a ver no trabalho no cotidiano que vocè faz, então é... o quanto que uma queixa, aparentemente objetiva, tem um contexto subjetivo...

... porque os residentes chegavam aqui e cuspiam os textos... eles odiavam... que esse cara isso... a criança expressa o desejo na terra, que loucura é esta, entendeu

... e a questăo de que tipo de maternagem é oferecida para essa criança..., que tipo de cuidador que tem essa criança, que tipo de dinåmica que tem na familia

... por uma dificuldade de estar vivenciando a... a angústia de separação grande da måe...

... é... eu tenho um trabalho numas creches assim... hoje não existe... a... eu sempre brinco assim, que a desnutriçăo maior que existe é da falta de estimulação de linguagem..., primeiro que não escuta direito, e depois porque não é estimulada... e na verdade... năo tem nem diálogo... de dia vé pouco pai e mãe, e de noite... escuta televisão... ninguém lế historinha para eles...

... você vê a constituição das familias, a população das familias nessa área... 


\begin{tabular}{|c|c|c|}
\hline & $\begin{array}{l}\text { muita criança que não consegue parar... não é porque é hiperafivo, é porque é } \\
\text { ansioso mesmo,... tem muita criança que... nåo sabe o que tem que fazer... } \\
\text { que a época do limite passou... entăo... mete a måo pelos pés... então... tem } \\
\text { muita criança fóbica,... criança com... com... a criança... o... o provocador... } \\
\text { sabe que... chama porrada... }\end{array}$ & \\
\hline $\begin{array}{c}\text { ACCAOO DOS } \\
\text { PEDIATRAS FRENTE } \\
\text { AOS PROBLEMAS } \\
\text { DE SAÚDE MENTAL } \\
\text { NAINFÁNCIA }\end{array}$ &  & $\begin{array}{l}\text { que não sabe o que fazer com elas... mas tem coisa para fazer..., tem a } \\
\text { vigilåncia para chegar a ser um escolar. } \\
\\
\text {... eu trabalharia melhor a questão da formaçăo e da informaçăo do pessoal } \\
\text { da área em todos os niveis, nivel técnico, nivel, nivel... das măes... }\end{array}$ \\
\hline
\end{tabular}




\begin{tabular}{|c|c|c|}
\hline \multicolumn{3}{|c|}{ MAPA DE VERBALIZAÇÕES, EXPLICAÇÕES E ATRIBUIÇÕES DE SIGNIFICADO - ENTREVISTA 7} \\
\hline $\begin{array}{l}\text { UNIDADES } \\
\text { TEMÁTICAS }\end{array}$ & VERBALIZAÇÕES & EXPLICAÇŌES E ATRIBUIÇÕES DE SIGNIFICADO \\
\hline $\begin{array}{l}\text { CONCEPÇÃO DE } \\
\text { PROBLEMA DE } \\
\text { SAÚDE MENTAL NA } \\
\text { INFÁNCIA }\end{array}$ & $\begin{array}{l}\text {... quando vocé começou a falar de saúde mental, a primeira coisa que me } \\
\text { ocorreu foi ... as doenças mentais. } \\
\text {... é aquilo que a gente chama de ambiente emocional, é mais do que doença } \\
\text { mental, não sei o que ... saúde mental é ... então é a familia, ... é ambiente } \\
\text { geralmente muito desestruturado também, a criança acaba refletindo de } \\
\text { alguma forma,... }\end{array}$ & $\begin{array}{l}\text { Depois eu achei que, se é para pediatra, acho que,... não sei se é isso que } \\
\text { vocé está procurando ou se é mais o que a gente coloca como problemas de } \\
\text { comportamento, como dificuldades de relacionamento, ai mais um sofrimento } \\
\text { mental, se quiser chamar assim... }\end{array}$ \\
\hline $\begin{array}{l}\text { RECONHECIMENTO } \\
\text { DOS PROBLEMAS } \\
\text { DE SAÜDE MENTAL } \\
\text { NA INFÂNCIA }\end{array}$ & $\begin{array}{l}\text { Se for doença mental mesmo, ai realmente a gente ... eu pelo menos, acho } \\
\text { que não consigo fazer algum diagnostico. } \\
\text {... essa queixa de hiperatividade é uma queixa que as mães vem contando } \\
\text { freqüentemente, e normalmente, eu sou meio dificil de aceitar esse } \\
\text { diagnóstico de hiperatividade... } \\
\text {... é uma coisa que a gente vê muito, quando a gente sente algum problema } \\
\text { na área de comportamento da criança, pode procurar na família, a gente } \\
\text { procura mesmo, e a coisa é mais ampla, é um pouco por ai... } \\
\text { Se a gente for pensar outros sintomas que alertam a gente, aquelas crianças } \\
\text { com comportamentos muito diferentes do que a gente espera para idade ... } \\
\text {... é a criança sem limite, esse talvez seja o problema mais freqüente. } \\
\text {... dificuldades escolares de modo geral também são bastante freqüentes... }\end{array}$ & $\begin{array}{l}\text { Outro dia tinha uma de } 5 \text { anos, ... 4, quase } 5, . . \text { muito dificil de ser examinada, } \\
\text { escorrega, se esconde embaixo da mesa, então aquela criança que a mãe } \\
\text { não consegue colocar limite nenhum nela, ... essa também chama a atençãa. } \\
\text { Outra, é uma criança quieta, retraída demais, que quase não te olha, elà até é } \\
\text { passiva, deixa, você examina fácil, mas ela quase não faz contato com você, } \\
\text { tá, tá muito dificil, năo brinca, năo aceita, esse contato ... } \\
\text { E ai se manifesta de várias formas, então desde algumas crianças com } \\
\text { dificuldades de desmame... } \\
\text { Quando você fala saúde mental você tá pensando a área emocional como um }\end{array}$ \\
\hline
\end{tabular}




\begin{tabular}{|c|c|c|}
\hline & $\begin{array}{l}\text {... eu fiquei na maior dúvida, quer dizer, (...) se era de um autismo, apareceu } \\
\text { até a própria creche comentou e me perguntou se era. Sou incapaz de fazer } \\
\text { um diagnostico desse, ... num bebê? Năo sei, essa é uma dificuldade, falta } \\
\text { talvez uma formaçăo melhor nessa área, então encaminhei. Isso que a gente } \\
\text { sente, que a gente não tem instrumentos para lidar com isso, então ... isso é } \\
\text { uma coisa... }\end{array}$ & $\begin{array}{l}\text { todo ou não... } \\
\text { Mesmo esse menino que eu estava te falando, de } 9 \text { anos, eu não tenho assim } \\
\text { uma certeza de escrever que ele é um menino hiperativo. Não sei. Năo sei se } \\
\text { è só resultado al do ambiente, também hoje năo deu nem para aprofundar, } \\
\text { mas nem que eu conseguisse ter o tempo todo que eu preciso, falta talvez } \\
\text { algum instrumento melhor, uma formaçăo melhor para eu definir os casos, } \\
\text { isso a gente năo consegue, eu năo consigo. }\end{array}$ \\
\hline & $\begin{array}{l}\text { E isso que eu estava te falando, se tivesse alguém para gente discutir os } \\
\text { casos eu acho que ajuda, porque na hora que vocé discute eu acho que } \\
\text { sempre vocé acaba entendendo esse caso, ai o próximo fica um pouco mais } \\
\text { fácil de você lidar, então ... acho que disso ... se a gente tivesse aqui o } \\
\text { pessoal da área de mental, atendendo também crianças, ou discutindo os } \\
\text { casos com a gente, mesmo que não atendesse diretamente, isso facilitaria } \\
\text { muito. } \\
\text { (Dificuldades) Até mais ou menos de como abordar, ... por onde ir, ... o que } \\
\text { mais investigar, ... como a gente pode atuar um pouco antes de estar } \\
\text { encaminhando tudo, porque ás vezes tem coisas que a gente poderia ... } \\
\text {... vê que a coisa é mais grave, que é mais complicada, e que você năo vai } \\
\text { dar conta, e vocé entăo quer fazer um encaminhamento ... Muitas vezes eles } \\
\text { săo resistentes, mas porque? }\end{array}$ & 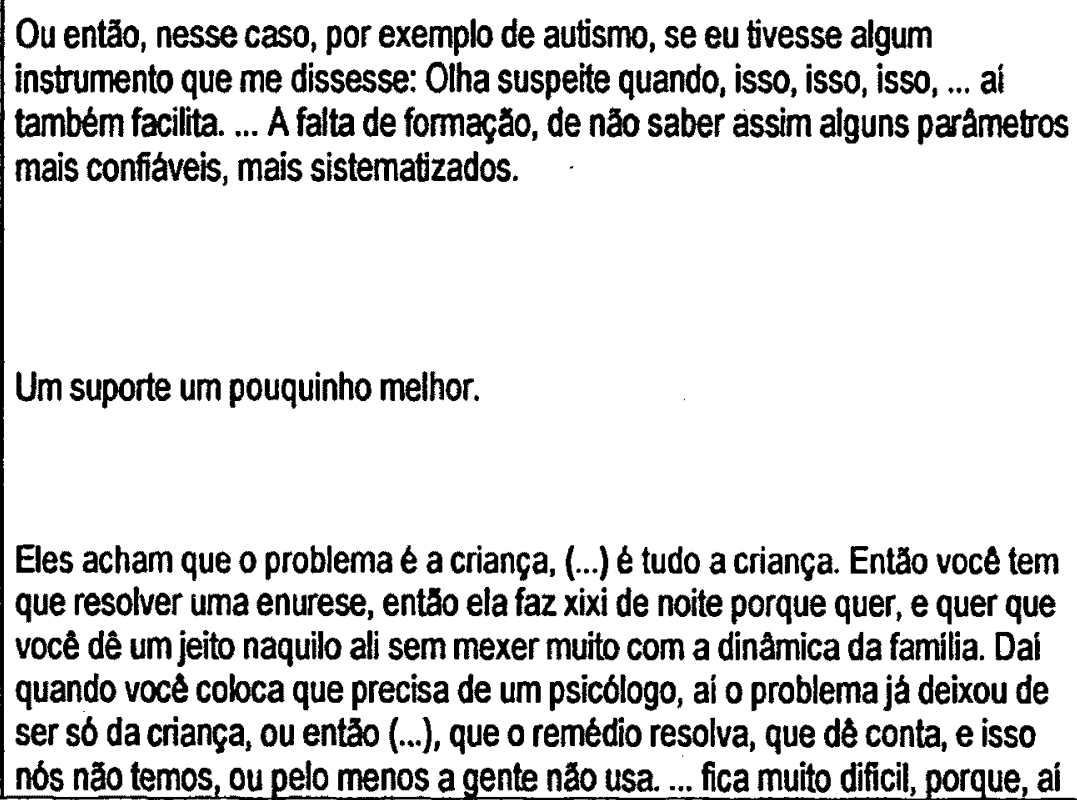 \\
\hline
\end{tabular}




\begin{tabular}{|c|c|c|}
\hline & 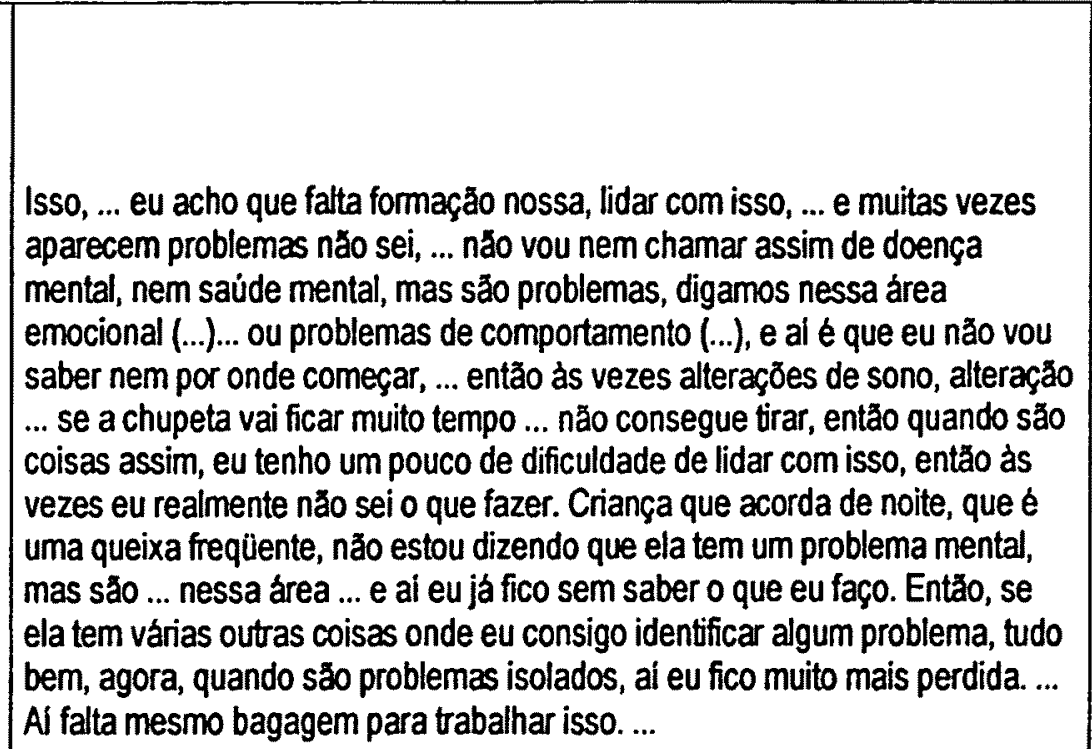 & $\begin{array}{l}\text { vem um monte de problemas, desde ... alguns reais, que não tem para onde } \\
\text { ir, outros ... de quem vai levar, ... ou é longe, ... ou ... eu trabalho, nåo posso, } \\
\text {...e mil coisas. E geralmente elas são resistentes... }\end{array}$ \\
\hline
\end{tabular}




\begin{tabular}{|c|c|c|}
\hline \multicolumn{3}{|c|}{ MAPA DE VERBALIZAÇÕES, EXPLICAÇÕES E ATRIBUIÇÕES DE SIGNIFICADO - ENTREVISTA 8} \\
\hline $\begin{array}{l}\text { UNIDADES } \\
\text { TEMÁTICAS }\end{array}$ & VERBALIZAÇŐES & EXPLICAÇŐES E ATRIBUIÇÕES DE SIGNIFICADO \\
\hline $\begin{array}{l}\text { CONCEPÇÃO DE } \\
\text { PROBLEMADE } \\
\text { SAÜDE MENTAL NA } \\
\text { INFANCIA }\end{array}$ & $\begin{array}{l}\text {... em dúvida a pediatria é desenvolvimento ...crescimento e desenvolvimento } \\
\text { sendo provavelmente o futuro da pediatria, } \\
\text { Seria uma referência para a atenção integral à saúde da criança } \\
\\
\text {...uma herança do Pedro de Alcântara, ... de certa forma ele que é o } \\
\text { responsável... por ter formado toda uma geração de pessoas que tivesse } \\
\text { preocupaçăo com a questăo da interferência do emocional no orgânico } \\
\text { e a questão da importância do, ... na verdade, do ... de certa forma do } \\
\text { ambiente de vida, na verdado é tudo, quer dizer, desde, ... tanto fisico quanto } \\
\text { no ambiente afetivo interferindo naquela avalią̧ão que deveria fazer na } \\
\text { criança no dia a dia. }\end{array}$ & $\begin{array}{l}\text { ou seja, fala-se tanto em atençăo integral, quando na verdade ela não é tão } \\
\text { integral assim, porque integral no sentido da medicina orgânica, porque todos } \\
\text { os programas, eles privilegiam, então vocé pega a atenção integral às } \\
\text { doenças prevalentes na infância, você tem lá a diarréia, você tem as doenças } \\
\text { respiratórias da infåncia, tem as doenças nutricionais (...), como focos } \\
\text { principais da discussão, então a repercussão disso sobre a saúde global do } \\
\text { individuo, inclusive na saúde mental, isso em nenhum momento é abordado, } \\
\text { quer dizer, até porque normalmente quem elabora as estratégias de saúde } \\
\text { não consegue enxergar a necessidade de você ter um foco adicional, (...) } \\
\text { sempre vai ter uma repercussão em sua saúde mental... }\end{array}$ \\
\hline $\begin{array}{l}\text { RECONHECIMENTO } \\
\text { DOS PROBLEMAS } \\
\text { DE SAÜDE MENTAL } \\
\text { NA INFÂNCIA }\end{array}$ & a gente observa mais recentemente o surgimento de grupos que se & $\begin{array}{l}\text { quer dizer, se coloca até a questão da culpa e da responsabilidade do médico, } \\
\text { no sentido de que ele não pode falhar em estar detectando problemas } \\
\text { orgânicos, seja a nivel de prevençãa ou seja a nivel de diagnóstico precoce e } \\
\text { de certa forma você acaba diminuindo essa responsabilidade no sentido da } \\
\text { questão do desenvolvimento, e da manutenção da saúde do individuo como } \\
\text { um todo, inclusive nos aspectos de saúde mental... } \\
\text { quer dizer, você precisa ter a criaçăo de um grupo especialmente voltado para }\end{array}$ \\
\hline
\end{tabular}




\begin{tabular}{|c|c|c|}
\hline & 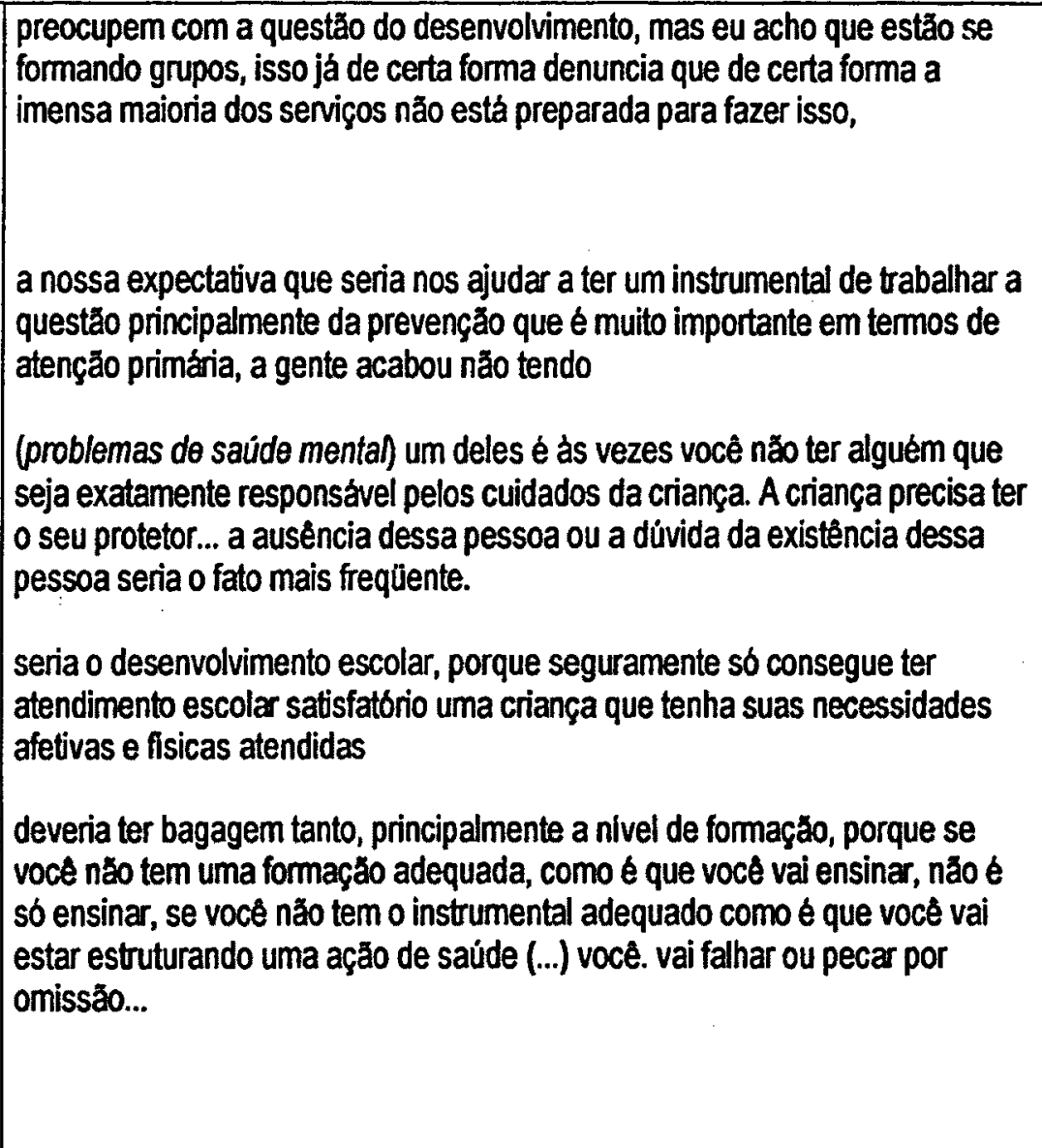 & $\begin{array}{l}\text {...não conhece exatamente uma coisa nåo dá para dizer nada, nem que é } \\
\text { mais fácil nem que é mais díficil, talvez fosse tăo ... năo digo tão fácil, mas tão } \\
\text { natural quanto vocẻ analisar o crescimento, se vocé. tivesse, veja sua } \\
\text { graduação, o peso adequado, está certo, acho que tem que, acho que uma } \\
\text { coisa nem pode ser maior ou menor, mas acho que ela tem que ter o peso } \\
\text { adequado para que vocé possa interferir positivamente na vida daquela } \\
\text { pessoa. Entăo não sei dizer ... sei dizer que existe uma deficiência, o quanto é } \\
\text { deficiente realmente não sei dizer. }\end{array}$ \\
\hline $\begin{array}{c}\text { AÇAO DOS } \\
\text { PEDIATRAS FRENTE } \\
\text { AOS PROBLEMAS } \\
\text { DE SAUUDE MENTAL } \\
\text { NA INFȦNCIA }\end{array}$ & $\begin{array}{l}\text { a gente observa mais recentemente o surgimento de grupos que se } \\
\text { preocupem com a queståo do desenvolvimento } \\
\text { Entåo algumas tentativas que foram feitas de integração mais recentemente } \\
\text { náo deram certo e a nossa expectativa que seria nos ajudar a ter um } \\
\text { instrumental de trabalhar a queståo principalmente da prevençăo que é muito }\end{array}$ & $\begin{array}{l}\text {... precisa ter a criação de um grupo especialmente voltado para o } \\
\text { desenvolvimento ou para saúde mental, porque de certa forma há uma } \\
\text { deficiência do serviço básico... } \\
\text {... trabalhava muito com a questão da profilaxia, e agora a questão é mais } \\
\text { psicanálise, trabalhava com a questão de tratamento mesmo da criança que } \\
\text { tenha distürbio, năo é só prevençăo. }\end{array}$ \\
\hline
\end{tabular}




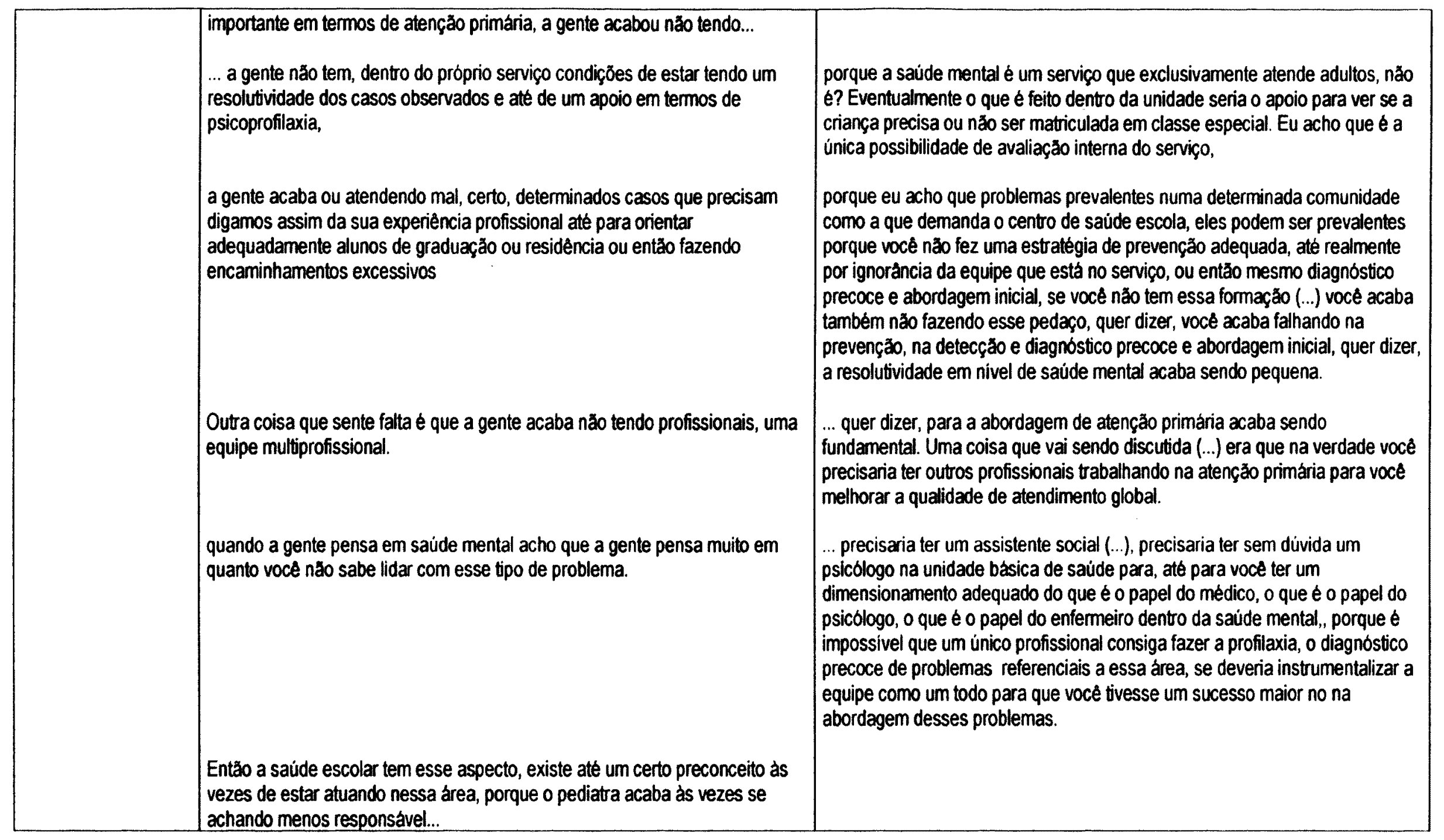




\begin{tabular}{|c|c|c|}
\hline \multicolumn{3}{|c|}{ MAPA DE VERBALIZAÇŐES, EXPLICAÇŐES E ATRIBUICC̄ES DE SIGNIFICADO - ENTREVISTA 9} \\
\hline $\begin{array}{l}\text { UNIDADES } \\
\text { TEMÁTICAS }\end{array}$ & VERBALIZAÇÕES & EXPLICAÇÕES E ATRIBUIÇÕES DE SIGNIFICADO \\
\hline $\begin{array}{l}\text { CONCEPÇÃO DE } \\
\text { PROBLEMA DE } \\
\text { SAÜDE MENTAL NA } \\
\text { INFANCIA }\end{array}$ & 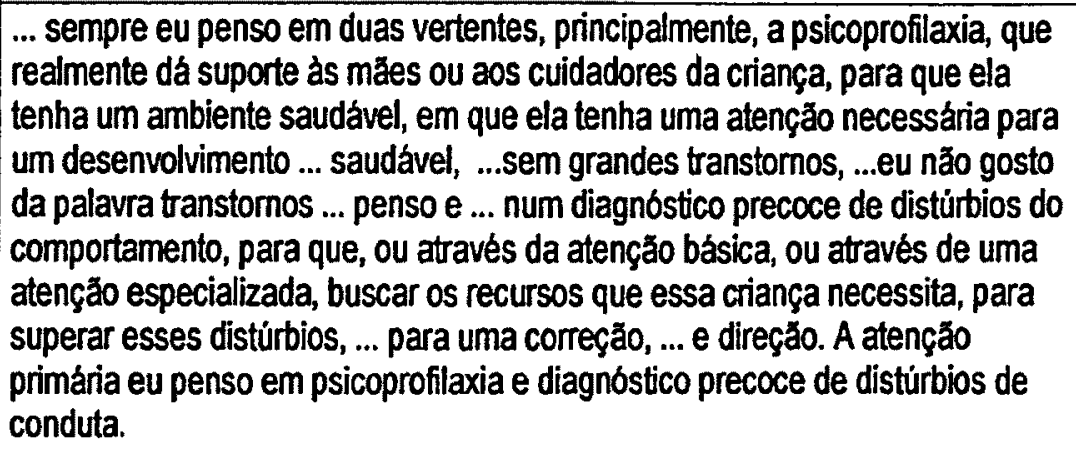 & $\begin{array}{l}\text {... (distúrbio de comportamento, de conduta) eu não sei, para mim é muito } \\
\text { intuitivo, eu năo tenho conhecimento assim, claro, sobre o significado de um } \\
\text { ou do outro, muitas vezes ele acaba usando como sinónimos, quando na } \\
\text { verdade năo são. Acabam sendo muito como sinónimos, quando a criança } \\
\text { apresenta um comportamento que chama a atençåo (...) comportamentos que } \\
\text { fogem do esperado para sua faixa, ou da expressão do seu sentimento às } \\
\text { vezes estão exacerbados ou pouco demonstrados, de tal forma que mostra } \\
\text { que tem ali alguma questão que precisa ser revista. }\end{array}$ \\
\hline $\begin{array}{c}\text { RECONHECIMENTO } \\
\text { DOS PROBLEMAS } \\
\text { DE SAÜDE MENTAL } \\
\text { NA INFÁNCIA }\end{array}$ & $\begin{array}{l}\text {...vou tentar dividir por faixa etária, que talvez fique mais fácil. No lactente, } \\
\text { acho que o problema maior que a gente encontra atualmente é a criança ... a } \\
\text { falta de uma relaçăo afetiva mais forte, as crianças (...) demonstrando uma } \\
\text { certa... isolamento afetivo ... do ponto de vista afetivo, ... um certo isolamento } \\
\text { afetivo que as crianças acabam sofrendo, ...o lactente... falta de estimulaçăo } \\
\text { mesmo, tambem, principalmente nessas crianças que ficam em creches, a } \\
\text { gente observa muito por aqui. } \\
\text { Depois, o outro distúrbio que a gente vai encontrar, depois, em seguida vão } \\
\text { ser as crianças desadaptadas socialmente, as crianças que văo para os seus } \\
\text { grupos, não se adaptam ou ficam excessivamente introvertidas, ou } \\
\text { excessivamente agressivas, mostrando dificuldade. Eu acho que mais tarde, } \\
\text { no escolar, com seus disturbios de aprendizagem... } \\
\\
\text {... eu acho que a gente não tem uma formaçăo. }\end{array}$ & $\begin{array}{l}\text { Eu vejo até pela carga horária, se v. pegar programa de quarto ou de quinto } \\
\text { ano, ..., que onde a gente trabalha atençáo básica. Ela é inteiramente voltada } \\
\text { para a doença. Existe uma dificuldade muito grande de se ensinar o } \\
\text { crescimento normal, o desenvolvimento normal, a ... uma dificuldade muito } \\
\text { grande de se ensinar psicoprofilaxia ... de ambiente saudável, de casa } \\
\text { saudável, de familia saudável. São assuntos, ... se v. pegar o programa de } \\
\text { graduaçăo v. vai ter } 1 \text { hora, ...ou } 2 \text { horas ... relacionadas ao normal, e a partir } \\
\text { dai v. começa com, ou prevençăa de doença, ou diagnóstico precoce de }\end{array}$ \\
\hline
\end{tabular}




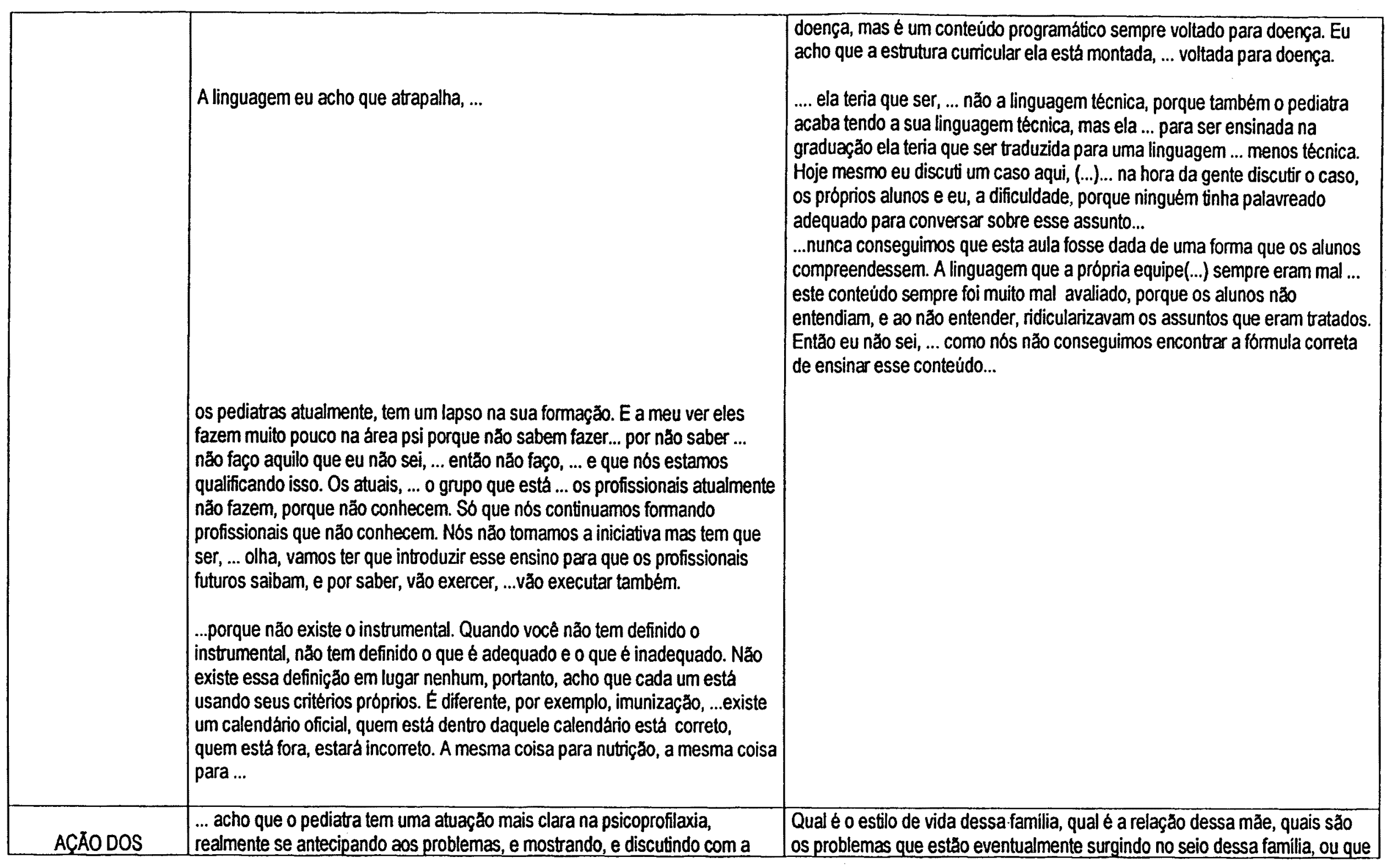




\begin{tabular}{|c|c|c|}
\hline $\begin{array}{c}\text { PEDIATRAS FRENTE } \\
\text { AOS PROBLEMAS } \\
\text { DE SAÚDE MENTAL } \\
\text { NA INFANCIA }\end{array}$ & 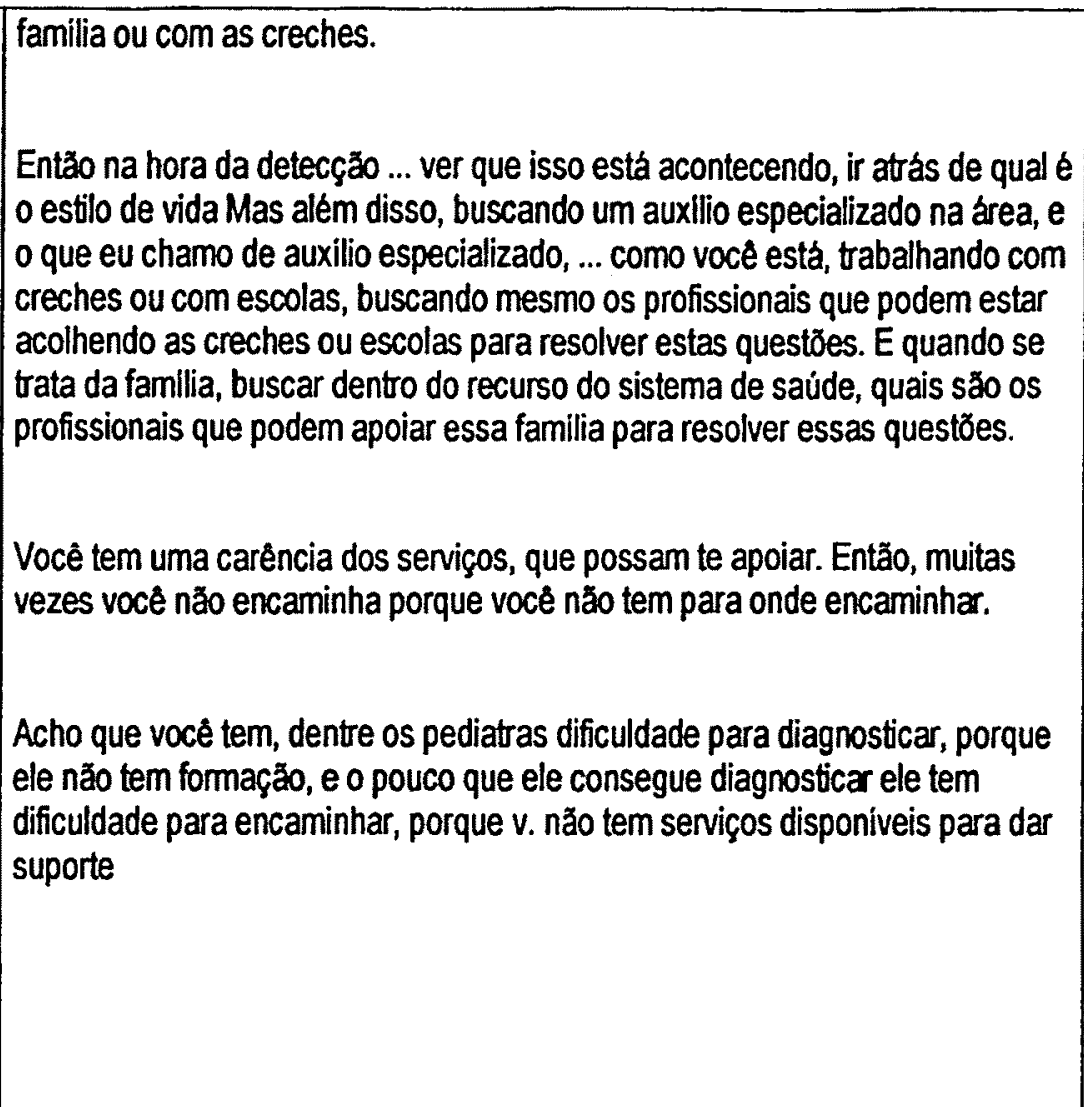 & $\begin{array}{l}\text { problemas essa criança está atravessando na creche, que tipo de creche ela } \\
\text { está freqüentando. } \\
\text { Eu acho que realmente na hora que os distúrbios já estão instalados vocé } \\
\text { acaba tendo que buscar ajuda. O pediatra, a meu ver, seria muito mais ... uma } \\
\text { pessoa que mais rapidamente consegue ver o problema, que estă } \\
\text { acontecendo, ... mas acho que o seu nivel de atuação acaba ficando mais } \\
\text { restrito quando o distúrbio jáa está instalado. Ele vai precisar dos recursos de } \\
\text { mais alguém, dentro desse sistema, ou do sistema educacional ou do sistema } \\
\text { de saúde, ... para ajudá-lo. } \\
\\
\text { muitas vezes não dispõe dos serviços e recursos, então você. identifica, essa } \\
\text { criança precisaria de um encaminhamento, e busca, e você não encontra, e } \\
\text { vocé fica lidando com o problema, ou, ... lidando com o problema muito mal } \\
\text { dentro do seu dia a dia, ou v. passa a ignorar o problema, vocé fala: bom, para } \\
\text { isto eu não tenho uma solução e eu não tenho um sistema que acolha esse } \\
\text { problema. E isto é uma questão terrivel para nós. Se vocé hoje aqui identificar } \\
\text { uma criança que vocé acha que precisa de um apoio ... psicológico, ou precisa } \\
\text { de uma avaliaçăo especializada nessa área, você nåo tem para onde } \\
\text { encaminhar }\end{array}$ \\
\hline
\end{tabular}




\begin{tabular}{|c|c|c|}
\hline \multicolumn{3}{|c|}{ MAPA DE VERBALIZAÇÕES, EXPLICAÇÕES E ATRIBUIÇÕES DE SIGNIFICADO - ENTREVISTA 10} \\
\hline $\begin{array}{l}\text { UNIDADES } \\
\text { TEMÁTICAS }\end{array}$ & VERBALIZAÇŌES & EXPLICAÇŌES E ATRIBUIÇŌES DE SIGNIFICADO \\
\hline $\begin{array}{l}\text { CONCEPÇÃO DE } \\
\text { PROBLEMA DE } \\
\text { SAÜDE MENTAL NA } \\
\text { INFANCIA }\end{array}$ & $\begin{array}{l}\text { O que me vem à cabeça quando se fala em saúde mental (...) a gente } \\
\text { encontra, de desvios de comportamento, nas alteraçōes que existem dentro } \\
\text { do comportamento da criança, (...), que causam uma certa apreensão } \\
\text { Entăo eu vejo assim, uma área que eu acho que é muito fruto do ambiente em } \\
\text { que a criança vive, sem dúvida alguma, eu sempre defendi essa... acredito } \\
\text { mesmo no fato da criança ser fruto do ambiente que ela vive, e } \\
\text { consequentemente muito dos desvios, dos comportamentos, enfim, das } \\
\text { alteraçổes que ela tem ocorrem em funçăo dessa variaçăo do ambiente. } \\
\text { O pediatra, eu acho que ele tem que ver a criança como um todo, ... não só do } \\
\text { ponto de vista fisico e tal... }\end{array}$ & $\begin{array}{l}\text { Há necessidade muitas vezes de vocé. interpretar ou procurar esclarecer o } \\
\text { que é normal ou esperado, dentro do desenvolvimento da criança. }\end{array}$ \\
\hline $\begin{array}{l}\text { RECONHECIMENTO } \\
\text { DOS } \\
\text { PROBLEMASDE } \\
\text { SAUUDE MENTAL NA } \\
\text { INFANCIA }\end{array}$ & $\begin{array}{l}\text { Eu acho que muitas vezes passa desapercebido alguns aspectos. } \\
\text { Eu acho que existe o individuo às vezes especialista na moléstia, por assim } \\
\text { dizer, ele às vezes vê o aspecto bem organizado da doença ou da } \\
\text { especialidade đ̀ qual ele tem o atendimento, seja um atendimento } \\
\text { emergencial, seja a caracteristica da causa da solicitaçăo do atendimento, } \\
\text { mas muitas vezes ele não aborda, tem uma certa, ...um certo constrangimento } \\
\text { de dizer ... } \\
\text { acho que o pediatra tem que ser um sensor geral. Ele tem que estar aberto e }\end{array}$ & $\begin{array}{l}\text {...depende um pouco da atençăo que o residente dá ao caso. } \\
\text { No segundo semestre o pessoal já vem de enfermaria, ... UTI, ... berçário, e } \\
\text { tal, do próprio pronto socorro, então ele jáa vem com uma conotaçăo } \\
\text { assistencial de intervençăo, de tentar resolver o problema doença ... } \\
\text {... não que piora, ... muda, ... muda o enfoque sabe, você tem que puxar às } \\
\text { vezes o cara para realidade, às vezes, ... exemplificando, ... vamos supor, } \\
\text { vamos pegar uma patologia que possa ter um efeito psicossomático de } \\
\text { influência, na asma, por exemplo, o asmático no primeiro semestre, acho que } \\
\text { você pode até colocar todos os fatores etiologicos da asma, até comportam } \\
\text { um aspecto psicossomático, da dinâmica familiar... às vezes pode } \\
\text { desencadear até uma asma... no segundo semestre às vezes esquece desse } \\
\text { detalhe, eles imaginam muito mais o asmático como broncoespasmo com o } \\
\text { seu corticóide, com o seu ou betabloqueador, enfim, toda a interferência } \\
\text { medicamentosa e muitas vezes esquece, porque ele vem de uma área } \\
\text { eminentemente assistencial a nivel de unidade de internaçăo, de pronto } \\
\text { socorro. } \\
\text { porque quando você tem tempo e tem o vinculo terapêutico e tudo o mais, }\end{array}$ \\
\hline
\end{tabular}




\begin{tabular}{|c|c|c|}
\hline & 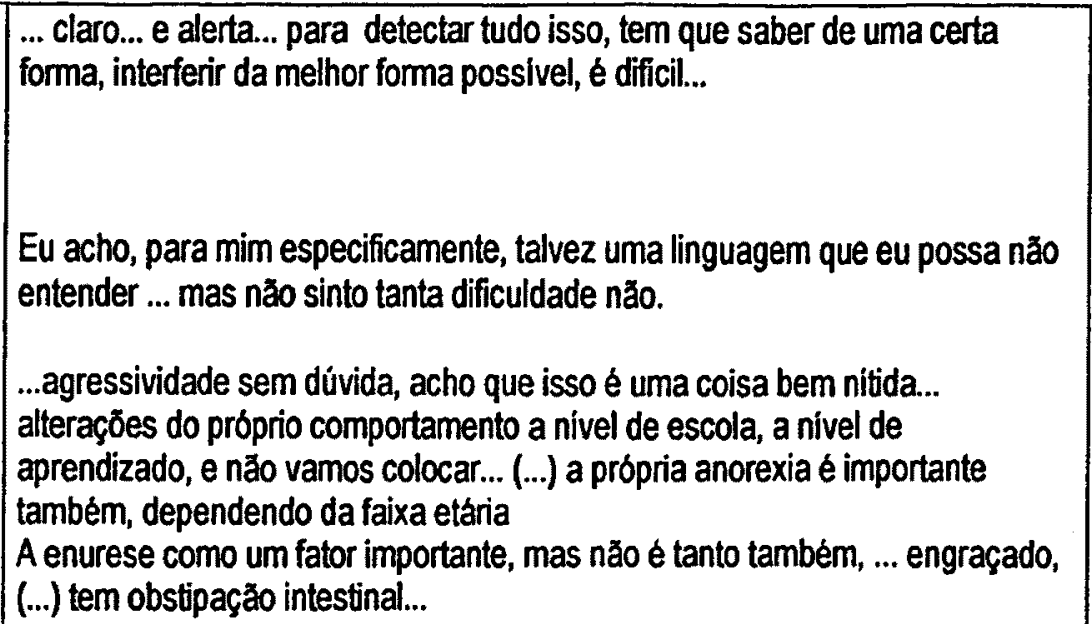 & $\begin{array}{l}\text { efetivamente vocé detecta muita coisa, você dá abertura e é aquela velha } \\
\text { história, muitas vezes a queixa da mãe efetivamente é uma queixa que parece } \\
\text { nåo estar relacionada, e você não vể a causa, mas o negócio está dentro da } \\
\text { área comportamental... }\end{array}$ \\
\hline $\begin{array}{l}\text { AÇÃO DOS } \\
\text { PEDIATRAS FRENTE } \\
\text { AOS PROBLEMAS } \\
\text { DE SAÚDE MENTAL } \\
\text { NA INFÂNCIA }\end{array}$ & 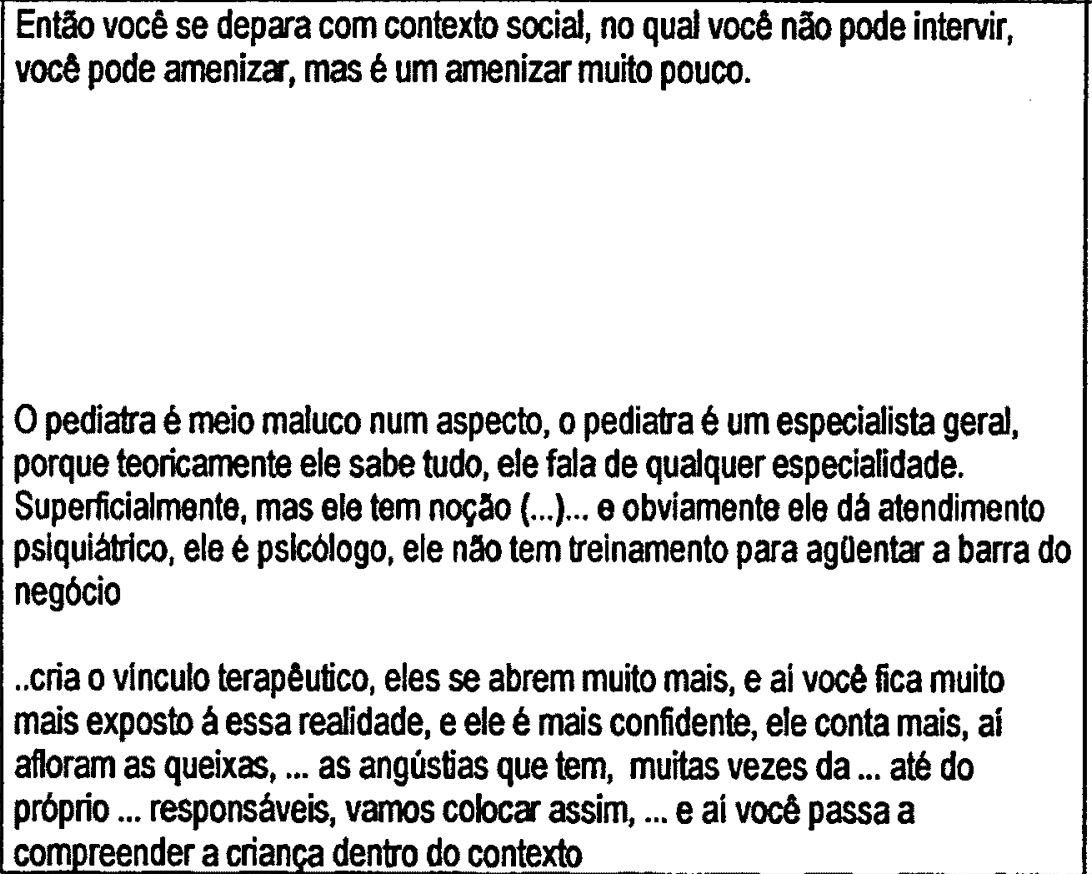 & 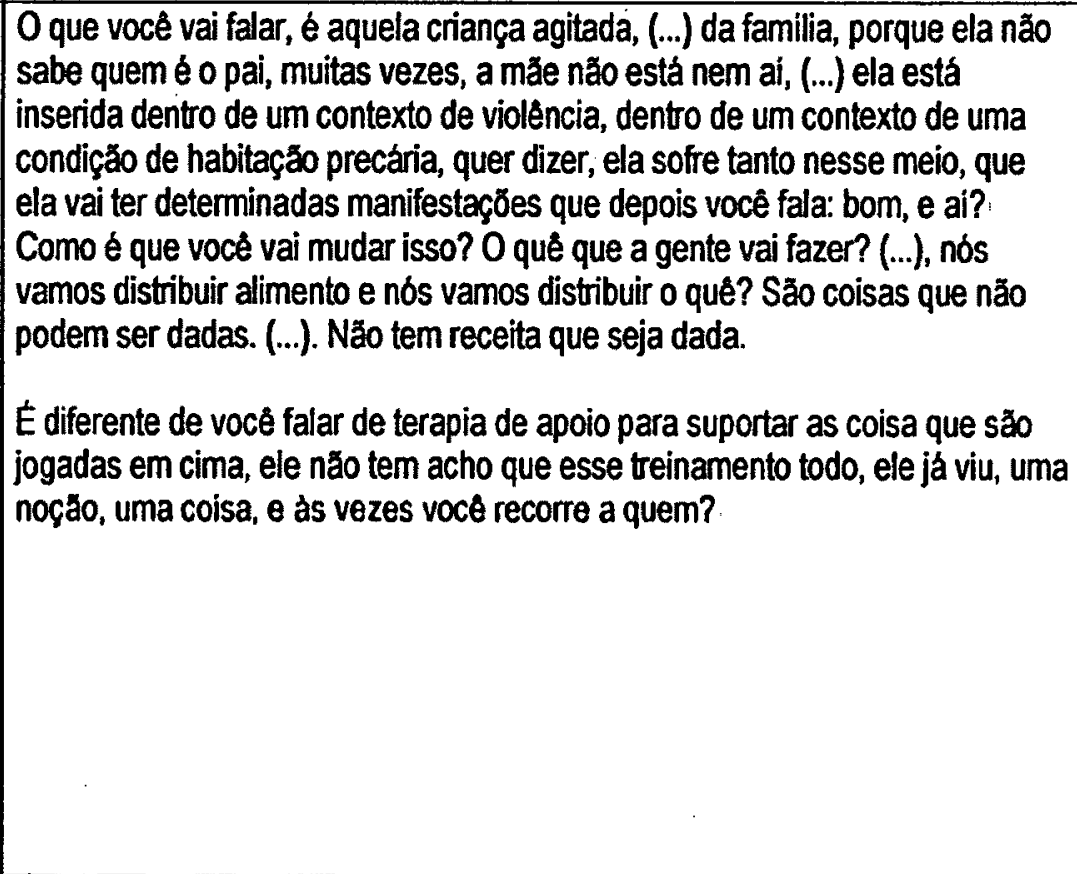 \\
\hline
\end{tabular}


Tem ás vezes que dá medo, eu acho, se você começar cavocar esse negócio você vai mexer em estruturas que podem abalar a base da pessoa, e al, o qué que v. faz?

... quando voce. fala assim: olha, vou encaminhar voce para um profissional da área de saúde mental, vamos colocar (como se diz, ... genérico?), a gente vai... psicólogo, psiquiatra, até bonito, até dá status, imagina, fazer terapia, qualquer coisa mas há anos atrás era o contrário, você falava... vou mandar para o psiquiatra, coisa de louco, não quer nem saber, e existe muitas vezes o receio também da própria familia de se aprofundar nessas questőes que vocé pode detectar, que sabe lá o que vai encontrar lá embaixo...

... mas você não sabe nem o que tem do outro lado do túnel, a pessoa que vai atender ... dá um certo receio. E eu tenho muito medo nessa área, tipo de encaminhamento... o tipo de abordagem... o que eles vão fazer... vocé está entendendo...é uma coisa ... fica um vazio, é um túnel sem fim, sabe...

acho que a proximidade do profissional, e uma interface, um diálogo é que facilita isso. e esse é outro problema que eu acho que também reflete, porque quando vocé encaminhar alguém para algum lugar, não vou... também ensinar o cara a ir para Santos... tem que mostrar o caminho, no inicio, até para confiança dele (...), ele tem que saber o caminho, tem que saber a estrada, e você tem que ter uma certa ciência também de segurança.

Tem ás vezes que dá medo, eu acho, se vocé começar cavocar esse negócio vocé vai mexer em estruturas que podem abalar a base da pessoa, e al, o quê que voce faz?

Aqui, por exemplo, no centro de saúde, pelo fato da gente ter um serviço de fono aqui do lado, que faz alguns testes audiométricos, audiometria e tudo 0 mais, comparado a outros locais, a gente tem uma facilidade muito grande (...) de fazer essa avaliação, então ao nivel de fono(...) você está mais atento a esse tipo de problema, pela facilidade de recurso que está ao lado. 


\begin{tabular}{|c|c|c|}
\hline \multicolumn{3}{|c|}{ MAPA DE VERBALIZACCŌES, EXPLICAÇÕES E ATRIBUIÇÕES DE SIGNIFICADO - ENTREVISTA 11} \\
\hline $\begin{array}{l}\text { UNIDADES } \\
\text { TEMATICAS }\end{array}$ & VERBALIZAÇÕES & EXPLICAÇŐES E ATRIBUIÇŐES DE SIGNIFICADO \\
\hline $\begin{array}{l}\text { CONCEPÇÃO DE } \\
\text { PROBLEMA DE } \\
\text { SAÚDEMENTAL NA } \\
\text { INFÁNCIA }\end{array}$ & $\begin{array}{l}\text {...um plano geral da criança, quer dizer, vendo a criança nåo só como nosso } \\
\text { paciente aqui, mas como vivendo fora, vivendo... dentro da... da... da casa, } \\
\text { dentro da familia, e ai, sem dúvida alguma, entram todas as... os problemas, } \\
\text { que a gente pode estar relacionando em termos de saúde mental. }\end{array}$ & $\begin{array}{l}\text {...contexto dela familiar, toda relação familiar, a relaçăo dela com, com o } \\
\text { ambiente } e . . . \text { pode estar influenciando na, na... no problema que ela está } \\
\text { apresentando, então a gente procura ter um enfoque desse tipo. }\end{array}$ \\
\hline $\begin{array}{l}\text { AÇÃO DOS } \\
\text { PEDIATRAS FRENTE } \\
\text { AOS PROBLEMAS } \\
\text { DE SAUUDE MENTAL } \\
\text { NA INFÂNCIA }\end{array}$ & $\begin{array}{l}\text {... digamos assim uma triagem e a maior parte desses casos a gente acaba } \\
\text { fazendo acompanhamento e descobrindo realmente que... a dinámica familiar } \\
\text { é bastante... é... alterada e que... a gente procura estar conversando um } \\
\text { pouquinho com a... com a... com a måe, até antes de estar encaminhando, } \\
\text { para ver se às vezes é um caso que precisa encaminhar ou não. } \\
\\
\text {... alguns problemas desse tipo a gente acaba tendo dificuldades para, para... } \\
\text { abordar,... e... e... que precisaria... de uma, de uma equipe maior, quer dizer, }\end{array}$ & $\begin{array}{l}\text {... existe uma série de, de, de problemas às vezes a gente pega numa fase } \\
\text { inicial, que vocé consegue detectar que existe algum distúrbio, ã.. å.. da } \\
\text { criança, existe alguma alteraçåo de dinåmica familiar e a criança está sentindo } \\
\text { isso, está tazendo alguma... alguma... está trazendo algum efeito para essa } \\
\text { criança... e a gente não custa fazer às vezes a prevenção nisso, vocé não } \\
\text { consegue estar fazendo um acompanhamento mais adequado por falta de... } \\
\text { de... subsidios mesmo. } \\
\text {... uma abordagem com mais profissionais, quer dizer, u... um espaço onde o } \\
\text { pediatra e outro profissional pudessem estar discutindo, pudessem estar }\end{array}$ \\
\hline
\end{tabular}


nåo só... pediatras,. quer dizer, uma, uma equipe multiprofissional, que esses casos pudessem estar sendo discutidos...

um espaço onde essas questz̄es poderiam ser discutidas,... aqui no centro de saúde nåo tem

...abordagem (no serviço especializado), por ser um grupo mais especifico, por problemas crónicos, ela acaba sendo diferente da forma como a gente abordaria outros problemas aqui, entăo precisaria ter, assim, realmente alguém, a...., que trabalhasse dentro da atençăo primária...

... eu acho que ele (o pediatra) é importante na hora de detectar, de descobrir que existe um problema e de que forma estar encaminhando melhor essa criança (...) não é a funçăo dele estar, estar fazendo toda esse... ă... o acompanhamento, o tratamento, não...

... pegamos os casos e de repente olha esse caso eu não sei o que fazer... cada um vai ler $e$ ai a gente senta e discute, olha eu vou fazer isso, vou encaminhar para tal lugar, então eu acho que... a... a... e assim... é uma, é uma abordagem dificil porque a gente năo tem esse preparo,

... existe uma...uma...uma... ã... uma dificuldade de vocé achar serviços que façam um acompanhamento psicológico, um acompanhamento psiquiátrico eu acho que se tem... se você tem uma reguar... retaguarda eficiente, que você possa estar fazendo alguma coisa em conjunto, eu acho que... melhoraria bastante.

... a familia é... é... é pouco preparada ou ela não quer ver... então o que a gente acaba às vezes, é... percebendo aqui são esses dois lados, ou ela realmente não quer ver...então na hora que você começa a fazer uma acompanhando o caso, sem dúvida alguma, seria muito interessante, eu acho que... que é uma coisa enriquecedora, para ambos, uma troca de... de... de.. é... observaçð̃es paralelas e quem vai ganhar, sem dúvida alguma, é a criança,

... eu acho que ele é uma figura super importante porque ele é um filtro...... então quer dizer, quando ele tem um... um... embasamento importante, eu acho que ele é... ele é... uma... uma... è... uma... personagem extremamente importante nesse... no acompanhamento da criança, å... mas ele sozinho năo vai fazer nada, então eu acho que é importante a, a... penso que assim, eu acho que as escolas deveriam estar a... a... ampliando um pouco a parte de... de prevençẵo, de promoção da, da, da saúde mental para que isso fosse, é... fizesse parte do currículo do pediatra.

...eu acho que se a gente tivesse algum ã... um serviço mais ã... não sei... um trabalho dentro do centro de saúde, eu acho que a gente conseguiria resolver uma série de coisas.

... facilitaria muito... å... se a gente, por exemplo, pudesse ter um contato maior, onde vocé pudesse, como eu falei, de repente detectar precocemente e estar podendo saber que vocé vai encaminhar e aquela criança vai ser atendida. Que às vezes, muitas vezes a gente... quer dizer, algumas vezes, a gente já encaminhou paciente para... para acompanhamento psicológico, e que... é... são poucos os que retornam com algum dado positivo...

... saúde mental, de higiene mental para criança, que muitas vezes quando vocé, muitas måes às vezes quando a gente aborda alguma coisa ela vai dizer: mas eu năo sou louca, o meu filho não é louco... quer dizer, então o 
abordagem, vocé começa a mostrar, olha, existe esse problema, nós vamos acompanhar, uma criança que precisa, a criança precisa de um

acompanhamento especifico, de um especialista, então às vezes a mãe se

retrai, ou ela não traz, ã... começa a entrar nos faltosos... então a gente às

vezes tem as crianças faltosas, ah, essa criança precisava estar fazendo esse

acompanhamento e al com a abordagem a mãe acaba se distanciando, então

eu acho que existe um estigma, sem dúvida alguma existe, é por mais que a

gente consiga procurar trabalhar a... a... a discussz̃o duma saúde ampla da

criança, existe um estigma, na hora que você fala que a criança vai precisar ir

para um psicólogo... psiquiatra nem pensar, vocé falar... então vocé acha que

a criança vai precisar fazer um acompanhamento, é até dificil porque às vezes

não consegue nem encontrar um termo, vai falar saúde mental a mãe arregala

o olho, psicólogo, psiquiatra então ela... quase infarta... estigma e tão grande, que ela não consegue diferenciar å... a saúde mental. quer dizer, ela já leva para... para uma patologia, entåo eu acho que ele estigma é muito grande. Eu acho... eu acho... é d...e e dificil às vezes abordar. ă... vocé acaba tentando entrar por várias vias, para n... nåo chocar a mãe,... 